\title{
Design And Operation Of A Wireline Pressure Core Sampler (PCS)
}

\author{
OCEAN DRILLING PROGRAM \\ TEXAS A\&M UNIVERSITY \\ Technical Note 17
}

\author{
T. L. Pettigrew \\ Ocean Drilling Program \\ Texas A\&M University \\ 1000 Discovery Drive \\ College Station, Texas 77845-9547
}

Plorathros

Philip D. Rabinowitz

Director
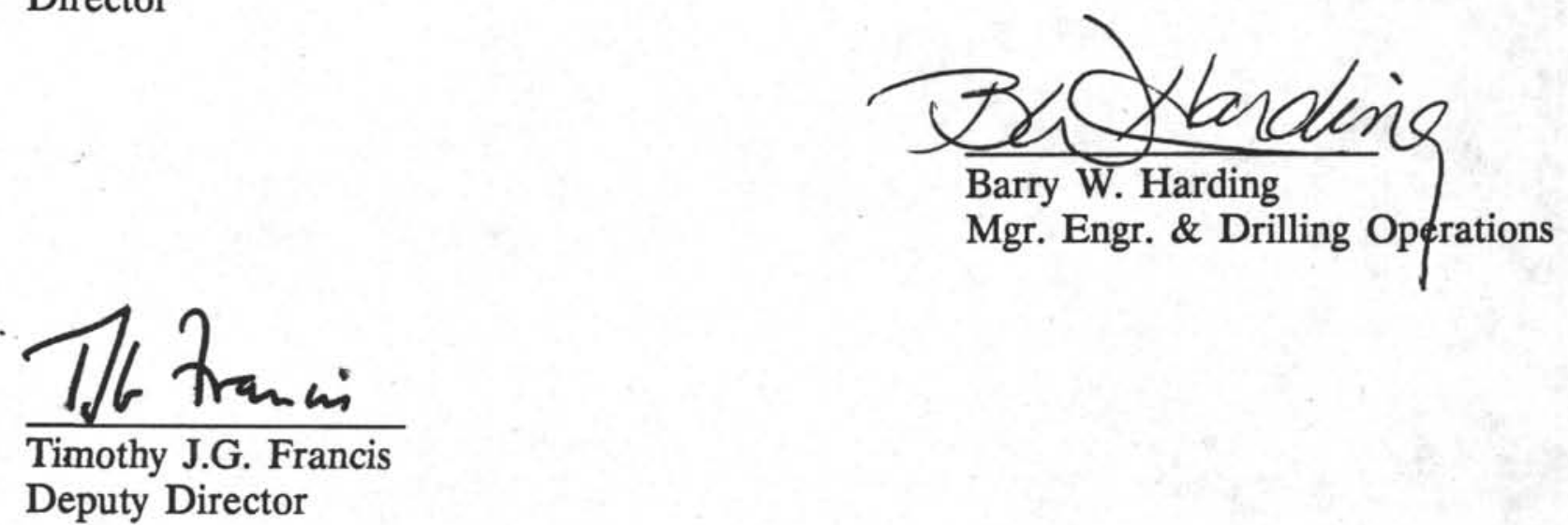

August 1992 
Material in this publication may be copied without restraint for library, abstract service, educational or personal research purposes; however, republication of any portion requires the written consent of the Director, Ocean Drilling Program, Texas A\&M University Research Park, 1000 Discovery Drive, College Station, Texas 778459547, as well as appropriate acknowledgment of this source.

Technical Note No. 17

First Printing 1992

Distribution

Copies of this publication may be obtained from the Director, Ocean Drilling Program, Texas A\&M University Research Park, 1000 Discovery Drive, College Station, Texas 77845-9547. In some cases, orders for copies may require a payment for postage and handling.

\section{I S C A I M ER}

This publication was prepared by the Ocean Drilling Program, Texas A\&M University, As an account of work performed under the international Ocean Drilling Program, which is managed by Joint Oceanographic Institutions, Inc., under contract with the National Science Foundation. Funding for the program is provided by the following agencies:

Academy of Sciences (Russia)

Canada/Australia Consortium for the Ocean Drilling Program

Deutsche Forschungsgemeinschaft ( Federal Republic of Germany)

European Science Foundation Consortium for the Ocean Drilling Program

(Belgium, Denmark, Finland, Iceland, Italy, Greece, the Netherlands, Norway, Spain, Sweden, Switzerland, and Turkey)

Institut Francais de Recherche pour l'Exploitation de la Mer (France)

Ocean Research Institute Of the University of Tokyo (Japan)

National Science Foundation (United States)

Natural Environment Research Council (United Kingdom)

Any opinions, findings, and conclusions or recommendations expressed in this publication are those of the author(s) and do not necessarily reflect the views of the National Science Foundation, the participating agencies, Joint Oceanographic Institutions, Inc., Texas A\&M University, or Texas A\&M Research Foundation. 


\section{FOREWORD}

\section{Ocean Drilling Program}

The Ocean Drilling Program (ODP) is an international scientific venture to explore the ocean basins, with Texas A\&M University designated as science operator. The ODP began coring in January 1985 . Largely funded by the U.S. National Science Foundation (NSF), the ODP includes the United States, Canada/Australia, Germany, France, Japan, Russia, the United Kingdom, and the European Science Foundation, a consortium representing 12 European countries. This partnership is called Joint Oceanographic Institutions for Deep Earth Sampling (JOIDES). The ODP is based on the deliberations of the first international Conference on Scientific Ocean Drilling convened in 1981 by JOIDES in order to determine how best to build on the successful work of the Deep Sea Drilling Project that had been under way since 1968.

\section{JOIDES Resolution}

The JOIDES Resolution (registered as SEDCO/BP 471) is the seagoing base for the ODP operations. The 143-meter former offshore oil exploration vessel is outfitted with the most modern laboratory, drilling and navigation equipment available. It utilizes an on-board computerized positioning system controlling 12 thrusters, to dynamically position the ship over a drill hole located in water as deep as 8,235 meters. The derrick rises 61.5 meters above the water line, and with a 400-ton heave compensator, the drilling system can handle 9,150 meters of drill pipe. The JOIDES Resolution recently completed a circumnavigation of the earth in the service of science.

\section{Coring Operations}

Most coring operations are conducted in very deep water, $3,500 \mathrm{~m}$ to $5,000 \mathrm{~m}$. All sites are carefully reviewed by a Safety Panel prior to drilling to ensure the potential of encountering a hydrocarbon reservoir is minimal. The cores are constantly monitored for hydrocarbons, and if a potential hydrocarbon source is encountered, the borehole is plugged with cement and abandoned. For these reasons no riser system or blowout preventer equipment is used. The core barrels are retrieved on wireline utilizing one of two winches with up to $9450 \mathrm{~m}$ of $3 \times 19$ wire rope. State-of-the-art shipboard laboratories are utilized to conduct comprehensive preliminary analysis immediately upon recovery of the cores. 


\section{ACKNOWLEDGMENTS}

The wireline Pressure Core Sampler was designed and developed by T. L. Pettigrew, Sr. Development Engineer in the Ocean Drilling Program engineering group, who also provided overall supervision of the project.

Thanks to Jim Aumann, Aumann and Associates, Salt Lake City, Utah, Co-designer of the initial version of the tool as well as later modifications. Mr. Aumann's contributions to the project were invaluable.

Special thanks to Eastman Christensen Engineering, Salt Lake City, Utah, for licensing ODP to use certain features of the Hydro-lift System (covered by patents 4,256,192, $4,553,613$, and $4,664,205$ ) in developing the PCS actuator subassembly.

I also thank the following individuals:

Gary Brass, University of Miami.

Philip Froelich, of the Lamont-Doherty Geological Observatory.

Andy Campbell of the MIT Earth Science Department (suggestion re: stainless steel vs. titanium).

Dick Campanella of UBC (University of British Columbia) (provided information on subminiature pressure transducers).

Marta von Breymann, Staff Scientist, Ocean Drilling Program.

Miriam Kastner and Joris Gieskes of the Scripps Institution of Oceanography.

Keith A. Kvenvolden of the U.S. Geological Survey.

Jean Whelan, Dempsey Lott and Fred Sayles of the Woods Hole Oceanographic Institution.

Michael A. Storms, Supervisor of Development Engineering at ODP, was co-developer of the Pressure Core Barrel, predecessor of the PCS.

Wayne Dunlap, Texas A\&M Department of Civil Engineering.

Bill Bryant, Texas A\&M Oceanography Department.

Bryan Trimm (suggestions re: pressurized physical properties tests). 


\section{TABLE OF CONTENTS}

I Design and Operation of a Wireline Pressure Core Sampler

Abstract $\ldots \ldots \ldots \ldots \ldots \ldots \ldots \ldots \ldots \ldots$

Introduction $\ldots \ldots \ldots \ldots \ldots \ldots \ldots \ldots \ldots \ldots$

Developmental History . . . . . . . . . . . 10

Why Pressurized Core Samples? . . . . . . . . 10

DSDP Legacy $\ldots \ldots \ldots \ldots \ldots \ldots \ldots \ldots \ldots \ldots \ldots \ldots$

ODP Advancement .............. 11

Why a Pressure Core Sampler? . . . . . . . . . . 11

PCS Phase I Design . . . . . . . . . . . . 13

General Description ............... 13

Phase I Development Goal . . . . . . . . . . 13

Ball Valve Subassembly . . . . . . . . . . . 13

Actuator Subassembly . . . . . . . . . . . . 14

Latch Subassembly ... . . . . . . . . . . 14

Accumulator Subassembly $\ldots \ldots \ldots \ldots \ldots \ldots$

Manifold Subassembly . . . . . . . . . . . 15

Detachable Sample Chamber . . . . . . . . . 16

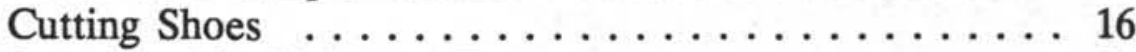

Sampling Manifold and Temperature ........ 17

Controlled Bath

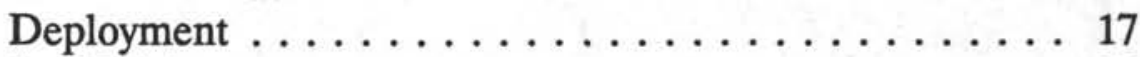

Sea Trials ................. 20

Modifications ................. 20

Additional Deployments . . . . . . . . . . 20

PCS Phase II Design $\ldots \ldots \ldots \ldots \ldots \ldots \ldots \ldots \ldots$

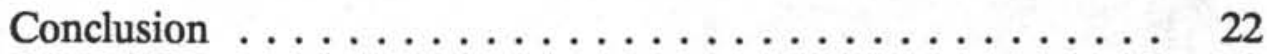

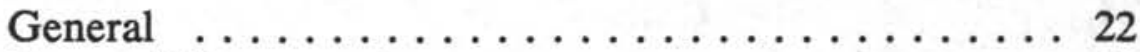

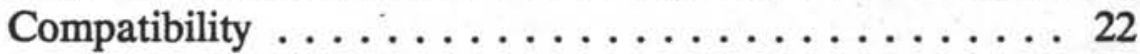

Problems .................. 23

Recommendations ................... 25 
II Figures

1. DSDP Pressure Core Barrel version III (PCB-III) $\ldots \ldots \ldots .30$

2. PCS Phase I Operating Schematic $\ldots \ldots \ldots \ldots \ldots \ldots . \ldots \ldots$

3. PCS I Ball Valve Subassembly $\ldots \ldots \ldots \ldots \ldots \ldots \ldots \ldots 32$

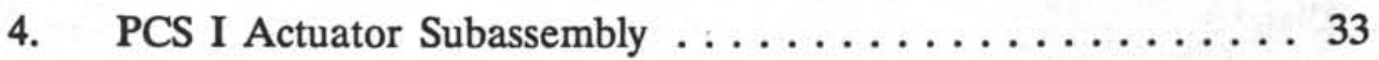

5. PCS I Latch Subassembly $\ldots \ldots \ldots \ldots \ldots \ldots \ldots \ldots \ldots$

6. PCS I Accumulator Subassembly $\ldots \ldots \ldots \ldots \ldots \ldots \ldots$

7. PCS I Manifold Subassembly $\ldots \ldots \ldots \ldots \ldots \ldots \ldots \ldots$

8. PCS I Sample Chamber $\ldots \ldots \ldots \ldots \ldots \ldots \ldots \ldots$

9. PCS I Cutting Shoe $\ldots \ldots \ldots \ldots \ldots \ldots \ldots \ldots \ldots \ldots$

10. PCS I Sampling Manifold $\ldots \ldots \ldots \ldots \ldots \ldots \ldots \ldots$

11. PCS I Probe and 2nd Port Modifications ........ 40

III Tables

I. PCS Operational Results $\ldots \ldots \ldots \ldots \ldots \ldots \ldots \ldots$

IV Appendices

A. Gas Hydrate Drilling in the Ocean Drilling Program ................... 43

B. Report on Sampling of Formation Fluids

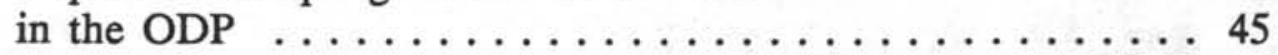

C. The Clathrate Study System (Progress Report) $\ldots \ldots \ldots \ldots 53$

D. PCS Phase I Design Statement of Work $\ldots \ldots \ldots \ldots \ldots 7$

E. PCS Phase I Design Calculations $\ldots \ldots \ldots \ldots \ldots 61$ 
F. PCS Phase I Manifold Design Questionnaire $\ldots \ldots \ldots \ldots 71$

G. Performance of the ODP Pressure Core

Sampler $(\operatorname{Leg} 124 \mathrm{E}) \ldots \ldots \ldots \ldots \ldots \ldots \ldots \ldots \ldots$

H. PCS Phase I Modifications Design Statement

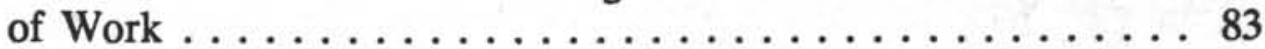

I. Leg 131 PCS Engineering Report $\ldots \ldots \ldots \ldots \ldots \ldots$

J. Leg 139 PCS Engineering Report $\ldots \ldots \ldots \ldots \ldots \ldots$

K. Leg 141 PCS Engineering Report $\ldots \ldots \ldots \ldots \ldots \ldots \ldots$

L. PCS Phase II Design Statement of Work . . . . . . . 105

M. PCS Technical Manual . . . . . . . . . . . . . . . . . 109

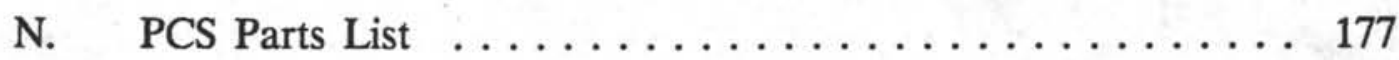

O. PCS Assembly Drawings $\ldots \ldots \ldots \ldots \ldots \ldots \ldots \ldots$

P. PCS Machine Drawings $\ldots \ldots \ldots \ldots \ldots \ldots \ldots \ldots$ 


\title{
DESIGN AND OPERATION OF A WIRELINE PRESSURE CORE SAMPLER
}

\begin{abstract}
This Ocean Drilling Program (ODP) Technical Note No. 17 discusses the design and operation of the wireline Pressure Core Sampler (PCS), and the development history beginning in 1973 with the Deep Sea Drilling Project (DSDP). The PCS project is a continuation of the development of a wireline tool to retrieve cores at near in situ pressure. It was developed by the ODP to replace the DSDP Pressure Core Barrel version III (PCB-III). The PCS uses both current conventional oil field pressure coring technology as well as technology developed by the DSDP. The PCS is compatible with the standard ODP Advanced Piston Corer (APC)/Extended Core Barrel (XCB) Bottom Hole Assembly (BHA) and wireline coring system. The PCS does not require any special subs or additional hardware to be added to the drill string and thus can be deployed anytime the APC/XCB BHA is in the hole. The pressurized core sample is trapped inside a sample chamber by closing a hydraulically actuated ball valve. The PCS has the ability to recover $0.86 \mathrm{~m}$ (32 in) of core at pressures up to $68.9 \mathrm{MPa}(10,000 \mathrm{psi})$. The core diameter is restricted to $42 \mathrm{~mm}$ (1.65 in) diameter by the geometrical constraints of the APC/XCB BHA.
\end{abstract}

The PCS was developed to replace the PCB-III for the following reasons:

1. Provide compatibility with the ODP APC/XCB bottom hole assembly.

The PCB-III is only compatible with the Rotary Core Barrel (RCB) BHA and required a special bit.

2. Increase pressure containing capability, and thus depth capability.

The PCB-III is limited to $34.5 \mathrm{MPa}(5,000 \mathrm{psi})$.

3. Establish the ability to transfer a pressurized core sample from the core barrel to a pressurized testing chamber while maintaining near in situ pressure.

The PCB-III core sample can only be accessed after the pressure has been released and the tool disassembled.

Sea trials for the PCS initial prototype (Phase I) took place during ODP Leg 124E off the Philippines (Jan/Feb 1989). Modifications to the prototype were tested during the first scientific deployment of the tool during Leg 131 in the Nankai trough off Japan (Mar/May 1990). 


\section{INTRODUCTION}

The remarkable success of the Ocean Drilling Program is evidenced by the voluminous samples and information acquired over the 7 years of its operation to date. The Program's success is also evidenced by its technological advancements. These advancements include refinement of drilling and coring equipment first developed during the Deep Sea Drilling Project (DSDP) and include a myriad of new tools and equipment required to meet the needs of scientists worldwide.

This Technical Report discusses the development history, design, operation and field testing of the wireline Pressure Core Sampler (PCS). The PCS is the result of a technological advancement made on the Pressure Core Barrel (PCB) originally developed during the DSDP. 


\section{WIRELINE PRESSURE CORING TOOLS DEVELOPMENTAL HISTORY}

The Pressure Core Sampler (PCS) project continues the development of a wireline tool to retrieve cores at near in situ pressure. The PCS was developed by the Ocean Drilling Program (ODP) to replace the Pressure Core Barrel (PCB) designed during the Deep Sea Drilling Project (DSDP) (Figure 1).

This Technical Report discusses the design, operation, and field testing of the PCS (Figure 2). The appendix includes several operational test reports, as well as a current assembly drawing and parts list. A report on gas hydrate drilling within the ODP is also included.

Why Pressurized Core Samples?

Scientific interest in the nature and existence of gas hydrates in marine sediments, plus a desire by geochemists to obtain pressurized samples of pore fluids and gases, resulted in a mandate to provide a coring tool capable of retrieving deep ocean cores at in situ or near in situ pressures.

Methane and other gas hydrates, or clathrates, have long been viewed with interest by the scientific community for several reasons, an obvious one being methane's potential as an alternate energy source. Perhaps a more urgent reason concerns the stability of man-made structures (e.g. drilling rig platforms) built on top of hydrate-bearing sediment. These hydrates, resembling dry ice, pose special problems for conventional analytical techniques because of their tendency to sublime when heated, in addition to the extra safety measures required due to the high pressure of the gas after sublimation.

Numerous properties of sediments can best be measured accurately in situ, including such properties as shear strength, compression, compressibility, velocity, porosity, permeability, thermal conductivity, pressure and temperature. Similarly, the chemical properties which require in situ measurement include salinity, $\mathrm{pH}, \mathrm{O}_{2}, \mathrm{H}_{2} \mathrm{~S}$, stationary gases, and dissolved ions by ion-specific electrodes. One consideration in testing such properties involves minimizing the introduction of inevitable disturbances to the sample, which could take any of four forms: mechanical, chemical, pressure, thermal. It was evident that we would be able to control only one of them (pressure) at best.

Reference Appendix A: "Gas Hydrate Drilling in the Ocean Drilling Program", Appendix B: "Report on Sampling of Formation Fluids in the Ocean Drilling Program", and Appendix C: "The Clathrate Study System Progress Report" for further input from the scientific community. 


\section{DSDP Legacy}

DSDP conducted an industry survey in 1972-73 and found that the only reliable pressure core barrel which was commercially available at that time was not wireline retrievable and could not be adapted to the DSDP BHA. The manufacturer of that tool, plus ten other oil field related companies, eventually declined to participate in a program to develop a tool designed expressly for DSDP needs. Thus, DSDP embarked on an engineering development effort, initially relying heavily on private consultants from industry, but eventually turning in-house for design engineering. The PCB went through three generations of testing, re-design and field tests, before a final version, the PCBIII, was developed. Reference DSDP Development Engineering Technical Report No. 16 for PCB development details.

The first wireline Pressure Core Barrel (PCB-I) was developed by Mr. M. A. Storms and Mr. B. W. Adams, DSDP Project Engineers. The PCB-I was first tested on DSDP Leg 42B in the Black Sea, May 1975.

Development of the PCB-II (second PCB version) was continued by Mr. Storms with the assistance of Larry Russell and Associates who designed the mechanically actuated ball valve mechanism. The PCB-II was first deployed in July 1978 on DSDP Leg 62.

Final modifications of the tool were accomplished by Mr. D. H. Cameron and resulted in the PCB-III. The PCB-III was first deployed in September 1980 during DSDP Leg 76.

\section{ODP Advancement}

The PCS is the next major step in the development of a wireline tool to recover pressurized core samples from the deep oceans. A PCS Phase I Design Statement of Work (Appendix D) was generated and the PCS development began. The PCS was designed and developed by Mr. T. L. Pettigrew, ODP Sr. Development Engineer, and Mr. J. T. Aumann, Aumann \& Associates, Salt Lake City, Utah. Reference Appendix E for pertinent design calculations. The PCS Phase I tool was first deployed on ODP Leg 124E in January 1989.

\section{Why a Pressure Core Sampler?}

The DSDP PCB-III was wireline-deployable and was able to recover core samples at pressures up to $5000 \mathrm{psi}$, but the following deficiencies were viewed as major hindrances to the future usefulness of the PCB within ODP:

1. The lack of compatibility with newer coring technology. 
2. Limitations in maintaining pressure severely hindered its ability to retrieve methane gas hydrate samples.

3. Inability to access the pressurized core sample without depressurizing and dismantling the tool.

4. Its large size prevented effective temperature control after recovery.

A workshop was held at the ODP offices at Texas A\&M University in College Station, Texas, in 1986 to discuss the design of a new Pressure Core Barrel. The workshop participants concluded that "the most important improvement to be made remains the design of a system that subsamples gas, interstitial waters, and sediments without depressurizing the sample."

Approximately six months were devoted to an evaluation of existing technology developed since the PCB, most of which had been developed by the petrochemical industry primarily to identify hydrocarbons. Other limitations were the fact that existing tools were conveyable only by drill string rather than wireline. At the direction of JOIDES, the ODP then began the design of a new tool, the Pressure Core Sampler (PCS). 


\section{PRESSURE CORE SAMPLER PHASE I DESIGN}

\section{PCS General Description}

The PCS is a free fall deployable, hydraulically actuated, wireline retrievable pressure coring system. When the PCS is deployed, it lands and latches into the BHA and is rotated with the BHA during coring operations. It is fully interchangeable with the APC and XCB coring systems, thus allowing a pressurized core sample to be taken at any time from the mudline down to indurated formations and/or basement rock. The PCS recovers a nominal 42 $\mathrm{mm}$ (1.65 in) diameter core sample, $0.86 \mathrm{~m}$ (34 in) long at pressures up to 68.9 $\mathrm{MPa}(10,000 \mathrm{psi})$.

In practice, the PCS is dropped down the drill string and landed in the BHA. The PCS is rotated by the top drive via the latch and drill string-BHA. During coring operations the rig pumps maintain flow down the drill string to keep the hole open and to cool/lubricate the PCS cutting shoe. Once the core has been cut the rig pumps are secured, the wireline is attached to the PCS and an up strain is applied to the PCS latch to release the check ball. The wireline is then slacked off and the rig pumps are restarted slowly, letting the pressure build to activate the actuator and stroke the sample chamber closed. When circulation is once again established, the sample chamber has been closed and the PCS is retrieved like any other wireline core barrel. Once on deck, the detachable sample chamber is removed from the PCS and placed in a portable temperature controlling bath/safety shroud where temperature and pressure monitoring equipment is attached. The sampler chamber can then be safely moved off the rig floor for scientific evaluation.

\section{PCS Phase I Development Goal}

The stated goal for the initial (Phase I) version of the PCS was to develop a prototype which could demonstrate and test the concept of improved techniques for obtaining pressurized core, gas, and water samples at near in situ pressure.

\section{PCS Ball Valve Subassembly}

The first design problem to be addressed was the most fundamental: how best to "close the door" after obtaining the sample. This led to the incorporation of a hydraulically actuated ball valve mechanism. Flapper valves were considered but rejected due to geometric constraints placed on the core barrel by the APC/XCB BHA. The ball valve subassembly (Figure 3 ) is the sealing mechanism on the bottom of the sample chamber. It also is the connection point for the cutting shoe used to trim the core sample to size. During 
deployment and coring operations the ball valve is open with the core tube extended through it into the cutting shoe. When the actuation subassembly is activated and the core tube has been pulled through the ball, the ball is rotated into the closed position, sealing the lower end of the sample chamber. The ball valve subassembly also provides a means for future connection of the sample chamber to a pressurized testing or shipping chamber. The ball valve subassembly also contains the pressure-containing body of the sample chamber and the seal receptacle used to seal the upper end of the sample chamber.

\section{PCS Actuator Subassembly}

The actuator subassembly (Figure 4) serves two functions. First it catches the actuation ball when released by the Latch Subassembly and by doing so stops all flow through the PCS. Secondly, when pressure is applied to the PCS, after releasing the actuation ball, the actuation subassembly unlatches and strokes through itself, pulling the core tube containing the core sample through the ball valve into the sample chamber. As the core tube is pulled into the sample chamber the ball valve is closed and the upper end of the core tube is pulled into a seal receptacle, thus sealing the sample chamber at both ends and trapping the core sample at hydrostatic pressure inside the PCS. When the actuation subassembly reaches the end of its stroke it latches once again, thus preventing premature opening of the ball valve.

After making a survey of all existing actuation technology, it was found that the approach taken by a system called the Christensen Hydro-lift, which Mr. Aumann helped design, proved to be the most appropriate solution. The principle embodies an external piston stroking up a fixed internal rod as pressure is applied. The mechanism was used to pull the core tube through the ball valve and then close the ball valve.

Eastman Christensen had been issued three U.S. patents for the Hydro-lift system, which had been in use for three years as part of a standard oil field pressure core barrel. Eastman Christensen was approached with regard to licensing the technology for use by the Ocean Drilling Program. Fortunately, Eastman Christensen had no reservations about licensing the technology to ODP, in exchange for the opportunity to commercially exploit any improvements which might be made in adapting their technology to the PCS actuator.

\section{PCS Latch Subassembly}

The latch subassembly (Figure 5) is a modification of the standard ODP XCB latch which serves five functions. First the latch subassembly contains the landing point for the PCS when deployed. The latch subassembly has a 4.000 inch outside diameter shoulder which cannot pass the 3.82 inch inside diameter 
throat of the BHA landing saver sub, thus preventing the PCS from passing completely through the BHA. Secondly, by latching into the BHA, the latch subassembly transmits torque from the BHA to the PCS, allowing the PCS cutting shoe to trim the core to proper size for entry into the sample chamber. Thirdly, the latch subassembly holds the actuation ball used in the actuation of the ball valve subassembly. When the latch subassembly is engaged by the wireline and an upward force is applied, the actuation ball is automatically released into the actuation subassembly. Finally, the latch subassembly diverts all flow down the drill pipe through the PCS and provides a place for the wireline to automatically attach itself during retrieving operations. The latch subassembly is attached to the PCS by a three lug quick release, allowing for handling in the same efficient manner as the other ODP coring systems.

\section{$\underline{\text { PCS Accumulator Subassembly }}$}

The accumulator subassembly (Figure 6) contains a pressure maintaining mechanism and primary safety pressure relief mechanism. The pressure maintaining mechanism is a gas charged accumulator, comprised of a cylinder and free-floating piston. The top side of the piston is charged with gas to approximately $75 \%$ of the anticipated hydrostatic pressure. During deployment, as the PCS nears the end of the drill string, the increasing hydrostatic pressure causes the piston to move upwards until the compressed gas pressure equals that of the hydrostatic pressure. The accumulator compensates for pressure losses due to small changes in volume from complete "stroking" of the tool after the initial seal is achieved and from "seal weeping" as differential pressure increases across the seals during retrieval of the tool by forcing fluid back into the chamber as the pressure losses occur.

The primary safety pressure relief mechanism of the Accumulator Subassembly is an adjustable back pressure relief valve. The back pressure relief valve is set to automatically vent the accumulator charge gas pressure should it exceed a predetermined limit, up to $68.9 \mathrm{MPa}(10,000 \mathrm{psi})$. By releasing the pressure, the accumulator piston can move upward effectively, increasing the sample chamber volume and thus reducing the pressure. The back pressure relief valve will maintain any pressure up to the preset release pressure. Thus if the pressure within the sample chamber were to increase, it would be maintained at the preset release pressure setting. Note that no material is lost from the sample chamber during this pressure release operation.

\section{PCS Manifold Subassembly}

The manifold subassembly (Figure 7) contains the secondary safety pressure relief mechanism, two sampling ports, an internal pressure monitoring device, and the core tube. The secondary safety pressure relief mechanism is a burst 
disk. Should the pressure relief valve in the accumulator fail to release pressure or if the sample chamber pressure increases above $68.9 \mathrm{MPa}(10,000$ psi) after the accumulator piston has reached the end of its travel, the safety bust disk will rupture, relieving all pressure from inside the PCS sample chamber. Note that all pressure, most gases, and some fluid will be lost if the burst disk ruptures.

Two sample chamber sampling ports are accessed through the Manifold Subassembly. Both ports are 1/4" NPT female connections. One sampling port leads directly to the volume within the core tube. The other sampling port leads to the annular volume between the core tube OD and the sample chamber ID. The sampling ports allow sampling of gases or fluids directly from the PCS sample chamber under pressure. Also, one sampling port can be used to inject a gas or fluid under pressure to drive samples out the other sampling port and thus maintain pressure within the sample chamber during sampling.

The Manifold Subassembly also contains an integral pressure transducer, thus allowing for the connection of monitoring equipment to constantly monitor the sample chamber internal pressure.

The core tube is a non-rotating metal tube with integral core catchers used to catch and contain the core sample. During coring operations the core tube is extended through the ball valve subassembly into the cutting shoe. The core tube is mounted on a bearing or swivel which allows the tube to remain stationary relative to the core sample as the cutting shoe is being rotated with the BHA. When the actuator subassembly is activated, the core tube is pulled through the ball valve into the sample chamber.

\section{PCS Detachable Sample Chamber}

The detachable sample chamber (Figure 8) is comprised of the ball valve and accumulator subassemblies. It is $92.2 \mathrm{~mm}$ (3.75 in) in diameter, $1.5 \mathrm{~m}$ (60 in) long and is attached to the PCS by a quick release connection which allows the pressurized sample chamber to be removed from the rest of the PCS for easier handling. Since the valve-accumulator subassembly is an integral part of the detachable sample chamber, the pressure can be continuously monitored. Also, gas and fluid samples can be taken directly from the sample chamber through a manifold.

\section{PCS Cutting Shoes}

The design of the cutting shoes (Figure 9) was critical in determining the shape of the sample. After approaching and consulting with four manufacturers, a design using staggered teeth with diamond impregnated segments in a 4-wing, 
stepped pilot type configuration evolved. The available cutting shoe structures for the PCS use both hard and soft matrix-impregnated diamonds, surface set diamonds, and geoset diamonds, as well as standard hard facing.

\section{PCS Manifold \& Temperature Controlled Bath}

In order to gain access to the sample chamber for sampling or monitoring while maintaining near in situ conditions, a manifold of some type was needed, along with a means of controlling the temperature when the core sample was brought on board. During the DSDP PCB operations, the sample chamber was immersed in an ice water bath to maintain the sample chamber at near in situ temperature. ODP PCS operations include actual measurement of in situ temperatures and then immersing the sample chamber in a bath of continuously circulated chilled water. The water is circulated through a chill unit which automatically maintains the temperature at the measured in situ temperature.

Designing an appropriate sampling manifold presented a special problem as it was more of a scientific (if not philosophical) question than an engineering or technical problem. This in turn reflected the lack of consensus within the scientific community with regard to their overall agendas, priorities, and needs for the use of the PCS. In March, 1988 a questionnaire (Appendix F) was sent out to numerous individuals within JOIDES to aid in optimizing the manifold design by determining their common points of interest.

By early 1990 it became evident that a generic sampling manifold and sampling method would not satisfy the needs of the scientists. A crude sampling manifold assembled from "off the shelf" $1 / 4$ " plumbing, capable of connecting to the two 1/4" NPT female ports, was used for testing during sea trials on ODP Leg 124E. A much more sophisticated manifold (Figure 10) was fabricated based on input from Dr. Jean Whelan for use on ODP Leg 139. The latter sampling manifold has become the basic configuration which is modified to meet the individual scientist's needs.

\section{PCS Deployment}

A typical deployment of the PCS is described below.

1. The PCS is inspected and completely pressure tested.

2. Using a gas booster, the accumulator is charged with nitrogen gas to approximately $75 \%$ of the anticipated hydrostatic pressure.

3. The latch is checked for installation of the actuation ball. 
4. The temperature control bath is adjusted to bottom hole measured temperature.

5. The sampling manifold is evacuated and made ready for attachment of the PCS.

6. Final assembly of the PCS occurs on the rig floor at the time of deployment.

7. With the bit off bottom and the heave compensator locked out, the drill string is opened.

8. The PCS is assembled and "go-deviled" or free fall deployed down the drill string.

9. As the PCS is free falling down the drill string, the drill string is closed and the wireline retrieving tool is started down the drill string behind it.

10. After confirmation of the PCS landing, the drill string is lowered until the bit is back on bottom.

11. One meter of hole is cored without circulation to keep contamination of the core sample as minimal as possible.

12. After cutting the core, the drill string is picked up off bottom to allow the non-heave compensated wireline retrieving tool to be attached to the PCS.

13. The wireline retrieving tool is attached to the PCS.

14. Using the wireline, the PCS is picked up off the landing seat to release the actuation ball.

15. Using the wireline, the PCS is set back down on the landing seat.

16. The circulation pumps are engaged and the drill string pressurized to approximately $500 \mathrm{psi}$ to hydraulically actuate the PCS.

17. The circulation pumps are shut down and the PCS is retrieved with the wireline.

18. At the rig floor, the drill string is opened and the pressurized sample chamber removed from the rest of the core barrel. 
19. The pressurized sample chamber is immediately immersed in the temperature control bath.

20. The pressure transducer is connected to a read out so that the internal pressure can be constantly monitored.

21. The sampling manifold is connected to the pressurized sample chamber to withdraw gas and/or fluid samples.

22. After all gas and/or fluid samples have been taken, the sample chamber is completely depressurized and opened to gain access to the core sample.

23. The PCS is thoroughly cleaned and refurbished as necessary for the next deployment. 


\section{PCS Sea Trials}

Reference Appendix G for the sea trials report entitled "Performance of the ODP Pressure Core Sampler on Leg 124E PCS Sea Trials".

\section{$\underline{\text { PCS Modifications }}$}

Following deployment and testing of the Phase I PCS during Leg 124E, the following enhancements were proposed for the tool:

1. Provide the ability to displace the fluid surrounding the core sample within the sample chamber with nitrogen, without loss of the trapped hydrostatic pressure.

2. Addition of a "probe" -- a small, removable sampling tube which is driven into the core as it enters the sample chamber, and allows for direct core gas and/or fluid sampling.

Achieving the first request required the addition of a second sampling port. This was no easy feat and required redesigning several existing parts as well as several new parts. The addition of the "probe" was a little more straight forward and required little in the way of modifications.

A statement of work for the PCS modifications design work (Appendix $\mathrm{H}$ ) was generated and Mr. Aumann was engaged to do the detailed design work. All requested modifications (Figure 11) were made and the "modified" PCS was first deployed on ODP Leg 131. Reference Appendix I for the "Leg 131 PCS Engineering Report".

\section{Additional Deployments}

The PCS has since been deployed on Leg 139 (Reference Appendix J: "Leg 139 PCS Engineering Report") on the Juan De Fuca Ridge off western Canada (July/Sept 1991) and Leg 141 (Reference Appendix K: "Leg 141 PCS Engineering Report") in the Chile Triple Junction off southern Chile. The PCS is now an ODP operational tool. Reference Table I "PCS Operational Results" for a complete listing. 


\section{PCS PHASE II DESIGN}

Having developed, tested and verified the overall reliability of the basic concept of the PCS Phase I tool, it was now time to move into the next development phase. Phase II would address two main PCS design goals:

1) Capability of direct access of the core sample under pressure.

2) Capability to transfer the core sample, without loss of pressure, into a shipping bomb or laboratory chamber.

It had been understood from the outset that Phase II and beyond would require a substantially greater investment both in terms of engineering effort as well as money. Of equal importance was the need for detailed input from the scientific community.

The stated design objectives for Phase II were:

1. Permit exterior operation while maintaining pressure by redesigning the ball valve.

2. Allow the core tube to be detached and transferred through the ball valve into a shipping bomb or lab chamber while maintaining pressure.

3. Design a manipulator device to physically transfer the core tube into the lab chamber.

4. Design a shipping bomb to accept the core sample transferred from the PCS which would include a means of continuously monitoring internal pressure and temperature of bomb.

5. Design a universal mating attachment for bomb, as well as intermediate device for same if deemed necessary.

Although a PCS Phase II Statement of Work (Appendix L) was generated, the development of the PCS Phase II was put on hold pending funding of a scientific proposal, by outside investigators, to develop the pressurized lab chamber. 


\section{CONCLUSION}

\section{General}

The ODP wireline Pressure Core Sampler (PCS) is the culmination of a long development program. Although the PCS is a major improvement over the Deep Sea Drilling Project (DSDP) Pressure Core Barrel (PCB) its development was based heavily on the PCB design and deployment history. The PCS is capable of recovering deep ocean sediment at pressures up to $68.9 \mathrm{MPa}(10,000$ psi). Being wireline retrievable, it can be run as many times as desired, and at any depth in the hole up to $6800 \mathrm{~m}(22,360 \mathrm{ft})$ without additional pipe trips. The PCS Phase I enables pressurized gas and fluid samples to be taken as well as unpressurized core samples. The current PCS configuration, Phase I, is considered to be an operational tool and is being supported as such aboard the JOIDES Resolution.

Future development of the PCS, Phase II, will allow pressurized gas and fluid samples to be taken as well as transfer of the pressurized core sample into a pressurized lab chamber for analysis, without loss of pressurization. The PCS Phase II development is currently on hold. Initiation of the Phase II development is dependent on a consensus being reached between the scientific community, JOIDES panels, PCOM and the ODP engineering with regard to:

1. Agendas, priorities and needs for the design and use of the tool.

2. Developing applications for the tool on specific ODP legs and objectives.

3. Aspects of the tool for which ODP is responsible and those which should be third-party responsibility.

4. Funding of a scientific proposal, by outside investigators, to develop the pressurized lab chamber.

\section{Compatibility}

The PCS was designed to be compatible with the standard ODP APC/XCB BHA. No special bits, subs or additional hardware are required beyond the standard APC/XCB BHA. Therefore, the PCS can be deployed any time the APC/XCB BHA is in the hole. The complete suite of ODP logging tools, and any other tools or instruments compatible with the APC/XCB BHA, can be deployed in a PCS hole.

Virtually any manifold, instrument or sampling bomb may be connected to the PCS. The only restrictions are, the equipment must be able to withstand either 
68.9 $\mathrm{MPa}(10,000 \mathrm{psi})$ or the maximum pressure within the sample chamber. Also the equipment must be compatible with the $1 / 4$ " NPT female ports.

A "High Temperature Trim Kit" is available for the PCS. With the PCS trimmed out for high temperature deployments it can withstand temperatures as high as $125^{\circ} \mathrm{C}$ for short times and still function. Reference Appendix M "PCS Technical Manual" and Appendix N "PCS Parts List" for further information regarding high temperature deployments.

\section{Problems}

Although the PCS is a much less complicated design than its predecessor, the PCB, it still requires intimate knowledge of its inner workings to ensure a successful deployment. The deployment history accumulated thus far probably does not represent the true capability of the tool. Besides trying to learn the capabilities and limitations of the tool several operators were being trained. Thus "pilot error" is revealed in the data as well as actual tool failures. However, a few problems have come to light as follows.

1. Detritus - The PCS is somewhat sensitive to the infiltration of detritus into its inner workings. This was revealed on Leg 131, Hole 808F, Core 2P, when the PCS was deployed into a very sandy formation. When actuated, the tool partially stroked closed and then seized with due to ingrained sand. Besides not recovering core or retaining pressure, the tool became a nightmare to disassemble. Two solutions to this problem have been initiated since this occurrence. First, the PCS is thoroughly cleaned and checked for free operation before deployment. Second, the core is now "drilled dry", that is, no circulation is used during cutting of the core. Coring without circulation lessens the chance of circulating cuttings into the PCS inner workings, and also reduces contamination of the core.

2. Seal Failure - The PCS has many types of seals. O-rings, an industry standard, are used extensively throughout the PCS. Although o-rings are a very forgiving seal, care must be taken during assembly not to damage them. Due to the placement of some of the o-rings, extra effort on the part of the operator is required to ensure undamaged assembly. The PCS uses polypak seals in a dynamic application. Although polypak seals are also an industry standard and very reliable, any dynamic seal is subject to damage. The ball valve uses a custom seal which to date has been very reliable even though it is a dynamic seal.

3. Bullet Valve Failure - The PCS uses small integral valves called Bullet Valves. These valves press a small diameter stainless steel ball into a metal seat, which is an integral part of the valve housing, to form a seal. 
These valves have been the source of numerous leaks. The metal seats corrode, reducing the effectiveness of the seal.

4. Actuator Latch - The actuator latch locks the ball valve open during deployment and coring operations. The latch also locks the ball valve closed during retrieval of the tool. The spacing between the two latch points is controlled by shims which must be adjusted to compensate for machining tolerances. Every time new parts are added to the assembly the shim spacing must be checked and adjusted as required. Twice the shim adjustment was found to be incorrect. At this time it is not clear whether the shim spacing was not properly checked after adding new parts to the assembly or if something else yet undetected influences the shim spacing. Only further deployments will reveal the answer.

5. Spring Housings - The PCS uses several springs in its assembly. Originally these springs were made from ferrous alloys. High temperatures and corrosive borehole fluids were anticipated on Leg 139, and thus the ferrous alloy springs were replaced with titanium springs. To minimize inventory, the titanium springs were made part of the standard PCS assembly. Due to the difference in material properties the titanium springs free lengths were considerably longer than those of the ferrous alloy springs. This makes assembly difficult and disassembly unsafe. 


\section{RECOMMENDATIONS FOR FUTURE IMPROVEMENTS}

In general the basic PCS concept functions exceptionally well. The tool is considerably less complicated than its predecessor and impacts rig floor operation very little. No major redesign is recommended at this time. However, Phase II in the PCS development, while maintaining the basic concept, will require several subassemblies, such as the ball valve and manifold, to be completely redesigned.

The seal failure problem, although frustrating, does not require further study at this time. However, as new parts are made, the seal gland configurations should be reviewed and optimized for increased reliability where possible. This optimization should carry over into the Phase II development.

The bullet valve failures can be reduced by making all replacement valve housings from a corrosion resistant material. Note that this change is in process at this time.

The actuator latch problems will have to be observed closely, and documented, in future deployments to determine the exact cause and a solution initiated.

The spring housings should be redesigned to eliminate the safety problems during assembly and disassembly. Note that this change is in process at this time.

An overall safety study should be carried out by a third party to review the PCS design and all aspects of its operation. Some of the aspects to be considered are:

1. Pressure containing capability of the sample chamber.

2. Pressure release safety mechanisms.

3. Handling of the pressurized tool on the rig floor.

4. Connection of sampling manifolds and monitoring equipment.

5. General sampling manifold design and operation. 


\title{
PCS ASSEMBLY DRAWINGS
}

Note: Due to space and budget constraints the PCS Assembly Drawings (OP6200, OP6202, and OP6204) have been omitted from this technical note. If you need to obtain a set of these drawings please contact the Ocean Drilling Program.

\author{
Ocean Drilling Program \\ Texas A\&M University \\ 1000 Discovery Drive \\ College Station, Texas 77845 \\ Attn: Engineering Department \\ (409) $845-8481$
}


Appendix A

Gas Hydrate Drilling In The Ocean Drilling Program 
Figures and Table 


\section{DESIGN AND OPERATION OF A WIRELINE PRESSURE CORE BARREL}

\section{STAGE 1}

1. BALL OPEN

2. ASSEMBLY LATCHED

3. CORING AHEAD

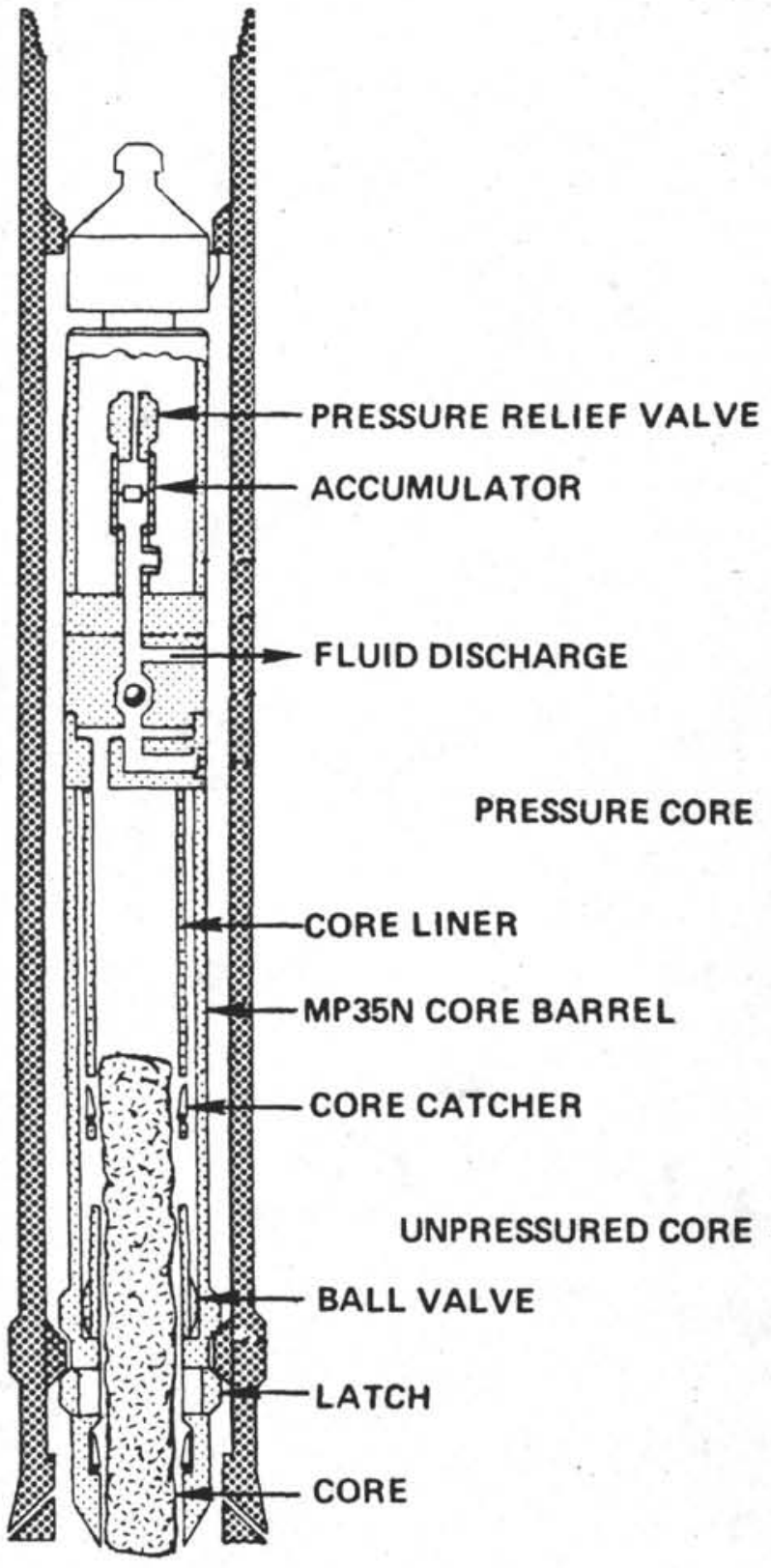

STAGE 2

1. BALL CLOSED

2. ASSEMBLY UNLATCHED

3. RETRIEVING PRESSURIZED CORE

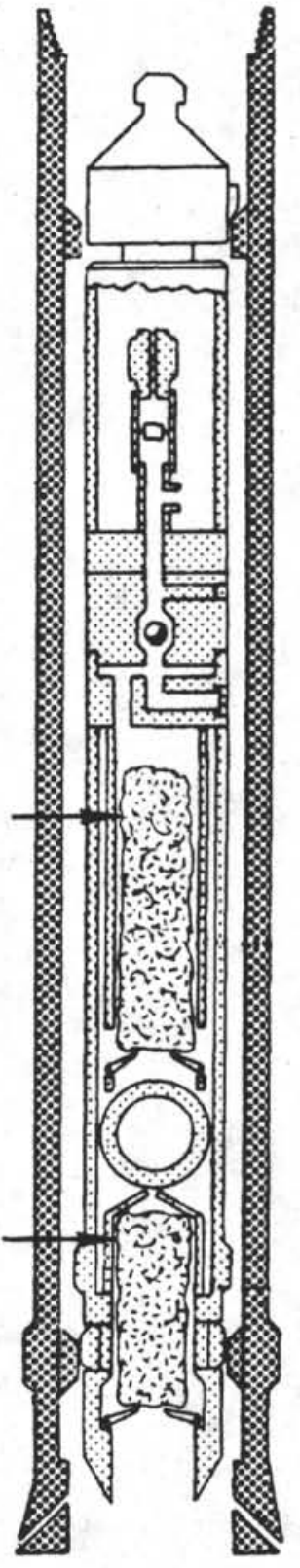

\section{FIGURE 1}




\section{PRESSURE CORE SAMPLER (PCS) OPERATING SCHEMATIC}

\section{CORING \\ $\underline{A H E A D}$}

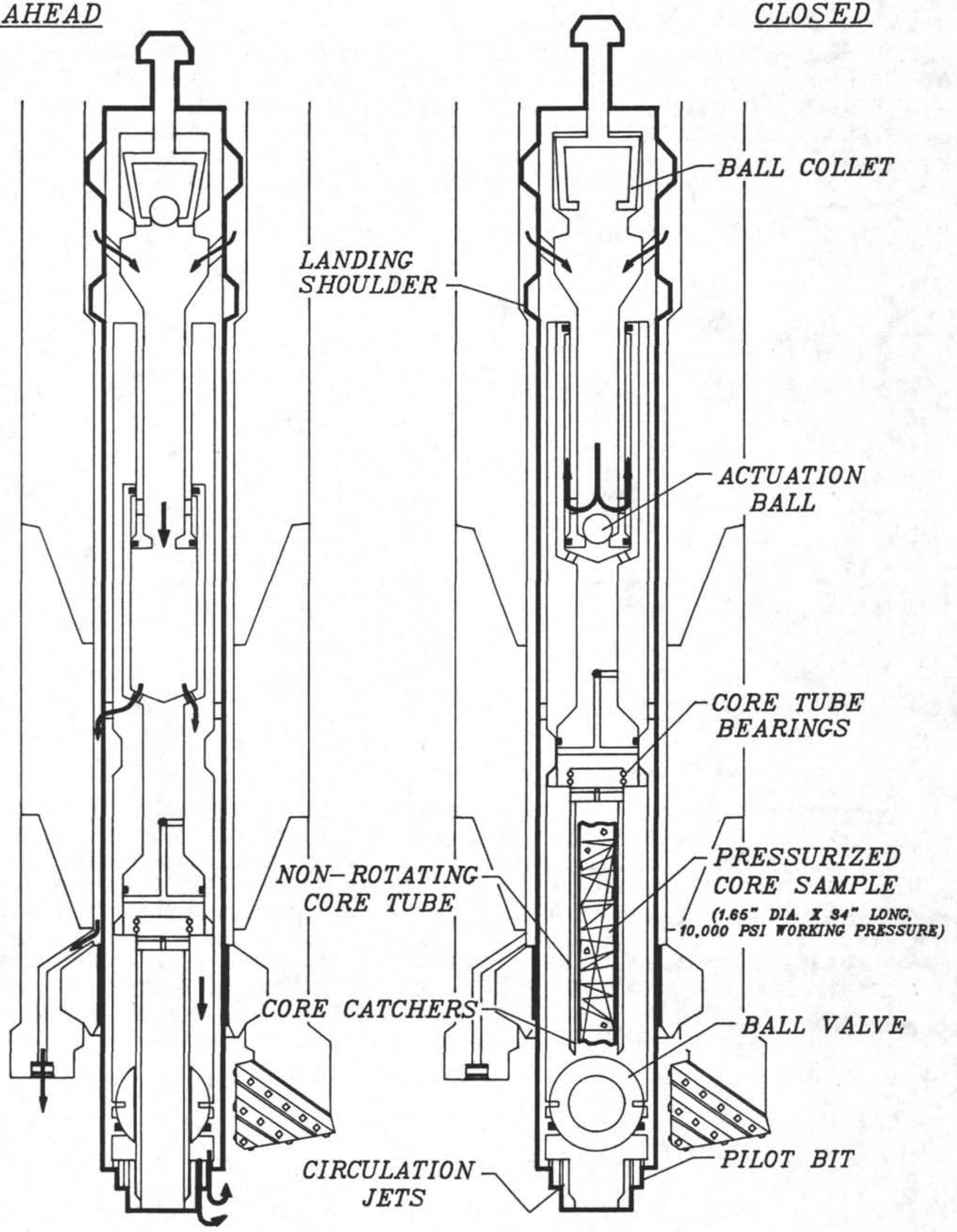




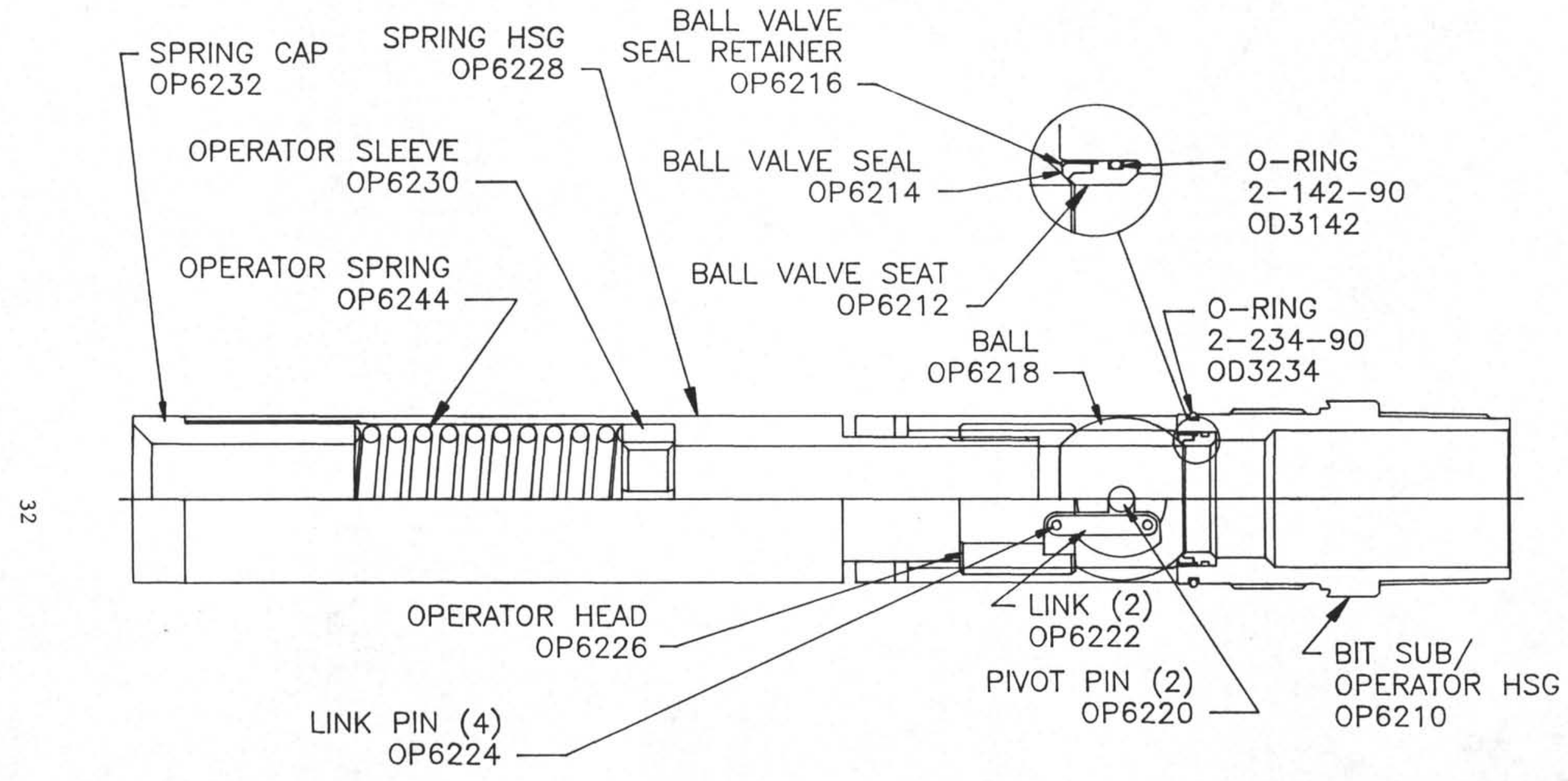

FIGURE 3

PCS I BALL VALVE SUBASSEMBLY 


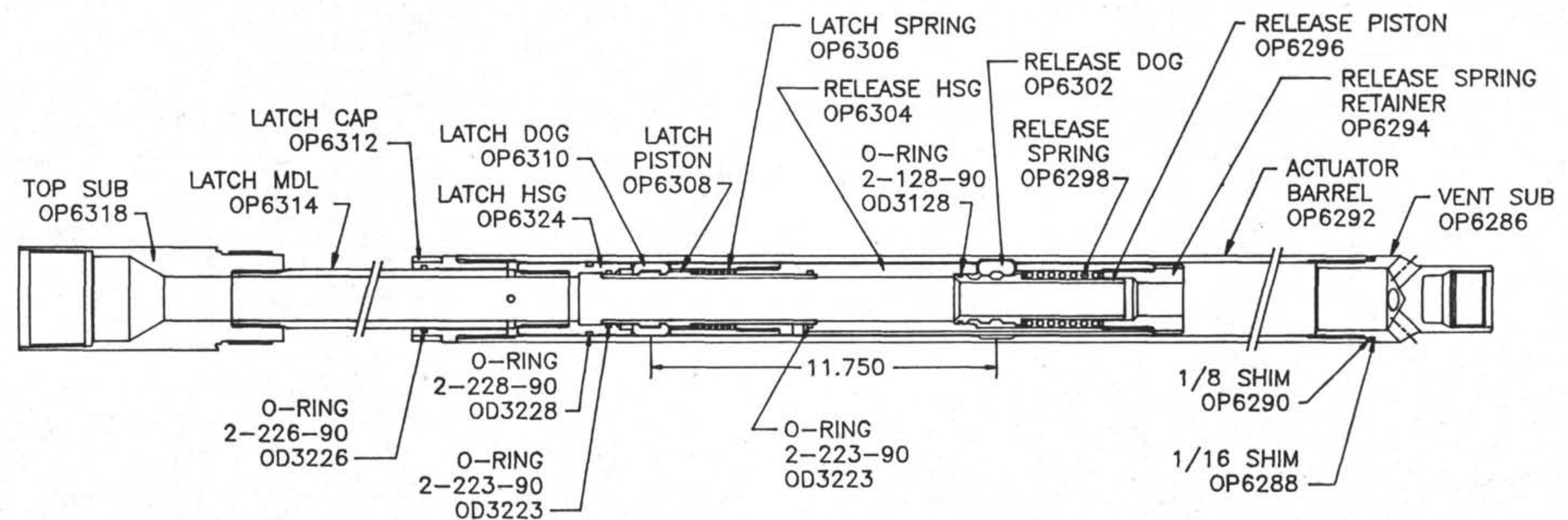

FIGURE 4 


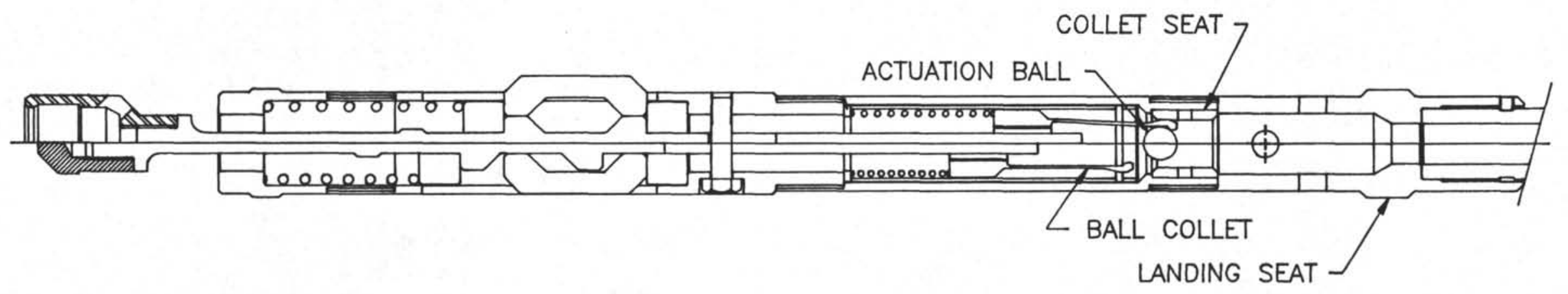

NOTE: REFERENCE ASSEMBLY DRAWING OP6200 FOR INDIVIDUAL PART NUMBERS

FIGURE 5

PCS I LATCH SUBASSEMBLY 


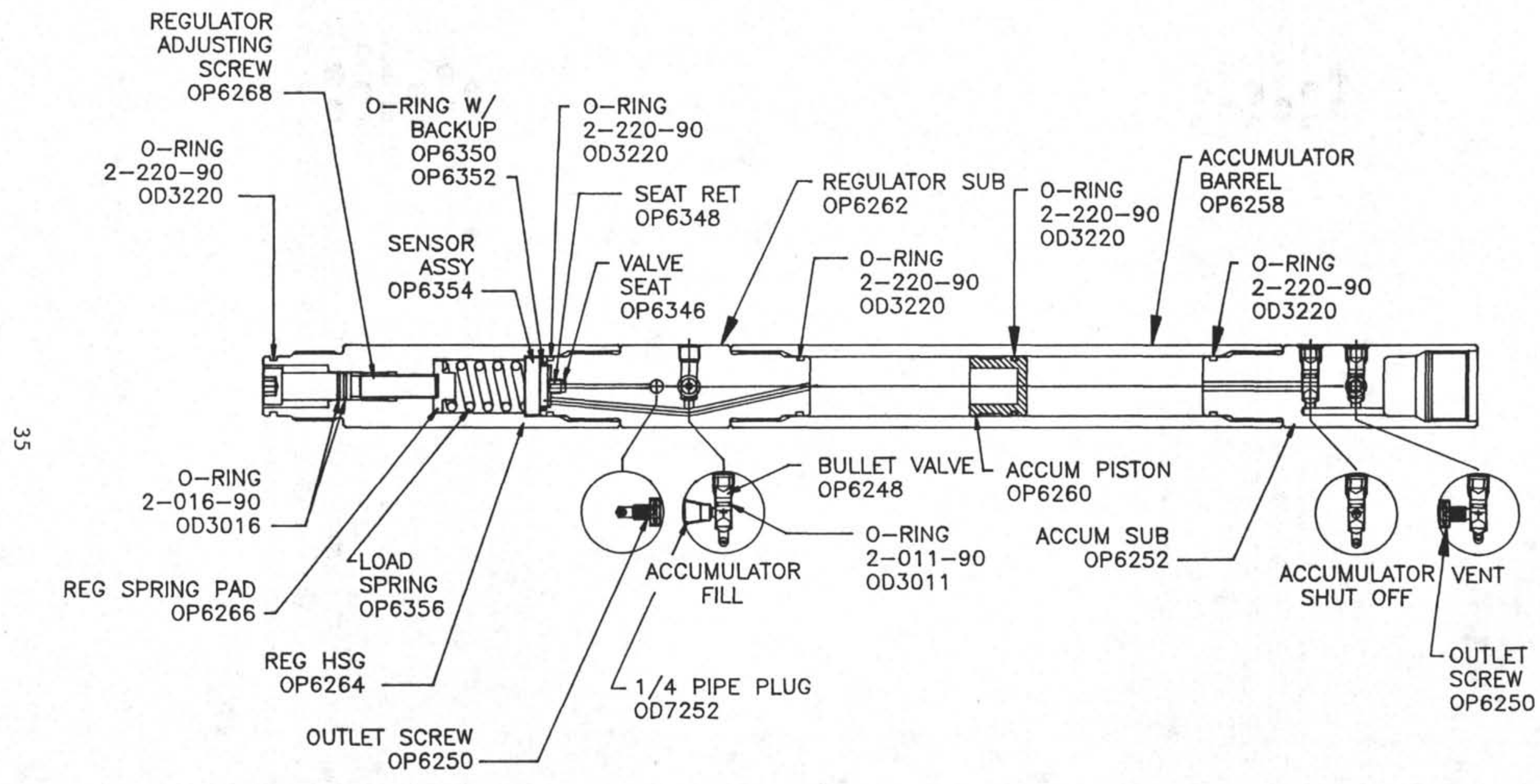

FIGURE 6

PCS I ACCUMULATOR SUBASSEMBLY 


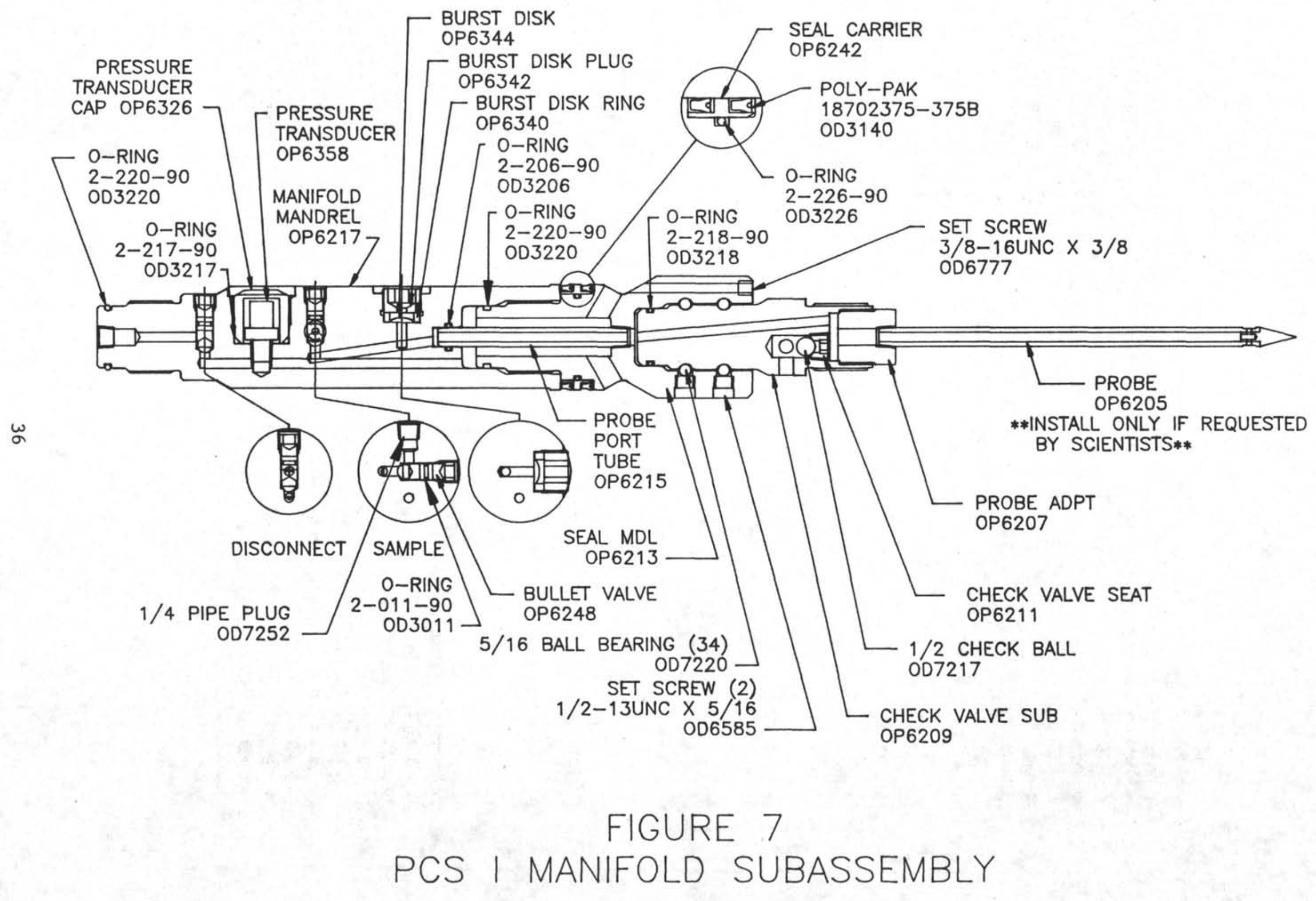




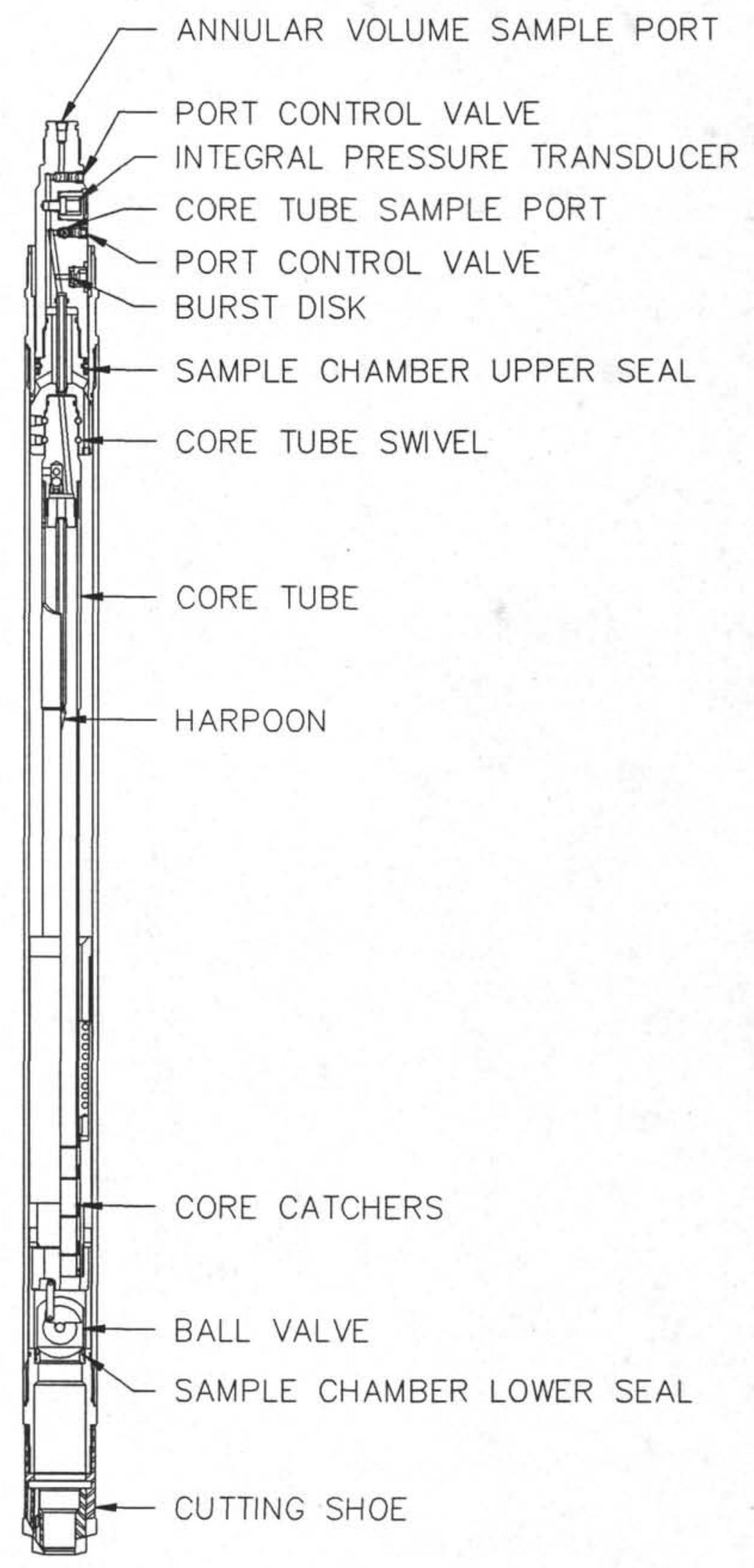

\author{
FIGURE 8 \\ PCS I SAMPLE CHAMBER
}



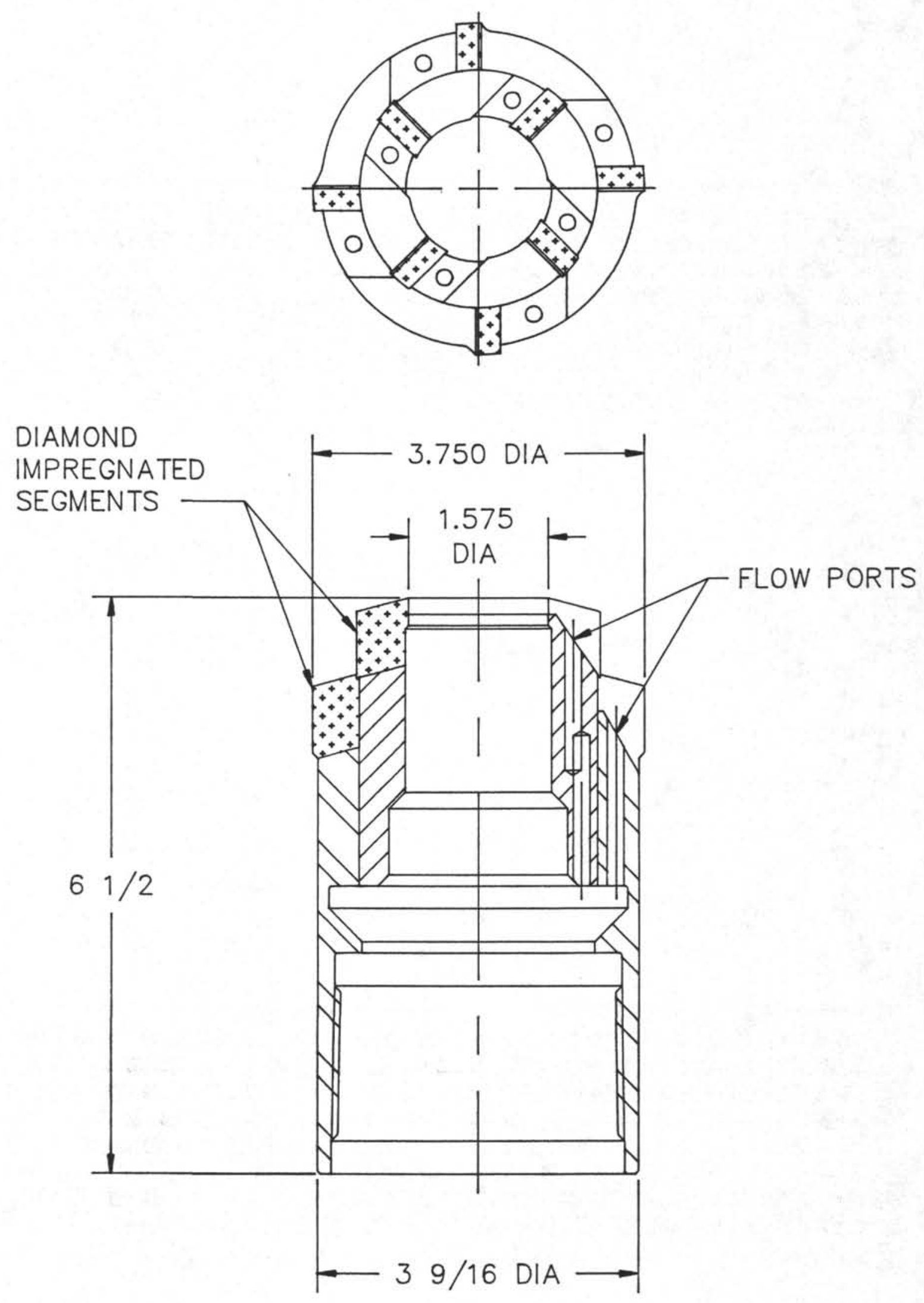

FIGURE 9

PCS I CUTTING SHOE 


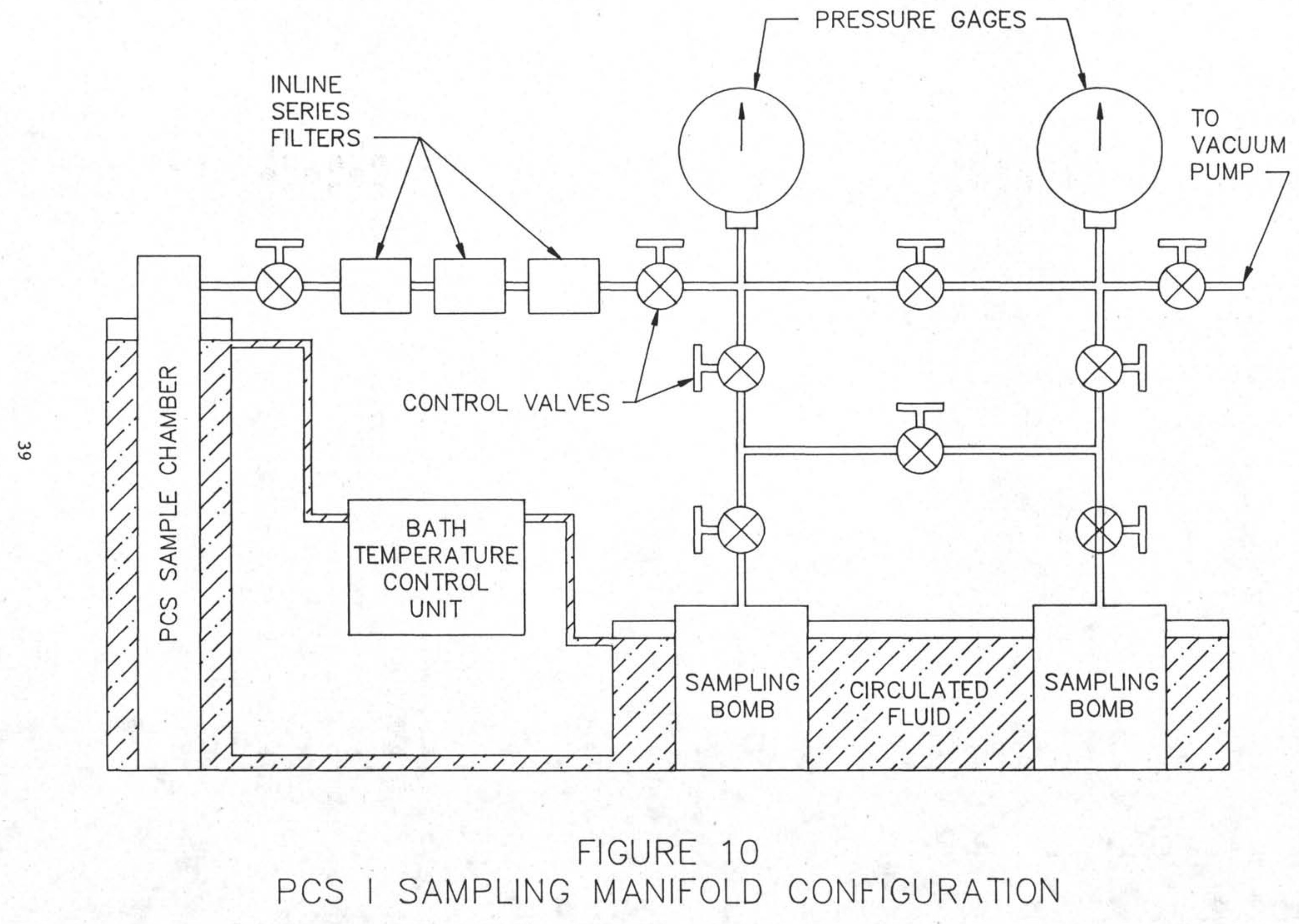




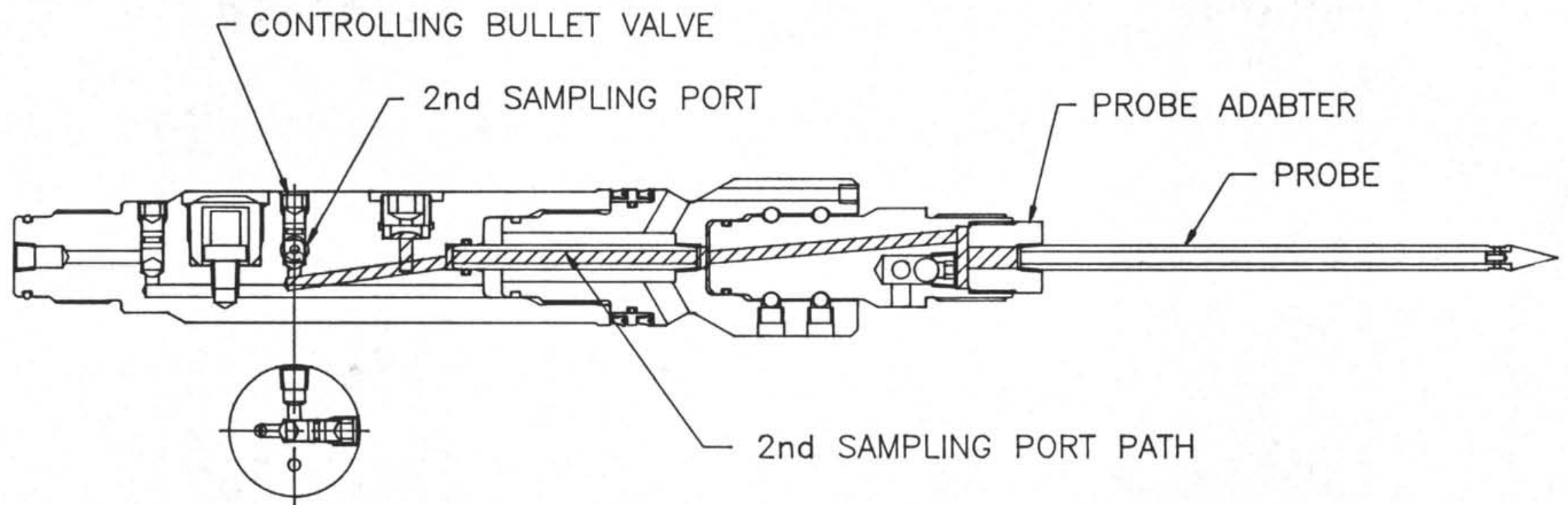

FIGURE 11

PCS I PROBE \& 2nd PORT MODIFICATIONS 
TABLE I: PCS OPERATIONAL RESULTS

LEG SITE CORE CORE

NO. NO. NO. DEPTH

$124 \mathrm{E} 772 \mathrm{n} / \mathrm{a} 1528.0 \mathrm{~m}$

$124 \mathrm{E} 772$

$5 \mathrm{P} \quad 1678.0 \mathrm{~m}$
CORE

$\mathrm{n} / \mathrm{a}$

$0.86 \mathrm{~m}$

\section{PRESSURE COMMENTS}

RECOVERY

2240 psi Initial water core taken to test mechanism without core contamination

500 psi $100 \%$ core recovery, pressure loss attributed to sticking accumulator piston

$124 \mathrm{E} 773 \quad 15 \mathrm{P} \quad 1871.0 \mathrm{~m} \quad 0.86 \mathrm{~m}$

2740 psi $100 \%$ core recovered, $100 \%$ hydrostatic pressure maintained

$131808 \mathrm{~F}$ 2P $4751.0 \mathrm{~m}$-0- $0-0$ Tool sanded up making it inoperable

$131808 \mathrm{G} \quad 6 \mathrm{P} \quad 4881.0 \mathrm{~m} \quad 0.69 \mathrm{~m} \quad 350 \mathrm{psi}$ Full hydrostatic pressure was believed to have been retrieved, low pressure indicated was measured after the tool had been placed in cold storage for $45 \mathrm{~min}$

139 857A 3P $2450.0 \mathrm{~m} \quad 0.05 \mathrm{~m} \quad$-0- o-ring leak, core washed away

$139.857 \mathrm{~A} 14 \mathrm{p} 2540.3 \mathrm{~m} \quad 0.56 \mathrm{~m} \quad-0-$ Ball valve did not latch closed

139 858A 10P $2492.0 \mathrm{~m} \quad 0.46 \mathrm{~m} \quad-0$

-0- No gas, pressure lost due to volume change whe n connecting sampling manifold

Core washed away, no pressure due to volume change when connecting sampling manifold

$139858 \mathrm{D} \quad 3 \mathrm{P} \quad 2445.0 \mathrm{~m} \quad 0.56 \mathrm{~m} \quad 800 \mathrm{psi}$
Reason for pressure loss unknown 


\begin{tabular}{|c|c|c|c|c|c|c|c|c|}
\hline 141 & $859 A$ & $9 \mathrm{P}$ & 2810.7 & $\mathrm{~m}$ & 0.03 & $\mathrm{~m}$ & $-0-$ & Open port valve \\
\hline 141 & $859 A$ & $12 \mathrm{P}$ & 2830.3 & $\mathrm{~m}$ & 0.24 & $\mathrm{~m}$ & $-0-$ & $\begin{array}{l}\text { Ball valve did not } \\
\text { latch closed }\end{array}$ \\
\hline 141 & $859 A$ & $15 \mathrm{P}$ & 2852.1 & $\mathrm{~m}$ & 0.37 & $\mathrm{~m}$ & 100 psi & Accumulator leaked \\
\hline 141 & $859 A$ & $21 P$ & 2899.8 & $\mathrm{~m}$ & 0.28 & $\mathrm{~m}$ & $350 \mathrm{psi}$ & $\begin{array}{l}\text { Possible volume } \\
\text { change pressure loss }\end{array}$ \\
\hline 141 & $860 B$ & $8 \mathrm{P}$ & 2217.0 & $\mathrm{~m}$ & 0.00 & $\mathrm{~m}$ & $3791 \mathrm{psi}$ & Core jam \\
\hline 141 & $860 B$ & $13 P$ & 2254.7 & m & 0.61 & $\mathrm{~m}$ & $3012 \mathrm{psi}$ & Good run \\
\hline 141 & $860 \mathrm{~B}$ & $15 \mathrm{P}$ & 2852.1 & $\mathrm{~m}$ & $-0-$ & & $-0-$ & $\begin{array}{l}\text { Ball valve did not } \\
\text { latch closed }\end{array}$ \\
\hline 141 & $861 C$ & $9 \mathrm{P}$ & 1734.5 & $\mathrm{~m}$ & 0.23 & $\mathrm{~m}$ & $-0-$ & Ball valve leaked \\
\hline 141 & $861 C$ & $20 P$ & 1833.7 & $\mathrm{~m}$ & $-0-$ & & $-0-$ & $\begin{array}{l}\text { B a } 1 \text { l v a l v } \\
\text { misassembled }\end{array}$ \\
\hline 141 & $861 \mathrm{C}$ & $26 P$ & 1883.6 & $\mathrm{~m}$ & 0.86 & $\mathrm{~m}$ & $115 \mathrm{psi}$ & Unknown leak \\
\hline 141 & $861 C$ & $30 P$ & 1911.8 & $\mathrm{~m}$ & 0.68 & $\mathrm{~m}$ & $190 \mathrm{psi}$ & Unknown leak \\
\hline
\end{tabular}




\section{Gas Hydrate Drilling in the Ocean Drilling Program}

T.J.G. Francis, A.W. Meyer, Ti Pettigrew, and M. von Breymann (All at: Ocean Drilling Program, 1000 Discovery Drive, Texas A\&M University, College Station, TX 77845) Talk presented by: K.A. Kvenvolden (U.S.Geological Survey, M/S999, 345 Middlefield Road, Menlo Park, CA 94025

The Ocean Drilling Program (ODP) is an international partnership of scientists and governments from 19 nations joined together to explore Earth's ocean basins. JOIDES Resolution, registered as SEDCOIBP 471, is the research drillship for ODP. The ship is 470 feet long with a derrick that towers 200 feet above the waterline; it can drill in water depths up to 27,000 feet and can suspend as much as 30,000 feet of drill pipe. A sevenstory laboratory stack functions as the heart of this floating research center, providing space and equipment for studies in sedimentology, paleontology, geochemistry, geophysics, petrology, paleomagnetics, and physical properties. Because of JOIDES Resolution's deep drilling and scientific capabilities, ODP provides an important platform for the study of gas hydrates occurring in oceanic sediments.

To discuss gas hydrate drilling in ODP, a workshop entitled "Gas Hydrates and Ocean Drilling" was recently held at ODP Headquarters in College Station, Texas. The meeting was co-chaired by Erwin Suess (GEOMAR, Univ. Kiel, F.R.G.) and Keith Kvenvolden (U.S.G.S., Menlo Park, CA); a total of about 35 scientists participated. The purpose of the meeting was to review the geological, physical-chemical, and geophysical aspects of gas hydrates in oceanic sediments in order to provide guidance to ODP for drilling, coring, and testing gas hydrates that will be encountered on future ODP legs. Discussions during the meeting centered around six main topics: gas hydrates and the global methane budget, physical-chemical characteristics of gas hydrates, geophysical characteristics of gas hydrates, technological developments of an ODP pressure core sampler (PCS), safety procedures for drilling of gas hydrates by ODP, and gas hydrate objectives for ODP during fiscal year 1992.

The two cruises planned for FY92 that have gas hydrate objectives are Leg 141 to study the Chile Triple Junction (17 November 1991-13 January 1992), and Leg 146 to study the Cascadia margin (26 September-21 November 1992). Drilling on Leg 141 will investigate the region of the Chile Trench between $45^{\circ}$ and $47 \circ \mathrm{S}$ latitude, where the active Chile Ridge spreading system intersects the Chile Trench in a ridge-trench-trench triple junction involving the South American, Antarctic, and Nazca plates. Of interest in gas hydrate research is Line 745 where three holes are scheduled for drilling. Along this line the BSR is quasi-continuous and two holes will penetrate the BSR if approved by the JOIDES Pollution Prevention and Safety Panel. In addition, one hole will be drilled near the toe of the slope on Line 750, and one hole will penetrate the region of the triple junction on Line 751.

Leg 146 will drill two transects of sites on the Cascadia margin to define fluid expulsion and physical properties. One transect of sites, drilled offshore Vancouver, will test diffuse fluid flow; another transect of sites, offshore Oregon, will test focused fluid flow. The objectives of the hydrate studies during Leg 146 are: (1) calibration of BSR pressuretemperature conditions; (2) measurement of velocity, porosity, permeability and estimates of heat flow; (3) calibration of seismic data; (4) testing of gas hydrate formation models; and, (5) evaluation of diagenetic associations of gas hydrates.

Current ODP drilling practices are capable of recovering partially decomposed samples of gas hydrate. To make the study of gas hydrates quantitative, ODP is developing a pressure core sampler which is capable of recovering cores at near in situ pressures. This device will not only provide information about gas hydrates, but also about the composition and concentration of fluids within and below the zone of gas hydrate stability. The current version of the PCS (Phase I) has a $6 \mathrm{ft}$. pressurized section containing a 32" 
core sample, and 2 fluid sampling ports; it provides for recovering gas and/or water samples under bottom hole pressure, but does not have the capability for the transfer of cored sediments under pressure. This Phase I prototype PCS has been tested 5 times, 3 times on Leg 124 and twice on Leg 131, with various degrees of success. The Phase II version of the PCS will allow for transfer of pressurized core samples while maintaining bottom hole pressure; Phase II development is on hold until a viable lab chamber proposal is submitted. This lab chamber would ideally be capable of receiving PCS core samples and allowing access to the samples for scientific purposes while maintaining bottom hole pressure. 
Appendix B

Report On Sampling Of Formation Fluids In The ODP 
Report on Sampling of Formation Fluids in the Occan Drilling Program

To: Sedimentary and Geochemical Processes Panel

OtSTINDRILINE

$\therefore x^{2}$

From: Subcommittee on Pore Fluids (Flip Froelich, Harry Elderfield, Fred Prahl)

September 24, 1989

(Revised January 7, 1990)

Prologue: Statement of the Problem

SGPP is concerned that the effort to understand fluid circulation, composition, and chemical interactions in sedimented ridges and accretionary prisms will require a dedicated effort by ODP to quickly perfect new fluid sampling techniques and procedures, including providing a functional technology (even if only an interim solution) for use during the Nankai Legs and beyond. This short paper addresses the shortcomings of present methods, and briefly reviews those parameters which are of highest priority to SGPP for any fluid sampling strategy.

Ideally, formation fluids must be recovered with their in situ compositions, temperatures, and pressures unaltered. Gas compositions are critical in accretionary prisms (volatile hydrocarbons, $\mathrm{CO}_{2}, \mathrm{CH}_{4}$, noble gases, $\mathrm{H}_{2} \mathrm{~S}$ ), particularly in clathrate zones. Chemical contamination and oxidation artifacts must be eliminated in order to obtain valid fluid compositions, particularly for the transition metals, in zones where metallogenesis processes are important (bare and sedimented ridge crests and active accretionary wedges). The capability must exist to recover high-temperature fluids (up to $400{ }^{\circ} \mathrm{C}$ ) from very corrosive and acidic environments (containing $\mathrm{H}_{2} \mathrm{~S}$ and soluble metal sulfides). Samples must also be demonstrably free of artifacts due to entrainment of drilling fluids. No one procedure seems capable of accomplishing all these goals and also of producing rapid (high resolution) down-hole fluid chemical compositions. Thus we believe that successful marriage of a modified shipboard sampling protocol with the new Pressure Core Barrel (PCB, which ODP calls a Pressure Core Sampler, PCS) may be the best short-term answer ( $<5$ years) toward accomplishing most of our goals. However, this committee is uncertain of the immediate plans for the PCB and wishes to be kept abrest of its development and testing via a direct link between the engineers/staff scientists most closely linked to this 
ject (Tom Pettigrew) and the members of this sub-committee. Our immediate concem is INTEROFFICE MEMORANDUM thase Ir or the Tes oc ready Tor usc curng the Nankin Legs.

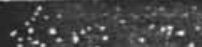

$\therefore+19=8$

$\therefore-\because$

OEEAN DAILLINL PROGRAT

ipboard vs. in situ Samples

These procedures, as presently practiced aboard JOIDES Resolution, have ficiencies. Shipboard sampling of wholerounds (Manheim-Sayles method), cut and ueezed immediately after core retrieval, can not provide reliable gas compositions nor eliminate artifacts due to pressure effects on solution-solid equilibria. However, in principle, shipboard squeezing can, with minor modifications, eliminate (or at least test for and minimize) temperature- and redox-artifacts. Squeezers composed of titanium or eith teflon jackets (rather than stainless steel) can eliminate contamination due to iron-alloy metals and the formation of surficial FeS surface phases that can sequester other metals from anoxic fluids. Carcful temperature control of the squeezers prior to loading and squeezing can climinate most tcmperature artifacts. By cutting, transferring, and loading wholerounds at the rail under an inert atmosphere, most redox artifacts can be minimized (at least those with slow kinetics), provided a suitably rapid and reliable mears of cutting and transferring whole-rounds on deck can be designed. Thus shipboard squeezing, with a few simple modifications, can generate much valuable high resolution down hole information. It has the advantage of being ship-time efficient (no additional wire-time is required). It has the disadvantages of being shipboard labor intensive and inappropriate for gases or other constituents with severe pressure artifacts.

In situ sampling has the advantage of being the only practical means of eliminating artifacts due to depressurization and is thus critical for obtaining information on gas compositions, particularly in clathrates. The present design of in situ sampler (Bames tool, based on harpoon technology) relies on separation of fluids from the formation at the bottom of the hole and can return samples without temperature and pressure artifacts of solution chemistry. This tool also provides an in situ temperature estimate and could be redesigned to measure electrical resistivity (in situ formation factors). However, this tool is ship-time inefficient, returns only one sample per wire-trip, has repeatedly proven unreliable, and massive failure risks the bottom of the hole. Chief Scientists are thus reluctant to employ this tool until after the final (bottom) hole objective is reached. In addition, it does not recover a sample of the formation from which the fluid was obtained, and can only be adapted to return either gas samples; or uncontaminated transition-metal samples, but not both at the same time. 
The newly-designed pressure core barrel (РСB), while still in development, could ntially return to the ship a sample of the formation and its fluids and gases under in situ sure and without contamination (if constructed of titanium). It is also potentially perature-controllable, so that it is capablc of recovering gas and fluid compositions out PT-artifacts. It has the disadvantage of returning only one sariple per wire trip, but the advantage that multiple lock-on chambers can be employed to separate the ccie material under in situ conditions into various subsamples for different purposes. We believe that the $\mathrm{PCB}$ contains the seeds of a reliable in situ sampling device that has the best chance of providing reliable data.

In the following paragraphs, we address (1) improvements in shipboard methods and protocols and (2) development of the pressure core barrel. Other features of SGPP's concerns for fluid sampling (packers, high-temperature sampling. instrumented holes) are either contained in the SGPP White Paper or will be addressed elsewhere.

Improvements in Shipboard Methods and Protocols

1. Squeezers should be composed of titantium (or some other inert, non-ferrous, material) to eliminate Fe-alloy contamination problems. (Froclich's titanium squeezer and designs have been forwarded to ODP and iie process is underway.)

2. Shipboard technicians should be instructed to pre-refrigerate squeezers at in situ temperaturcs in a T-controllable refrigerator prior to loading and squeezing. Some knowledge of the thermal gradient expected in each hole will be required.

3. ODP should consider alternative methods of separating pore fluids from sediments aboard ship, particularly for the upper $200 \mathrm{~m}$ of high porosity sediments such as those encountered on legs 113, 114,119, and 120. For example, ultra-centrifugation (gimbaled) inside a walk-in reefer has the advantage of being potentially amenable to controlling temperature- and redox-artif:cts in some types of sediments.

4. Abandon the $1 / 2$ round sampling strategy. (In effect.) 
mmittee will design a simple and appropriate strategy for retaining the initial redox state shipboard wholerounds for future considcrations and testing.

essure Core Barrel

ODP ACTION: This sub-committec requests that ODP provide SGPP with design drawings and text outlining the intended capabilities of the $\mathrm{PCB}$ through its various phases of development. (Note added in revision: Tom Pettigrew has provided Froelich with this information in late 1989). Our aim is to assist ODP in perfecting a device that best addresses the overall requirements of an in situ sampler.

This committec has only recently become aware of the PCB and is not up-to-date on developments by ODP. The highest priority mission for the PCB should be the recovery of gas compositions under in situ pressures since no other means is currently available to capture gases. Secondary missions should include (1) the cafability to separate fluids from the solids under in situ temperatures and pressures immediately after retrieval on deck, (2) to hold the solids at in situ temperatures and pressures shipboard for microbiological and physical properies measurements (presumably by remote sensing via lock-on chambers), and (3) to enable manipulations of a split of the sample through the use of a variety of lockon transfer chambers. We envision the ultimate development of a variety of user-specific PCB's and/or lock-on chambers, some with remote sensing capabilities to measure velocity, density, thermal and electrical conductivity, etc. under in situ conditions, others with the capability to add tracers or withdraw gases, solutions, or solids.

Specific Questions:

1. Can the PCB (Phase Il and beyond) be constructed from titantium (or some other material -- glassy carbon ??) to climinatc $\mathrm{Fe}$-alloy contamination and $\mathrm{H}_{2} \mathrm{~S}-\mathrm{Fe}$ interations ?

2. Thermal control: During testing and deployment of Phase I and II, the temperature of the sediment contained inside the PCB should be monitored during coring and recovery' to determine the thermal history of the recovered interval: Is the device sufficiently thermally insulated (or have a high enough thermal inertia) to limit the temperature rise to less than $2{ }^{\circ} \mathrm{C}$ over the time interval between coring and transfer to a T-controlled 


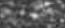

3. A pressure core barrel (for use as a deep-sea corer deployed on a hydrowire) has developed and tested by Dr. Rick Jahnke (Skidaway Inst. Oceanography). This ice uses the internal overpressure to "self-squeeze" (scparate the fluids from the solids) ugh ports segmented along the barrel. Can the ODP-PCB be designed to contain one such port or manifold (perhaps as an ancillary end cap) so that fluid samples can be obtained? Alternatively, can the PCB be designed as a giant squeezer? 
Appendix C

The Clathrate Study System (Progress Report) 


\section{THE CLATHRATE STUDY SYSTEM PROGRESS REPORT}

\section{G. Brass \&. Kastner}

1. IDAS: The Isothermal Decompression Analysis System (IDAS) is nearing completion at RSMAS. It consists of two Parr Model 4652 , 6000 psi pressure vessels, each capable of containing half a PCS core, a temperature controlled cooling bath, and a Helium pressurization manifold with high pressure (Snotrik) valves and fittings, and a calibrated, digital pressure gage. The pressure vessels contain a thermocouple well for temperature monitoring, a needle valve and gas pipette system with a $500 \mathrm{cc}$ expansion cylinder and a gas sampling port and, a dip tube for sampling fluids.

The IDAS system will be capable of studying samples which can be decompressed and either cryogenically stored or transferred immediately to the IDAS sample chambers. The system is fairly small and could be used aboard ship. After testing in Miami the IDAS will be transported to sIo in June for use on the samples collected during Leg 131 (the Nankai Leg). Other clathrate samples may be available in the Fall.

2. The next stage: Design studies are underway for the construction of a free piston squeezer for clathrate studies. This system will be designed to lock onto the ODP Pressure Core Sampler and transfer cores or parts of cores at pressure into a titanium squeezer. Helium will be used to pressurize the sample side of the squeezer and high pressure water will be used to manipulate the piston. This system will be able to make measurements of gas and pore fluid compositions during decompression. It will be able to add and then remove Helium in order to measure head space gas compositions and partial pressures. It will also permit the production of artificial clathrates in sediment samples. Instrumentation of the system for such studies as sound velocity and calorimetric measurements will be developed as "add ons". A proposal for the construction of this system as a "third party tool" will be submitted to NSF ODP as soon as the initial results of IDAS have been studied. 
Appendix D

\section{PCS Phase I Design Statement Of Work}


1. Must be compatable with ODP APC/XCB coring equipment and operations.

2. Working pressure $=7,500-10,000$ psi.

3. Design safety factor $=4: 1$.

4. Corrosion resistant.

5. Detachable from the core barrel and still maintain pressure containing ability.

6. Corrosion resistant ball type closure.

- NOTE: The ball closure will not be manipulated under differiential pressure loads.

7. Sample capacity of $300-1200 \mathrm{cc}$ with as large a core diarneter as possible.

8. Access port for subsampling gases and coupling to pressure maintaining and safety pressure relief equipment.

9. Means of continuious monitoring of sample temperature and pressure on deck and possibly down hole.

D. Design an actuation mechanism to manipulate the sample chamber ball closure down hole with the following capabilities and constraints:

1. Must be compatable with ODP APC/XCB coring equipment and operations.

2. Must be easily detachable from the sample chamber.

E. Design a redundant safety pressure relief mechanism with the following capabilities and constraints:

1. Must be compatable with ODP APC/XCB coring equipment and operations.

2. Working pressure $=7,500-10,000 \mathrm{psi}$.

3. Design safety factor $=4: 1$.

-

4. Must include at least a rupture disk and pressure relief value.

5. All pressure relief mechanisms are to be shrouded at all times in such a way as to prevent injury or damage to occur in the event that pressure is suddenly released. 
F. Design or lacate a container that will serve as safety shroud and constant temperature bath for the sample chamber when it is removed from the core barrel.

G. Design or locate a manifold that will allow gases and/or fluids to be withdrawn from the sample chamber into a vacuum container through a flow meter capable of monitoring total flow.

H. Specify instrumentation to display and record the sample temperature and pressure on deck.

I. Produce the necessary sketches, drawings, specifications and descriptions of the pressure core sampler components for fabrication and assembly.

II I. DEL IUERABLES

A. Accurate sketches or drawings of the pressure care sampler assembly, its components and any associated equipment required to assemble and operate the pressure core sampler which require fabrication, suitable for ODP to make complete machine drawings from.

B. Accurate descriptions of any and all purchased parts and equipment required to assemble and operate the pressure core sampler, suitable for ODP to procure such parts and equipment.

C. Complete written instructions including assembly, operation, handling, safety, maintenance and any other pertinent subject pertaining to the fabrication, assembly, operation and starage of the pressure core sampler.

D. Complete parts 1 ist.

E. Recommended spare parts 1 ist. 
Appendix E

\section{PCS Phase I Design Calculations}


The variables for the origlonal barrel area

$$
\begin{array}{ll}
D:=3.75 \cdot \mathrm{in} & \mathrm{d} z=3.25 \cdot \mathrm{in} \\
\mathrm{P} z:=7500 \mathrm{ps} 1 & { }_{y} \quad z=220000 \cdot \mathrm{ps} 1
\end{array}
$$

Where:

$$
\begin{aligned}
& D=\text { Tube Outer Diameter } \\
& \text { d }=\text { Tube Inner Diameter } \\
& \mathbf{P}=\text { Internal Pressure } \\
& \sigma^{1}=\text { Ultimate Strength }
\end{aligned}
$$

First, determine whether to use the thin or thick wall equation for cylinders. If $D / t<10$ the thick wall equation must be used.

$$
\begin{aligned}
& r:=\frac{D}{D-d} \quad r=7.5 \quad \text { (Use thick walleq.) } \\
& t:=\frac{d^{2}+D^{2}}{D^{2}-d^{2}} \cdot P \text { when } P \text { outside }=0 \quad \begin{array}{l}
\text { (the worst case } \\
\text { is at the surface) }
\end{array}
\end{aligned}
$$

Where $\sigma$ is the tangential stress at an internal pressure of $P$,

For the varlables entered above we solve to get:

$\sigma_{t}=52768 \cdot \mathrm{ps} 1$

Now determine the factor of safety:

$N:=\frac{\sigma_{y}}{\sigma_{t}}$

$N=4.169$ Which is above our design goal of 4. 
Fill Ie: ODP-SPR.MCD

PRESSURE CORE SAMPLER

BALL VALVE OPERATOR SPRING DESIGN

Variables:

$D=$ mean coil dis desire dian nenumber of active coils $F=$ force

$G=$ torsional modulus $K=s p r i n g$ constant $T=\max$ shear stress

$\mathrm{D}:=2.562 \mathrm{in}$

$d:=.331 \cdot$ in

$$
K:=100 \cdot \frac{1 b}{\text { in }}
$$

$$
\text { G }:=11.5 \cdot 10^{6} \text { Psi } \quad F_{\text {solid }}:=425 \cdot 1 \mathrm{~b}
$$

CALCULATIONS:

$$
\begin{aligned}
& n:=\frac{d^{4} \cdot G}{8 \cdot D^{3} K} \\
& n=10.261 \\
& L \quad k:=\frac{4 \cdot c-1}{4 \cdot c-4}+\frac{.615}{c} \\
& \text { free } \quad=\frac{\text { solid }}{K}+d \cdot(n+1.5) \\
& \text { free }=8.143 \cdot 1 n
\end{aligned}
$$

SOLID HEIGHT

$$
\begin{aligned}
& \mathrm{F} \quad:=425 \cdot 1 \mathrm{~b} \\
& \text { s } \\
& \tau_{s}:=k \cdot \frac{8 \cdot F \cdot D}{\pi \cdot d} \\
& \tau_{\text {s }}=91041 \mathrm{psi}
\end{aligned}
$$

$$
L_{s}:=L_{\text {free }}-\left[\frac{F}{K}\right]
$$$$
\text { L } \quad=3.893 \cdot \mathrm{in}
$$

WORKING HEIGHT 1

$$
\mathrm{F}_{1}:=300 \cdot 1 \mathrm{~b}
$$

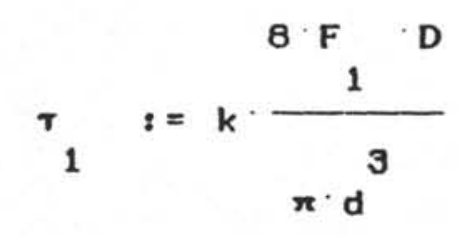

$$
\tau_{1}=64264 \cdot \mathrm{psi}
$$

$$
L_{1}:=L_{\text {free }}-\left[\frac{F}{K}\right]_{2}:=L_{\text {free }}-\left[\frac{2}{K}\right]
$$

$L=5.143 .1 \mathrm{n}$
WORKING HEIGHT 2

$$
\begin{array}{r}
\mathrm{F}:=400 \cdot 1 \mathrm{~b} \\
8 \cdot \mathrm{F} \cdot \mathrm{D}
\end{array}
$$$$
\tau_{2}:=k \cdot \frac{2}{3}
$$$$
\tau=85686 \cdot \mathrm{ps} 1
$$

$$
L=4.143 \cdot 1 n
$$

64 
Variables:

$$
\begin{aligned}
& F_{r e l}:=200 \cdot 1 b_{f} \quad \ldots f o r c e \text { of spring at release } \\
& d:=1.0625 \text { in } \quad \ldots d i a \text { of bore in piston } \\
& D:=2 \cdot \text { in } \quad \text {.. dia of bore in front of piston } \\
& D_{\text {seal }}:=1.6875^{\circ} \text { in } \ldots d i a \text { of piston seal } \\
& \mu:=1.5 \mathrm{cp} \quad \text {...fluid (sea water) viscosity } \\
& 16 \\
& p:=8.4 \cdot \frac{m}{g a l} \quad \ldots \text { mud (sea water) density }
\end{aligned}
$$

The various cross-sectional areas are calcuated as follows:
Aiston $:=\pi \cdot \frac{d^{2}}{4}$
$2 \quad 2$
2 D

And the pressure at which the release piston moves is:

$$
\begin{aligned}
& P_{\max }:=\frac{\mathrm{A}_{\text {rel }}}{\mathrm{P}_{\max }=89 \text { psi }} \quad \begin{array}{l}
\text { This is the pressure drop at } \\
\text { which the Piston would move. }
\end{array}
\end{aligned}
$$

To see if we have laminar flow (fat chance) or turbulent flow we calculate the Renolds Number $(R)$. But first calculate the velocities in the bores for the maximum expected flow.

$$
\begin{aligned}
& Q:=300 \cdot \frac{g a l}{m i n} \quad V:=\frac{Q}{A_{\text {bore }}} \quad v:=\frac{Q}{A} \quad \text { piston } \\
& R:=\frac{d \cdot v \cdot P}{\mu} \quad \text { (Renolds Number) } \\
& R=599172
\end{aligned}
$$


Since flow is turbulent when the Renolds Number is greater then 2000 we must use the turbulent flow equations. The piston is simliar in cross-section to a venturl and since the piston entry is tapered like a venturi and exits into a tube of the same size 1 ' 11 use a discharge coefficient of .95.

$$
\begin{aligned}
& \text { C : : }=.95 \\
& P:=P \cdot \frac{v^{2}}{2} \cdot\left[1-\frac{d}{D}\right] \\
& 2 \cdot \mathrm{C} \\
& \text { v } \\
& P=42 \mathrm{ps} 1 \text { o } 300 \mathrm{gmm} \text {... and the piston will not move. }
\end{aligned}
$$

Using this approach we can determine the flow rate required to move the piston and release the lock:

$$
\begin{aligned}
& Q:=C C^{A} \text { Piston } \sqrt{\frac{2 \cdot P}{\max }} \\
& Q=440 \cdot \frac{g a l}{m i n} \quad \begin{array}{l}
\text {. so we have a factor of safety of about } 1.5 \\
\text { that the piston will not open at } 300 \text { gpm. }
\end{array}
\end{aligned}
$$

A less conservative but probably more accurate approach is to use the equations for a pipe contraction:

$$
\begin{aligned}
& D_{\text {ratio }}:=\frac{d}{D} \\
& \text { ratio }_{\text {ratio }}=0.531
\end{aligned}
$$

$K$ is called the resistance coefficeint and is determined experimentally as a function of the diameter ratio.

$$
\text { for D.ratio }=.53, \quad K:=.32 \text { (from a table in a text book) }
$$

The pressure drop can now be calculated using:

$$
\begin{aligned}
& 2 \\
& P:=P \cdot K \cdot \frac{v}{2} \\
& P=26 \text { psi ...again, the piston will not move } \\
& \text { (it takes } 89 \text { psi to move it) }
\end{aligned}
$$


As before we can calculate the maximum flow rate before the piston moves but this time with the contraction equations instesd of the venturi equations:

$Q:=A_{\text {piston }} \sqrt{\frac{2 \cdot P}{\max }} \quad v:=\frac{Q}{A_{\text {piston }}}$
$Q=561 \cdot \frac{\mathrm{gal}}{\mathrm{mIn}}$

\section{Conclusions:}

The flow would have to be over $440 \mathrm{gPm}$ (about $1.5 \mathrm{times}$ greater then expected before the plston would move and release the lock unexpectedly using the conservative venturi model or over $550 \mathrm{gpm}$ using the more realistic pipe contraction equations.

Note that slug flow or a rapid change in pump velocity could trip the piston due to inertia of the fluid column, so care should be used in starting the pumps. 
PRESSURE CORE SAMPLER

RELEASE PISTON SPRING DESIGN

Variables:

$D=$ mean coll dia dewire dia nenumber of active coils $F=f o r c e$ $G=$ torsional modulus $K=s p r i n g$ constant T=max shear stress

$$
D:=1.875 \text { in } \quad d:=.23 \cdot \text { in } \quad K:=100 \cdot \frac{1 \mathrm{~b}}{\mathrm{in}}
$$

$$
\mathrm{G}:=11.5 \cdot 10^{6} \mathrm{ps} \quad \mathrm{F} \text { solid }:=225 \cdot 1 \mathrm{~b}
$$

\section{CALCULAT IONS:}

$$
\begin{aligned}
& n:=\frac{d^{4} \cdot G}{8 \cdot D^{3} \cdot k} \\
& c:=\frac{D}{d} \\
& n=6.103 \\
& k:=\frac{4 \cdot c-1}{4 c-4}+\frac{.615}{c} \\
& L_{\text {free }}:=\frac{\text { solid }}{K}+d(n+1.5) \\
& \mathrm{L}_{\text {free }}=3.999 .1 \mathrm{n} \\
& \text { SOLID } \\
& \text { AT RELEASE } \\
& \text { PRELOAD } \\
& \text { F }:=225 \cdot 1 \mathrm{~b} \\
& \mathrm{~F}_{1}:=200 \cdot 1 \mathrm{~b} \\
& \mathrm{~F}_{2}:=163 \cdot 1 \mathrm{~b} \\
& \tau_{s}:=k \cdot \frac{8 \cdot F \cdot D}{\pi \cdot d^{3}} \\
& T_{1}:=k \cdot \frac{8 \cdot F \cdot D}{\pi \cdot d^{3}} \\
& \tau_{\text {s }}=104216 . \mathrm{ps} 1 \\
& \tau_{1}=92636 \cdot \mathrm{ps} 1 \\
& \tau_{2}:=k \cdot \frac{8 \cdot F^{\cdot D}}{\pi \cdot d^{3}} \\
& \text { L }:=L_{\text {free }}-\left[\frac{F}{K}\right] \\
& L_{1}:=L_{\text {free }}-\left\{\begin{array}{l}
F \\
1 \\
K
\end{array}\right] \\
& \tau_{2}=75499 \cdot \mathrm{ps} 1 \\
& \mathrm{~L}_{\mathrm{s}}=1.749 \cdot \mathrm{in} \\
& \mathrm{L}_{1}=1.999 \cdot \mathrm{in} \\
& L_{2}:=L_{\text {pree }}-\left\lfloor\frac{2}{k}\right\rfloor \\
& \mathrm{L}_{2}=2.369 \cdot 1 \mathrm{n}
\end{aligned}
$$


To

Project $\quad$ ) $c$

Engineering and 1000 Discovery College Station, Texas 77840 ;

Subject $\quad N\left(1, \ldots, r^{\prime}(0)\right.$

Telex: 792779 DP TAM

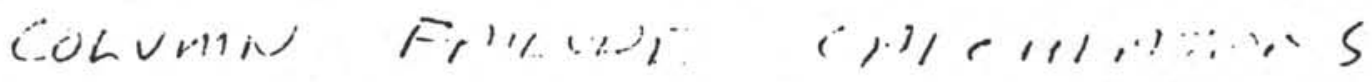

InHTL: STHAJESS STEEL

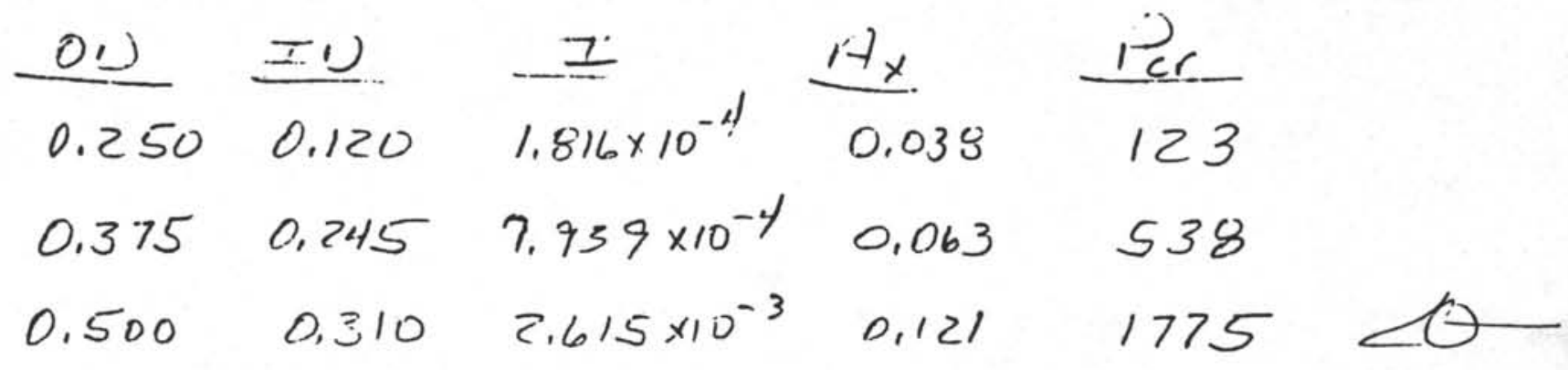

$$
\begin{aligned}
& I=\pi / 64\left(d_{0}{ }^{4}-d_{i}{ }^{4}\right) \\
& P_{c r}=n \pi^{2} E I / l^{2}
\end{aligned}
$$

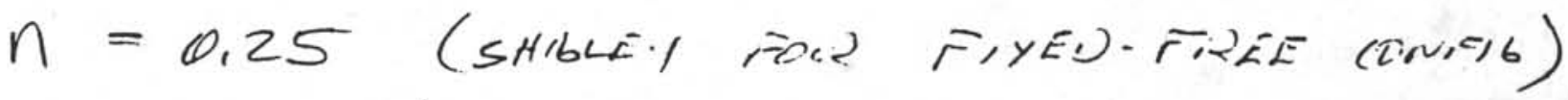

$$
\begin{aligned}
& E=27.5 \times 10^{6}, \mathrm{~N}_{51} \\
& l=10 \mathrm{in}
\end{aligned}
$$

69

OCEAN DRILLING PROGRAM 
Appendix F

\section{PCS Phase I Manifold Design Questionnaire}


PCS SAMPLING MANIFOLD DESIGN QUESTIONNAIRE

March 10, 1988

Dear:

The concept for the new ODP Pressure Core Sampler (PCS) is complete and detail drawings are being made for fabrication . A detachable pressurized sample chamber, 3-3/4 inch in diameter and approximately 60 inches long, has been designed with a 10,000 psi working pressure (see Fig. 1). The actual core size is 1-9/16 inch diameter and 32 inches long. The first version of the PCS will recover pressurized cores and allow for subsampling of the gases and interstitial water before decompressing of the sample.

In order to design the subsampling manifold for extracting gas and water subsamples from the PCS sample chamber your input is needed. Please refer to the attached figures in answering the following questions. Where applicable, indicate the priority or importance of your response. We are on a tight development schedule so, if at all possible, I need your response by March 25 th.

1. Will immersing the PCS sample chamber in ice water suffice as a means of temperature control during subsampling?

2. Is it necessary to have a thermistor inside the PCS sample chamber?

3. If a thermistor is required inside the PCS sample chamber and can not be placed in direct contact with the core itself, will placing the thermistor in the fluid surrounding the core suffice (see Fig. 1)?

4. When taking gas subsamples, will the sampling port be required to be positioned above the main body of the PCS sample chamber (see Fig. 2A)?

5. Will the PCS sample chamber be required to be shaken, vibrated or otherwise agitated during subsampling?

6. Will some type of internal agitation device, inside the PCS sample chamber be required during subsampling?

7. When taking water subsampling, will the sampling port be required to be positioned below the main body of the PCS sample chamber (see Fig. 2B)? 
8. Is it necessary to maintain temperature, i.e., immersed in ice water, while taking water subsamples?

9. Is it necessary to maintain pressure while taking water subsamples?

10. Will pressure transducers be required to be placed in the subsampling manifold? If so, please indicate where (see Fig. 3)?

11. Will flow rate measuring devices be required to be placed in the subsampling manifold? If so, please indicate where, required accuracy, types and manufacturers, if known (see Fig. 3).

12. Will the subsampling manifold need to be evacuated or flushed before subsampling? If so, please describe procedures typically used.

13. Are metering or regulating valves required in the sampling manifold? If so, indicate where and required accuracy of valves (see Fig. 3 ).

14. Is a filtering system required in the subsampling manifold? If so, please indicate to what degree, where, type and manufacturer, if known (see Fig. 3).

15. What connection would be most universal for attachment of sample cylinders?

16. Should there be more than one sample cylinder connection available in the subsampling manifold?

17. What other types of sampling devices would be connected to the subsampling manifold and what type of connection will be required?

18. What is the optimum tubing ID for the subsampling manifold?

19. Will the PCS sample chamber and/or subsampling manifold need to be weighed before and after sampling? If so, to what accuracy?

20. Are there any other factors which might effect the design of the PCS sample chamber or subsampling manifold? 
If you have any questions or comments, please do not

hesitate to call Tom Pettigrew, PCS Project Engineer, after March 22 nd as he will be out of his office until then. Tom's telephone number is (409) 845-2329.

Best Regards,

M. A. Storms

Supervisor of

Development Engineering

$\mathrm{TP} / \mathrm{cmr}$

cc: Barry Harding

Audrey Meyer

Glen Foss

Tom Pettigrew

Kay Emeis

Elliot Taylor

Heino Rhode 


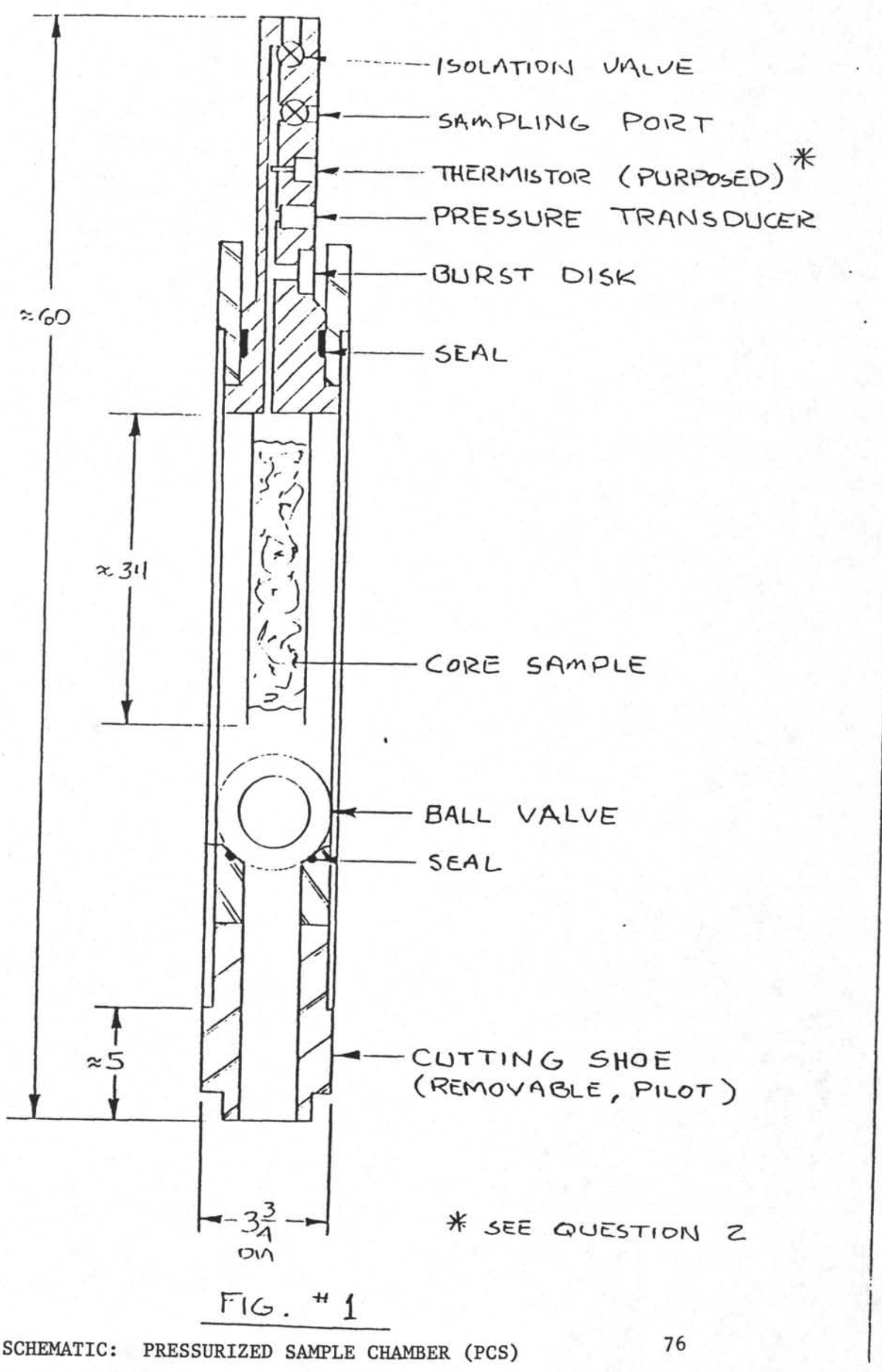




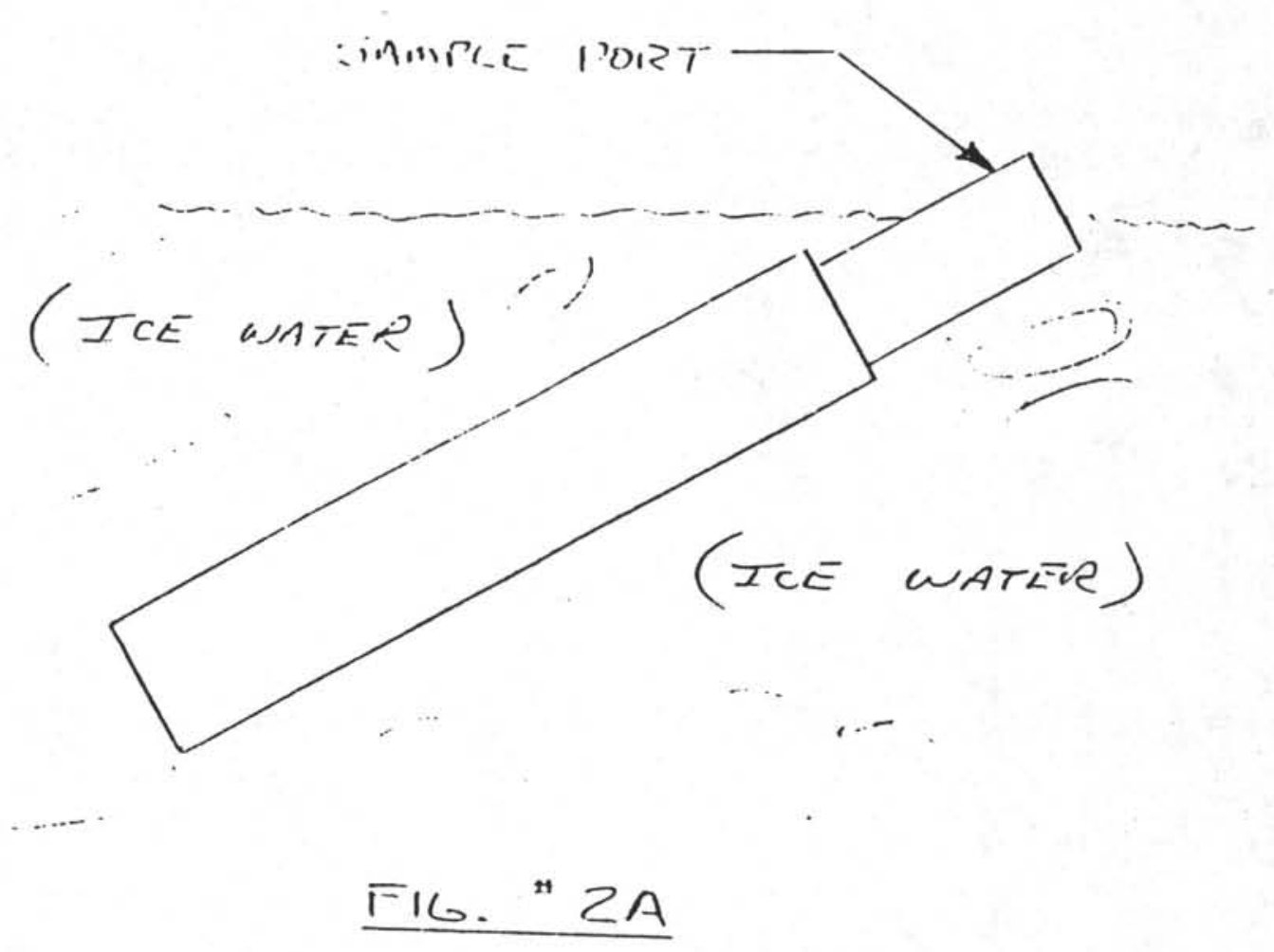

POSSIBLE ORIENTATION OF SAMPLE CHAMBER FOR GAS SAMPLING

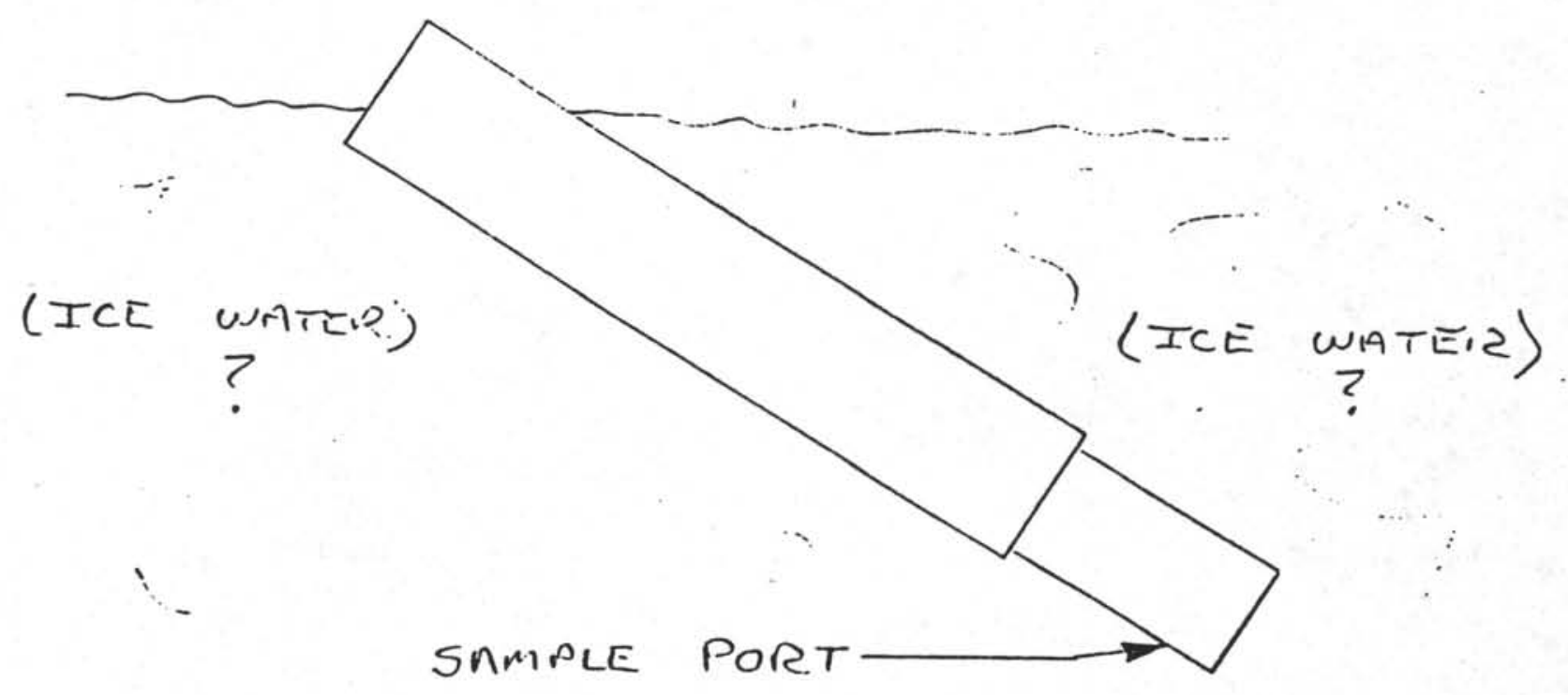

FIG. $* 2 B$

POSSIBLE ORIENTATION OF SAMPLE CHAMBER FOR LIQUID SAMPLING

77 

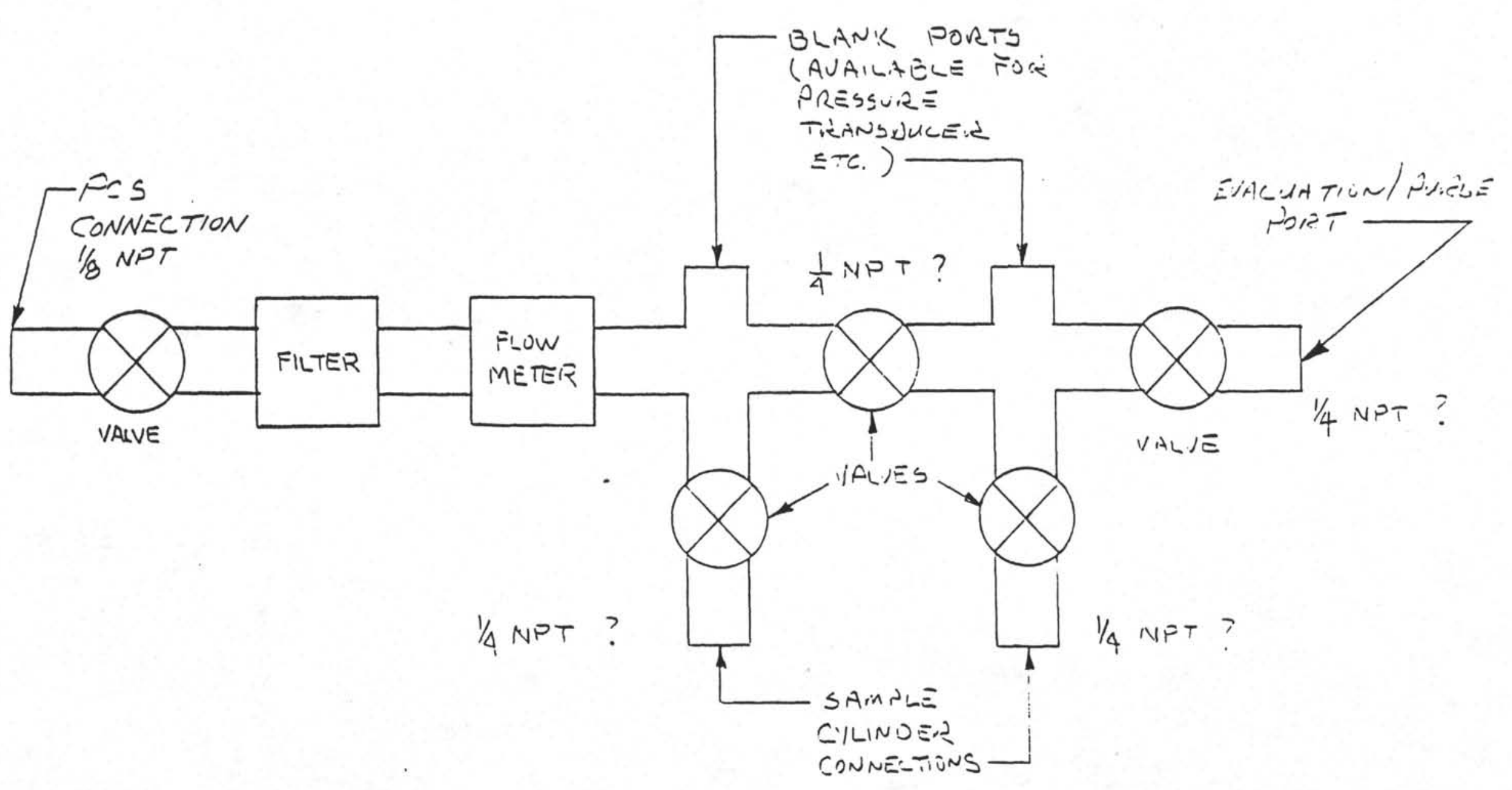

POSSIBLE SAMPLING MANIFOLD CONFILUMEATIOU

Fit. 3 
Appendix G

Performance Of The ODP Pressure Core Sampler (Leg 124E) 


\title{
7. PERFORMANCE OF THE ODP PRESSURE CORE SAMPLER ON LEG 124E SEA TRIALS'
}

\author{
Thomas L. Pettigrew²
}

\section{INTRODUCTION}

The pressure core sampler (PCS) project is a continuation of the development of a tool to retrieve core at near in-situ pressure. The PCS was developed by the Ocean Drilling Program (ODP) to replace the Pressure Core Barrel (PCB), which was designed during the Deep Sea Drilling Project (DSDP).

The main differences between the two tools are as follows.

\begin{tabular}{lll}
\multicolumn{1}{c}{ Feature } & \multicolumn{1}{c}{ PCS } & \multicolumn{1}{c}{ PCB } \\
Working pressure & 10,000 psi & \multicolumn{1}{c}{5,000 psi } \\
Actuation & Hydraulic & Mechanical \\
Pressurized core length & 32 in. & $6 \mathrm{~m}$ \\
Unpressurized core length & N/A & $1.8 \mathrm{~m}$ \\
Compatibility & APC/XCB & RCB only
\end{tabular}

Note: $\mathbf{N} / \mathbf{A}=$ not applicable; $A P C=$ advanced hydraulic piston corer;

$\mathrm{XCB}=$ extended core barrel; $\mathrm{RCB}=$ rotary core barrel.

The reduced sample length was requested by interested scientists to aid handling in the pressurized state.

The PCS tested on Leg 124E was a prototype of phase 1 in the development of the tool. The prototype tool was designed to test the new concept and to recover core under near in-situ (hydrostatic) pressure by means of gas and water sampling. Phase 2 of the development will produce a tool capable of direct access to the core under pressure. That will be accomplished by transferring the core under pressure to another pressure vessel with special ports for scientific testing.

\section{SHORE-BASED TESTING}

Due to unforeseen delays in the design and fabrication of the PCS, the tool was not ready for testing until just prior to shipping for use on Leg 124E. The tool was assembled and tested at the ODP Test Facility (TFAC) at Texas A\&M University, College Station, Texas. The shore-based testing involved the following procedures.

The actuation mechanism of the PCS is activated hydraulically by pumping against an activation ball. The activation ball is held in the (modified XCB) latch on top of the tool and is released by picking up on the pulling neck with the standard wireline and sinker-bar assembly, allowing the weight of the tool to shift the ball-retaining collet. Pressure is then applied to the tool via the drill string by the rig pumps to activate the mechanism and close the pressure chamber.

The PCS latch was assembled and the actuation ball drop mechanism tested by placing the latch assembly in a vise, and then using a hoist to pull on the pulling neck and shift the ballretaining collet. A load cell was used to measure the force required to shift the ball collet. The shifting force is controlled by

\footnotetext{
1 Harding. B. W., Storms, M. A., et al., 1990. Proc. ODP, Init. Repts., 124E: College Station, TX (Ocean Drilling Program).

2 Shipboard engineering and scientific parties are as given in the listing of participants preceding the contents.
}

the XCB latch-spring force plus the secondary latch-spring force and was designed to be less than the total weight of the tool (approximately $300 \mathrm{lb}$ ). The test revealed a shifting force of approximately $350 \mathrm{lb}$, which is below the total weight of the tool and was determined to be acceptable.

By using a hoist, the latch assembly was pulled through a typical ODP drill-string tool joint held in a vise. This was done to determine if the pulling neck would shift as a result of friction of the latch dogs retracting as they pass through the tool joint. The test revealed that the pulling neck did not move, and therefore that the activation ball remained held inside the latch.

The accumulator subassembly above the accumulator piston was pressure-tested to 10,000 psi for 15 min with no indications of leakage. This test was repeated three times, each time with no indication of leakage.

The accumulator piston was pumped back and forth through the accumulator barrel to check for free movement. Each time the piston moved freely.

Pressure was applied below the disconnect valve in the manifold mandrel to the ball valve. Immediately the sample port valve on the manifold mandrel began to leak. Upon disassembly of the valve, a cut $\mathrm{O}$-ring was found and replaced, and pressure integrity was achieved. The pressure in the tool was increased as follows:

$\begin{array}{ccc}\text { Pressure } & \text { Time } & \text { Results } \\ 2000 \mathrm{psi} & 5 \mathrm{~min} & \text { No leaks } \\ 4000 \mathrm{psi} & 5 \mathrm{~min} & \text { No leaks } \\ 6000 \mathrm{psi} & 5 \mathrm{~min} & \text { No leaks } \\ 8000 \mathrm{psi} & 5 \mathrm{~min} & \text { No leaks }\end{array}$

The accumulator shut-off valve was closed, and the disconnect valve was opened, to introduce pressure across the accumulator sub-manifold mandrel connection. The pressure in the tool was increased as follows:

$\begin{array}{lll}\text { Pressure } & \text { Time } & \text { Results } \\ 2000 \mathrm{psi} & 5 \mathrm{~min} & \text { No leaks } \\ 4000 \mathrm{psi} & 5 \mathrm{~min} & \text { No leaks } \\ 6000 \mathrm{psi} & 5 \mathrm{~min} & \text { No leaks } \\ 8000 \mathrm{psi} & 5 \mathrm{~min} & \text { No leaks }\end{array}$

The accumulator shut-off valve was opened to introduce pressure to a point below the accumulator piston. The pressure in the tool was increased as follows:

$\begin{array}{lll}\text { Pressure } & \text { Time } & \text { Results } \\ 2000 \mathrm{psi} & 5 \mathrm{~min} & \text { No leaks } \\ 4000 \mathrm{psi} & 5 \mathrm{~min} & \text { No leaks } \\ 6000 \mathrm{psi} & 5 \mathrm{~min} & \text { No leaks } \\ 8000 \mathrm{psi} & 5 \mathrm{~min} & \text { No leaks }\end{array}$

The pressure was then increased slowly from 0 to 10,000 psi to test the 10,000-psi burst disk. When the pressure reached $10,000 \mathrm{psi}$, it was held approximately $15 \mathrm{~s}$, at which time the burst disk ruptured and released the pressure. 


\section{SEA TRIAIS ON LEG; 124F,}

The PCS was first tested on Site 772, the first site drilled. The water depth was approximately $1600 \mathrm{~m}$.

Shipboard preparation began with complete disassembly and cleaning of the PCS tool. The tool was then redressed, reassembled, and checked by hydrostatically testing the ball valve, manifold, and accumulator below the accumulator piston to 5000 psi. No leaks were found. The accumulator above the accumulator piston was pressure-tested with nitrogen using the backpressure regulator valve to increase the pressure to $6000 \mathrm{psi}$. The accumulator pressure was bled down through the nitrogen-supply manifold to $4000 \mathrm{psi}$ and left overnight. No leaks were found. The accumulator pressure was bled down further to an accumulator-charge pressure of $1800 \mathrm{psi}$.

The PCS was deployed by pumping it to bottom with 50 strokes per minute (spm; $250 \mathrm{gpm})$ from the rig pumps. The bottom-hole assembly (BHA) was positioned just above the mud line at $1528 \mathrm{~m}$, and the hydrostatic pressure was calculated at $2218 \mathrm{psi}$. Once the tool was in place in the BHA, the pressure drop across the tool was determined as follows:

$\begin{array}{ccc}\begin{array}{c}\text { Strokes } \\ \text { (spm) }\end{array} & \begin{array}{c}\text { Flow } \\ (\mathrm{gpm})\end{array} & \begin{array}{c}\text { Pressure } \\ \text { (psi) }\end{array} \\ 10 & 52 & 20 \\ 20 & 103 & 45 \\ 30 & 155 & 125 \\ 40 & 207 & 230 \\ 50 & 259 & 380 \\ 56 & 289 & 400\end{array}$

The sinker-bar assembly was deployed and latched onto the pulling neck of the PCS tool. The tool was picked up to release the actuation ball and set back down. The rig pumps were engaged, and the drill-pipe pressure was brought up to 300-350 psi and held for $30 \mathrm{~s}$ to actuate the closing mechanism. After actuation, the tool was retrieved. Once the tool was on deck, the internal pressure was checked via the integral-pressure transducer. The captured pressure was found to be approximately $2380 \mathrm{psi}$, although the exact pressure could not be determined. However, the readout was thought to be within $\pm 200-300$ psi.

The problem was threefold. First, the in-line amplifier used to amplify the transducer signal was found to be shorted out. A makeshift signal-amplifying circuit was built aboard ship to replace the amplifier. Second, the transducer was calibrated against a pressure gauge with limited accuracy. Third, the transducer was not thermally stable, and, after being at approximately $40^{\circ} \mathrm{F}$ at the seafloor, it took at least an hour to warm up and give a stable reading.

The tool was reassembled and deployed again a short time later at a depth of $1678 \mathrm{~m}$. It again was pumped down with 50 spm $(259 \mathrm{gpm})$. The first attempt at cutting a core began with the bit rotating at $10-15 \mathrm{rpm}$ and a circulation of $15-20 \mathrm{spm}$ (77-103 gpm). The tool was actuated with $400-500$ psi and then retrieved. The internal pressure was measured at approximately 500 psi. The pressure was bled off, and the sample chamber opened. A gray claystone core was found from the top of the core catchers to the top of the core barrel, a distance of approximately 26 in.

Examination into the reasons the tool did not maintain full hydrostatic pressure began. The accumulator, which had not been checked between runs, was now checked. The accumulator was found to be pressurized to $1800 \mathrm{psi}, 200-300$ psi below desired charged pressure. Upon disassembly, the accumulator piston was found in a partially stroked position and was thought to have been the cause of the problem. The PCS was completely redressed for the next deployment.
The next deployment came at Site 773 (the original ENG-1 sitc) in $1871 \mathrm{~m}$ of watcr. The accumulator was charged to 2100 psi, and the tool was deployed again using $50 \mathrm{spm}(258 \mathrm{gpm})$ to pump it to bottom. Another attempt at cutting a core was begun using $60-\mathrm{rpm}$ bit rotation, 30-spm (155-gpm) circulation, and $10,000 \mathrm{lb}$ of weight on the bit. The tool was actuated using $400-500 \mathrm{psi}$ and retrieved. The internal pressure was determined to be approximately 2720 psi.

Several gas samples were taken through a makeshift sampling manifold, and the internal pressure was verified with an in-line pressure gauge. The gas samples revealed mostly air with traces of methane and carbon dioxide. The air came from the large volume of the manifold, which was not purged before taking the samples.

The tool was disassembled, and the core sample removed. Two pieces of basalt approximately $3 / 4 \mathrm{in}$. in diameter were found on top of approximately 8 in. of gray claystone core. Two larger pieces of basalt were wedged in the throat of the bit, causing a core jam.

\section{CONCLUSIONS}

The first sea trials of the PCS were successful from an engineering standpoint. Full hydrostatic pressure was retrieved on two of the three deployments, and the cause of the lost pressure on the other deployment was determined. The tool functioned exactly as designed-i.c., actuation ball dropping, hydraulic actuation, ball valve closing, accumulator function, rig-floor operations, etc.

It appears as though the accumulator may be the weak link in the tool. Special attention must therefore be given the accumulator in terms of redressing after each deployment to ensure proper operation.

\section{PROBLEMS TO BE SOLVED}

1. As mentioned previously, the accumulator was the cause of lost pressure on one run and appears to require complete redressing after each deployment.

2. All three deployments were made into a claystone, which plugged the jets in the PCS cutting shoe each time.

3. The core is very difficult to remove from the small-diameter core tube without excessive disturbance.

4. The trash-barrier seal on the core-catcher guide caused excessive drag on the cutting shoe, impeding core-tube rotation, and had to be left out. This allowed claystone to partially extrude into the waterway behind the cutting shoe inside the tool. This extrusion did not hamper the function of the tool in any way.

\section{RECOMMENDATIONS}

The PCS will need many more deployments in different formations and depths to analyze the tool fully. However, based on the Leg $124 \mathrm{E}$ sea trials, the following recommendations are made.

1. An attempt must be made to improve circulation to the cutting shoe.

2. An alternate core tube, possibly of a different material such as composite plastic, should be designed that allows easier access to the core.

3. The existing O-ring trash-barrier seal should be replaced, perhaps with a teflon $O$-ring to reduce the drag on the cutting shoe.

4. Because the concept performed as designed, the phase 2 design, which allows for core transfer into another pressure vessel under pressure, should proceed.

Ms 124E-107 
Appendix H

PCS Phase I Modifications Design Statement Of Work 
PRESSURE CORE SAMPLER PHASE I MODIFICATION

STATEMENT OF WORK

\section{INTRODUCTION}

The Ocean Drilling Program (ODP) has been directed to modify the existing Pressure Core Sampler, to provide the following capabilities for use on Leg 131 (April-May 1990).

1. Ability to displace the fluid surrounding the core sample within the sample chamber, without loss of the trapped hydrostatic pressure.

2. Addition of a removable "harpoon" sampling probe.

To provide these capabilities, the PCS must be modified as follows.

II. WORK ITEMS

A. Redesign the manifold section of the PCS Phase I, adding another sampling port within the following constraints.

1. The PCS manifold section must retain a working pressure capability of 10,000 psi with a safety factor of $4: 1$.

2. The flow path of the additional sampling port must be separate from the existing sampling port.

3. The additional sampling port must have a shut-off or control valve similar to the existing sampling port.

4. The additional sampling port must provide a means of attaching external plumbing (manifold, backpressure valve, nitrogen source, etc.) preferably via a 1/8" NPT female connection.

5. The addition of another sampling port should not interfere with the addition/use of the "harpoon" sampling probe (see section II-B).

B. Redesign the seal mandrel and check valve sub to allow for the use of a removable "harpoon" sampling port (see the attached detailed conceptual drawing) with the following constraints.

1. The "harpoon" must be removable. 
2. Once the "harpoon" has been removed, the check valve ball and seat must be able to be reinstalled.

3. A separated ported inner core barrel (core tube) may be used when the "harpoon is in place.

4. The "harpoon" shall have as small an outside diameter as possible without sacrificing structural strength.

5. The "harpoon" shall be 12 - 16 inches long.

6. The "harpoon" port shall be on the side near the tip.

7. The check valve sub must be redesigned such that when the "harpoon" is not in place and the check ball and seat is in place, the sampling port can not be closed or restricted by the check valve.

\section{DELIVERABLES}

A. Accurate sketches or drawings suitable for fabricating from.

B. Parts list of any additional parts for the PCS required by the modification.

c. Written instructions including assembly, operation, handling, safety, maintenance and any other pertinent subject pertaining to the PCS that is different existing PCS instructions.

D. Recommended spare parts list for sea trials.

E. Invoice containing break down of time spent on this project and the hourly rate.

IV. PERIOD OF PERFORMANCE

Estimated completion date: February 9, 1990

Amount to be invoiced: Not to exceed $\$ 2000.00$

Work to be completed:

Prepare sketches/drawings, parts list, written instructions and recommended spare parts list as described in section III. DELIVERABLES. 


\section{Appendix I}

\section{Leg 131 PCS Engineering Report}




\author{
ENGINEERING REPORT \\ LEG 131 \\ GUAM TO PUBAN, ROREA \\ 27 MARCF 1990 TO 2 JUNE 1990
}

\title{
PRESSURE CORE BAMPLER (PC8)
}

The Phase I prototype Pressure Core Sampler (PCS) was deployed at 0400 hrs, 28 May, in Hole $808 \mathrm{~F}$ at a depth of $4753 \mathrm{~m}$ (55 mbsf). The $1 \mathrm{~m}$ PCS core was dry drilled in an attempt to recover a more pristine core. When the PCS was retrieved it was found to have only partially stroked closed and no core or pressure was captured. The partial stroke caused misalignment of the connections, inhibiting disassembly and tuggers had to be used in attempt to stroke the PCS further. During the process, the links and operator head were damaged and the link pins were pulled from the operator head. Upon complete disassembly, the ball valve subassembly was found packed with sand and would not function. The damaged links and operator head were repaired and the PCS was redressed for redeployment.

The PCS was deployed again at $1300 \mathrm{hrs,} 29$ May, in Hole $808 \mathrm{G}$ at a depth of $4881 \mathrm{~m}$ (196.5 mbsf). The rig pumps were maintained at $50 \mathrm{spm}$ during cutting of the $1 \mathrm{~m}$ PCS core. The first attempt at stroking the PCS closed indicating the circulation ball had not been released from the modified XCB latch. The ball releasing and stroking procedures were repeated and indications were that the ball had released and the PCS stroked closed. Upon recovery, the PCS was found to have stroked completely closed.

The integral pressure transducer could not be calibrated and was not in place. After isolating the connection between the accumulator sub and the manifold mandrel, pressure was bled off the connection indicating some pressure was trapped in the PCS. The pressurized sample chamber was quickly taken to refrigerated storage to lower it's temperature back to near in situ. During this time the accumulator was removed from the PCS and checked. The accumulator isolation valve was opened and movement of the accumulator piston, with associated escaping pressurized water, indicated that pressure inside the sample chamber was at lest equivalent to the accumulator charge pressure. The accumulator pressure was checked and found to be 5600 psi.

After approximately $45 \mathrm{~min}$. in cold storage the PCS sample chamber was removed for sampling. A back pressure valve with pressure gage and sample coil was attached to the PCS. When the PCS sampling port valve was opened no pressure registered on the pressure gage. The gage being used required approximately 500 psi to move the indicator needle. Upon opening of the sampling port to the atmosphere, it was estimated that approximately 300 psi remained in the pressure chamber. The back pressure valve was removed and the PCS sampling port was left opened to ensure no pressure remained in the chamber during disassembly. 
The pressure chamber was immediately opened and the core tube with $0.49 \mathrm{~m}(19.75 \mathrm{in})$ of core was quickly removed. The core consisted of a clay like material and would have had to have been extruded to be removed from the core tube. Since the extrusion process would have caused sever damaged to the core, the core tube was sacrificed and cut into $20 \mathrm{~cm}(8 \mathrm{in})$ long sections. The core tube sections, with core intact, were immediately immersed in liquid nitrogen. The frozen samples were to be transported to land based laboratories for analysis.

When the PCS was further disassembled, one of the seal mandrel poly-pak seals was found damaged. One lip had been pinched, presumably during assembly and the energizing o-ring was extruded. The pinched seal is part of a redundant pair of seals while the other seal showed no signs of damage. No other damaged seals were found and it was evident that near in situ pressure existed inside the PCS when broken down at the rig floor. Based on that, it is presumed that the extruded o-ring held the seal mandrel against the side of the seal housing allowing pressure to slowly weep past the remaining undamaged seal. The PCS was completely broken down, cleaned and prepared for long term storage. 
Appendix J

Leg 139 PCS Engineering Report 
OCEAN DRILLING PROGRAM

LEG 139 ENGINEERING REPORT

\author{
Tom Pettigrew \\ Sr. Development Engineer \\ 17 September 1991
}

\title{
PRESSURE CORE SAMPLER (PCS)
}

The Pressure Core Sampler (PCS) was deployed five times during Leg 139. Details of each deployment are listed below.

PCS-1:

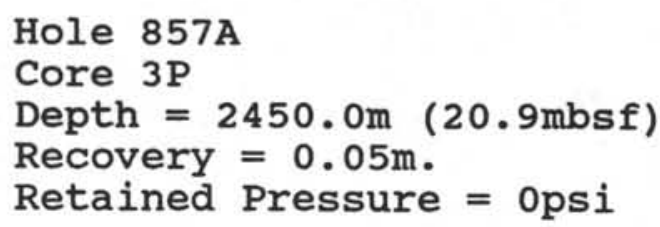

The PCS was pressure tested in an attempt to determine how/where loss of pressure occurred. Retesting revealed the ball valve subassembly connection o-ring leaking. Unfortunately, the PCS must be partially disassembled after pressure testing to reset the ball valve. The ball valve subassembly connection is one of the connections which must be broken after testing. Although it originally tested ok, the o-ring may have been nicked or cut when the connection was made up.

PCS-2:

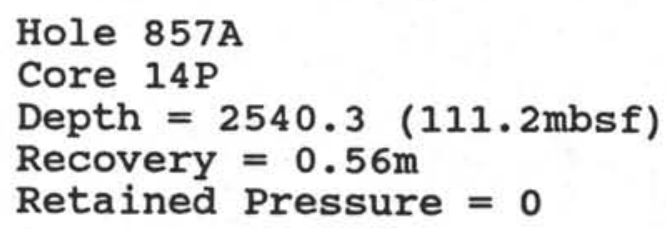

Upon retrieval, the ball valve was found open. Definite actuation pressure had been observed on the rig floor. Subsequent inspection of the tool revealed insufficient shims were installed, resulting in the tool not being able to latch closed after actuation. The ball valve probably vibrated open as the PCS was being retrieved.

$\underline{\text { PCS }-3:}$

Hole 858A

Core 10P

Depth $=2492.0 \mathrm{~m}(72.9 \mathrm{mbsf})$

Recovery $=0.46 \mathrm{~m}$

Retained Pressure = ?? 
Some pressure was retained as evidenced by vented pressure while breaking out the accumulator. The integral pressure transducer was not installed due to the possibility of encountering elevated bottom hole temperatures. The core sample was taken from a hot, estimated $130^{\circ} \mathrm{C}$ static bottom hole temperature, dry, nongaseous sediment. What pressure was retained was lost due to the volume increase upon connecting the PCS sample chamber to the sampling manifold.

PCS-4:

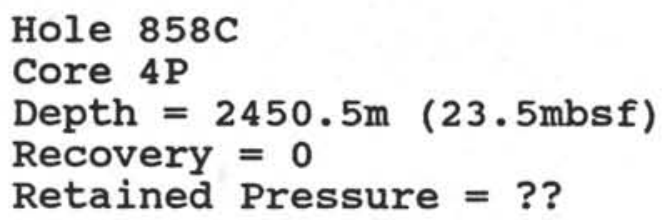

Again, some pressure was retained as evidenced by vented pressure while breaking out the accumulator. No recovery was attributed to excessive circulation rate during coring. The retained pressure was lost upon opening the sample chamber to the sampling manifold.

PCS-5:

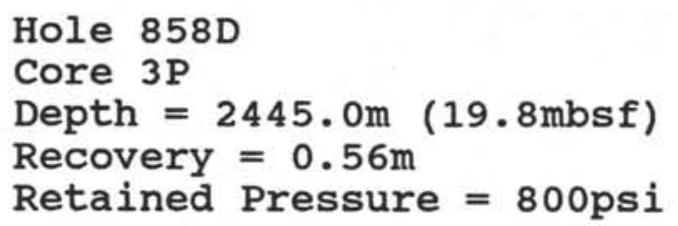

While breaking out the PCS sample chamber from the rest of the core barrel, a pressure gage was attached to the \#2 sample port before the accumulator was disconnected. $800 \mathrm{psi}$ was recorded at the rig floor. The pressure gage and accumulator were then removed and the sample chamber connected to the sampling manifold. Approximately 130psi was recorded on the manifold pressure gages. The pressure quickly dropped to zero as the sample container was opened.

The first sampling container was removed for analysis. A second sampling container was connected to the manifold and left for several hours. The first sampling container contained mostly $\mathrm{CO} 2$ gas. Surprisingly, the second sampling container contained a wide range of hydrocarbon gasses. The core recovered revealed traces of liquid hydrocarbons.

This was the first "extensive" scientific use of the PCS. The ship board geochemist, Dr. Jean Whalen, who was working with the PCS during Leg 139, concluded that the tool functioned fairly well. Dr. Whalen has written a suggested sampling procedure for use of the PCS and manifold system. 
Appendix K

\section{Leg 141 PCS Engineering Report}




\section{OCEAN DRILLING PROGRAM}

\section{LEG 141 ENGINEERING REPORT}

\section{PRESSURE CORE SAMPLER (PCS)}

The Pressure Core Sampler (PCS) was deployed 12 times during Leg 141. Actual downhole hydrostatic pressure was trapped on two occasions and moderate success was achieved with the tool on several other runs. The main scientific objective for the PCS on Leg 141 was to capture in-situ gas hydrates from the BSR (Bottom Simulating Reflector) noted on the seismic map. After each successful run of the tool, the entire outer barrel assembly was taken down to the Second Look Lab for further analysis of the trapped contents. The Geochemist on board for Leg 141 was Dr. Philip Froelich. Dr. Froelich's analysis's of the gases and waters trapped in the PCS are summarized in the Organic and Inorganic chemistry reports for each site. The PCS was run more frequently on Leg 141 than any other leg since its initial field trials. Several problems were encountered with the tool but most problems were field repairable and overall good success was achieved. The PCS was sent back to College Station after Leg 141 for some minor engineering design changes. The next anticipated use of the tool will be in Cascadia on Leg 146 in October of 1992. Table 1. summarizes each pressure core sample taken.

TABLE 1.

\begin{tabular}{|c|c|c|c|c|c|c|c|}
\hline HOLE & CORE & TOP & воттом & TOP-BSF & BOT-BSF & RECOV & PSI \\
\hline $859 A$ & 09P & 2810.7 & 2811.7 & 57.4 & 58.4 & 0.03 & 0 \\
\hline $859 A$ & $12 \mathrm{P}$ & 2830.3 & 2831.3 & 77.0 & 78.0 & 0.24 & 0 \\
\hline $859 A$ & $15 \mathrm{P}$ & 2852.1 & 2853.5 & 98.9 & 100.2 & 0.37 & 100 \\
\hline $859 A$ & $21 P$ & 2898.8 & 2899.8 & 145.5 & 14.0 & 0.28 & 350 \\
\hline $860 \mathrm{~B}$ & 08P & 2215.5 & 2217.0 & 58.4 & 59.9 & 0.00 & 3791 \\
\hline $860 \mathrm{~B}$ & $13 P$ & 2254.7 & 2256.2 & 97.6 & 99.1 & 0.61 & 3012 \\
\hline $860 \mathrm{~B}$ & $18 \mathrm{P}$ & 2294.2 & 2295.7 & 137.1 & 138.6 & 0.00 & 0 \\
\hline $860 \mathrm{~B}$ & $42 \mathrm{P}$ & 2514.8 & 2516.3 & 357.7 & 359.2 & 0.30 & 0 \\
\hline $861 C$ & 09P & 1734.5 & 1736.0 & 69.5 & 71.0 & 0.23 & 0 \\
\hline $861 C$ & $20 \mathrm{P}$ & 1833.7 & 1835.7 & 168.2 & 170.2 & 0.00 & 0 \\
\hline $861 C$ & $26 P$ & 1883.6 & 1885.1 & 218.6 & 220.1 & 1.00 & 115 \\
\hline $861 C$ & $30 \mathrm{P}$ & 1911.8 & 1912.8 & 247.3 & 248.3 & 0.68 & 190 \\
\hline
\end{tabular}


The details for each run are as follows:

\section{Site 859:}

09P: We initially had problems getting the accumulator charged with nitrogen. The accumulator back pressure regulator would not achieve an initial seal and any pressure applied to the tool would leak out the relief valve. The problem area seemed to be the Tescom Valve Sensor assembly and we decided to override the Tescom back pressure assembly altogether. We found that by tightening the Regulator Adjusting Screw (OP6268) down completely, which would disable the back pressure assembly, a pressure seal could be maintained. This procedure would eliminate the safety feature of over pressurizing the tool but anticipated pressures were only one fourth of the rated strength of the tool.

The accumulator was then charged to $3100 \mathrm{psi}$, approximately 80 percent of the expected hydrostatic pressure. After the run, the connection between the accumulator sub (OP6252) and the manifold mandrel (OP6246) was isolated and the vent opened. There was no indication of any pressure. It was discovered that the bullet valve for the sample port was left open, thus venting all pressure to the inner and outer barrel assembly. The accumulator charge pressure was checked afterwards and it registered 2900 psi pressure.

12P: More troubleshooting of the accumulator was done with little success. The main suspect was still the Tescom Valve Sensor and the way the needle valve seats in the valve seat. Since every possible combination of spare parts was tried and no combination proved to work any better, we ultimately decided to override the back pressure assembly again and tightened the adjustment screw down completely.

The accumulator was pressured up to approximately $80 \%$ of the expected hydrostatic pressure (about $3200 \mathrm{psi}$ in this case).The core catcher configuration was (2) each 4-finger catchers with no o-ring on the core catcher guide.

At the surface a small amount of trapped pressure was released when the vent valve was opened to break the connection between the accumulator and the manifold subassembly. This initial indicator raised our hopes for some trapped pressure in the core barrel.

Zero pressure was recorded at the Sample Port and the Disconnect Port.

Later Analysis:

The ball valve seals were packed with core material (mostly silty clays) so we decided to pressure test the ball valve subassembly. Even with dirty seals the assembly tested like a champ and held 3000 psi with no problem. 
We then questioned the amount of core material surrounding the ball valve assembly and concluded that the core catchers provide a flow path from the core barrel to the cutting shoe flow path and ultimately up into the ball valve assembly. The core catchers have holes in which the spring loaded dogs sit just like any other fingered core catcher. However, all other systems are surrounded by a flow isolation sleeve while the PCS core catchers are not. This left a question as to how a core should be cut. Is it then mandatory to cut the core dry to prevent the flow from washing out the core through the core catchers? Or does cutting a dry core allow the core material to "toothpaste" its way up through the core catcher windows and into the ball valve subassembly.

15P: The accumulator was charged with the Regulator Adjusting Screw tightened down completely. The core catcher configuration was one core catcher guide and three core catcher spacers. No core catchers were used. The PCS was advanced 1-1/2 meters with about $20 \mathrm{spm}$. The sinker bar assembly was lowered and the tool was lifted to drop the actuation ball. The tool was then set back down and $1500 \mathrm{psi}$ was applied.

At the surface the connection between the accumulator sub and the manifold mandrel was isolated and the vent opened. A small amount of pressure was observed venting from port. A pressure gauge was attached to the top of the manifold mandrel and the Disconnect port was opened allowing the annulus pressure to reach the gauge. The observed pressure was approximately $100 \mathrm{psi}$. The gauge was then attached to the Sample Port and the same 100 psi was observed.The tool was taken to second look lab for further analysis.

The accumulator was checked and zero pressure was found on the gas side of the piston. The accumulator was broken apart and redressed.

\section{Analysis of the PCS after core 15P!!:}

RE: Sensor needle valve preload:

The needle valve on the Tescom Sensor has a preload spring that should provide the initial seal. A tolerance problem exists with both ODP parts and Tescom parts in this area. With some luck, the particular parts that hold a seal may be selected. If the needle valve doesn't seat utilizing the preload of the spring then a seal is never achieved. Two ways to lengthen the travel distance of the needle are to reduce the inner shoulder of the sensor that holds the needle or to reduce the thickness of the base of the spring pad. Two sensor's have been modified by reducing the internal shoulder in the sensor.

RE: Trapped pressure above the sensor:

On several occasions the regulator adjustment screw on the accumulator froze up with trapped pressure above the Tescom sensor and below the adjusting screw o-rings. Further analysis proved the following:

Checked all three Regulator Housings (OP6264) for depth of pocket to Tescom seat. Spec calls out for 2.60 inches from end. Two subs were within tolerance and one measured 43/64" 
or 2.671. Confirmed that this sub is the one that would leak pressure up above the sensor and into the Regulator Adjusting Screw area. Marked as NFG.

Checked both Regulator Subs (OP6262) for depth of valve seat. Spec calls out for 0.698/0.692. One sub measured 0.699 and the other measured 0.709 . This pocket depth was apparently not a problem when using the "modified needle" Tescom sensor.

RE: Leak in manifold assembly at burst disk:

The Burst Disk (OP6344) has a Burst Disk Ring (OP6340) and a Burst Disk Plug (OP6203). A small leak around the threads plagued any pressure test. Some liquid teflon seal and a lot of torque seemed to do the trick.

RE: Bullet valves:

The Bullet Valve has a hex head with an internal pocket. Some existing valves have a shallow pocket while some have a deeper pocket - 5/16". The deeper pocket screws are much better as they have far less tendency to strip out. A pre-seating trick of dropping a $3 / 8$ " ball into the valve seat and tapping it with a hammer is mandatory for first time installation.

\section{SITE 859 (Con't):}

21P: The accumulator was pressured up and the relief valve spring was set at 4500 psi. The chamber was then bled off to $80 \%$ of hydrostatic or about 3400 psi. The core catcher configuration was a core catcher guide and core catcher spacers. No core catchers were used. The PCS was advanced 1-1/2 meters with about $20 \mathrm{spm}$. The sinker bar assembly was lowered and the tool was lifted to drop the actuation ball. The tool was set back.down and 1500 psi was applied.

At surface the connection between the accumulator sub and the manifold mandrel was isolated and the vent opened. Again a small amount of pressure was observed venting from the port. The pressure gauge was attached to the top of the manifold mandrel and the Disconnect Port was opened. The observed pressure was approximately 350 psi pressure.

When the manifold was bled off it was noted that the released pressure was all water. This raised a question as to how much pressure was lost when the regulator and its hardware were attached to the annulus port. Therefore the sampling port was not connected to at the rig floor.

The tool was then taken down to the second look lab for further analysis. The accumulator pressure was checked while back in the core tech shop and found to have 4300 psi on top of the piston. This raised questions as to where the migrating gas within the sample chamber ultimately ends up. It seemed conceivable that hydrostatic pressure below the piston could compress the gas above the piston to a pressure equal to hydrostatic. If this was the case then a small amount of pressure should of been trapped below the piston and above the shut off valve. A spare regulator sub was attached to the bottom of the accumulator sub and the thru hole was blocked off on the lower end. This allowed a way to attach a gauge and sample bottles to the lower side of the accumulator. Upon opening the lower sample port zero pressure was recorded. Since no pressure existed where a sample was desired, the gas above the accumulator was vented and a portion was caught in 5 separate $300 \mathrm{cc}$ sample 
bottles. The thinking was that the o-ring on the piston must have leaked and hydrostatic pressure was able to force its way above the piston. The trapped pressure above the piston contained both gas and water.

The piston and o-ring were removed from the accumulator and analyzed. The o-ring was slightly distorted but it was not possible to conclude that it had leaked.

\section{CHECKING PRESSURE UTILIZING THE PRESSURE TRANSDUCER}

The means of checking the PCS pressure at the surface up until this point had been to attach a manifold assembly and gauge to the Sample and/or annulus ports. The amount of compressed water which is allowed to fill the attached manifold (when the bullet valve is opened) is enough to lower the pressure significantly from hydrostatic. The pressure transducers were not utilized due to the misconception that the transducers were not temperature compensated and therefore not reliable. It was decided to calibrate the transducer by removing the Manifold Mandrel and plugging the bottom end with a modified Accumulator Sub. This configuration allowed the manifold to be pressured up and also provided a means of attaching a gauge to the 1/4" NPT connection. The assembly was then placed in a regulated bath in the Second Look lab and the pressure was monitored as the temperature was varied. An analog pressure gauge was attached to the NPT connection and a Newton digital voltmeter was attached to the transducer. The Ideal Gas Law shows that the temperature gradient should be $17.1 \mathrm{psi} / \mathrm{deg}$ Celsius. The gradient obtained in the lab was $16.52 \mathrm{psi} / \mathrm{deg}-\mathrm{C}$. The conclusion was to start checking the transducer at the surface utilizing the digital voltmeter. Table 2 . lists the data recorded by Dr. Froelich. Figure 1 . is the plot of the data.

TABLE 2.

\begin{tabular}{|c|r|c|c|c||}
\hline Sample & \multicolumn{1}{|c|}{ Date/Time } & Temp. (deg-C) & Press. (gauge) & Press. (ducer) \\
\hline \hline 1 & $12 / 7 / 91 \quad 14: 00$ & 20.0 & 4700.00 & 4724.00 \\
\hline 2 & $19: 00$ & 15.0 & 4700.00 & 4656.00 \\
\hline 3 & $22: 30$ & 10.0 & 4575.00 & 4578.00 \\
\hline 4 & $12 / 8 / 9100: 20$ & 5.0 & 4525.00 & 4492.00 \\
\hline 5 & $02: 30$ & 5.0 & 4500.00 & 4488.00 \\
\hline 6 & $04: 50$ & 2.5 & 4475.00 & 4444.00 \\
\hline 7 & $06: 50$ & 7.5 & 4560.00 & 4531.00 \\
\hline 8 & $08: 30$ & 12.5 & 4650.00 & 4617.00 \\
\hline 9 & $11: 00$ & 17.5 & 4700.00 & 4693.00 \\
\hline 10 & $14: 30$ & 22.5 & 4810.00 & 4786.00 \\
\hline
\end{tabular}




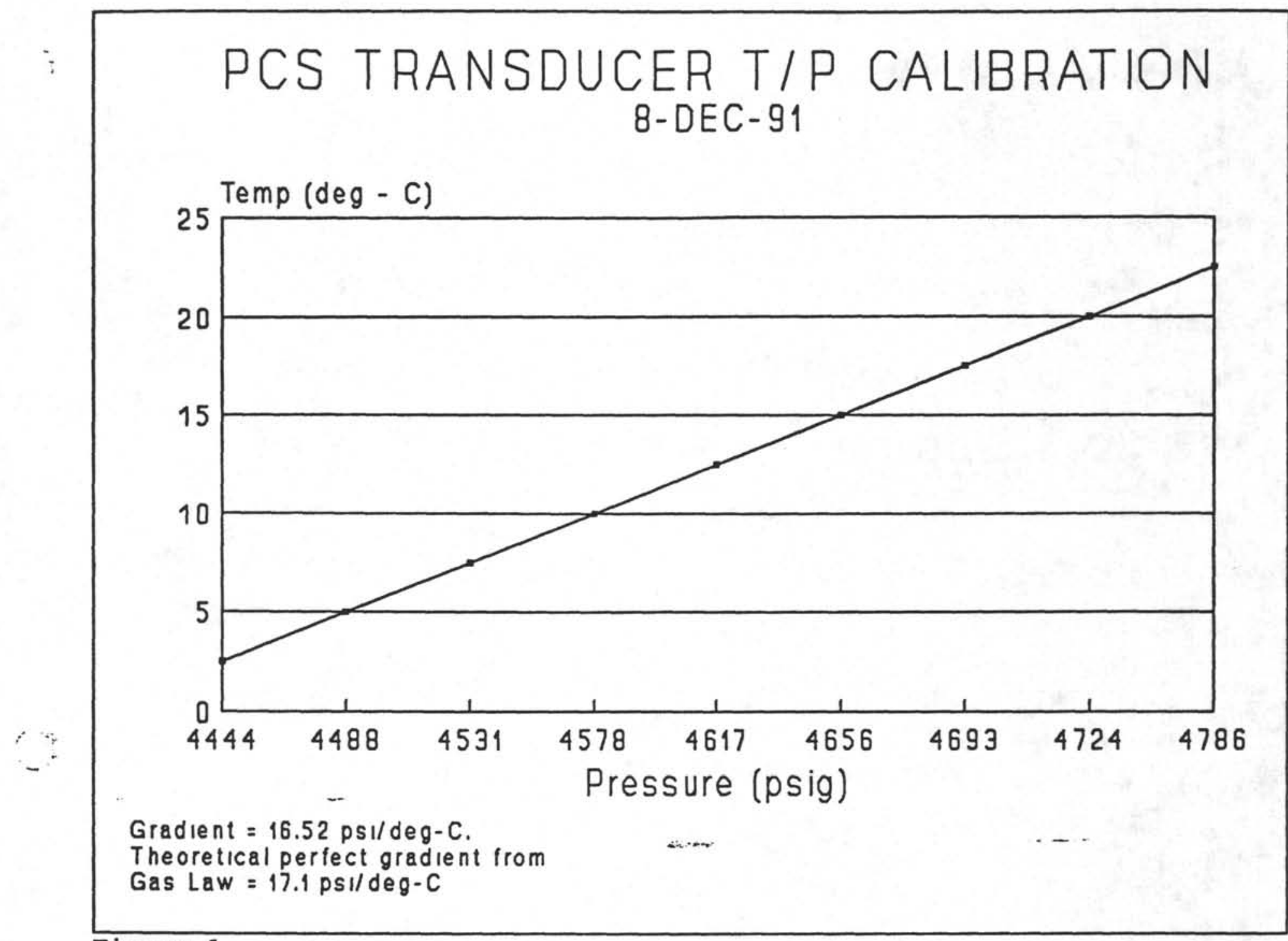

Figure 1 .

SITE 860:

8P:

Core $8 \mathrm{p}$ was the first true success at trapping hydrostatic pressure within the core barrel. The first look at the pressure within the tool was accomplished by attaching the voltmeter to the pressure transducer while the tool was still on the rig floor. The pressures were later verified through attachment of a gauge while in the lab. The key to the initial fluctuations on the digital readout proved to be a grounding problem which was easily fixed with a grounding strap between the voltmeter and the core barrel. The core was transferred to the second look lab for further analysis. After bleeding off and trapping the headspace the 
remaining pressure was bled off the core. If hydrates were trapped the pressure was then expected to start increasing. No pressure buildup occurred and the core was subsequently removed. The cutting shoe was jammed full and negligible core was in the end of the core barrel.

13P: Core 13P was the second major success at trapping near hydrostatic pressure. It was also taken to the second look lab. After analysis of the core under pressure, the core was removed with $71 \%$ recovery in the core barrel. No hydrates were evident.

18P: Core 18P failed to fully stroke closed while downhole. No pressures were trapped and no core was recovered. Later analysis of the shim distances proved that an additional 1/16" shim was required. This allowed full engagement of the actuator dogs in the locked up position.

42P: On core 42P the actuator again failed to lock in the closed position. A failed o-ring above the ball seat in the actuator was discovered put down as the current culprit. Although the tool did hold pressure from the pumps during the shift sequence. One would think that holding pump pressure would be sufficient with or without a good o-ring.

\section{ANALYSIS OF THE ACTUATOR AFTER 42P:}

We noticed a slight tolerance problem when retrieving the PCS tool at the rig floor. When breaking the quick release and inserting the dog releasing tool some additional resistance was encountered when tightening the screw. After lifting the outer barrel with the tool clamp and disconnecting the quick connect coupling we realized the dogs weren't released completely and some additional downward force was required to fully stroke the actuator open. Further examination proved that the upper dogs needed a small chamfer on all sharp corners that rest on the inner rod $* * *$.

\section{SITE 861:}

Some interesting problems had been encountered with the PCS after enjoying good success on the last hole. The problems started with core $18 \mathrm{P}$ on hole $860 \mathrm{~B}$ when the actuator failed to engage the upper dogs. The ball valve also failed to achieve a seal but these events are not necessarily related. Previous thinking showed that by checking the shim spacing an extra $1 / 16$ " shim was needed. (Don't know why, it worked before that.) On core 42P in 860B the actuator failed to lock once again. A failed (sliced) o-ring above the ball seat in the actuator was discovered and seemed to be the logical reason for failure on that particular run.

9P: Core 9P achieved actuation but the ball valve did not seal. A sheared link pin on the ball valve itself allowed the ball to over-rotate and go past the sealing orientation thus preventing any chance of achieving a seal. One pin was sheared completely, the other three on the link mechanism were about half sheared. We have yet to determine why the pins failed but the specs call for drill rod and the pins are clearly not heat treated as you would expect when drill rod is specified. We need to make some new pins out of something like Maraging 350. 
20P: Core 20P failed to achieve actuation and the ball valve also failed to close. The ball valve operator housing was not screwed completely on due to operator error after maintenance following the previous run. The failed actuation was still a mystery and a entire new actuator assembly was put together from spares out of desperation.

26P: Core 26P worked well and recovered a full core but the pressure trapped within the barrel was only 115 psi. The second (backup) actuator was assembled from parts and solved the actuation problem. The mystery of why the first actuator suddenly failed to quit working was never solved. The new mystery is now the fact that the tool functions properly but only traps several hundred pounds of pressure. The seals did not seem to be leaking because the pressure that was monitored in the tool at the rig floor was maintained while the tool was in the lab for further analysis.

30P: The final core, 30P, also functioned well, but again trapped only $190 \mathrm{psi}$. The chamber maintained the pressure while the sample was analyzed in the 2nd look lab. There still exists some confusion as to why we managed to trap full hydrostatic pressure on some runs and then trapped pressures started to come up in the 100-200 psi range. The bullet valves with rusting seats are strong candidates for the problem source, however. 
Appendix L

\section{PCS Phase II Design Statement Of Work}




\author{
OCEAN DRILLING PROGRAM \\ PRESSURE CORE SAMPLER DESIGN \\ PHASE II \\ STATEMENT OF WORK
}

I. INTRODUCTION

The Ocean Drilling Program (ODP) has been directed to upgrade the ODP Pressure Core Sampler (PCS) Phase I tool. The Phase II PCS will combine the proven technology used in the Phase I tool with the ability to access the core sample under pressure. The phase II tool will allow the core to be transferred, while maintaining pressure, into a shipping boinb or laboratory chamber.

This statement of work only applies to the Phase II development of the ODP Pressure Core Sampler.

II. WORK ITEMS

A. Review existing ODP coring equipment configurations and operations with ODP engineers.

B. Review existing ODP PCS Phase I design with ODP engineers.

C. Redesign the PCS ball valve subassembly to permit exterior operation while maintaining pressure.

D. Redesign the existing PCS manifold subassembly to allow the core tube to be detached and transferred through the open ball valve into a shipping bomb or laboratory chamber while maintaining pressure.

E. Design a manipulator device (as necessary) for physically transferring the core tube into shipping boinb or laboratory chamber.

F. Design a shipping bomb which will accept the core sample transferred from the PCS. The shipping bomb should include a means of continuously monitoring the internal pressure and temperature of the bomb.

G. Design a universal mating attachment to be used on a shipping bomb or laboratory chamber.

H. Design an intermediate device for mating the shipping boinb and the laboratory chamber to the PCS if such a device is deemed necessary.

I. Produce accurate schematics depicting any hydraulic now is themanifolds etc., required for transferring of the core sample. 
J. The PCS Phase II design should retain the following attributes of the Phase I design.

1. Must be compatible with $\mathrm{ODP} \mathrm{APC} / \mathrm{XCB}$ bottom hole assembly.

2. 10,000 psi working pressure.

3. Design safety factor $4: 1$

4. Corrosion resistant in critical areas.

5. The sample chamber must be detachable from the core barrel while maintaining pressure.

6. Sample capacity of 300 - $1200 \mathrm{cc}$ with as large a diameter as possible.

7. Port for accessing the sample chamber.

\section{DELIVERABLES}

A. Accurate sketches or drawings of the PCS Phase II assembly, it's components and any associated fabricated equipment required to assemble and operate the tool, perferably in AUTOCAD format on diskette.

B. Complete PCS Phase II parts list.

C. Accurate description of any and all purchased parts and equipment required to assemble and operate the PCS Phase II tool, suitable for ODP to procure such parts and equipment.

D. Complete written instructions including special fabricated notes, assembly, handling, safety, maintenance, storage and any other pertinent subject pertaining to the PCS Phase II tool.

E. Recommended PCS Phase II spare parts list. 
Appendix M

\section{PCS Technical Manual}




\title{
OCEAN DRILLING PROGRAM \\ PRESSURE CORE BAMPLER (PCB) \\ TECHNICAL MANUAL
}

\author{
Tom Pettigrew \\ Ocean Drilling Program \\ Texas A\&M University
}

August 1991 


\section{PRESSURE CORE SAMPLER TECHNICAL MANOAL}

TABLE OF CONTENTS

November 1991

Description

Section

DESCRIPTION

General Description

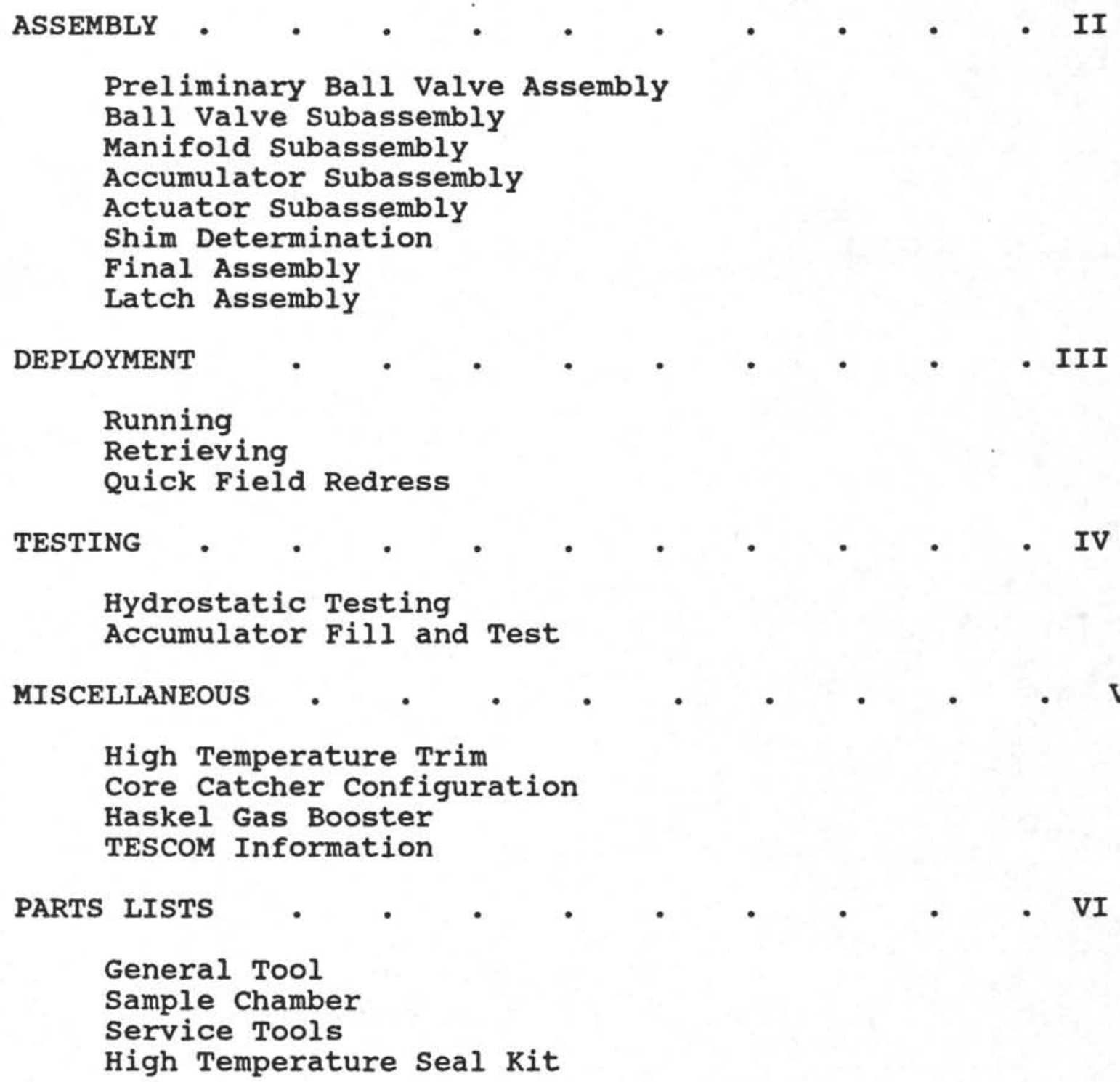

Assembly Drawing 


\title{
OCEAN DRILLING PROGRAM \\ PRESBURE CORE BAMPLER (PCB) \\ GENERAL DESCRIPTION
}

\author{
July 1991
}

\section{GENERAL}

The Pressure Core Sampler (PCS) is a free fall deployed, hydraulically actuated, wireline retrievable pressure coring tool capable of retrieving core samples maintained at bottom hole pressures. The PCS utilizes both current conventional oil field pressure coring technology and technology developed by the Deep Sea Drilling Project (DSDP). The PCS is completely compatible with the existing ODP bottom hole assemble (BHA) used for the Advanced Piston Corer (APC) and Extended Core Barrel (XCB). The PCS is not compatible with the ODP Rotary Core Barrel (RCB) BHA.

The PCS is free fall deployed and lands in the BHA. The PCS latches into the BHA and is rotated with the BHA during coring operations similar to the XCB. The PCS is completely interchangeable with the APC and XCB coring tools thus allowing a pressurized core sample to be taken at anytime from the mud line down to indurated formations and/or into basement. The PCS recovers a nominal $42 \mathrm{~mm}$ ( $1.65 \mathrm{in}$ ) diameter core sample $.86 \mathrm{~m}$ (34in) long at pressures up to $690 \mathrm{bar}(10,000 \mathrm{psi})$.

The PCS contains six main components or subassemblies. They are latch subassembly, actuator subassembly, accumulator subassembly, manifold subassembly, ball valve subassembly and detachable sample chamber.

\section{LATCH SUBASSEMBLY}

The PCS latch subassembly is a modified XCB latch. The latch subassembly contains the landing point for the PCS when free fall deployed. The latch subassembly latches into the BHA thus transmitting torque from the BHA to the PCS. The PCS cutting shoe is rotated with the BHA trimming the core sample to proper size for entry into the sample chamber. The latch subassembly diverts all flow down the drill string through the inside of the PCS. The latch subassembly holds the actuation ball during deployment and coring operations. When the latch subassembly is engaged by the coring wireline and an upward force is applied, the actuation ball is automatically released, dropping into the actuation subassembly. Finally, the latch subassembly provides a receptacle for attachment of the coring wireline during retrieval of the PCS.

ACTUATOR SUBASSEMBLY

The PCS actuator subassembly has a dual latch system which latches the ball valve open during coring operations and closed 
after actuation. The actuation subassembly catches the actuation ball when released by the latch subassembly. The actuation ball diverts all flow through the PCS to the actuation piston. After the actuation ball has been released and pressure is applied to the PCS the actuation subassembly automatically unlatches and strokes through itself pulling the core tube through the ball valve and into the sample chamber. As the core tube is pulled through the ball valve it mechanically rotates the ball valve closed. During actuation, seals at the top of the core tube are pulled into a seal sub thus closing the sample chamber at both ends. When the actuation subassembly reaches the end of its stroke, it automatically latches once again holding the sample chamber closed.

\section{ACCUMULATOR SUBASSEMBLY}

As the name implies, the accumulator subassembly contains an accumulator. As the ball valve closes, a small change in volume occurs. To offset the volume change, the accumulator forces fluid into the sample chamber thus maintaining bottom hole pressure. The accumulator also compensates for any fluid loss due to weeping seals as the differential pressure increases inside the sample chamber during retrieval of the PCS. The PCS accumulator subassembly also contains a pressure relief mechanism. An integral back pressure valve relieves pressure from the gas charged side of the accumulator in the event of over pressurization of the sample chamber.

\section{MANIFOLD SUBASSEMBLY}

The PCS manifold subassembly contains integral valves that enable the sample chamber to be isolated and removed. Two sample ports for collecting gas and/or fluid samples also controlled by integral valves are contained in the manifold subassembly. The sample ports have separate flow paths into the sample chamber. One flow path leads to the inside of the core tube and the other flow path leads to the annular volume surrounding the core tube. The manifold subassembly also contains a burst disk which vents all pressure from the sample chamber should the internal pressure exceed the designed working pressure of 690 bar $(10,000 \mathrm{psi})$. An optional pressure transducer can also be installed in the manifold subassembly enabling monitoring of the sample chamber internal pressure.

\section{BALL VALVE SUBASSEMBLY}

The PCS ball valve subassembly forms the sample chamber lower seal when actuated. The ball valve is mechanically closed as the actuation subassembly pulls the core tube through the ball valve subassembly. The ball valve subassembly also serves as the connection point for the PCs cutting shoe. 
The PCS detachable sample chamber consists of the manifold subassembly, ball valve subassembly and pressure case. The sample chamber when detached from the PCS is $92.2 \mathrm{~mm}$ (3.75in) in diameter and $1.8 \mathrm{~m}$ ( $6 \mathrm{ft}$ ) long. When the sample chamber is stroked closed and removed from the core barrel, the two sampling ports and their associated integral valves as well as the integral pressure transducer are easily accessible. A sampling manifold can be attached to either or both sampling ports for sampling fluids and/or gasses.

\section{PCS OPERATION}

The PCS is free-fall deployed. The PCS is rotated with the BHA similar to the XCB. Once the core sample has been cut, the rig pumps are shut off and the coring wireline is attached to the PCS. The PCS is picked up off the BHA landing shoulder to release the actuation ball. The PCS is then lowered back onto the BHA landing shoulder. The rig pumps are reengaged to pressurize the drill string which actuates the actuation subassembly, stroking the sample chamber closed. The PCS is then retrieved via the coring wireline.

Once on deck, the detachable sample chamber is removed and placed in a temperature control bath. A sampling manifold is attached and gas and/or fluid samples are then extracted.

\section{ACKNOWLEDGEMENTS}

Development of the PCS was directed by the ODP/TAMU Engineering and operations staff. Primary design work was carried out by $\mathrm{Mr}$. James Aumann, Aumann and Associates, Salt Lake City, Utah. The actuation subassembly is an Eastman Christensen, Salt Lake City, Utah, patented mechanism used by permission. 


\section{PRELIMINARY BALL VALVE ASSEMBLY (NEW TOOL)}

(Reference Figures $1,2 \& 3$ )

1. Press Pivot Pins (OP6220) into Bit Sub/operator Housing (OP6210) flush with Bit Sub/Operator OD.

2. Press Link Pins (OP6224) into Operator Head (OP6226) and Ball (OP6218) flush with milled sides.

3. Lay Operator Head on flat surface, ball side up and place Ball on Operator Head in open position. Install two Links (OP6222). Rotate Ball to full open position and check bore through assembly for alignment. If Ball does not fully open, elongate holes in Links. Caution, distance between Pivot Pin holes in Links control Ball rotation. Therefore, do not over elongate holes or over rotation will occur. If Ball over rotates, new Links will have to be made with Pivot Pin holes moved closer together.

4. Assemble seat (OP6212) without Seal, Seal Retainer or O-Ring into Bit Sub/Operator Housing (OP6210). Slip Ball with Links and operator Head into operator Housing and onto Pivot Pins (ref fig 2). Check rotation of Ball. If Ball does not rotate freely $360^{\circ}$, face off bottom of seat and recheck for free rotation. There should be at least .005" clearance between Ball and seat when Ball is in open position.

5. Assemble Spring Housing (OP6228) through Bit Sub/Operator Housing into operator Head. Pull spring Housing upward closing $\mathrm{Ball}$ and check that Ball is positioned properly over seal seat at same time Operator Head makes contact with Bit Sub/Operator Housing (ref fig 3 ).

NOTE: If Ball does not completely close, face off top of operator Head until it does. Do not remove excess material or over rotation will occur. If over rotation occurs, operator Head must be lengthened.

6. Disassemble.

7. Reinstall Seat, O-Ring (OD3142), Seal (OP6214) and Seal Retainer (op6216). Install Ball and Rotate it. Ball should rotate with some resistance.

8. Remove Ball and check Seal for cutting. If Seal is cut, first check edges of hole through Ball for smoothness. It may be necessary to deepen seal cavity in Seat to reduce squeeze on Seal or deepen seat cavity in operator Housing to increase clearance between Ball \& Seat. 


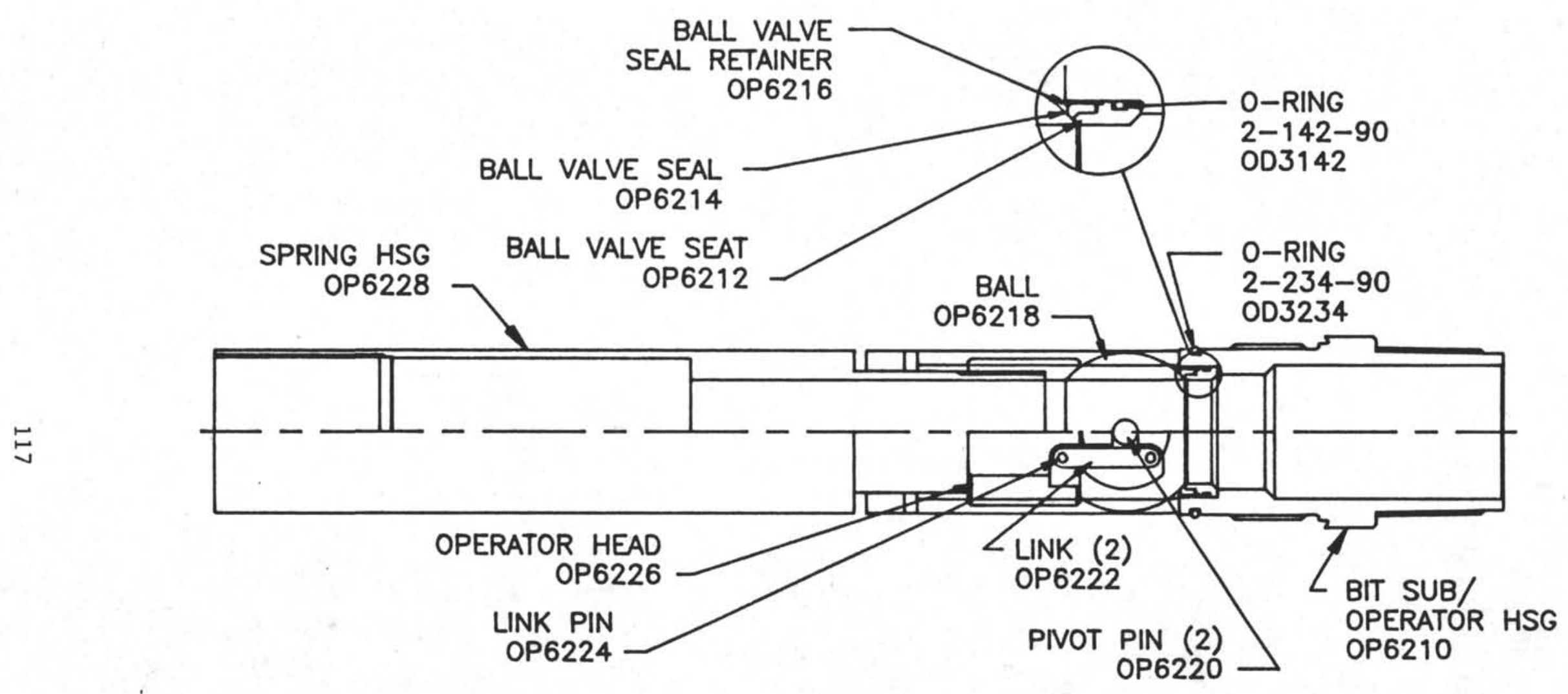

PCS FIG 1: BALL VALVE SUBASSEMBLY 

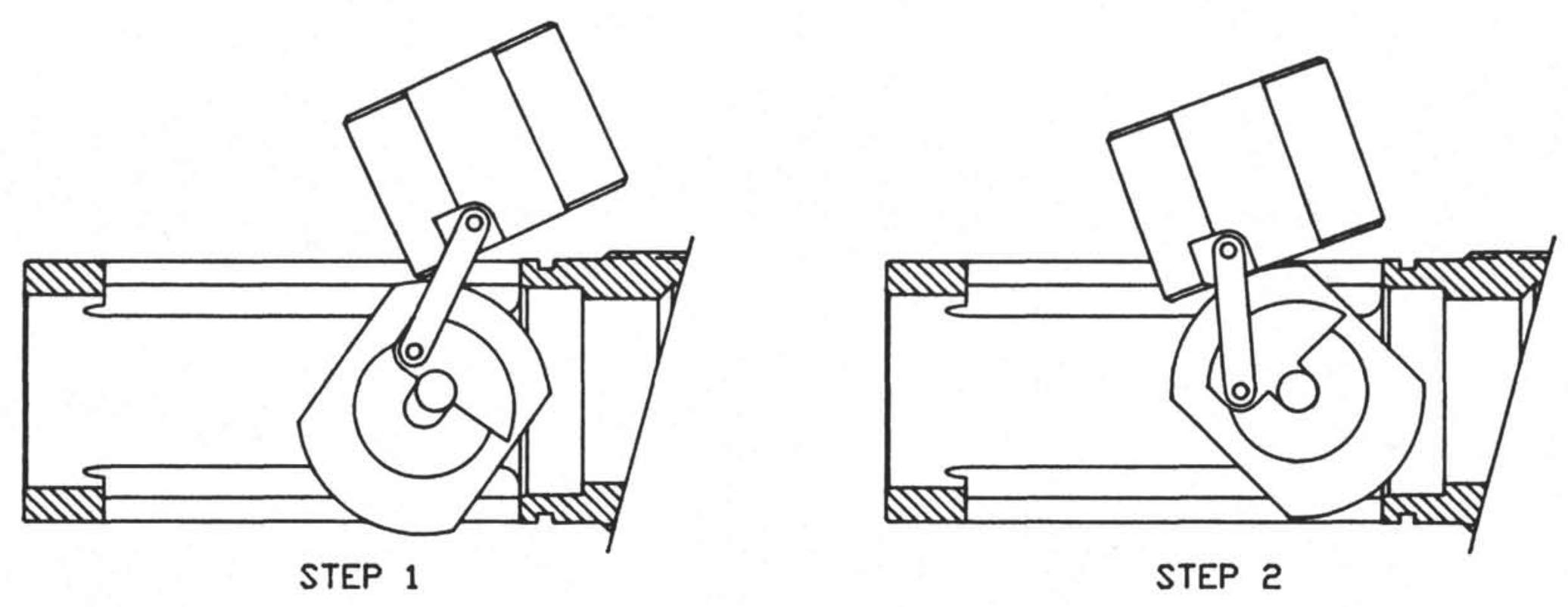

$\underset{\infty}{\rightleftarrows}$
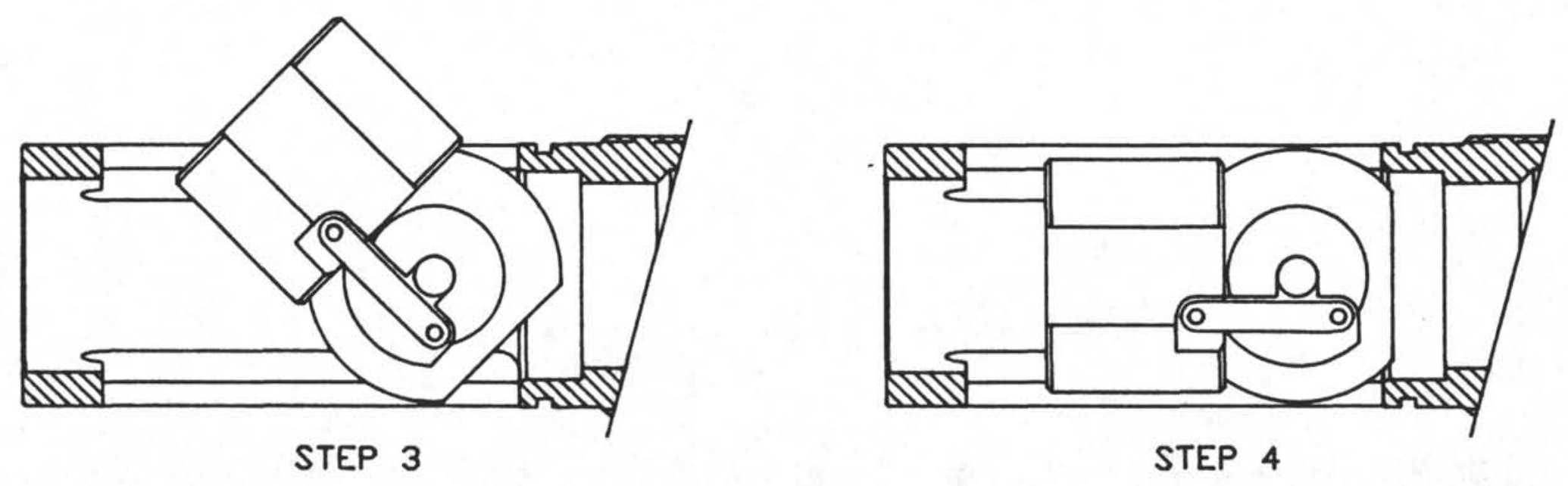

PCS FIG 2: BALL \& DPERATUR HEAD INSTALLATION 


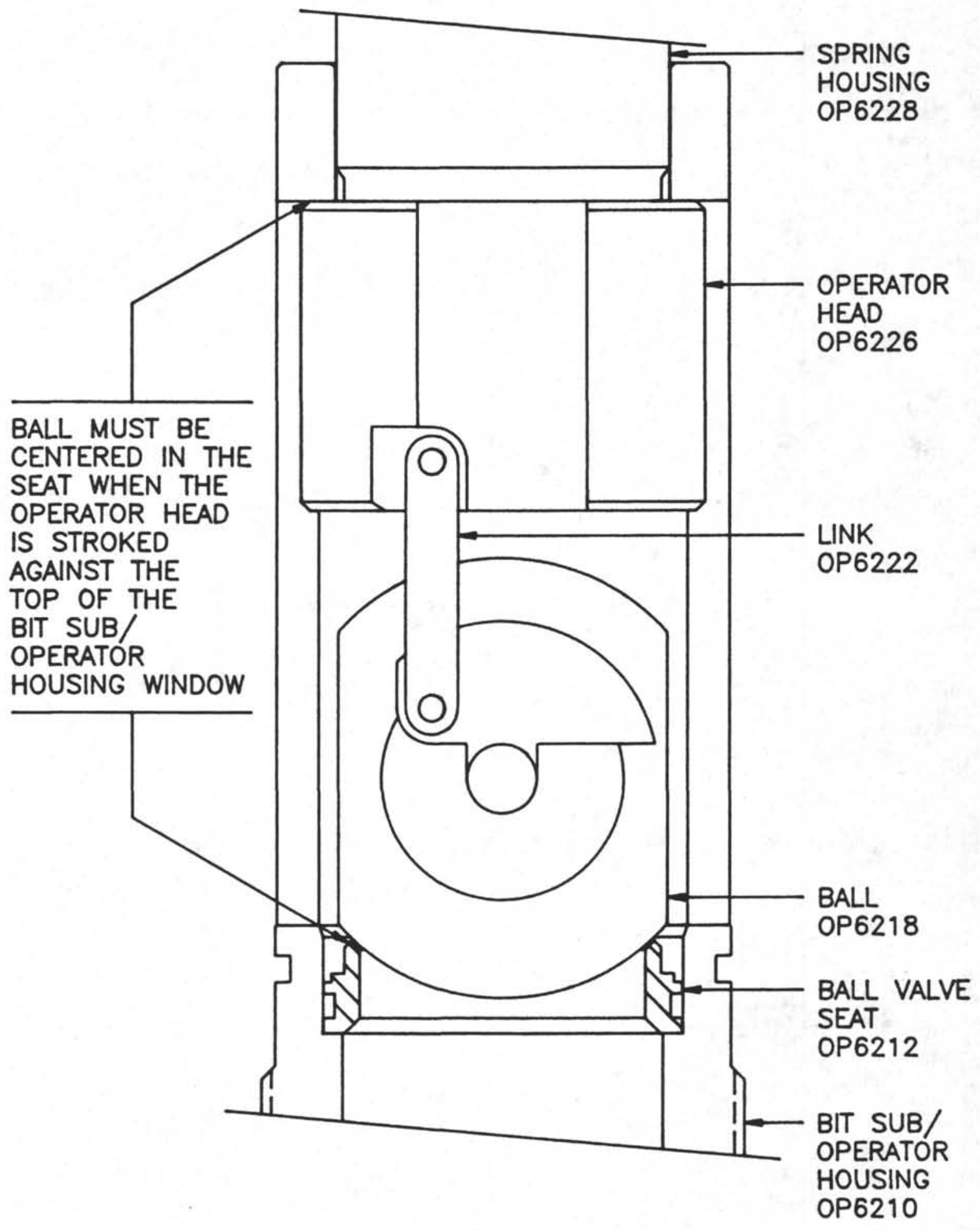

PCS FIG 3: BALL VALVE ROTATION 
BALL VALVE SUBASSEMBLY

(Reference Figures $2 \& 4$ )

1. Assemble Seat (OP6212), O-Ring (OD3142), Seal (OP6214), and Seal Retainer (OP6216) into Bit Sub/Operator Housing (OP6210).

NOTE: If assembling for first time see section entitled "PRELIMINARY BALL VALVE ASSEMBLY (NEW TOOL)".

2. Lay Operator Head (OP6226) on a flat surface, Ball side up. Place Ball (OP6218) on Operator Head in open position. Install two Links (OP6222).

3. Lift and rotate Ball away from seat as far as possible. Insert this assembly into Bit Sub/operator Housing and onto Pivot Pins (ref fig 2). Rotate Ball on Pivot Pins into full open position.

4. Install operator Sleeve (OP6230), Operator Spring (OP6244) and Spring Cap (OP6232) into Spring Housing (OP6228).

NOTE: Threads on Spring Cap are long enough to use to preload spring without a special tool. However, force must be applied to spring Cap while starting thread. Stand spring Housing on end and lean on spring Cap while starting thread.

CAUTION: WHEN DISASSEMBLING SPRING HOUSING, SPRING CAP WILL BE EJECTED FROM SPRING HOUSING BY FORCE OF SPRING. DO NOT STAND IN FRONT OF SPRING CAP WHILE DISASSEMBLING.

Note: This problem arose as a result of changing spring material to Titanium (which required a longer spring) and exists with the Leg 139 version. This problem will be correct in next redesign scheduled for Leg 141. Cost of Titanium springs is not much more than alloy steel springs. Thus titanium springs will replace alloy steel springs as standard springs.

5. Insert Spring Housing into Bit Sub/Operator Housing and make up to operator Head.

6. Install O-Ring (OD3234) on Bit Sub/Operator Housing.

7. Set Ball Valve Subassembly aside. 

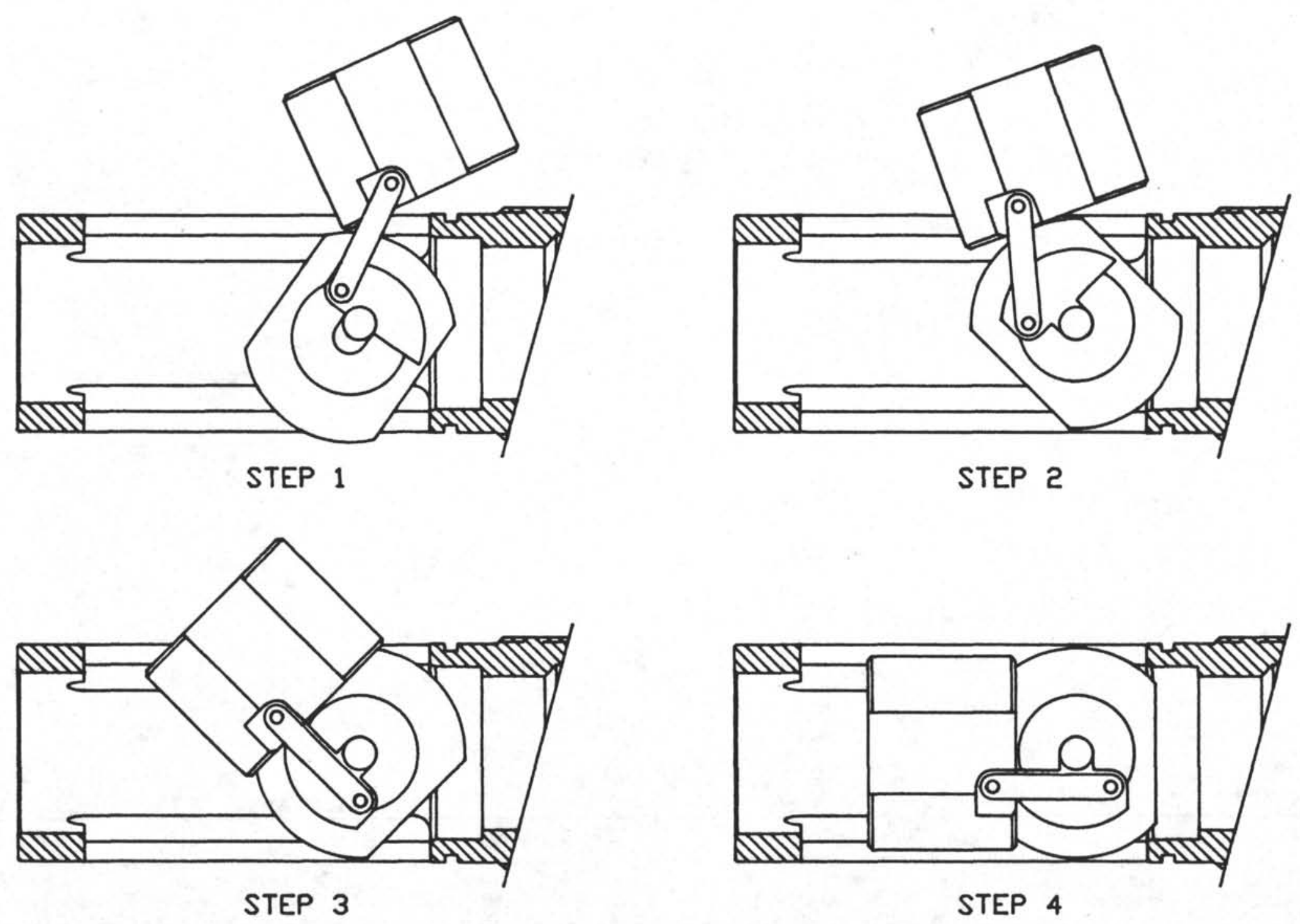

PCS FIG 2: BALL \& DPERATIR HEAD INSTALLATION 


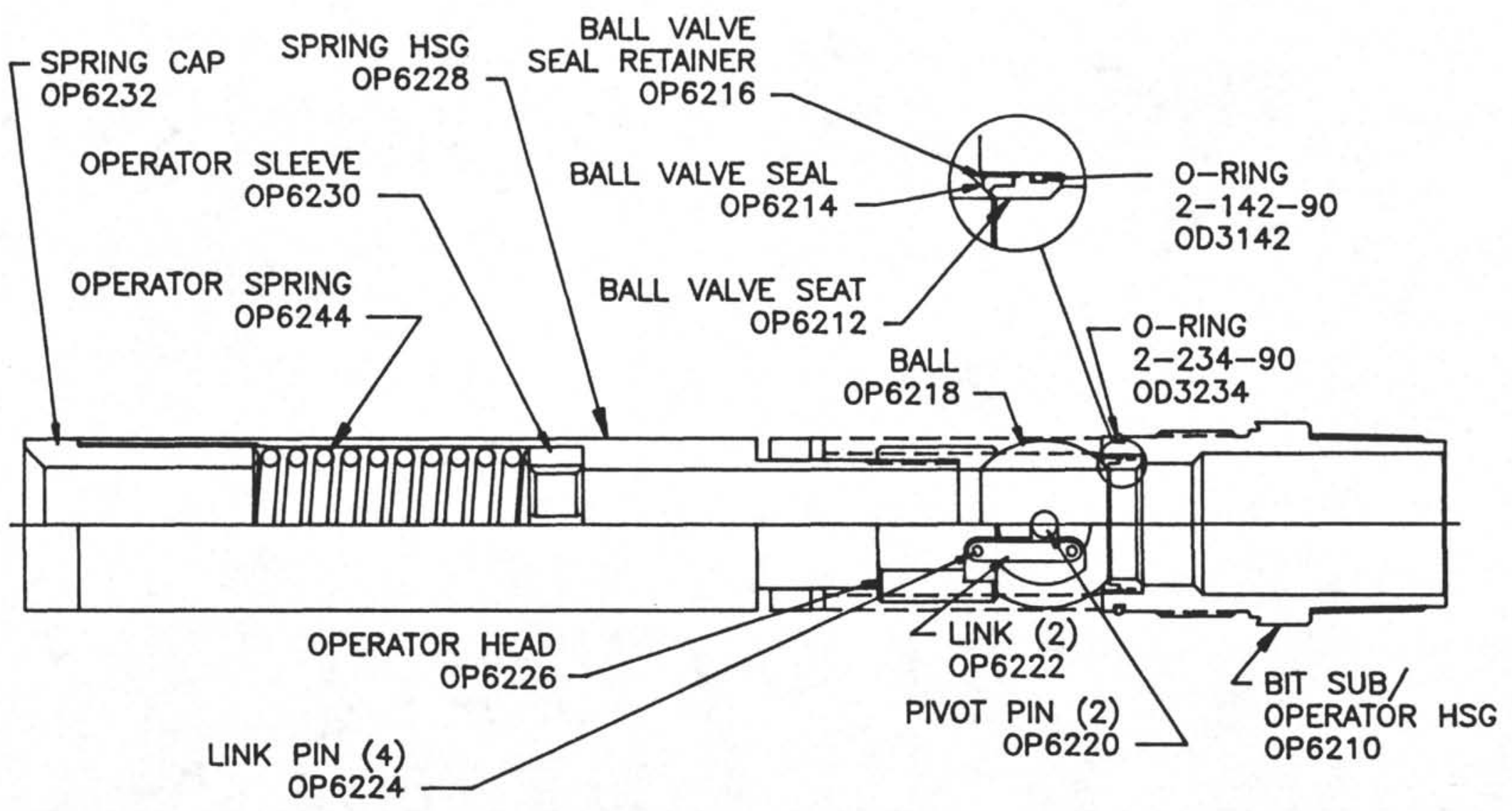

PCS FIG 4: BALL VALVE SUBASSEMBLY 


\section{MANIFOLD SUBASSEMBLY \\ (Reference Figures $5,6,7 \& 8$ )}

1. Install 1 each Check Valve Ball (OD7217) into Check Valve Sub (OP6209).

2. Install Check Valve Seat (OP6211) into check Valve Sub.

3. Install Probe Adapter (OP6207) into Check Valve Sub.

4. Install Probe (OP6205) into Probe Adapter.

NOTE: Install probe only if requested by scientists.

6. Install 1 each O-Ring (OD3220) into Check Valve Sub.

7. Install Check Valve Sub subassembly into Seal Mandrel (OP6213) using 34 each 5/16" ball bearings (OD7220) and 2 each Set Screws (OD6585) as shown in assembly drawing op6200.

8. Makeup Probe Port Tube (OP6215) into Seal Mandrel.

NOTE: Do not wrench on Probe Port Tube seal surface. Makeup Manifold Mandrel (OP6217) to Seal Mandrel and check that Manifold Mandrel shoulders against Seal Mandrel and not the Probe Port Tube. If Manifold Mandrel shoulders against the Probe Port Tube, remove Manifold Mandrel and Probe Port tube. Tap Probe Port Tube threads in Seal Mandrel deeper using a 1/4" NPT tap. Once the Manifold Mandrel is determined to shoulder on the Seal Mandrel and not the Probe Port Tube, remove the Manifold Mandrel.

9. Install 1 each O-Ring (OD3226) onto Seal Mandrel.

10. Install 2 each Poly-Pak Seals (OD3140 - 18702375-375B) onto Seal Carrier (OP6242) as indicated in figure 6 .

11. Install Seal Carrier subassembly onto Seal Mandrel as indicated in figure 6 .

12. Install 1 each O-Ring (OD3206) onto Manifold Mandrel (OP6217).

13. Makeup Seal Mandrel subassembly to Manifold Mandrel.

14. Install 1 each Burst Disk (OP6344) into Manifold Mandrel (ref fig 7). 
15. Install 1 each Burst Disk Ring (OP6340) into Manifold Mandrel with Burst Disk Ring rounded ID edged towards Burst Disk (ref fig 7).

16. Install 1 each Burst Disk Plug (OP6203) into Manifold Mandrel.

17. Install 1 each Pressure Transducer (OP6358) into Manifold Mandrel.

NOTE: Be sure Transducer is screwed in far enough to clear Transducer Cap. If not use 1/4" NPT flat bottom tap to recut threads until Transducer clears the cap.

18. Install 1 each O-Ring (OD3217) into Manifold Mandrel (ref fig 7).

19. Install 1 each Pressure Transducer Cap (OP6328) into Manifold Mandrel.

20. Drop a $3 / 8^{\prime \prime}$ ball bearing into bullet valve ports and peen with punch and hammer to form a seat. Remove ball bearing.

21. Install 1 each O-Ring (OD3011) onto 2 each Bullet Valves (OP6248).

NOTE: To aid in installing o-rings on Bullet valves, partially screw Bullet valves into Manifold Mandrel upside down (ref fig 8).

22. Install Bullet Valves into Manifold Mandrel.

23. Install 1 each O-Ring (OD3220) onto Manifold Mandrel. 


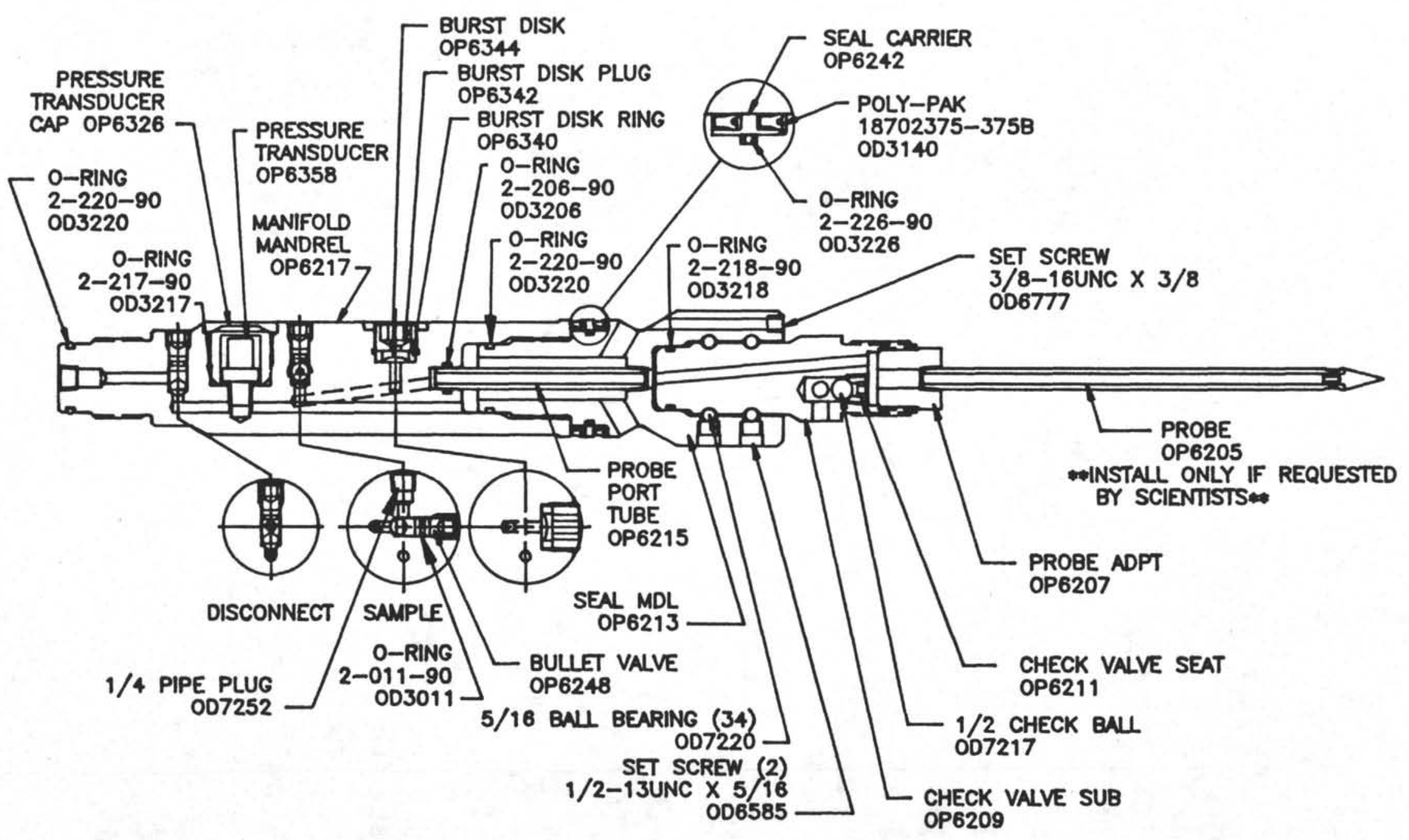

PCS FIG 5: MANIFOLD SUBASSEMBLY 


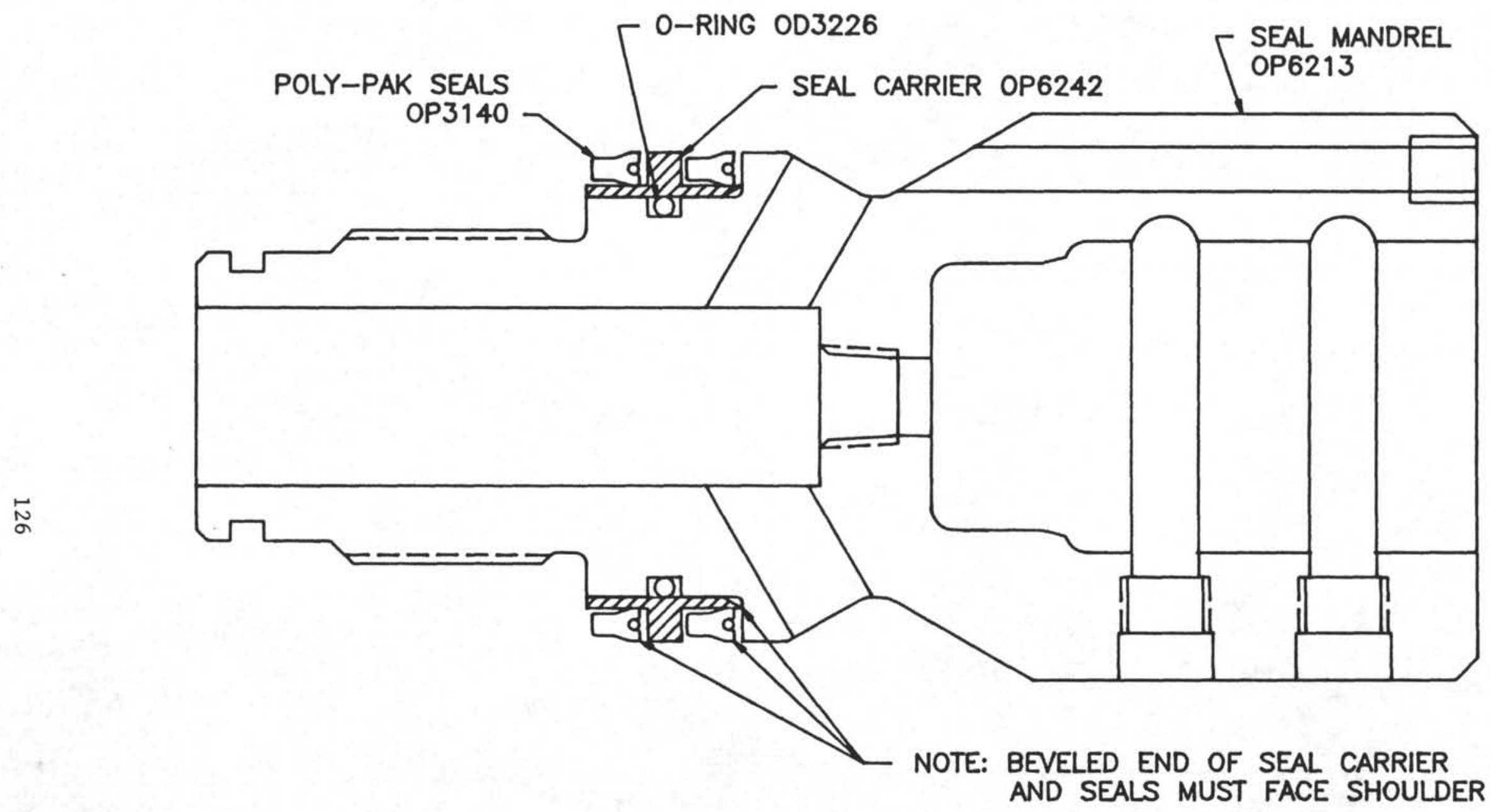

PCS FIG 6: SEAL CARRIER DETAIL 


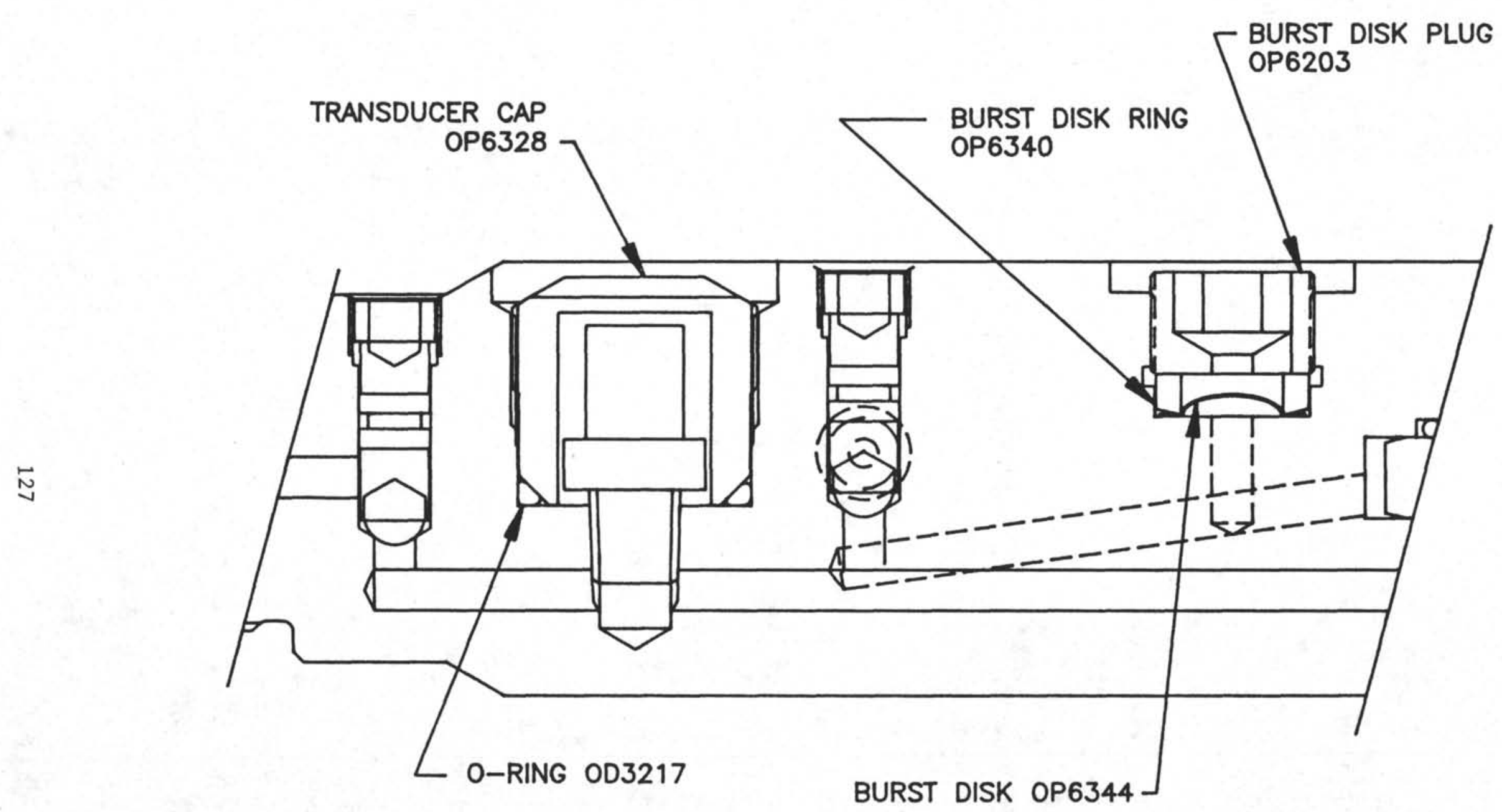

PCS FIG 7: MANIFOLD MANDREL DETAIL 


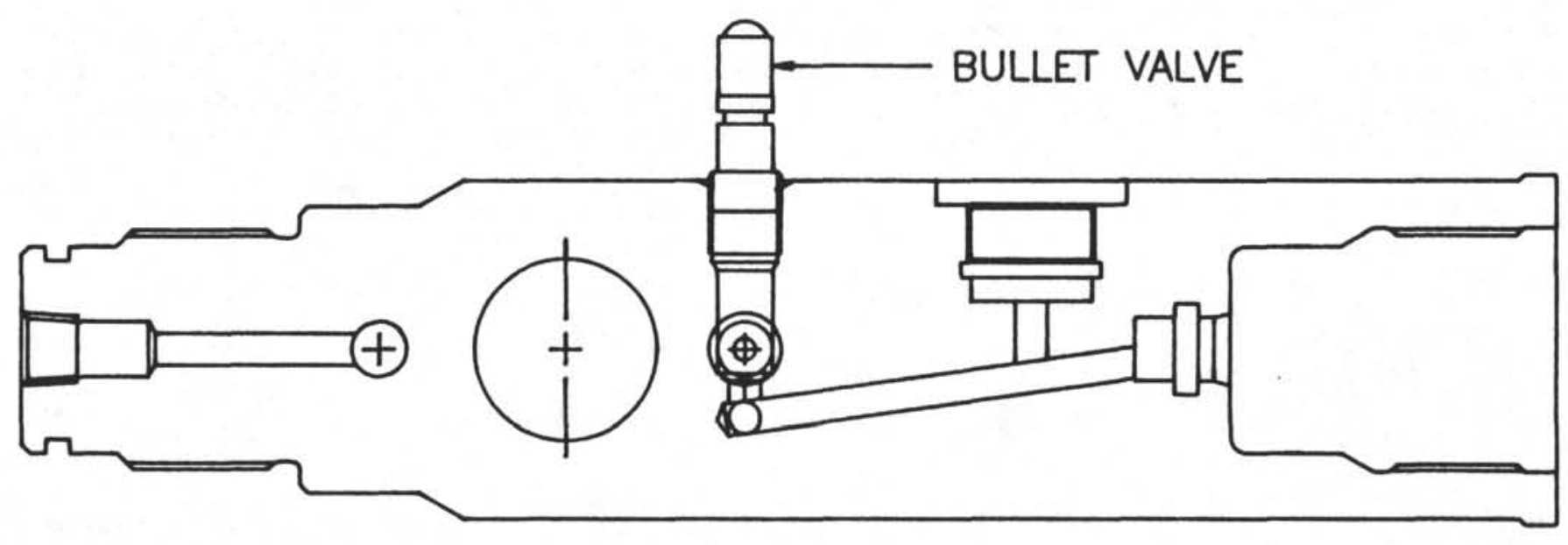

PCS FIG 8: BULLET VALVE O-RING INSTALLATION 
ACCUMULATOR SUBASSEMBLY

(Reference Figure 8, $9 \& 10$ )

1. Install 1 each O-Ring (OD33011) onto a Bullet Valve (OP6248).

NOTE: Bullet Valve can be partially screwed in upside down to aid in installing 0-Ring (ref fig 8 ).

2. Install Bullet Valve into Regulator Sub (OP6262).

NOTE: If Regulator Sub is new or if Bullet Valve is suspected of leaking, drop a $3 / 8^{\prime \prime}$ ball bearing into Bullet Valve pocket. Using a hammer and punch, drive ball bearing downward to reform seat, then remove ball bearing.

3. Install 1 each outlet Screw (OP6250) into Regulator Sub.

4. Install Valve Seat (OP6346 - TESCOM PN 1036) and Seat Retainer (OP6348 - TESCOM PN 1743-2) into Regulator Sub (ref fig 10).

5. Install 1 each O-Ring (OD3220) onto Regulator Sub.

6. Install 1 each O-Ring (OP6350 - TESCOM PN 5200-001227), 1 each Backup Ring (OP6352 - TESCOM PN 5476-11220) and 1 each Sensor Assembly (OP6354 - TESCOM PN 1738-20) into Regulator Sub (ref fig 10).

NOTE: $\quad$ Reference Tescom schematic for Sensor Assembly detail (OD must be turned down).

7. Install 1 each Regulator Spring Pad (OP6266) and 1 each Load Spring (OP6356 - TESCOM PN 1051) into Regulator Housing as shown in assembly drawing op6200.

8. Makeup Regulator Housing (OP6264) to Regulator Sub (OP6262).

9. Install 2 each O-Rings (OD3016) onto Regulator Adjusting Screw (OP6268) and install Regulator Adjusting Screw into Regulator Housing.

10. Install ' 1 each O-Ring (OD3220) onto Accumulator Piston (OP6260) and install Accumulator Piston into Accumulator Barrel (OP6258) with Piston pocket facing outward.

11. Makeup Regulator Sub to same end of Accumulator Barrel. NOTE: Accumulator Piston pocket should be facing the Regulator sub. 
12. Install 1 each O-Ring (OD3011) onto 2 each Bullet Valves (OP6248).

NOTE: Bullet Valves can be partially screwed into Accumulator Sub (OP6252) upside down to aid in installing 0-ring (ref fig 8).

13. Install 2 each Bullet Valves into Accumulator Sub (OP6252).

NOTE: If Accumulator Sub is new or if Bullet Valves are suspected of leaking, drop a $3 / 8$ " ball bearing into Bullet Valve pocket. Using a hammer and punch drive ball bearing downward to reform seat.

14. Install 1 each outlet Screw (OP6250) into Accumulator Sub.

15. Makeup Accumulator Sub onto Accumulator Barrel.

NOTE: The tool should be hydrostatically tested at this point. See section entitled "HYDROSTATIC TESTING PROCEDURES". 


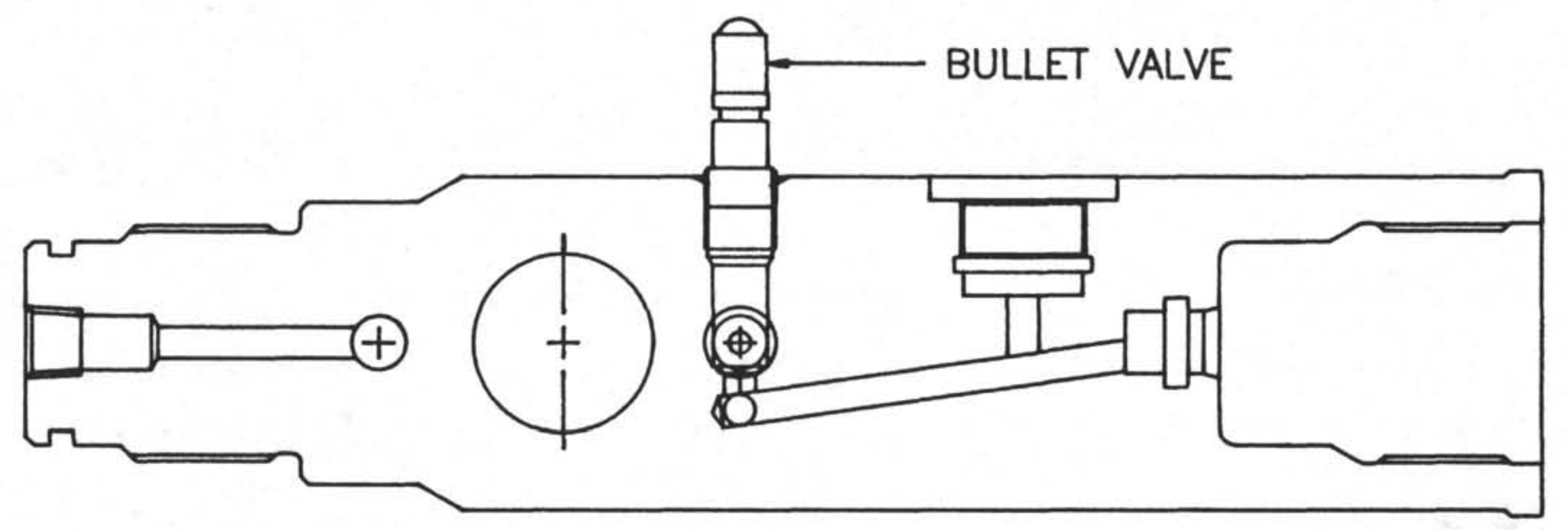

PCS FIG 8: BULLET VALVE O-RING INSTALLATION 


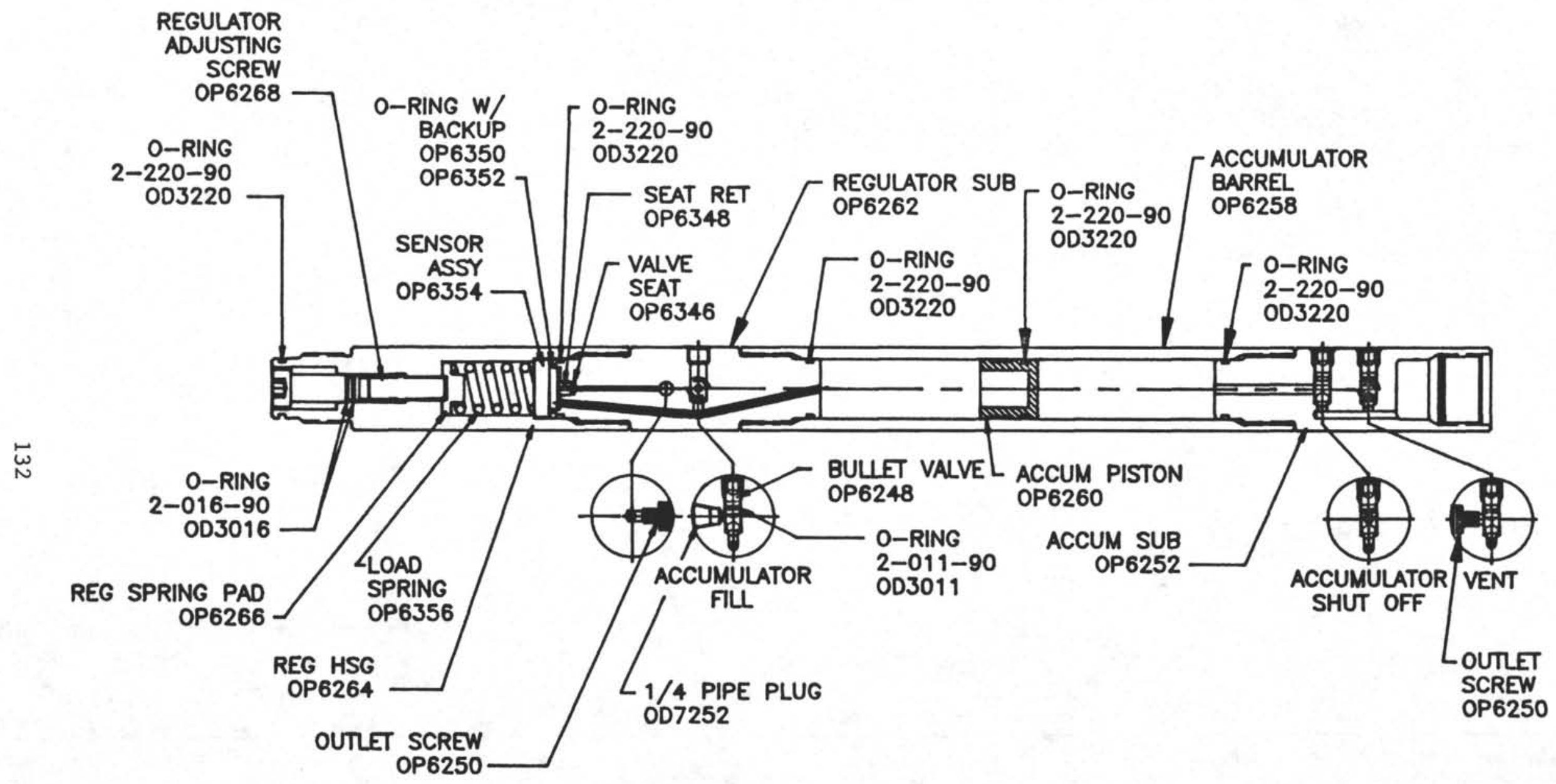

PCS FIG 9: ACCUMULATOR SUBASSEMBLY 


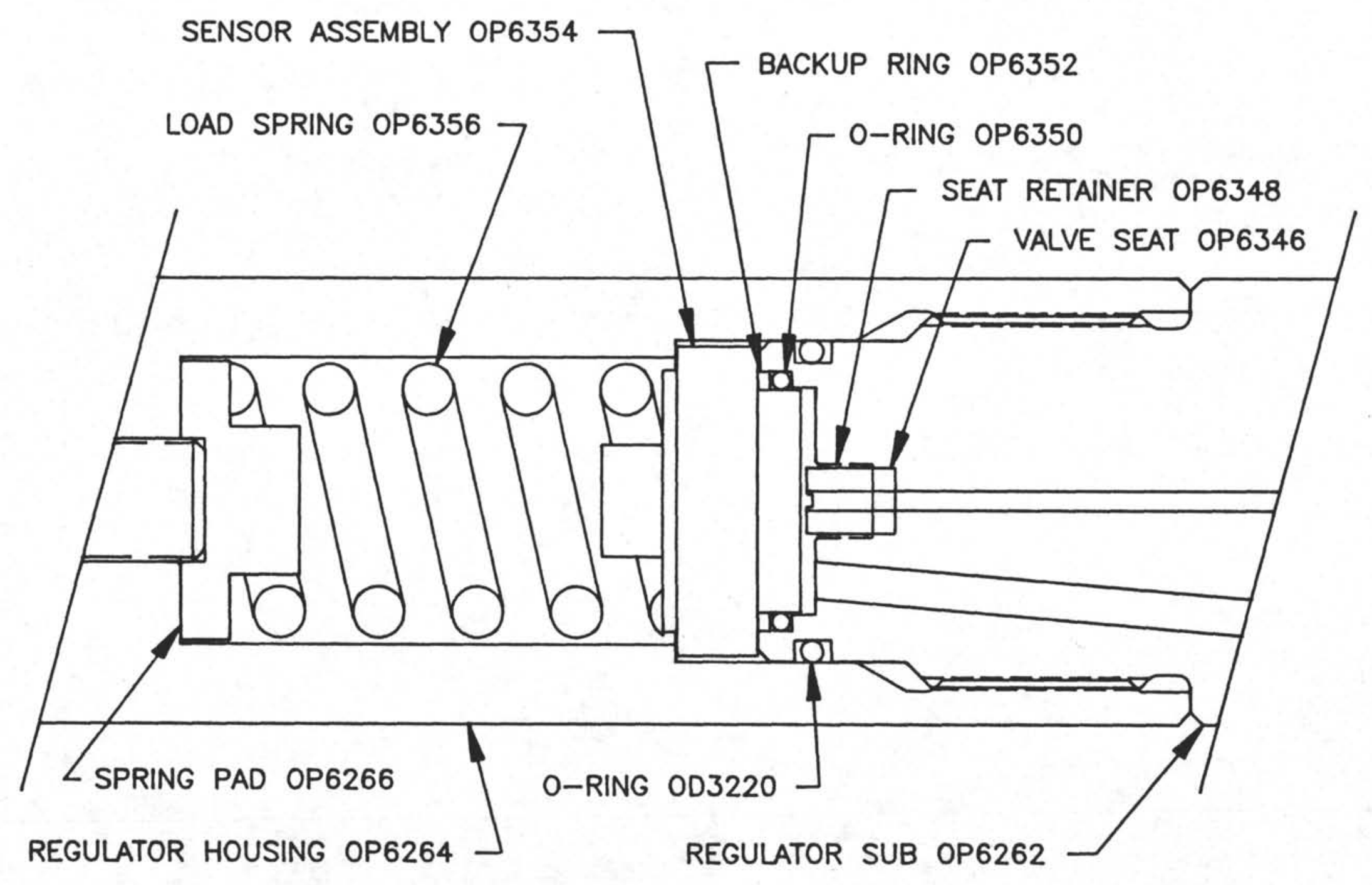

PCS FIG 10: BACK PRESSURE REGULATOR SENSOR DETAIL 


\section{ACTUATOR SUBASSEMBLY}

(Reference Figure 11)

1. Install 1 each O-Ring (OD3223) into Latch Housing (OP6324).

2. Install Latch Piston (OP6308) and Latch Spring (OP6306) into Latch Housing.

3. Install 1 each O-Ring (OD3223) into Release Housing (OP6304).

4. Makeup Latch Housing to Release Housing.

5. Install 1 each O-Ring (OD3128) onto Release Piston (OP6296).

6. Install Release Piston and Release Spring (OP6298) into Release Housing.

7. Install Release Spring Retainer (OP6294) into Release Housing. NOTE: $\quad$ Release Spring Retainer thread is long enough to preload spring without a special tool.

8. Install 1 each O-Ring (OD3228) onto Latch Housing.

NOTE: $\quad$ Remove all wrench marks from Latch Housing OD so as not to cut $0-$ Ring during installation.

9. Makeup Latch Mandrel (OP6314) with holes towards Latch Housing, to Latch Housing.

CAUTION: DO NOT WRENCH ON LATCH MANDREL EXCEPT WITHIN 1" OF HOLES.

10. Install 1 each O-Ring (OD3226) into Latch Cap (OP6312).

11. Install Latch Cap over Latch Mandrel with threaded end towards Latch Housing.

12. Assemble Top Sub (OP6318) onto Latch Mandrel.

13. Makeup Female Quick Release (OP5922) to Top Sub.

14. Makeup Vent Sub (OP6286) and 1 each 1/8" Shim (OP6288) and 2 each 1/16" Shims (OP6290) to Actuator Barrel (OP6292) (reference assembly drawing op6200).

CAUTION: Actuator Barrel has different threads on each end to ensure it is installed properly. See section entitled "SHIM DETERMINATION". 
15. Insert Release Resetting Tool (OP6384) into Actuator Assembly and tighten Jack Screw to compress Release Spring.

16. Install 3 each Release Dogs (OP6302) (reference assembly drawing 0P6200) using grease to hold them in place.

17. Slide Actuator Barrel over Release Housing until Release Dogs are covered.

18. Remove Release Resetting Tool and insert Latch Resetting Tool (OP6376) into Actuator Assembly and tighten Jack Screw to compress Latch Spring.

19. Install 4 each Latch Dogs (OP6310) using grease to hold them in place.

20. Slide Actuator Barrel over Actuator Assembly until Release Dogs latch into control groove.

NOTE: When Latch Dogs are latched into control groove there should be approximately $12^{\text {" }}$ between Latch Cap and Top Sub.

21. Makeup Latch Cap to Actuator Barrel.

22. Remove Latch Resetting Tool. 


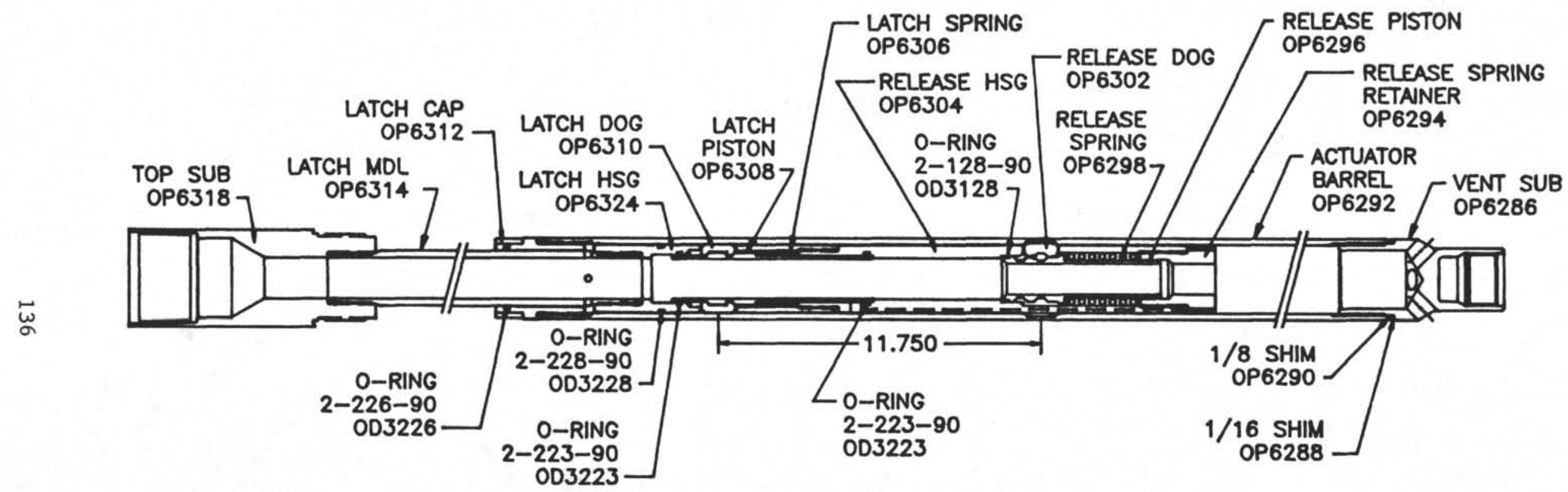

\section{PCS FIG 11: ACTUATOR SUBASSEMBLY}




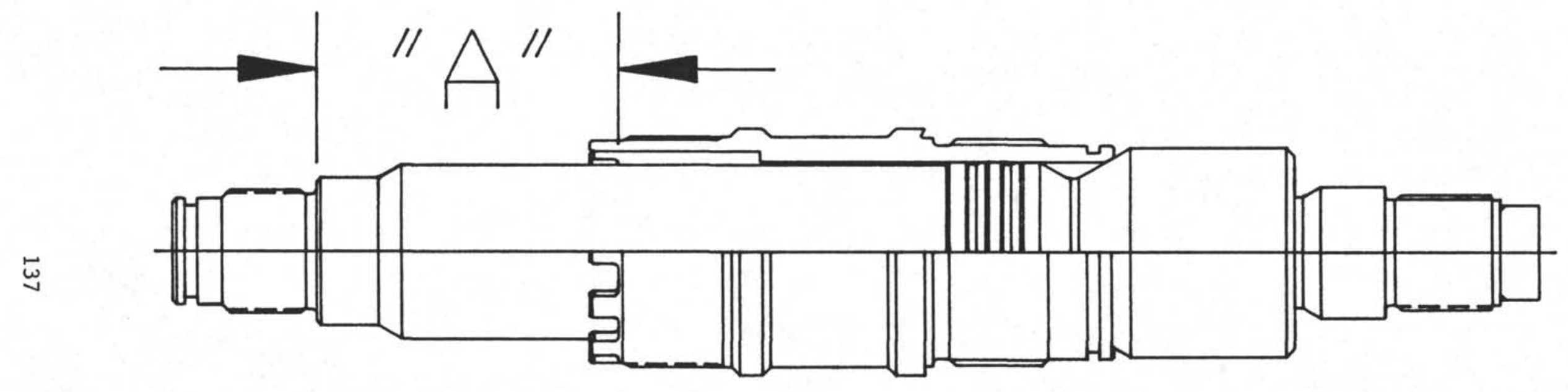

PCS FIG 12: SHIMMING DIMENSIDN " $A$ " 


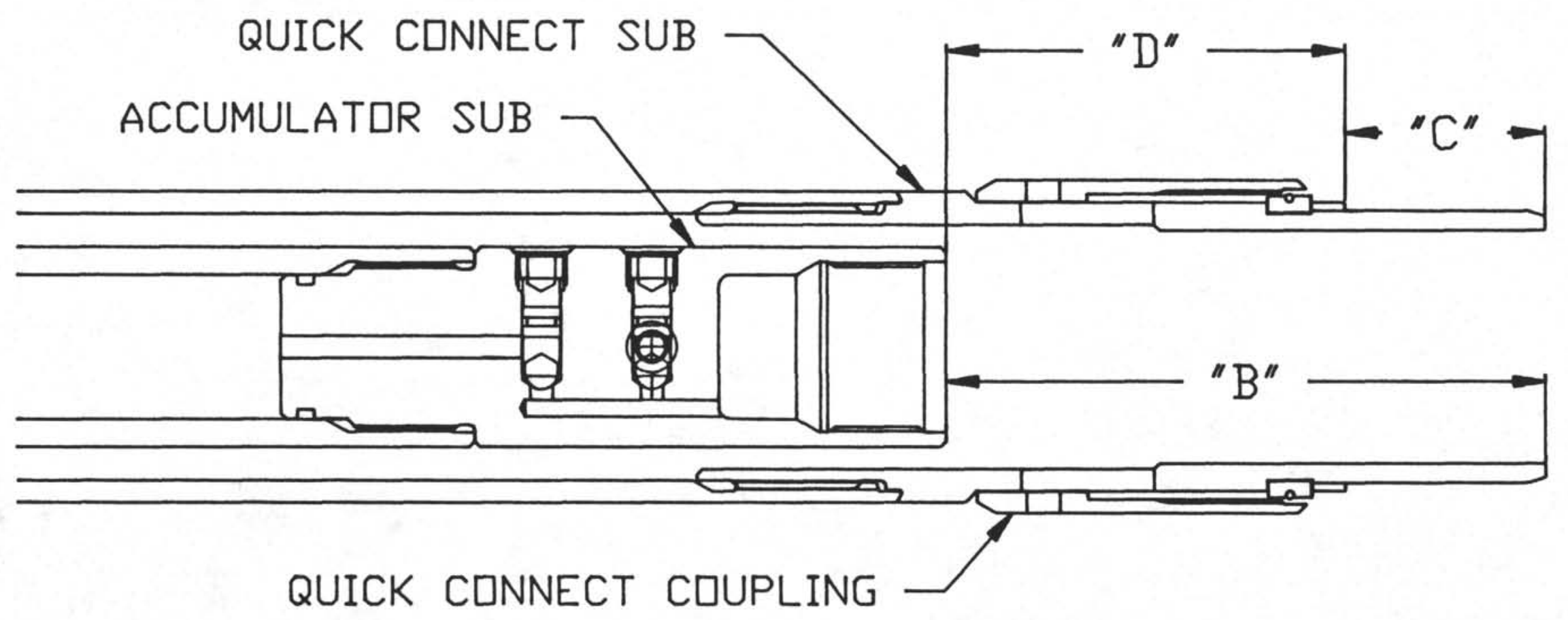

PCS FIG 13: SHIMMING DIMENSIONS " $B$ " " $C$ " \& " $D$ " 


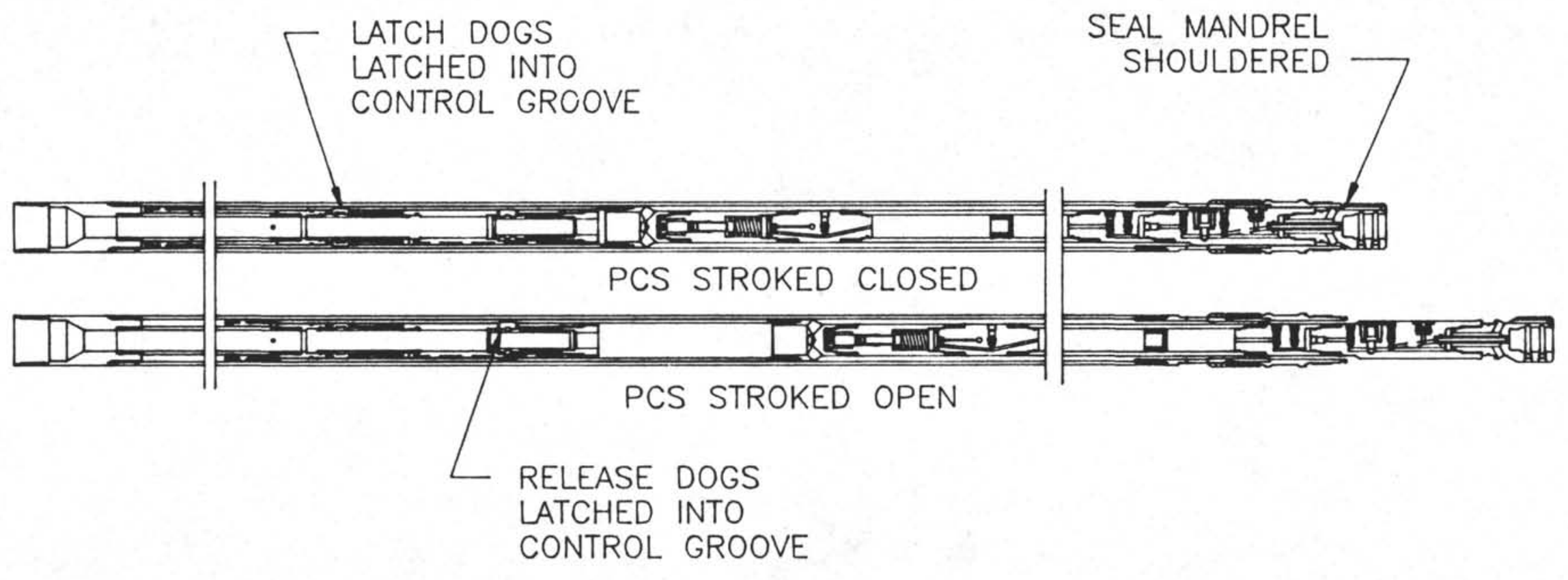

PCS FIG 14: SHIM DETERMINATION VERIFICATION 


\section{FINAL ASSEMBLY \\ (Reference Figures $15 \& 16$ )}

NOTE: Check "ALL" Bullet Valves for proper position during final assembly (ref fig 15).

$$
\begin{aligned}
& \text { Shut off - - OPEN } \\
& \text { Vent - O CLOSED } \\
& \text { Disconnect - - OPEN } \\
& \text { Sample - - CLOSED }
\end{aligned}
$$

"LOWER ASSEMBLY" (ref fig 16)

1. Place Outer Barrel (OP6236) in vice.

2. Slide Ball Valve Subassembly into outer Barrel and torque up connection.

CAUTION: Be sure Ball Valve remains in full open position.

3. Makeup Inner Barrel (Core Tube oP6234) to Manifold Subassembly.

NOTE: Do not install core Catchers yet.

4. Slide Manifold Subassembly into outer Barrel until Inner Barrel extends past Bit Sub/Operator Housing.

5. Install Core Catchers (see "Core Catcher Configuration" section).

6. Install 1 each O-Ring (OD3234) onto Seal Housing and makeup Seal Housing to Outer Barrel.

7. Push Manifold Assembly towards Seal Housing until Manifold Mandrel extends past top of Seal Housing.

CAUTION: Do not push Manifold Subassembly up too far or Ball Valve will close.

8. Makeup PCS Cutting Shoe (OC0990) to Bit Sub/Operator Housing.

9. Set this assembly aside until ready to deploy.

"UPPER ASSEMBLY" (ref fig 16)

10. Place Top Connection of Actuator Subassembly/Accumulator Subassembly in vice.

11. Using Release/Reset tool, stroke out Actuator Subassembly until Latch Dogs are latched into control groove. 
12. Install Upper Barrel.

NOTE: Do not torque up Upper Barrel. 


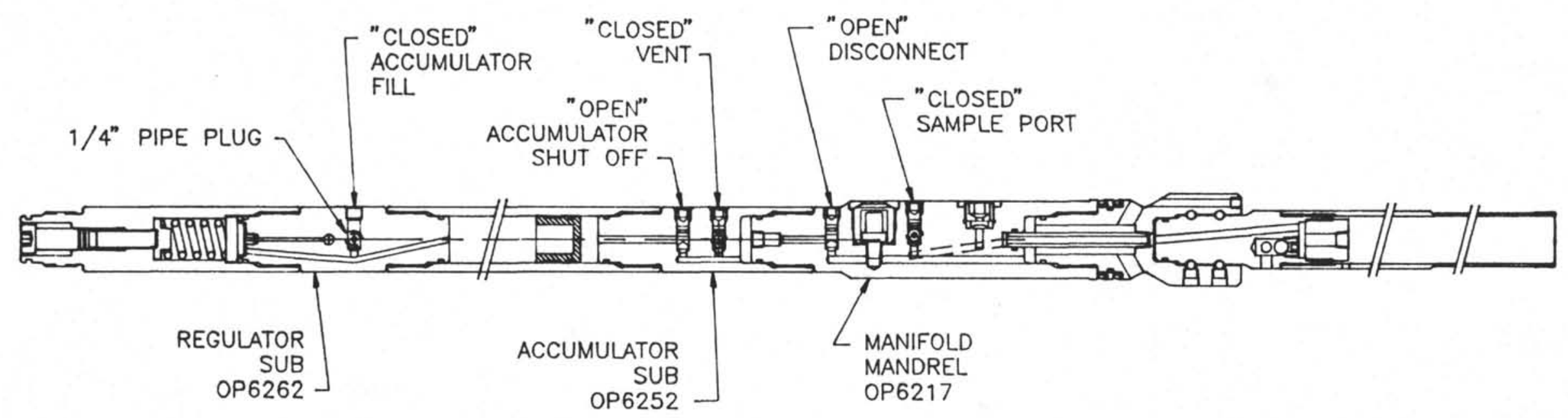

NOTE: REFERENCE ASSEMBLY DRAWING OP6200 FOR INDIVIDUAL PART NUMBERS

PCS FIG 15: RUN-IN VALVE CONFIGURATION 


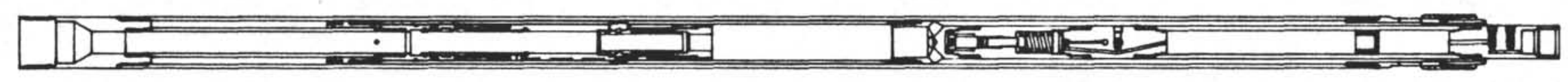

$$
\text { UPPER ASSEMBLY }
$$

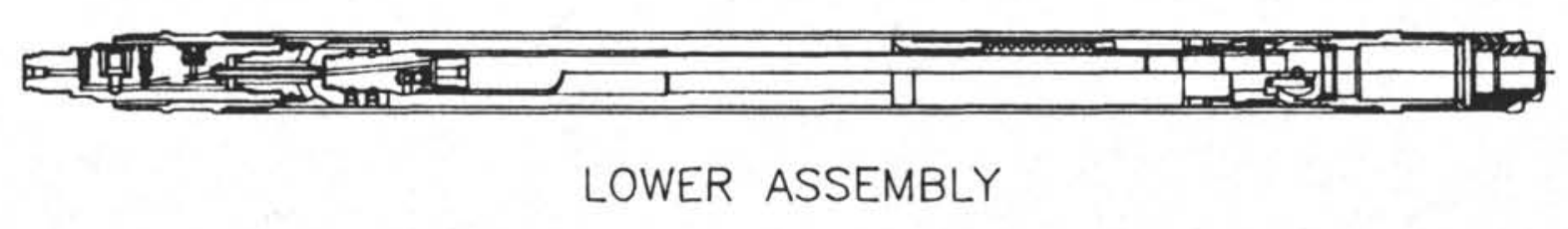

PCS FIG 16: FINAL ASSEMBLIES 
LATCH ASSEMBLY

(Reference Figure 17)

1. Assemble PCS Latch like a standard XCB latch using PCS Pulling Neck OP6282.

2. Slip Spacer Ring OP6280 and Secondary Latch Spring OP6284 over bottom of Pulling Neck.

3. Makeup Ball Collet op6276 onto Pulling Neck until it shoulders.

4. Install Kickout Body OP6270 by orientating Kickout Bar so it passes between Ball collet fingers.

5. Install Collet Sub OP6272 and make it up to XCB Latch Body OP4475.

6. Place a 1 1/4" Ball OD7218 in Ball Collet and drive Collet Seat op6274 into collet sub.

NOTE: With Collet Seat in place, $11 / 4 "$ ball should not be able to fall out of collet.

7. Makeup Landing Sub op6278 to collet Sub.

8. Makeup Sealing Quick Releases and Inner Barrels as indicated by assembly drawing op6200. 
MALE QUICK RELEASE OP5920

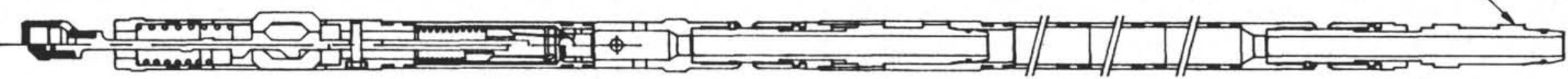

NOTE: REFERENCE ASSEMBLY DRAWING OP6200 FOR INDIVIDUAL PART NUMBERS

PCS FIG 17: LATCH SUBASSEMBLY 
RUNNING PROCEDURES

(Reference Figure $18 \& 19$ )

1. Place Actuator Subassembly Top Connection in vice.

2. Remove Upper Barrel.

3. Charge Accumulator to proper pressure (approximately $80 \%$ of anticipated hydrostatic pressure, reference "ACCUMULATOR FILL AND TEST PROCEDURES").

4. Make sure Actuator Subassembly is fully stroked out and latched.

5. Install Upper Barrel.

6. Makeup PCS Cutting Shoe to Bit Sub/Operator Housing.

7. Makeup Ball Valve assembly to Actuator assembly by making up Manifold Mandrel to Accumulator Sub (ref fig 18).

8. Makeup Quick Connect Coupling.

9. Place handling clamp on Top Sub just below Female Quick Release.

10. Pickup lower PCS assembly and place in handling shuck.

11. Be sure Actuation Ball is in Ball collet (ref fig 19).

NOTE: If Actuation Ball is not installed, break Landing Sub off Collet Sub, pull out Collet Seat, place Ball in Ball collet, reinstall Collet seat and makeup Landing sub to collet Sub.

12. Place handling clamp on Collet Sub. just below XCB Latch Body.

13. Pickup upper PCS assembly by handling clamp and stab into lower assembly.

14. Makeup Quick Release.

15. Pickup and remove handling clamp from Top Sub.

CAUTION: DO NOT PICK PCS UP BY FISHING NECK AND OR RUN IT IN ON WIRELINE. TO DO SO WOULD DROP ACTUATION BALL INTO ACTUATION ASSEMBLY CAUSING PCS TO STROKE CLOSED IMMEDIATELY UPON PUMPING. 
16. Lower PCS into drill pipe using a standard $\mathrm{XCB}$ landing plate just below Landing sub to land on.

17. Remove handling clamp from Collet Sub.

18. Pull out landing plate and free fall PCS to bottom.

NOTE: PCS may be pumped to bottom similar to a standard XСВ barrel. 


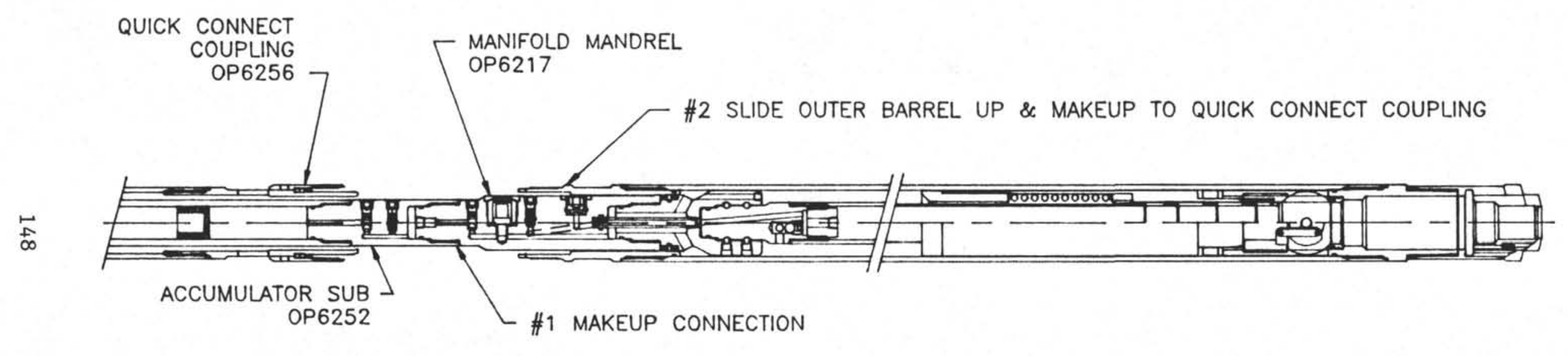

NOTE: REFERENCE ASSEMBLY DRAWING OP6200 FOR INDIVIDUAL PART NUMBERS

PCS FIG 18: FINAL ASSEMBLY 


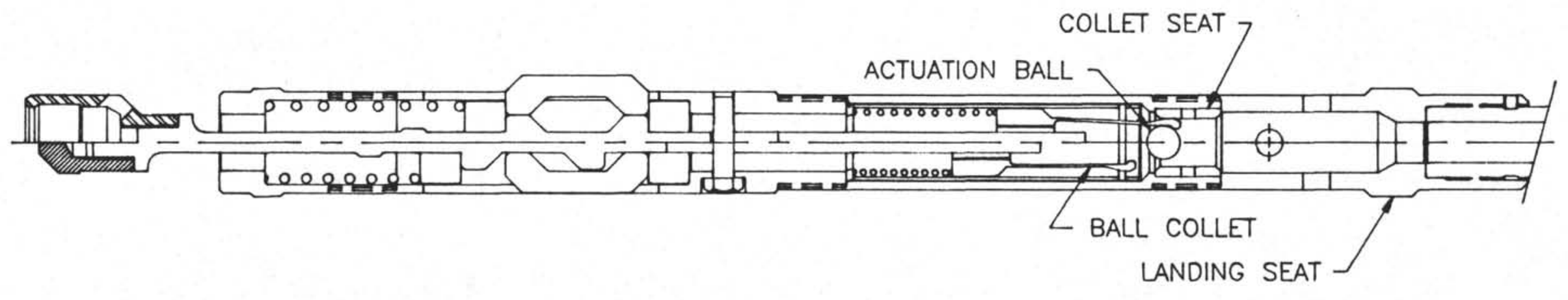

NOTE: REFERENCE ASSEMBLY DRAWING OP6200 FOR INDIVIDUAL PART NUMBERS

PCS FIG 19: ACTUATION BALL 


\section{RETRIEVING PROCEDURES}

(Reference Figure 20)

1. Install handling clap on Collet Sub just under XCB Latch Body.

2. Remove sinker bar assembly.

3. Pickup PCS with handling clamp and install another handling clamp on Top sub just under Female Quick Release.

4. Break Quick Release and lay down upper PCS assembly.

5. Retrieve Actuation Ball from Release Piston with Ball Pickup Tool (OP6360).

6. Install Latch Resetting Tool (OP6376) in Actuator Assembly and tighten Jack Screw to release Latch Dogs.

NOTE: Leave Latch Resetting Tool in Actuator Assembly.

7. Pickup lower PCS assembly from drill pipe and install another handling clamp on Seal Housing.

8. Break PCS Quick Connect Coupling and pick up until Release Dogs latch into control groove.

NOTE: An audible "click" sound can be heard when Release Dogs latch into control groove.

9. Close Disconnect Bullet Valve on Manifold Mandrel (ref fig 20).

10. Close Accumulator Shut off Bullet Valve on Accumulator Sub (ref fig 20).

11. Open Vent Bullet Valve on Accumulator Sub to vent pressure across Manifold Mandrel-Accumulator Sub joint (ref fig 20).

12. Break connection between Accumulator Sub and Manifold Mandrel.

13. Remove and lay down Actuator Assembly. 
14. Remove Sample Chamber from drill string and place in Safety Shroud/Bath.

NOTE: Pressure transducer cap can be removed and a direct connection made to pressure transducer for monitoring sample chamber internal pressure. This transducer is not thermally stable and will read low until it has warmed up (approximately $1 \mathrm{hr}$ ). 
2) Close acCuMulator Shut ofF VALVE $7>$ 1) CLOSE DISCONNECT VALVE

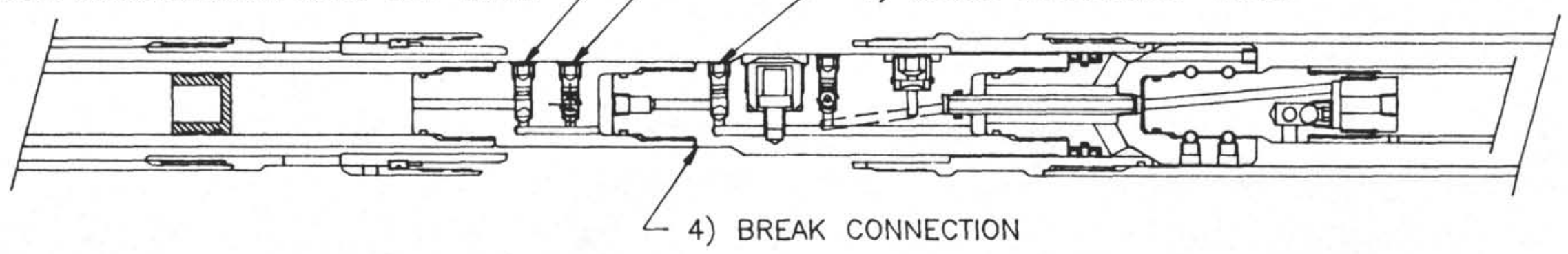

NOTE: REFERENCE ASSEMBLY DRAWING OP6200 FOR INDIVIDUAL PART NUMBERS

PCS FIG 20: SAMPLE CHAMBER BREAK-OUT 
NOTE: FOLLOWING PROCEDURE ASSUMES THAT ALL PRESSURE HAS BEEN BLED FROM BALL VALVE ASSEMBLY.

\section{ACTUATOR/ACCUMULATOR}

1. Remove Latch Resetting Tool from Actuator Assembly.

2. Remove Actuation ball if not already removed.

3. Open Accumulator Shut off Valve slowly to bleed trapped water.

3. Place Top Sub in vice and remove Upper Barrel.

4. Remove Accumulator Fill Port pipe plug in Regulator Sub.

5. Attach gage with bleed valve to Accumulator Fill Port.

6. Open Accumulator Fill Bullet Valve and check Accumulator pressure.

6a. Add Nitrogen if necessary.

7. Close Accumulator Fill Bullet Valve, bleed gage set and remove gage.

8. Replace Accumulator Fill Port pipe plug.

9. Reinstall Upper Barrel.

\section{SAMPLE CHAMBER}

10. Remove Bit.

11. Break out Bit Sub/Operator from Outer Barrel and slide it out of Outer Barrel until ball is exposed.

NOTE: Bit Sub/Operator Housing can not pass core catchers therefor it can not be removed completely.

12. Rotate ball to open position, slide operator Housing/Bit Sub back into outer Barrel and makeup connection.

13. Push Manifold Subassembly towards Bit Sub/operator Housing until core catchers are exposed.

14. Remove core catchers from Inner Barrel.

15. Remove Seal Housing from Outer Barrel.

16. Pull Manifold Subassembly with Inner Barrel from outer Barrel. 
17. Remove Inner Barrel and clean it or replace it with a clean one.

18. Reinstall Inner Barrel Assembly, Core Catchers and Seal Housing.

19. Follow FINAL ASSEMBLY instructions. 
HYDROSTATIC TESTING PROCEDURES

CAUTION: WHEN OPENING OR CHECKING BULLET VALVES ALWAYS CLOSE FIRST, THEN OPEN ONE OR TWO TURNS. IF BULLET VALVES ARE OPENED TOO FAR, THEY CAN BECOME PROJECTILES.

1. Push Manifold Assembly down until Core Catchers extend passed Bit Sub/Operator Housing.

2. Remove Core Catchers.

3. Remove Seal sub from Outer Barrel.

4. Remove Manifold Assembly from Outer Barrel.

5. Drive Seal Sub onto Manifold Mandrel.

6. Install Seal Sub/Manifold Mandrel back into outer Barrel.

7. Remove Ball Valve Subassembly from outer Barrel.

8. Rotate Ball closed.

9. Reinstall Ball Valve Subassembly into outer Barrel.

10. Makeup Accumulator Assembly to Manifold Assembly.

11. Be sure Bullet Valves are in the following configuration (ref fig 15).

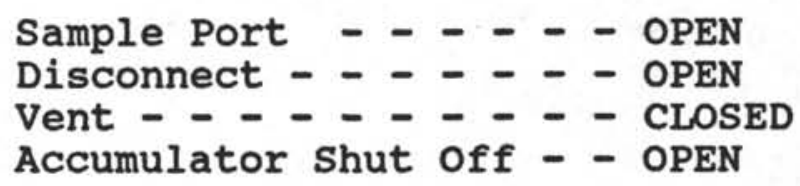

12. Connect a Sprague type pump to Manifold Mandrel sample port and fill with water.

NOTE: Bleed as much air as possible out of assembly using vent Bullet Valve.

13. Pressurize substantially above expected operating pressure but well below Burst Disk burst pressure.

NOTE: Allow barrel to sit at pressure for about an hour to monitor for leaks and changes in pressure. Some pressure changes may occur as barrel and water under go temperature changes.

14. Check all connections and Bullet Valves for leaks.

15. Relieve pressure through pump vent valve. 
16. Remove Bit Sub/Operating Housing from Outer Barrel.

17. Rotate Ball to open position.

18. Reinstall Ball Valve Subassembly into outer Barrel.

19. Remove Accumulator Subassembly from Manifold Subassembly.

20. Remove Seal Housing/Manifold Subassembly form outer Barrel.

21. Remove Manifold Subassembly from Seal Housing.

22. Slide Manifold Subassembly back into outer Barrel until Inner Mandrel extends past Bit Sub/Operator Housing.

23. Reinstall Core Catcher Assembly.

24. Reinstall Seal Housing and push Manifold Subassembly up until Manifold Mandrel connection threads are above Seal Housing.

CAUTION: Be careful not to close Ball valve.

NOTE: ACCUMULATOR SHOULD BE TESTED AND CHARGED AT THIS POINT. FOR PROCEDURES SEE SECTION ENTITLED "ACCUMULATOR FILL AND TEST PROCEDURES". 


\section{ACCUMULATOR FILL AND TEST PROCEDURES \\ (Reference Figure 21)}

1. Place Accumulator in vice.

2. Remove Accumulator Fill Port pipe plug.

3. Slowly Open Accumulator Shut off Bullet Valve.

4. Attach nitrogen supply hose (5,000 psi working pressure) to gas bottle and inlet port (3/8" SAE) of gas booster.

5. Attach high pressure nitrogen supply hose (10,000 psi working pressure) from gas booster outlet (1/4" Super Pressure) to Accumulator "FILL" port (1/4" NPT).

6. Attach air supply to gas booster (150 psi max).

7. Open Accumulator "FILL" Bullet Valve on Regulator Sub.

8. Close all bleed valves on hose sets.

NOTE: BOTH HOSE SETS TO SHOULD HAVE A SHUT OFF VALVE, GAGE AND A BLEED VALVE.

9. Open gas bottle valve.

NOTE: Both gages on hose sets should read delivery pressure of gas bottle.

10. Adjust Back Pressure Regulator.

NOTE: If gas escapes from Back Pressure Regulator Valve, screw in Adjustment screw until it stops. If gas does not escape from Back Pressure Regulator Valve, unscrew Adjustment Screw until it does and then screw Adjustment screw back in to stop flow.

11. Begin to pressurize Accumulator using gas booster. As pressure begins to escape from Back Pressure Regulator Valve, increase pressure by screwing Adjustment Screw in farther. Continue to increase pressure above expected bottom hole pressure but below burst disk pressure. This will be the Back Pressure Valve safety release pressure setting.

12. Stop gas booster. 
13. Bleed off Accumulator charge pressure using bleed valve in hose set, to:

$.80 \mathrm{X}$ ANTICIPATED BOTTOM HOLE HYDROSTATIC PRESSURE

NOTE: Hydrostatic pressure in psi $=1.467 \mathrm{X}$ depth in meters.

14. Close Accumulator Fill Bullet Valve.

15. Close nitrogen bottle valve.

16. Bleed supply hoses and disconnect.

17. Install Accumulator Fill Port pipe plug. 


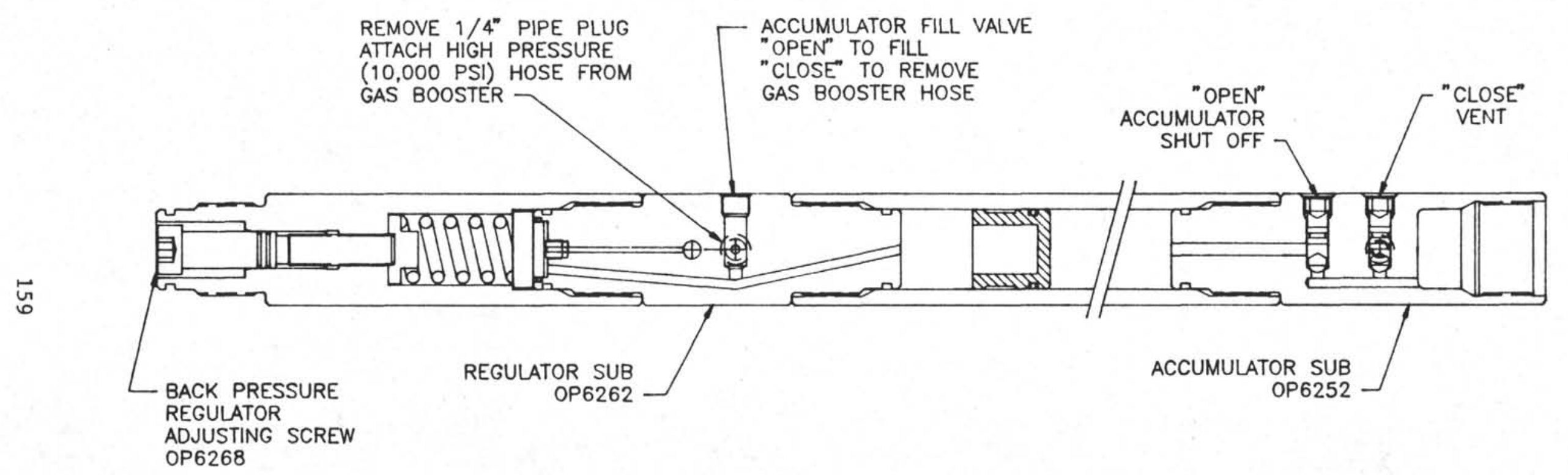

NOTE: REFERENCE ASSEMBLY DRAWING OP6200 FOR INDIVIDUAL PART NUMBERS

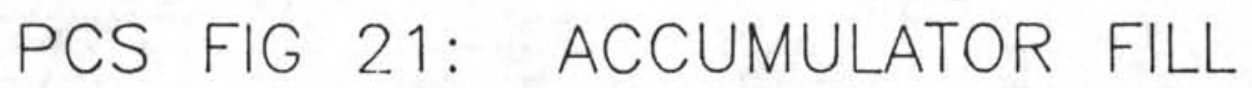


HIGH TEMPERATURE TRIM

(Reference Figure $22 \& 23$ )

August 1991

A high temperature seal kit OP6208 has been set up for "trimming out" the PCS for high temperature service. The PCS is assembled as usual except for substituting the high temperature seals listed for the standard seals. The high temperature seals are made from various Aflas compounds. Listed below are the standard or "LO-T" seals with their corresponding replacement high temperature, "HI-T", seals and backups.

The standard PCS springs are made from titanium and therefore are good for high temperature and/or sour service. All affected oring grooves have been widened to accept the PEEK backup rings. Figures 22 and 23 indicate the Aflas O-Ring - PEEK Backup Ring relationship. The backup ring always goes on the down stream side of any o-ring which might see a differential pressure while at an elevated temperature.

$\begin{array}{lllll}\text { LO-T PN } & \text { HI-T PN } & \text { OTY } & \text { DESCRIPTION } \\ \text { OD3011 } & \text { OD4011 } & 5 & \text { O-Ring, 2-011-90, Aflas } \\ & \text { OD4012 } & 1 & \text { O-Ring, 2-012-90, Aflas } \\ \text { OD3016 } & \text { OD4016 } & 2 & \text { O-Ring, 2-016-90, Aflas } \\ \text { OD3040 } & \text { OD4040 } & 1 & \text { O-Ring, 2-040-90, Aflas } \\ \text { OD3128 } & \text { OD4128 } & 1 & \text { O-Ring, 2-128-90, Aflas } \\ \text { OD3140 } & \text { OD4140 } & 2 & \text { Poly-Pak, 18702375-375B } \\ \text { OD3142 } & \text { OD4142 } & 1 & \text { O-Ring, 2-142-90, Aflas } \\ \text { OD3206 } & \text { OD4206 } & 1 & \text { O-Ring, 2-206-90, Aflas } \\ \text { OD3217 } & \text { OD4217 } & 1 & \text { O-Ring, 2-217-90, Aflas } \\ \text { OD3218 } & \text { OD4218 } & 1 & \text { O-Ring, 2-218-90, Aflas } \\ \text { OD3223 } & \text { OD4223 } & 2 & \text { O-Ring, 2-223-90, Aflas } \\ \text { OD3226 } & \text { OD4226 } & 2 & \text { O-Ring, 2-226-90, Aflas } \\ \text { OD3228 } & \text { OD4228 } & 1 & \text { O-Ring, 2-228-90, Aflas } \\ \text { OD3234 } & \text { OD4234 } & 2 & \text { O-Ring, 2-234-90, Aflas } \\ \text { OD3220 } & \text { OD4320 } & 7 & \text { O-Ring, 2-220-90, Aflas }\end{array}$




$\begin{array}{lllll}\text { OD2330 } & \text { OD4330 } & 2 & \text { O-Ring, 2-330-90, Aflas } \\ \text { OP6350 } & \text { OD4350 } & 1 & \text { O-Ring, 2-122-90, Aflas } \\ & \text { OD5011 } & 5 & \text { Backup Ring, 2-011, PEEK } \\ \text { OP6352 } & \text { OD5112 } & 1 & \text { Backup Ring, 2-012, PEEK } \\ & \text { OD5142 } & 1 & \text { Backup Ring, 2-142, PEEK } \\ & \text { OD5220 } & 7 & \text { Backup Ring, 2-220, PEEK } \\ & \text { OD5226 } & 2 & \text { Backup Ring, 2-226, PEEK } \\ \text { OP6214 } & \text { OD5234 } & 2 & \text { Backup Ring, 2-234, PEEK } \\ & \text { OP68B } & 1 & \text { Ball Valve Seal, Aflas }\end{array}$




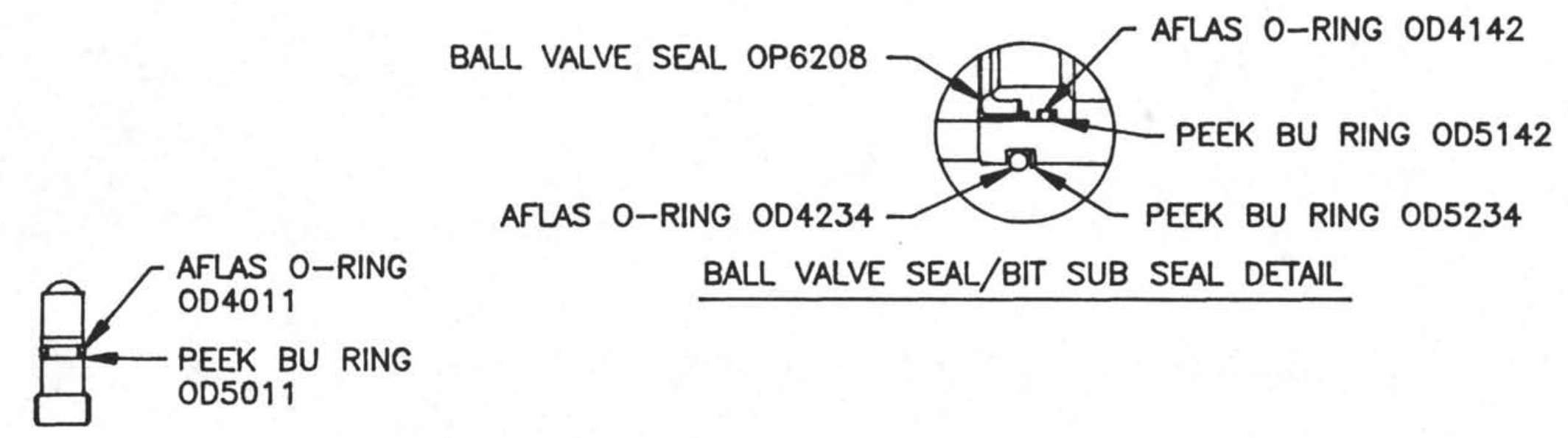

BULLET VALVE DETAIL

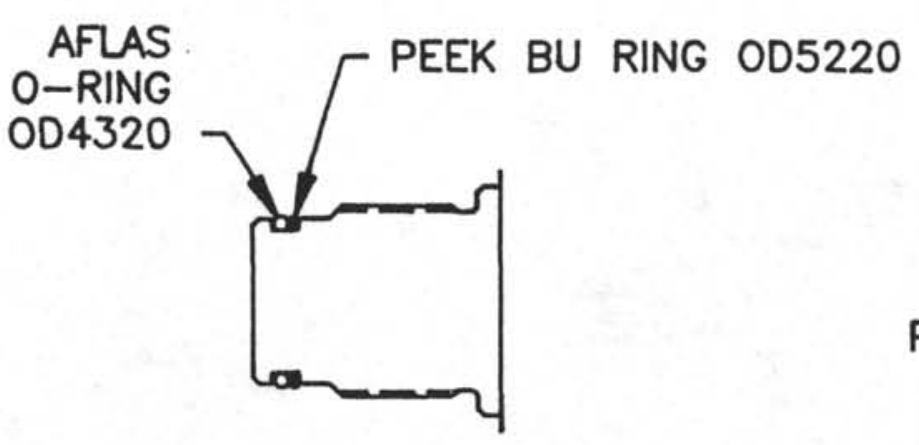

ALL 220 O-RING THREADED CONNECTION

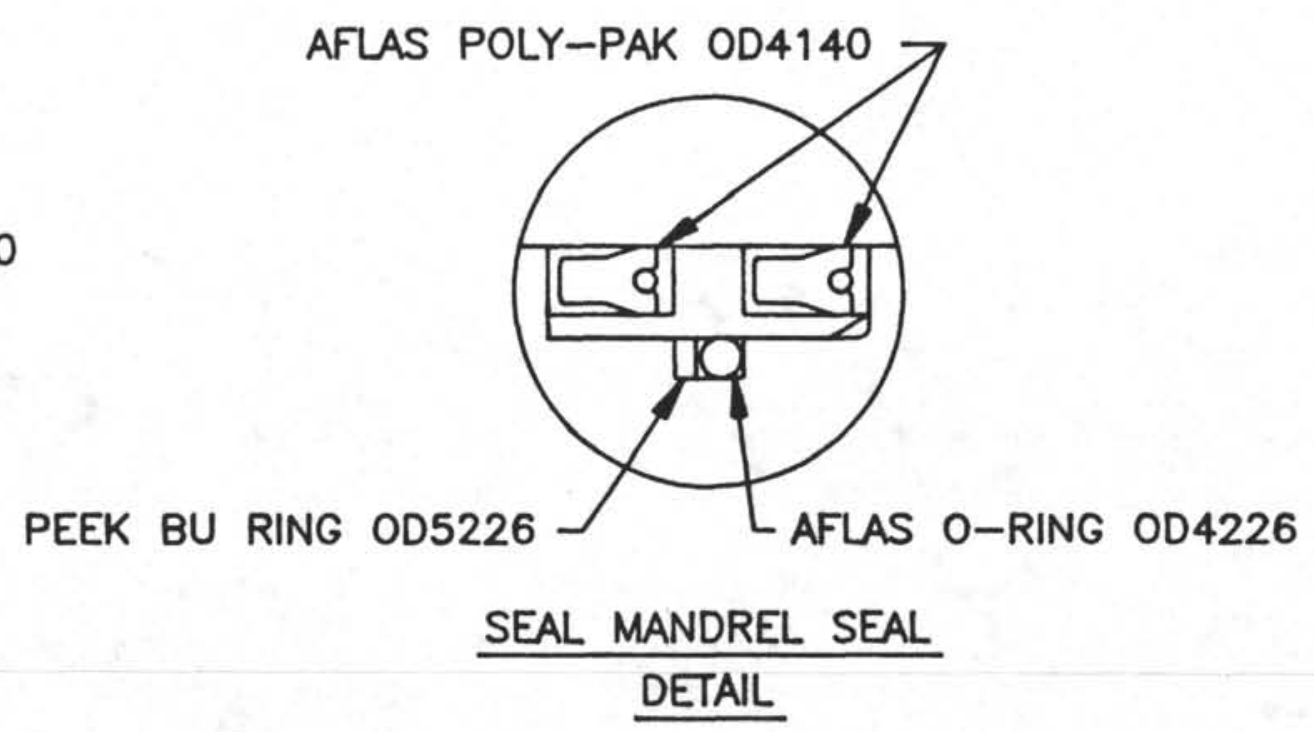

DETAIL

FIG 22: HIGH TEMPERATURE SEAL CONFIGURATION 


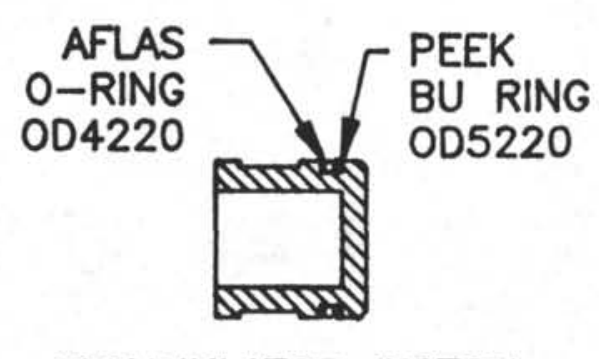

ACCUMULATOR PISTON

SEAL DETAIL
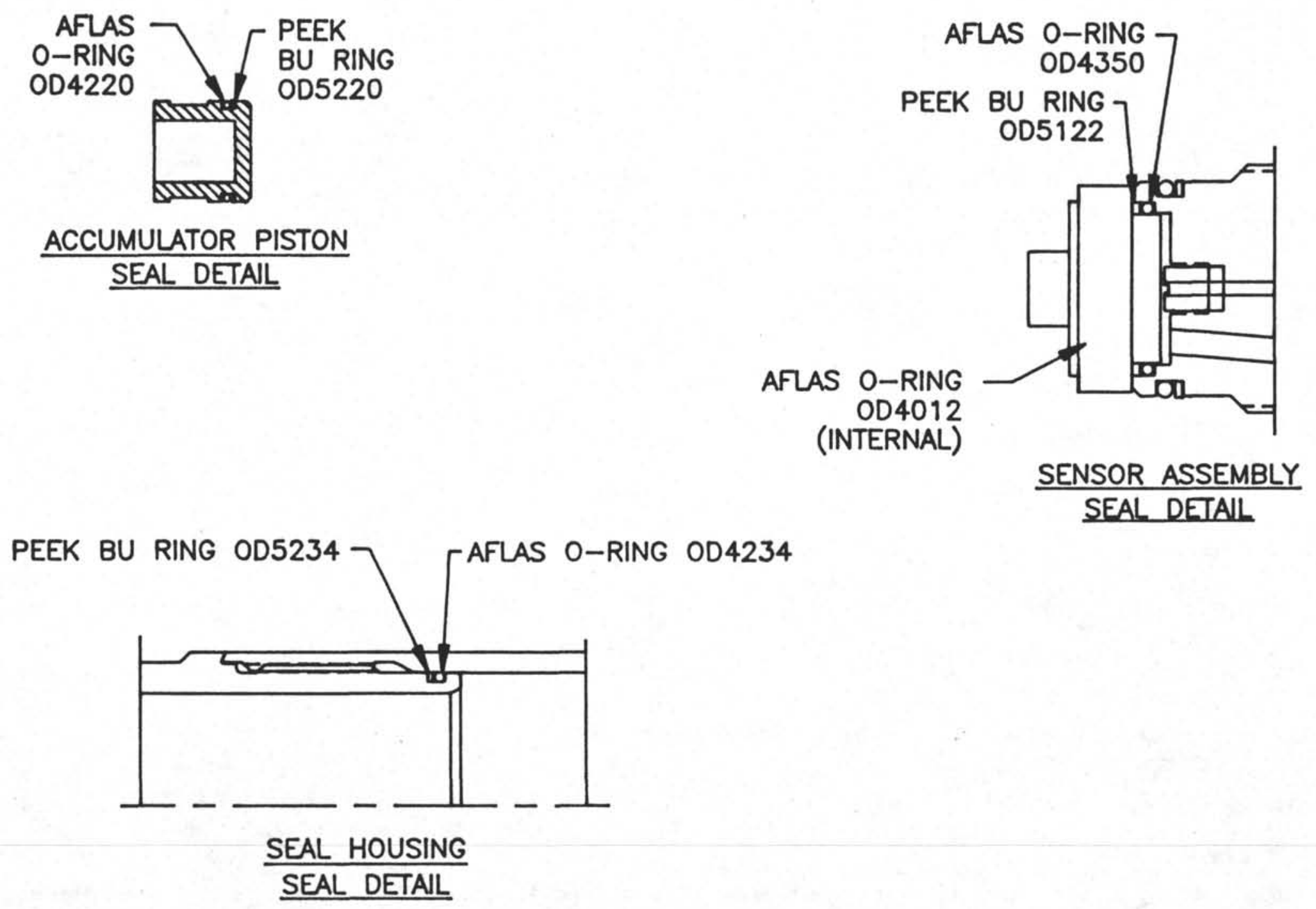

PCS FIG 23: HIGH TEMP SEAL DETAILS 
Length of core catcher assembly is fixed. Any combination of core catchers and spacer sleeves can be used as long as the overall length is equal to $79 / 32$ " plus or minus 1/16". To maintain proper length use one of the combinations as shown below.

\#1 Single Dog Type Core Catcher

1 OP-6372 PCS Flapper Spacer Sleeve $\left(\begin{array}{lll}4 & 1 / 2 \text { " } 19\end{array}\right)$

1 OP-6330 PCS 4 Finger Core Catcher

1 OP-6366 PCS Core Catcher Guide

\#2 Dual Dog Type Core Catcher

1 OP-6370 PCS Dual DCC Spacer Sleeve (2 5/16" lg)

2 OP-6330 PCS 4 Finger Core Catcher

1 OP-6366 PCS Core Catcher Guide 


\section{OCEAN DRILLING PROGRAM \\ PRESBURE CORE SAMPLER PHASE I \\ PARTS LIST OP6201}

April 1991

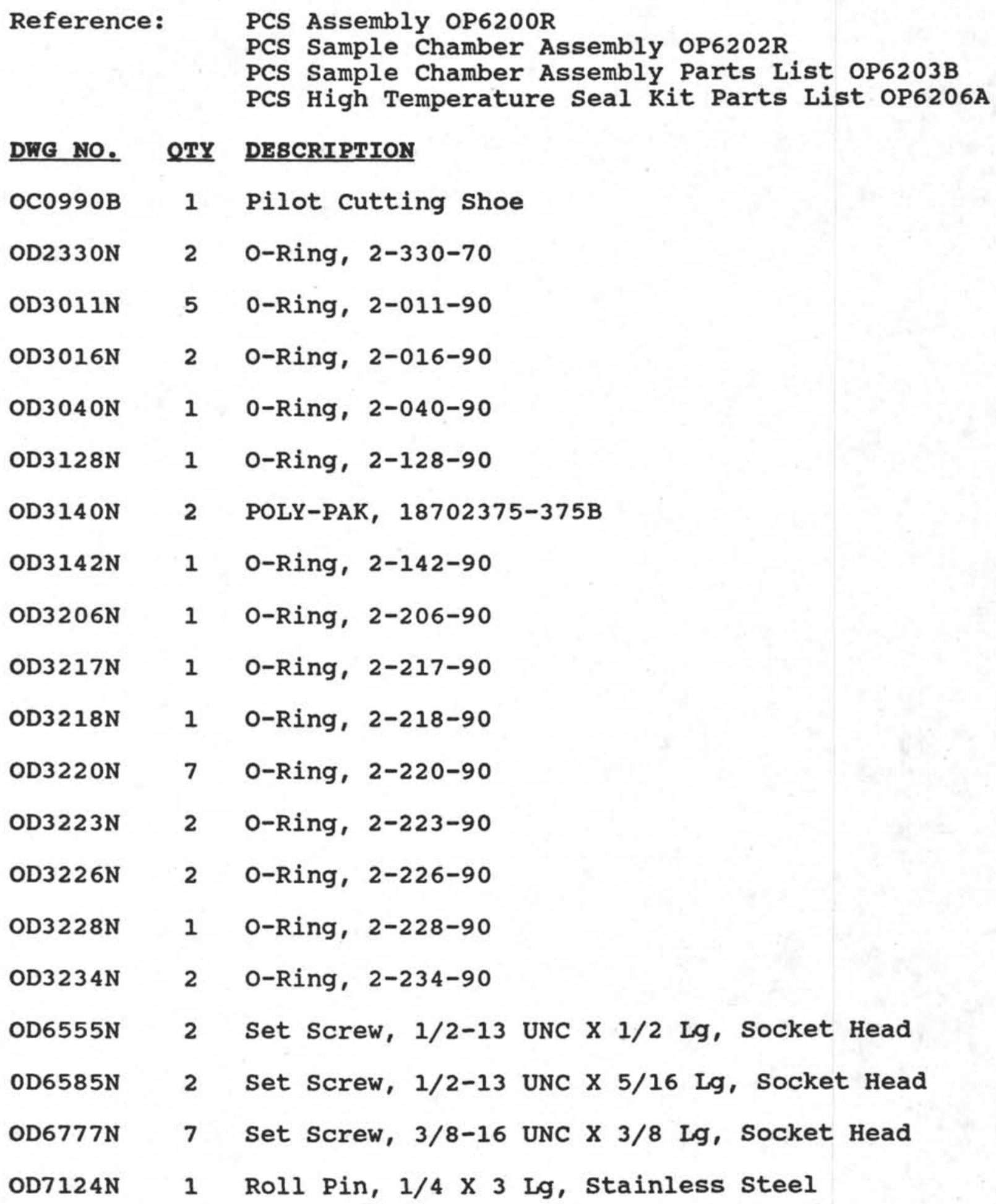




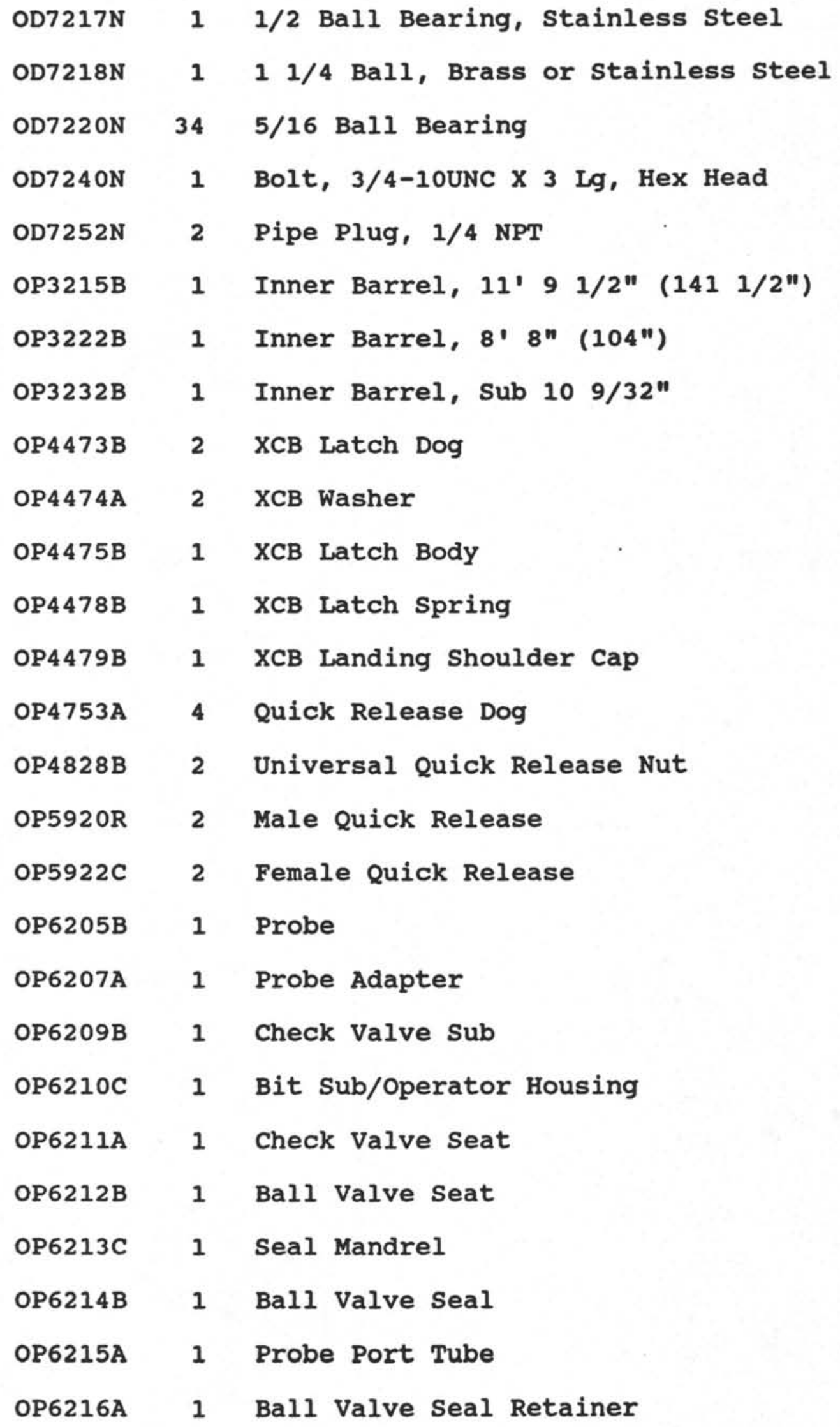




\begin{tabular}{|c|c|c|}
\hline OP6217C & 1 & Manifold Mandrel \\
\hline OP6218B & 1 & Ball Valve Ball \\
\hline OP6220A & 2 & Pivot Pin \\
\hline OP6222A & 2 & Link \\
\hline OP6224A & 4 & Link Pin \\
\hline OP6226B & 1 & Operator Head \\
\hline OP6228C & 1 & Spring Housing \\
\hline OP6230C & 1 & operator sleeve \\
\hline OP6232C & 1 & Spring Cap \\
\hline OP6234B & 1 & Inner Barrel \\
\hline OP6236B & 1 & Outer Barrel \\
\hline OP6242B & 1 & Seal Carrier \\
\hline OP6244A & 1 & operator spring \\
\hline OP6248B & 5 & Bullet Valve \\
\hline OP6250A & 2 & Outlet Screw \\
\hline OP6252C & 1 & Accumulator sub \\
\hline OP6254B & 1 & Split Ring \\
\hline OP6256B & 1 & Quick Connect Coupling \\
\hline OP6258B & 1 & Accumulator Barrel \\
\hline OP6260A & 1 & Accumulator Piston \\
\hline OP6262C & 1 & Regulator Sub \\
\hline OP6264C & 1 & Regulator Housing \\
\hline OP6266A & 1 & Regulator Spring Pad \\
\hline OP6268B & 1 & Regulator Adjusting screw \\
\hline OP6270B & 1 & Kick-out Body \\
\hline OP6272B & 1 & Collet Sub \\
\hline OP6274A & 1 & Collet seat \\
\hline
\end{tabular}




$\begin{array}{lll}\text { OP6276B } & 1 & \text { Ball Collet } \\ \text { OP6278B } & 1 & \text { Landing Sub } \\ \text { OP6280A } & 1 & \text { Spacer Ring } \\ \text { OP6282C } & 1 & \text { Pulling Neck } \\ \text { OP6284A } & 1 & \text { Secondary Latch Spring } \\ \text { OP6286C } & 1 & \text { Vent Sub } \\ \text { OP6288A } & 2 & \text { 1/16 Shim } \\ \text { OP6290A } & 2 & \text { 1/8 Shim } \\ \text { OP6292B } & 1 & \text { Actuator Barrel } \\ \text { OP6294B } & 1 & \text { Release Spring Retainer } \\ \text { OP6296B } & 1 & \text { Release Piston } \\ \text { OP6298A } & 1 & \text { Release Spring } \\ \text { OP6302B } & 3 & \text { Release Dog } \\ \text { OP6304C } & 1 & \text { Release Housing } \\ \text { OP6306A } & 1 & \text { Latch Spring } \\ \text { OP6308B } & 1 & \text { Latch Piston } \\ \text { OP6310B } & 4 & \text { Latch Dog } \\ \text { OP6312B } & 1 & \text { Latch Cap } \\ \text { OP6314C } & 1 & \text { Latch Mandrel } \\ \text { OP6316B } & 1 & \text { Upper Barrel } \\ \text { OP6318B } & 1 & \text { Top Sub } \\ \text { OP6320C } & 1 & \text { Quick Connect Sub } \\ \text { OP6322C } & 1 & \text { Seal Housing } \\ \text { OP6324C } & 1 & \text { Latch Housing } \\ \text { OP6326B } & 1 & \text { Pressure Transducer Cap } \\ \text { OP6328B } & 1 & \text { Q/R Adapter } \\ \text { OP6330B } & 2 & 4 \text { Finger Core Catcher Assembly }\end{array}$




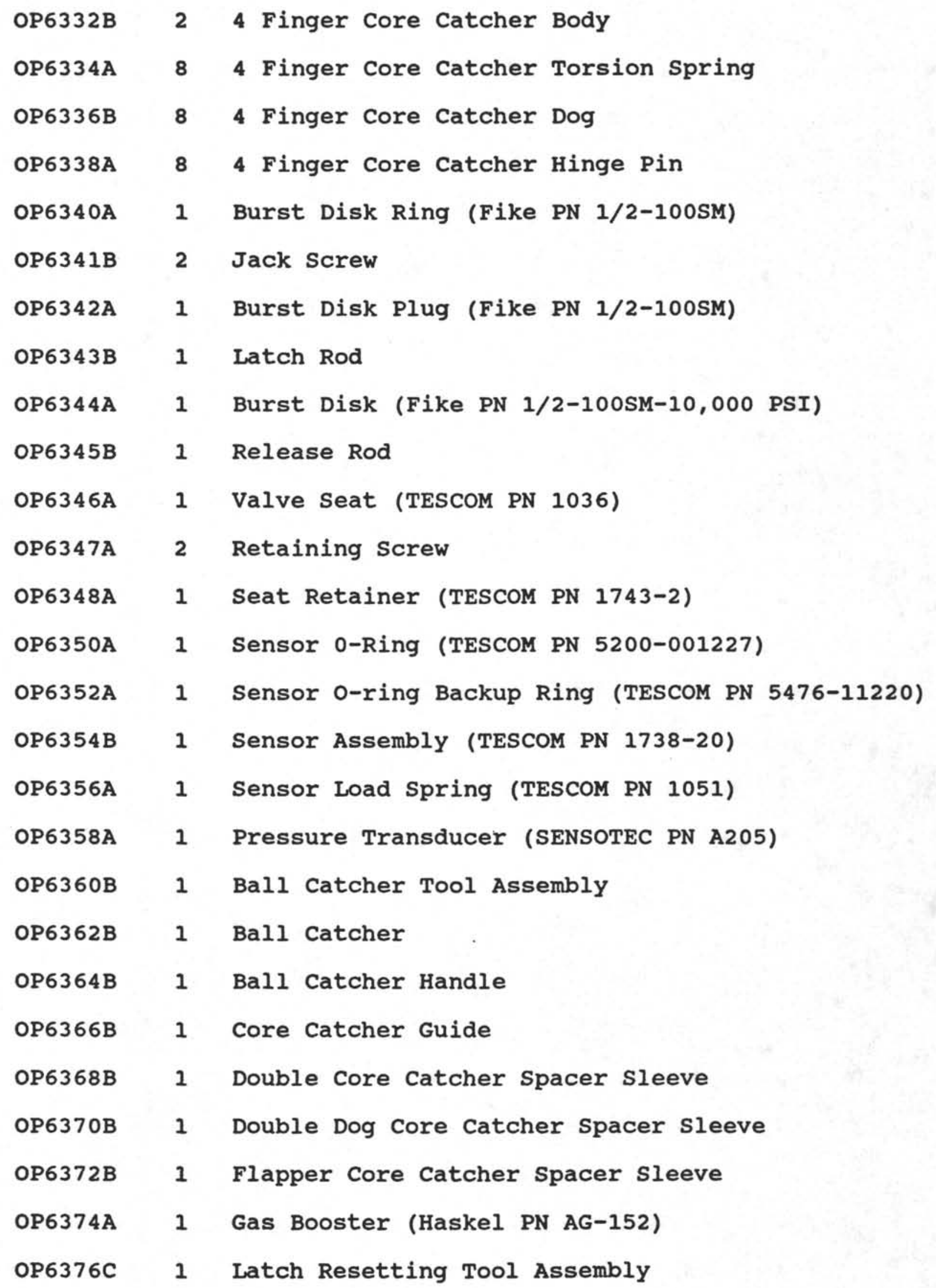




\begin{tabular}{|c|c|c|}
\hline OP6378B & 2 & Cap \\
\hline OP6380A & 1 & Latch Head \\
\hline OP6382N & 2 & $\begin{array}{l}\text { BOST Flanged Bushing } \\
1 " \text { OD } \times 7 / 8 " \text { ID } \times 1 / 4 \text { LG }\end{array}$ \\
\hline OP6384C & 1 & Release Resetting Tool Assembly \\
\hline OP6386A & 1 & Release Head \\
\hline OT2574B & 1 & "GS" Fishing Neck \\
\hline OT2586B & 1 & Optional "RS" Fishing Neck \\
\hline
\end{tabular}




\section{OCEAN DRILIING PROGRAM \\ PRESBURE CORE BAMPLER PHASE I \\ BAMPLE CHAMBER OP6202 \\ PARTS IIST OP6203}

November 1991

\begin{tabular}{|c|c|c|}
\hline Referenc & & PCS Sample Chamber Assembly Drawing OP6202R \\
\hline DWG NO. & QTY & DESCRIPTION \\
\hline ОСо99ов & 1 & Pilot cutting shoe \\
\hline OD3011N & 2 & 0-Ring, 2-011-90 \\
\hline OD3140N & 2 & POLY-PAK， 18702375-375B \\
\hline OD3142N & 1 & 0-Ring, 2-142-90 \\
\hline OD3206N & 1 & 0-Ring, 2-206-90 \\
\hline OD3217N & 1 & 0-Ring, 2-217-90 \\
\hline OD3218N & 1 & $0-$ Ring, 2-218-90 \\
\hline OD3220N & 2 & 0-Ring, 2-220-90 \\
\hline OD3226N & 1 & $0-$ Ring, 2-226-90 \\
\hline OD3234N & 2 & 0-Ring, 2-234-90 \\
\hline 0D6585N & 2 & Set Screw, 1/2-13 UNC x 5/16 Ig, Socket Head \\
\hline OD6777N & 7 & Set Screw, 3/8-16 UNC X 3/8 Lg, Socket Head \\
\hline OD7217N & 1 & 1/2 Ball Bearing, Stainless steel \\
\hline OD7220N & 34 & 5/16 Ball Bearing \\
\hline OD7252N & 1 & Pipe Plug, $1 / 4$ NPT \\
\hline OP6209B & 1 & Check Valve Sub \\
\hline OP6210C & 1 & Bit sub/Operator Housing \\
\hline OP6211A & 1 & Check Valve Seat \\
\hline OP6212B & 1 & Ball valve seat \\
\hline OP6213C & 1 & Seal Mandrel \\
\hline OP6214B & 1 & Ball Valve Seal \\
\hline
\end{tabular}




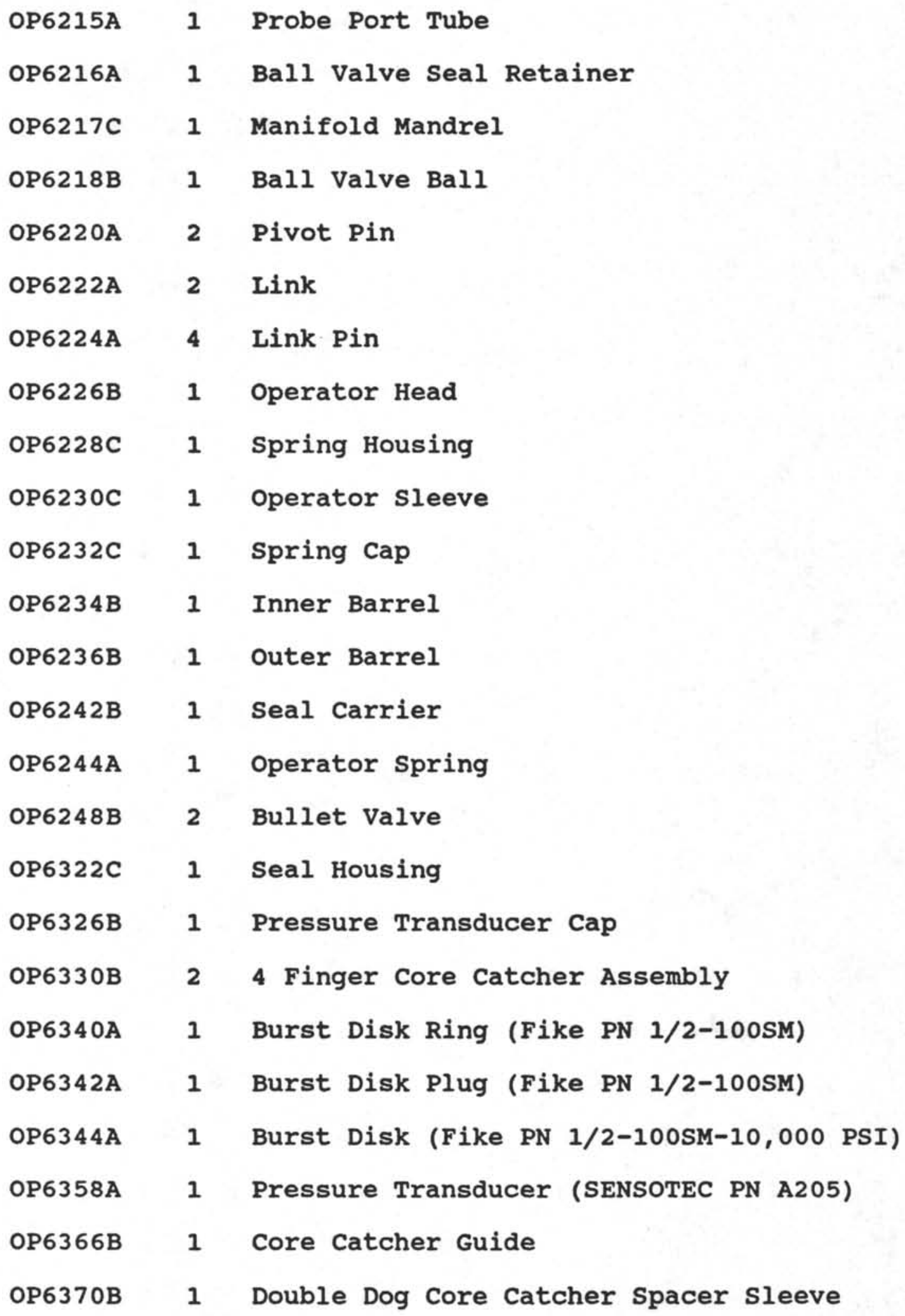




\section{OCEAN DRILLING PROGRAY \\ PRESSURE CORE SAMPLER PHASE I \\ PC8 8ERVICE TOOLS}

April 1991

\begin{tabular}{|c|c|c|}
\hline DWG NO. & QTY & DESCRIPTION \\
\hline OP6360B & 1 & $\begin{array}{l}\text { Ball Catcher Tool Assembly } \\
1 \text { - op6362B Ball Catcher } \\
1 \text { - op6364B Ball Catcher Handle }\end{array}$ \\
\hline OP6374A & 1 & Gas Booster (Haskel PN AG-152) \\
\hline OP6376C & 1 & $\begin{array}{l}\text { Latch Resetting Tool Assembly } \\
1 \text { - OP6341B Jack Screw } \\
1 \text { - OP6343B Latch Rod } \\
1 \text { - OP6347A Retaining Screw } \\
1 \text { - OP6378B Cap } \\
1 \text { - OP6380A Latch Head } \\
1 \text { - OP6382N BOST Flanged Bushing } \\
\quad 1 " \text { OD X 7/8" ID X 1 1/4 LG }\end{array}$ \\
\hline OP6384C & 1 & $\begin{array}{l}\text { Release Resetting Tool Assembly } \\
1 \text { - OP6341B Jack Screw } \\
1 \text { - OP6345B Release Rod } \\
1 \text { - OP6347A Retaining Screw } \\
1 \text { - OP6378B Cap } \\
1 \text { - OP6382N BOST Flanged Bushing } \\
1 \text { OD X 7/8" ID X } 1 \text { 1/4 LG } \\
1 \text { - OP6386A Release Head }\end{array}$ \\
\hline
\end{tabular}




\section{OCEAN DRILIING PROGRAM \\ HIGH TEMPERATURE SEAL KIT OP6206 \\ PARTS LIBT}

May 1991

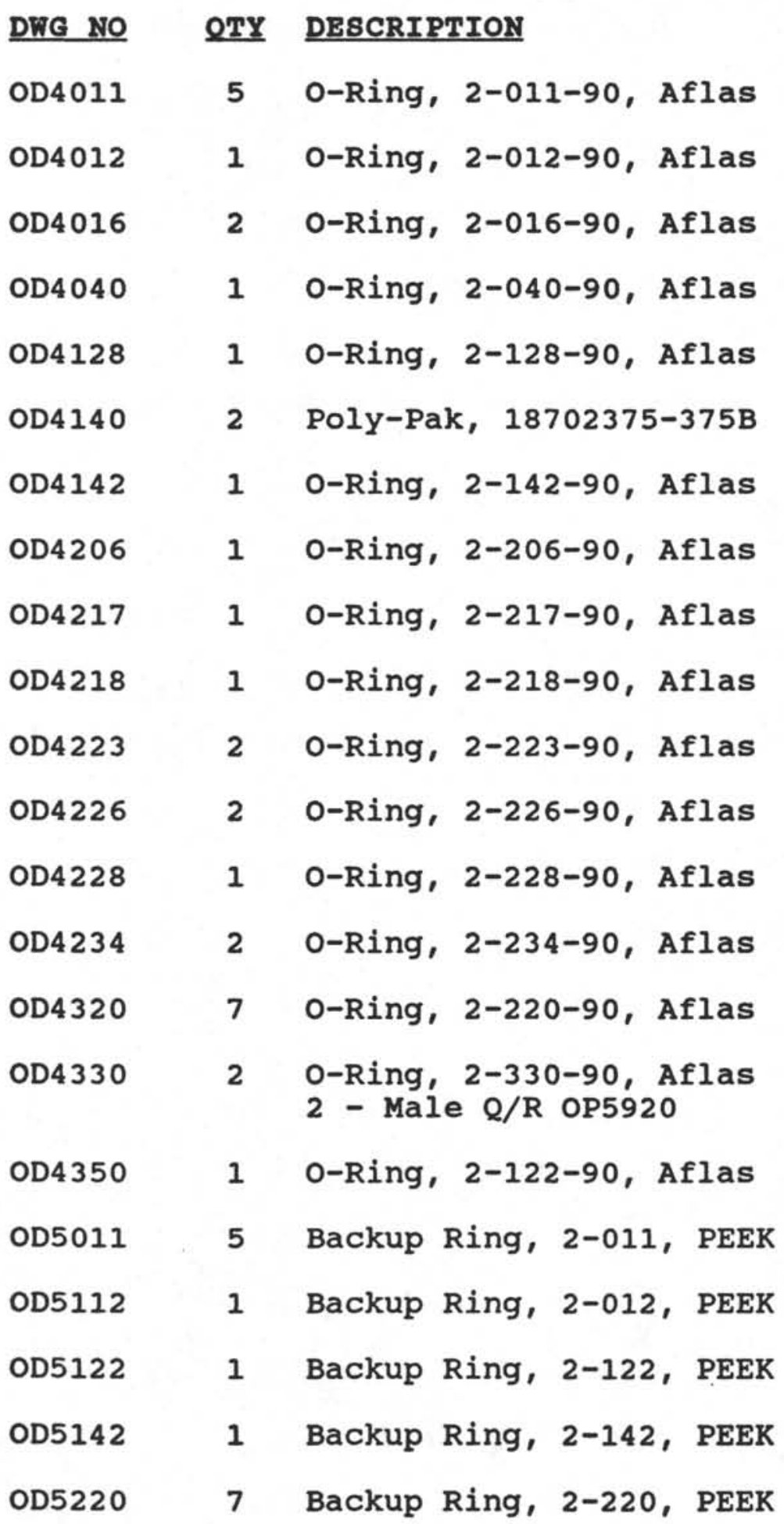




$\begin{array}{lll}\text { OD5226 } & 2 & \text { Backup Ring, 2-226, PEEK } \\ \text { OD5234 } & 2 & \text { Backup Ring, 2-234, PEEK } \\ \text { OP6208B } & 1 & \text { Ball Valve Seal, Aflas }\end{array}$


Appendix N

PCS Parts List 


\section{OCEAN DRILLING PROGRAM \\ PRESSURE CORE SAMPLER PHASE I \\ PARTS LIST OP6201}

April 1991

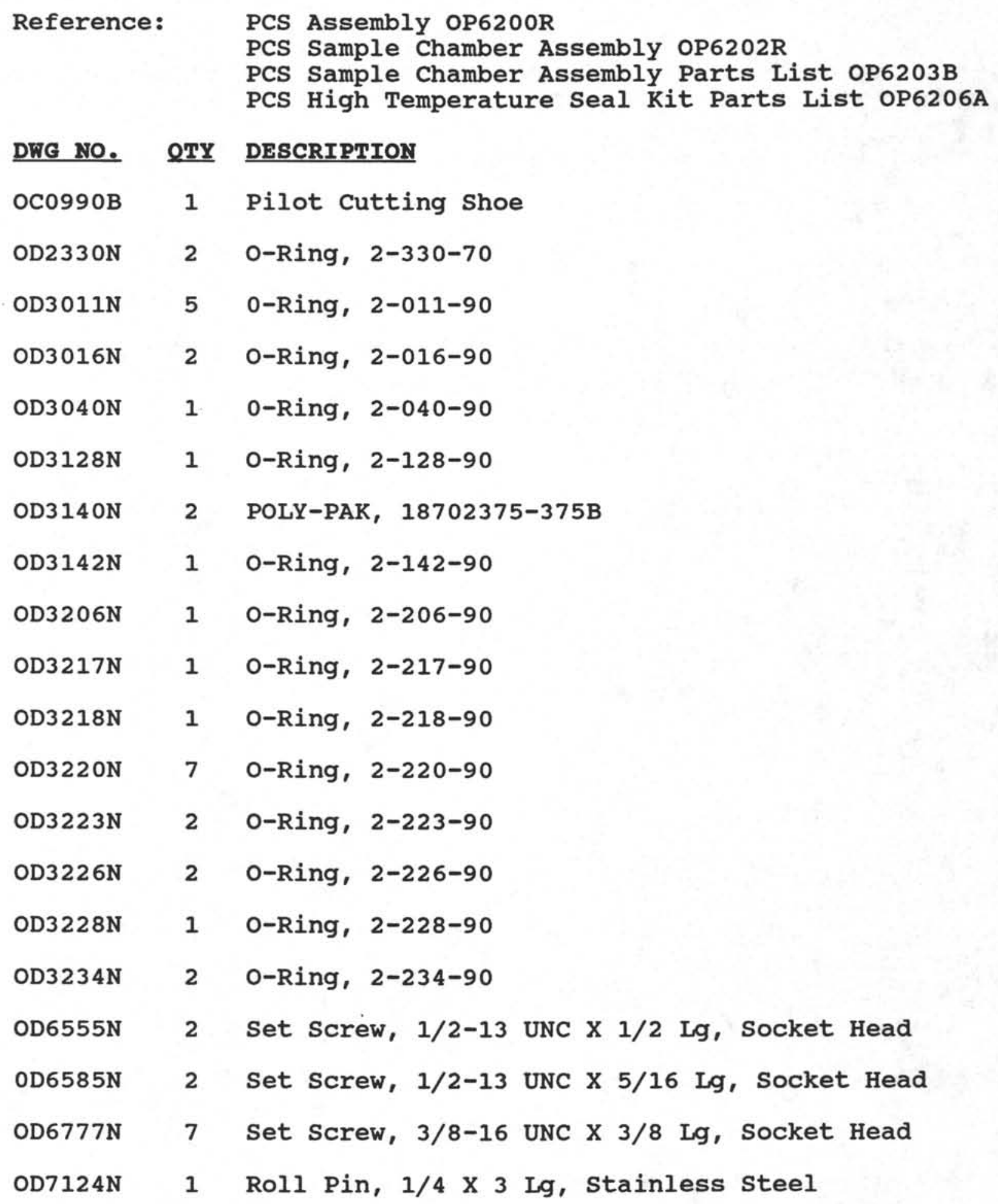




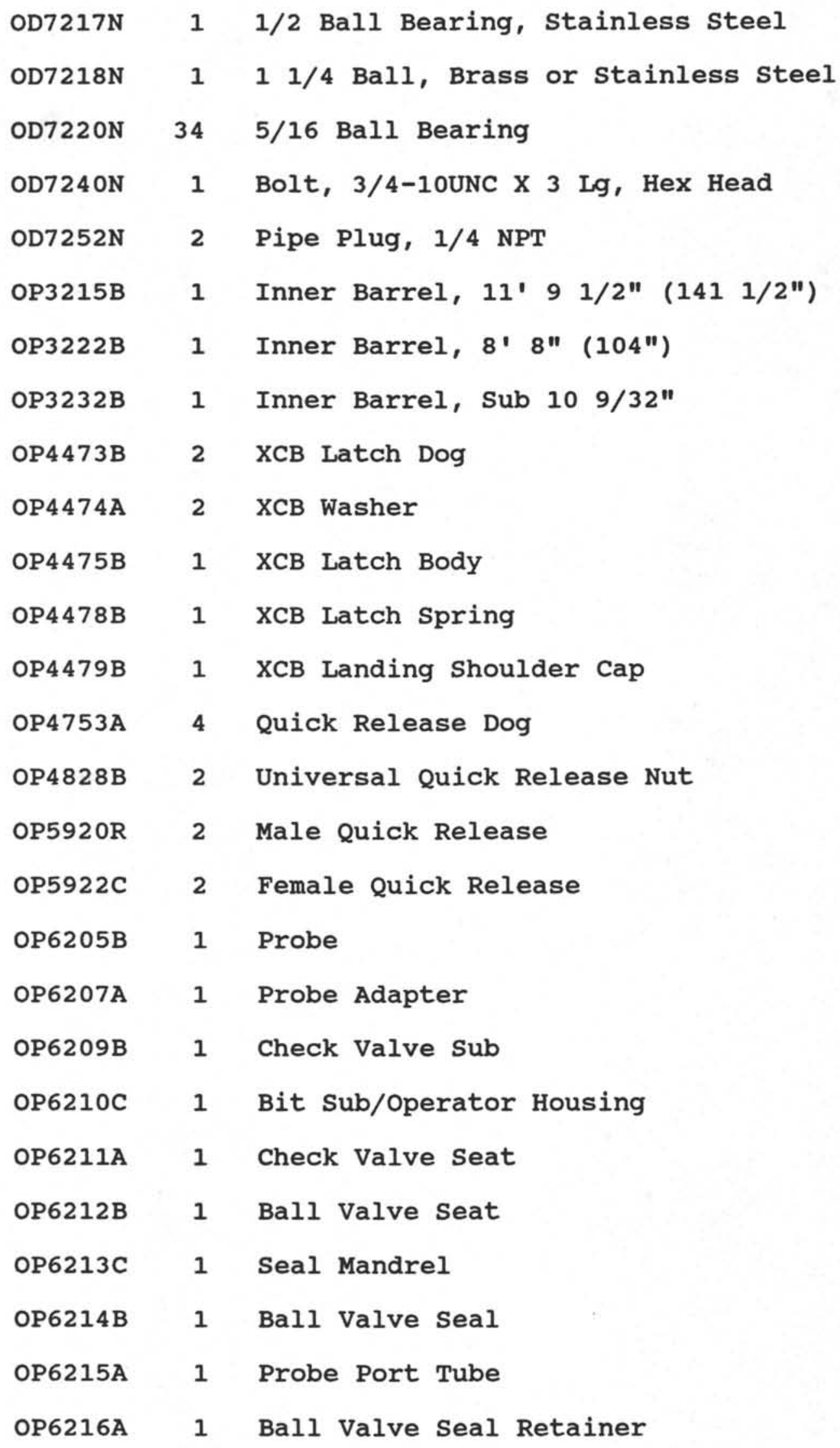




\begin{tabular}{lll} 
OP6217C & 1 & Manifold Mandrel \\
OP6218B & 1 & Ball Valve Ball \\
OP6220A & 2 & Pivot Pin \\
OP6222A & 2 & Link \\
OP6224A & 4 & Link Pin \\
OP6226B & 1 & Operator Head \\
OP6228C & 1 & Spring Housing \\
OP6230C & 1 & Operator Sleeve \\
OP6232C & 1 & Spring Cap \\
OP6234B & 1 & Inner Barrel \\
OP6236B & 1 & Outer Barrel \\
OP6242B & 1 & Seal Carrier \\
OP6244A & 1 & Operator Spring \\
OP6248B & 5 & Bullet Valve \\
OP6250A & 2 & Outlet Screw \\
OP6252C & 1 & Accumulator Sub \\
OP6254B & 1 & Split Ring \\
OP6256B & 1 & Quick Connect Coupling \\
OP6258B & 1 & Accumulator Barrel \\
OP6260A & 1 & Accumulator Piston \\
OP6262C & 1 & Regulator Sub \\
OP6264C & 1 & Regulator Housing \\
OP6266A & 1 & Regulator Spring Pad \\
OP6268B & 1 & Regulator Adjusting Screw \\
OP6270B & 1 & Kick-out Body \\
OP6272B & 1 & Collet Sub \\
OP6274A & 1 & Collet Seat \\
\hline
\end{tabular}




$\begin{array}{lll}\text { OP6276B } & 1 & \text { Ball Collet } \\ \text { OP6278B } & 1 & \text { Landing Sub } \\ \text { OP6280A } & 1 & \text { Spacer Ring } \\ \text { OP6282C } & 1 & \text { Pulling Neck } \\ \text { OP6284A } & 1 & \text { Secondary Latch Spring } \\ \text { OP6286C } & 1 & \text { Vent Sub } \\ \text { OP6288A } & 2 & \text { 1/16 Shim } \\ \text { OP6290A } & 2 & \text { 1/8 Shim } \\ \text { OP6292B } & 1 & \text { Actuator Barrel } \\ \text { OP6294B } & 1 & \text { Release Spring Retainer } \\ \text { OP6296B } & 1 & \text { Release Piston } \\ \text { OP6298A } & 1 & \text { Release Spring } \\ \text { OP6302B } & 3 & \text { Release Dog } \\ \text { OP6304C } & 1 & \text { Release Housing } \\ \text { OP6306A } & 1 & \text { Latch Spring } \\ \text { OP6308B } & 1 & \text { Latch Piston } \\ \text { OP6310B } & 4 & \text { Latch Dog } \\ \text { OP6312B } & 1 & \text { Latch Cap } \\ \text { OP6314C } & 1 & \text { Latch Mandrel } \\ \text { OP6316B } & 1 & \text { Upper Barrel } \\ \text { OP6318B } & 1 & \text { Top Sub } \\ \text { OP6320C } & 1 & \text { Quick Connect Sub } \\ \text { OP6322C } & 1 & \text { Seal Housing } \\ \text { OP6324C } & 1 & \text { Latch Housing } \\ \text { OP6326B } & 1 & \text { Pressure Transducer Cap } \\ \text { OP6328B } & 1 & \text { Q/R Adapter } \\ \text { OP6330B } & 2 & 4 \text { Finger Core Catcher Assembly }\end{array}$




\begin{tabular}{|c|c|c|}
\hline OP6332B & 2 & 4 Finger Core Catcher Body \\
\hline OP6334A & 8 & 4 Finger Core Catcher Torsion Spring \\
\hline OP6336B & 8 & 4 Finger Core Catcher Dog \\
\hline OP6338A & 8 & 4 Finger Core Catcher Hinge Pin \\
\hline OP6340A & 1 & Burst Disk Ring (Fike PN $1 / 2-100 S M$ ) \\
\hline OP6341B & 2 & Jack Screw \\
\hline OP6342A & 1 & Burst Disk Plug (Fike PN $1 / 2-100 S M$ ) \\
\hline OP6343B & 1 & Latch Rod \\
\hline OP6344A & 1 & Burst Disk (Fike PN $1 / 2-100$ SM-10,000 PSI) \\
\hline OP6345B & 1 & Release Rod \\
\hline OP6346A & 1 & Valve Seat (TESCOM PN 1036) \\
\hline OP6347A & 2 & Retaining Screw \\
\hline OP6348A & 1 & Seat Retainer (TESCOM PN 1743-2) \\
\hline OP6350A & 1 & Sensor 0-Ring (TESCOM PN 5200-001227) \\
\hline OP6352A & 1 & Sensor o-ring Backup Ring (TESCOM PN 5476-11220) \\
\hline OP6354B & 1 & Sensor Assembly (TESCOM PN 1738-20) \\
\hline OP6356A & 1 & Sensor Load Spring (TESCOM PN 1051) \\
\hline OP6358A & 1 & Pressure Transducer (SENSOTEC PN A205) \\
\hline OP6360B & 1 & Ball Catcher Tool Assembly \\
\hline OP6362B & 1 & Ball Catcher \\
\hline OP6364B & 1 & Ball Catcher Handle \\
\hline OP6366B & 1 & Core Catcher Guide \\
\hline OP6368B & 1 & Double Core Catcher Spacer Sleeve \\
\hline OP6370B & 1 & Double Dog Core Catcher Spacer Sleeve \\
\hline OP6372B & 1 & Flapper Core Catcher Spacer Sleeve \\
\hline OP6374A & 1 & Gas Booster (Haskel PN AG-152) \\
\hline OP6376C & 1 & Latch Resetting Tool Assembly \\
\hline
\end{tabular}




$\begin{array}{lll}\text { OP6378B } & 2 & \text { Cap } \\ \text { OP6380A } & 1 & \text { Latch Head } \\ \text { OP6382N } & 2 & \begin{array}{l}\text { BOST Flanged Bushing } \\ 1 " \text { OD X 7/8" ID X 1 1/4 LG }\end{array} \\ \text { OP6384C } & 1 & \text { Release Resetting Tool Assembly } \\ \text { OP6386A } & 1 & \text { Release Head } \\ \text { OT2574B } & 1 & \text { "GS" Fishing Neck } \\ \text { OT2586B } & 1 & \text { Optional "RS" Fishing Neck }\end{array}$




\section{OCEAN DRILLING PROGRAM \\ PRESSURE CORE SAMPLER PHASE I \\ PCS SERVICE TOOLS}

April 1991

\begin{tabular}{|c|c|c|}
\hline DWG No. & QTY & DESCRI PTION \\
\hline OP6360B & 1 & $\begin{array}{l}\text { Ball Catcher Tool Assembly } \\
1 \text { - op6362B Ball Catcher } \\
1 \text { - op6364B Ball Catcher Handle }\end{array}$ \\
\hline OP6374A & 1 & Gas Booster (Haskel PN AG-152) \\
\hline OP6376C & 1 & $\begin{array}{l}\text { Latch Resetting Tool Assembly } \\
1 \text { - OP6341B Jack Screw } \\
1 \text { - OP6343B Latch Rod } \\
1 \text { - OP6347A Retaining Screw } \\
1 \text { - OP6378B Cap } \\
1 \text { - OP6380A Latch Head } \\
1 \text { - OP6382N BOST Flanged Bushing } \\
\text { 1" OD X 7/8" ID X } 1 \text { 1/4 LG }\end{array}$ \\
\hline OP6384C & 1 & $\begin{array}{l}\text { Release Resetting Tool Assembly } \\
1 \text { - OP6341B Jack Screw } \\
1 \text { - OP6345B Release Rod } \\
1 \text { - OP6347A Retaining Screw } \\
1 \text { - OP6378B Cap } \\
1 \text { - OP6382N BOST Flanged Bushing } \\
\text { 1" OD X 7/8" ID X } 1 \text { 1/4 LG } \\
1 \text { - OP6386A Release Head }\end{array}$ \\
\hline
\end{tabular}




\section{Appendix 0}

\section{PCS Assembly Drawings}




\title{
PCS ASSEMBLY DRAWINGS
}

Note: Due to space and budget constraints the PCS Assembly Drawings (OP6200, OP6202, and OP6204) have been omitted from this technical note. If you need to obtain a set of these drawings please contact the Ocean Drilling Program.

\author{
Ocean Drilling Program \\ Texas A\&M University \\ 1000 Discovery Drive \\ College Station, Texas 77845 \\ Attn: Engineering Department \\ (409) $845-8481$
}


Appendix $\mathbf{P}$

\section{PCS Machine Drawings}




\begin{tabular}{|c|c|c|c|c|c|c|}
\hline & \multicolumn{3}{|c}{ REMSIONS } \\
\hline NO. & DESCRIPTION & DATE & BY & CH. & APR \\
\hline & & & & & \\
\hline
\end{tabular}
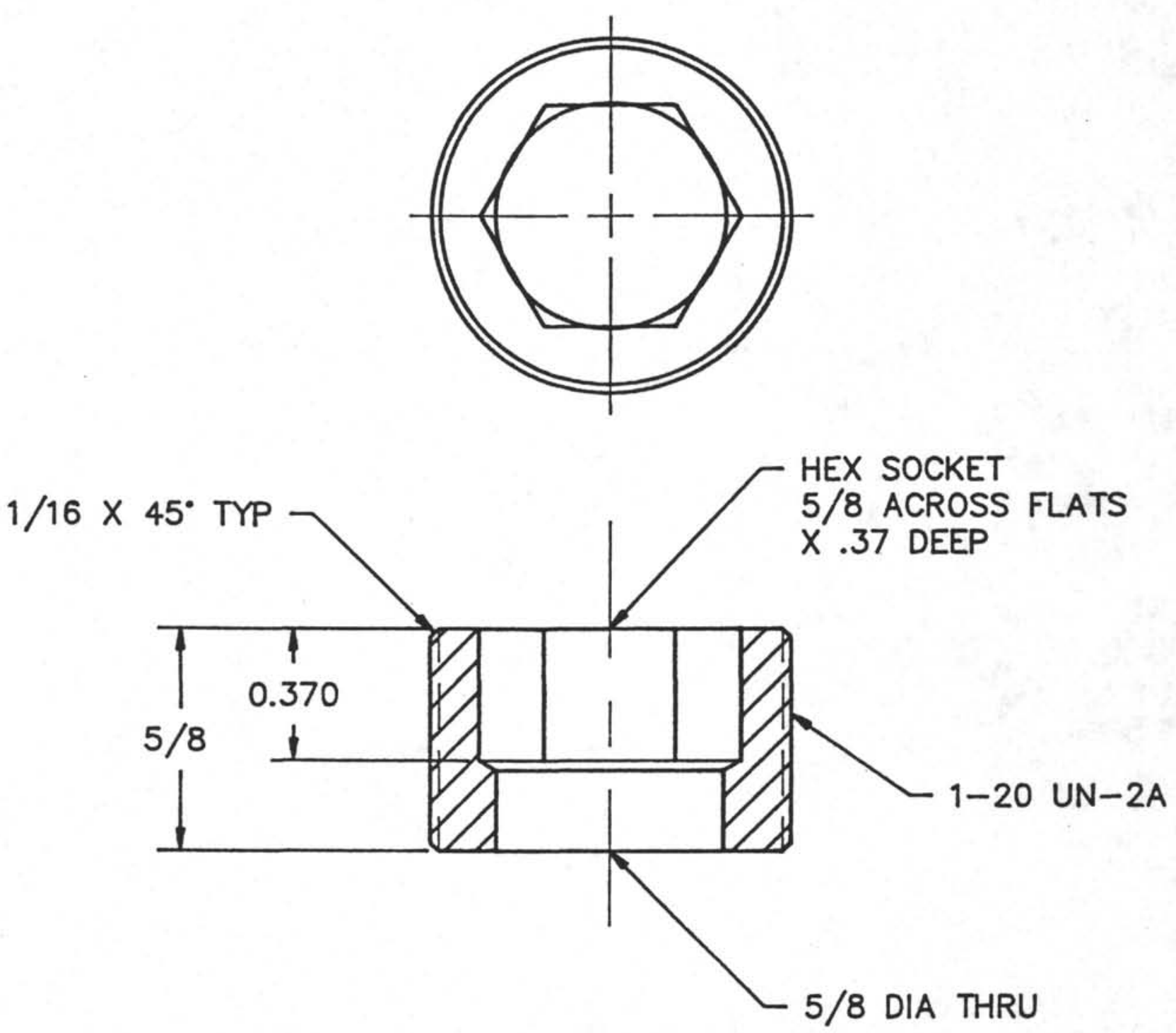

NOTE: MAKE FROM THE HEAD OF A 3/4 DIA CARBON STEEL SOCKET HEAD CAP SCREW

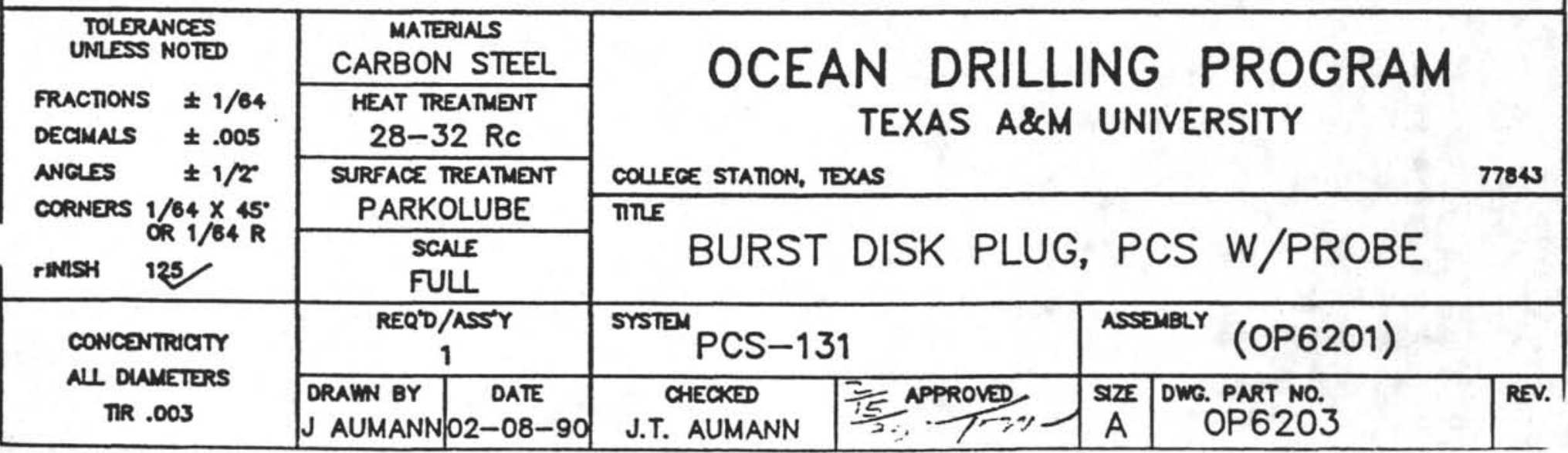




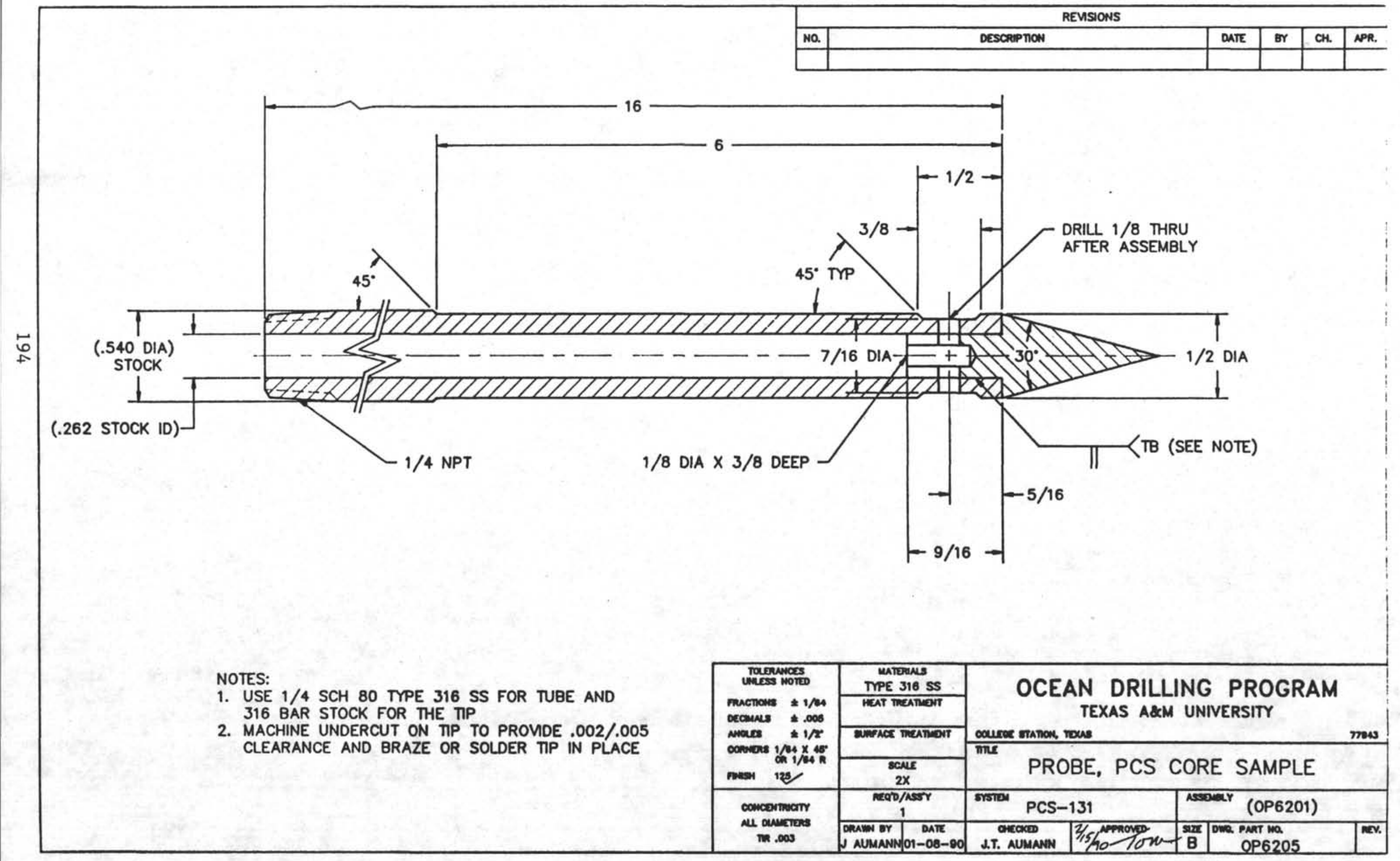




\begin{tabular}{|c|c|c|c|c|c|c}
\hline & \multicolumn{3}{|c}{ REVSIONS } \\
\hline NO. & DESCRIPTON & DATE & OY & CH. & NPR. \\
\hline & & & & & \\
\hline
\end{tabular}

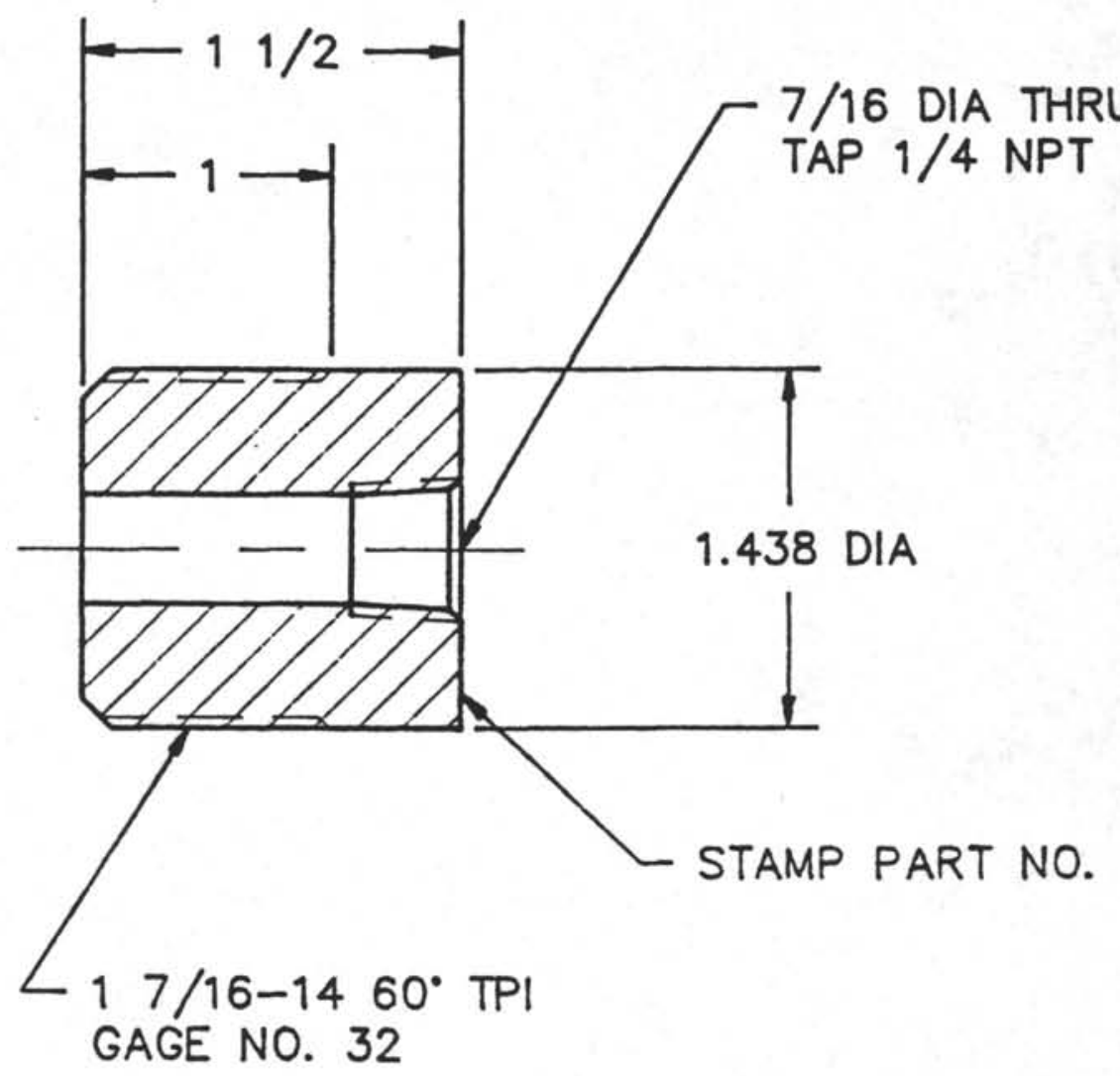

\begin{tabular}{|c|c|c|c|c|c|c|c|}
\hline \multicolumn{2}{|c|}{$\begin{array}{l}\text { TOLRANCES } \\
\text { TOULES NOTED }\end{array}$} & $\begin{array}{c}\text { MATERIALS } \\
\text { STL } 4130-4140\end{array}$ & \multirow{3}{*}{\multicolumn{5}{|c|}{$\begin{array}{l}\text { OCEAN DRILLING PROGRAM } \\
\text { TEXAS A\&M UNIVERSITY } \\
\text { COUECE STATON. TDAS }\end{array}$}} \\
\hline \multirow{3}{*}{$\begin{array}{l}\text { FRACTIONS } \\
\text { DEGMALS } \\
\text { ANGLS } \\
\text { CORNERS }\end{array}$} & \multirow{4}{*}{$\begin{array}{l} \pm 1 / 64 \\
\pm .005 \\
\pm 1 / 2 \\
/ 64 \times 45^{\circ} \\
R 1 / 84 R \\
25 \%\end{array}$} & \multirow{3}{*}{\begin{tabular}{|c|} 
HEAT TREATMENT \\
$28-32$ RC \\
SURFACE TREATMENT \\
PARKOLUBE \\
\end{tabular}} & & & & & \\
\hline & & & & & & & \\
\hline & & & \multirow{2}{*}{$\pi \pi E$} & \multirow{2}{*}{\multicolumn{3}{|c|}{ ADAPTER, PCS PROBE }} & \\
\hline & & $\begin{array}{l}\text { SCALE } \\
\text { FULL }\end{array}$ & & & & & \\
\hline \multirow{2}{*}{\multicolumn{2}{|c|}{$\begin{array}{c}\text { CONCENTRIATY } \\
\text { ALL DIAMETERS } \\
\text { TR .003 }\end{array}$}} & $\begin{array}{c}\text { REQ'D/ASSY } \\
1\end{array}$ & \multicolumn{2}{|c|}{ SYSTEM PCS-131 } & \multicolumn{3}{|c|}{ ASSEMBLY (OP6201) } \\
\hline & & \begin{tabular}{|l|c|} 
DRAMN BY & DATE \\
J AUMANN & $07-08-90$ \\
\end{tabular} & $\begin{array}{l}\text { CHECKED } \\
\text { J.T. AUMANN }\end{array}$ & $\frac{2}{5}$ APPROVED & $\begin{array}{c}\text { SIZE } \\
\text { A }\end{array}$ & $\begin{array}{r}\text { DWG. PART NO. } \\
\text { OP } 6207\end{array}$ & REV. \\
\hline
\end{tabular}




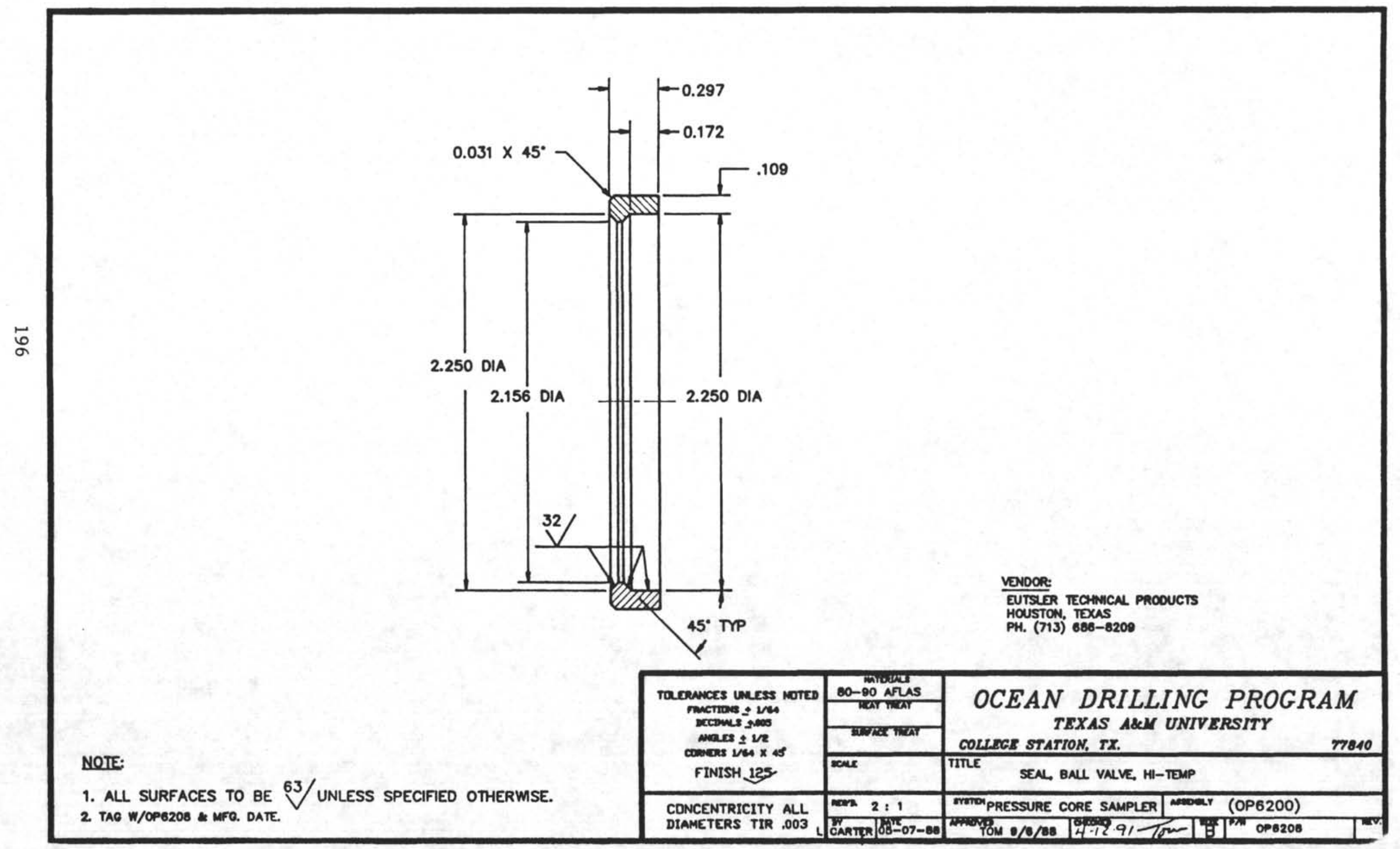



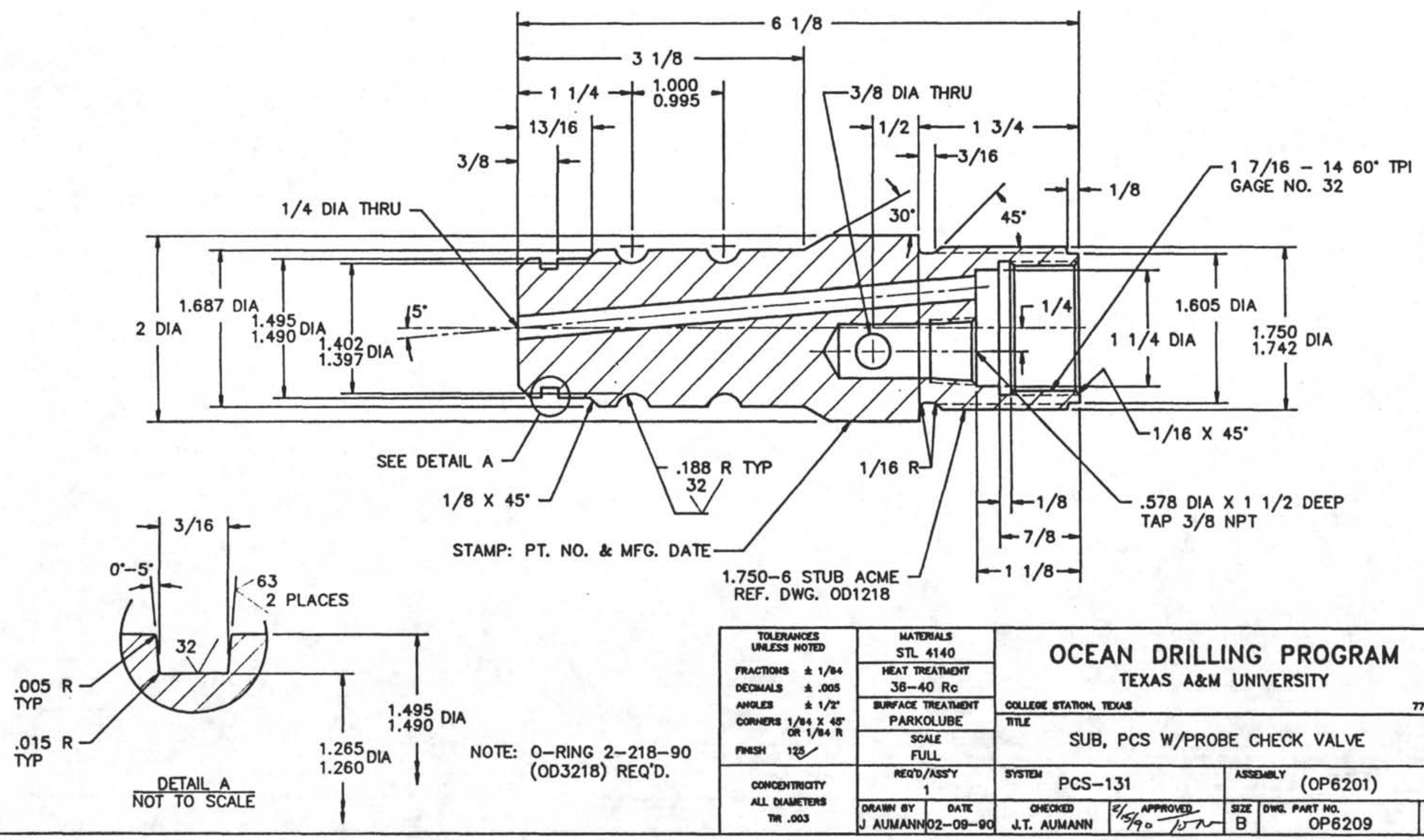

\begin{tabular}{|c|c|c|c|c|}
\hline \multirow{4}{*}{ 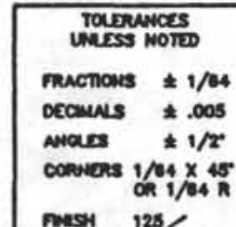 } & 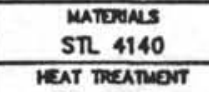 & \multirow{2}{*}{\multicolumn{2}{|c|}{$\begin{array}{l}\text { OCEAN DRILLING PROGRAM } \\
\text { TEXAS A\&M UNIVERSITY }\end{array}$}} & \\
\hline & 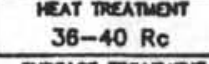 & & & \\
\hline & 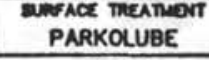 & \multirow{2}{*}{\multicolumn{3}{|c|}{$\begin{array}{l}\text { coucee stanous mus } \\
\text { miLe SUB, PCS W/PROBE CHECK VALVE }\end{array}$}} \\
\hline & $\begin{array}{l}\text { schese } \\
\text { FUL }\end{array}$ & & & \\
\hline \multirow{2}{*}{ 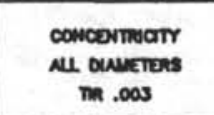 } & Necod/ast & Frरा104 PCS-131 & Ossorer (OP6201) & \\
\hline & 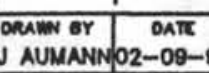 & \begin{tabular}{l|l} 
OHCowi & $2 / 5 / 9 N$ \\
LT. AUMNNN
\end{tabular} & \begin{tabular}{l|l} 
Szx & OWa PNer Wa \\
B & OP6209
\end{tabular} & nav. \\
\hline
\end{tabular}




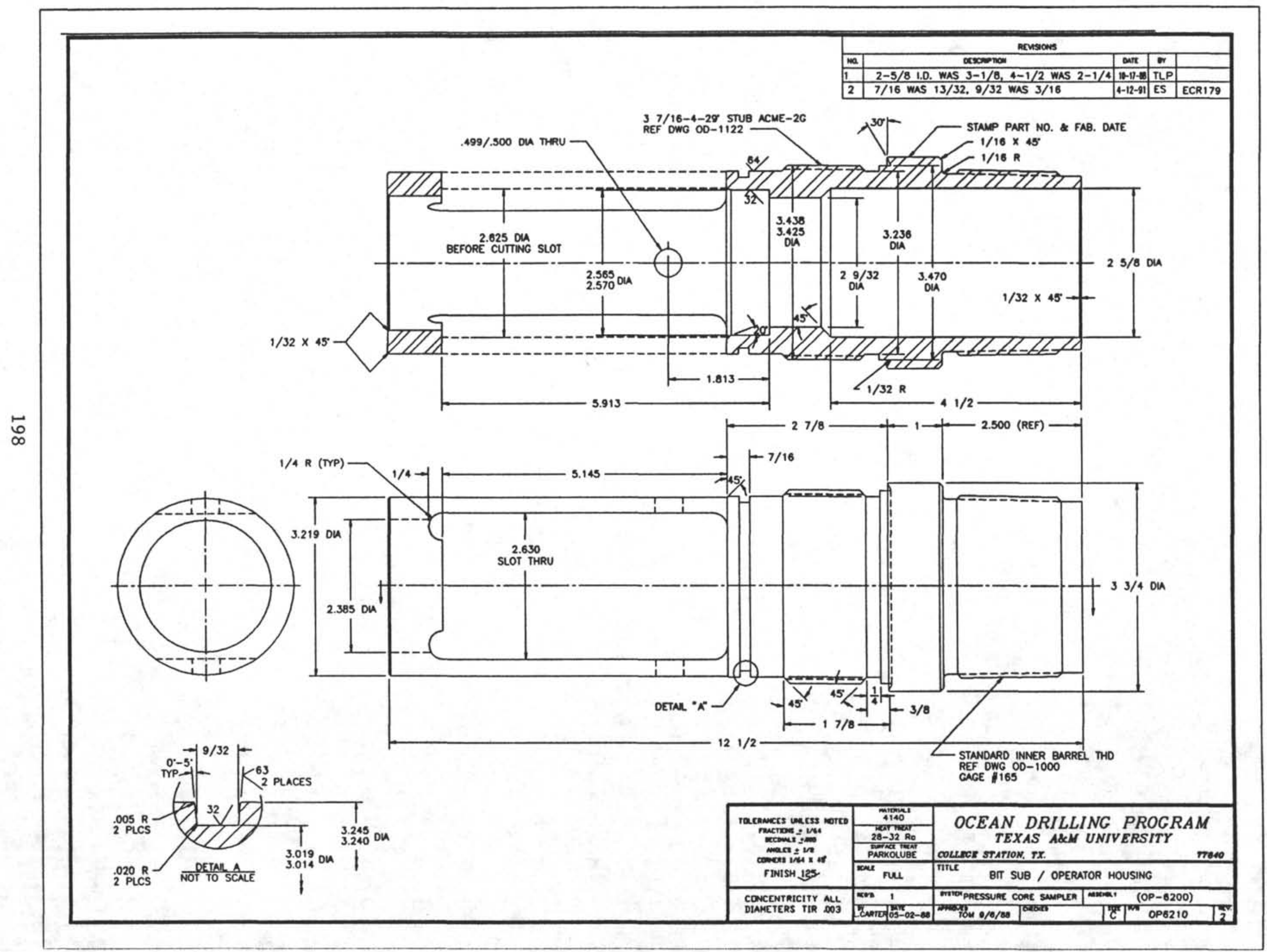




\begin{tabular}{|c|c|c|c|c|c|}
\hline \multicolumn{6}{|c|}{ REMSIONS } \\
\hline NO. & DESCRIPTON & DATE & BY & $\mathrm{CH}$. & APR. \\
\hline & & & & & \\
\hline
\end{tabular}
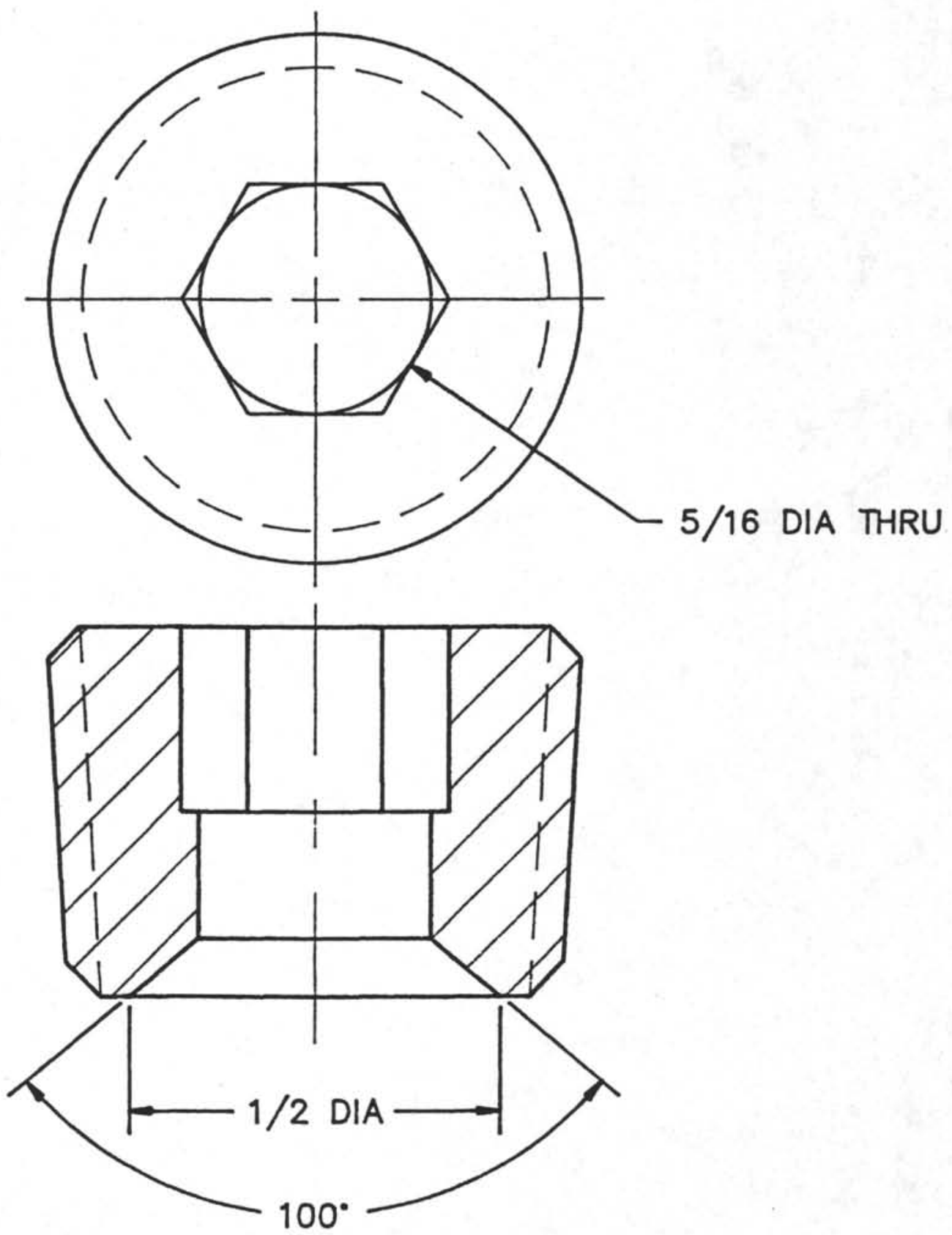

NOTE: MAKE FROM A $3 / 8$ NPT SS PIPE PLUG

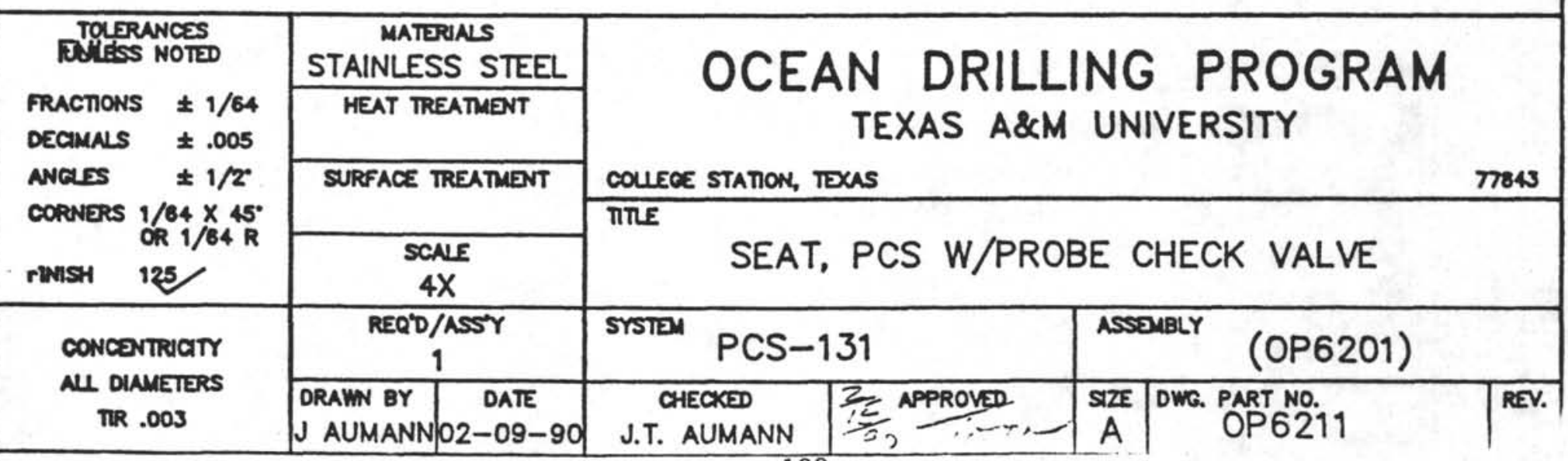




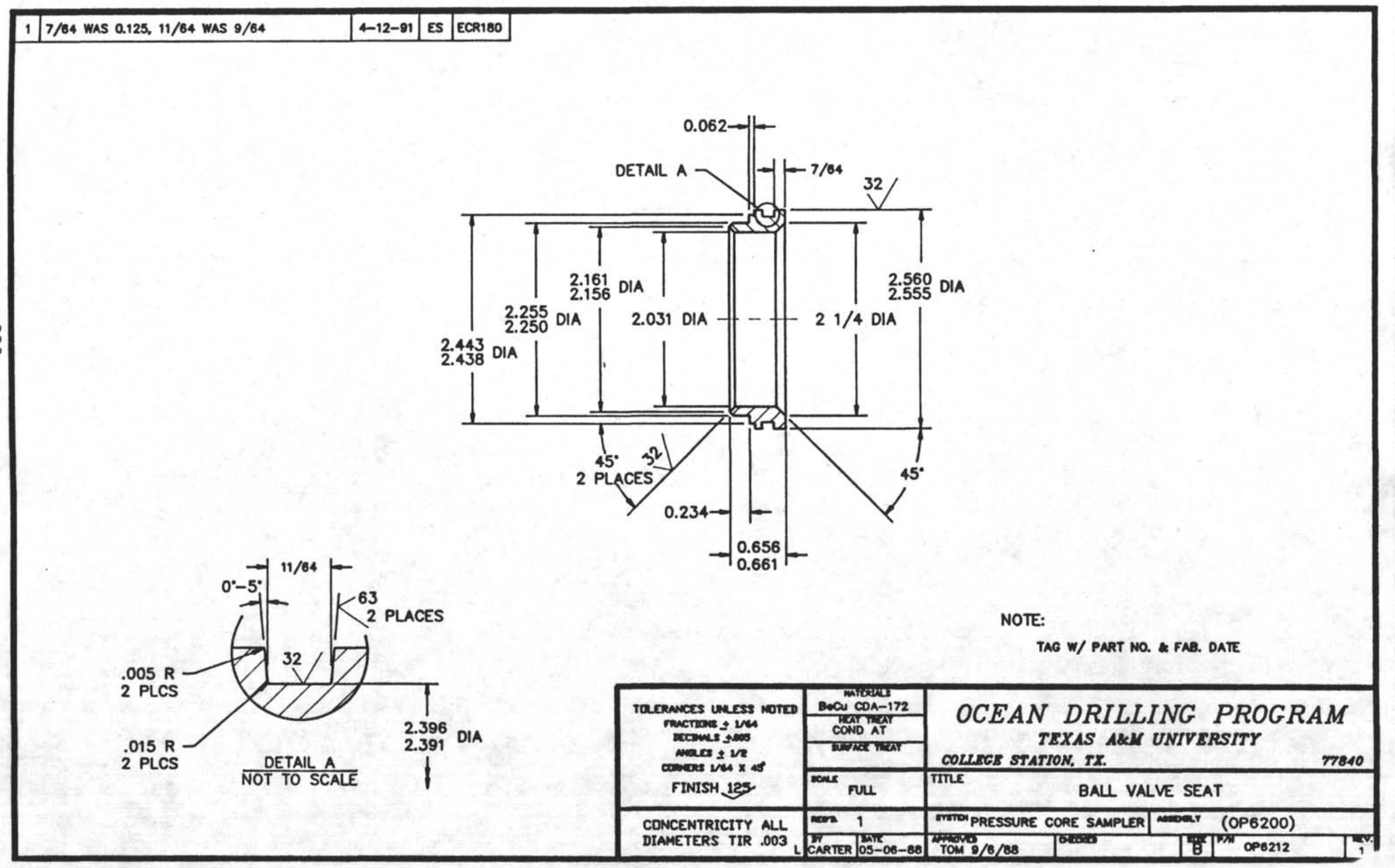


\begin{tabular}{|l|l|l|l|l|}
\hline $9 / 16$ WAS $17 / 32.13 / 32$ WAS $3 / 8.9 / 32$ WAS $3 / 16$ (0-RING GROOVE) & $4-12-91$ & ES & ECR181 \\
\hline
\end{tabular}

1 DU. FUAT OTM $\times 3-1 / 2$ DP. TAP $1 / 4$ NPT AT
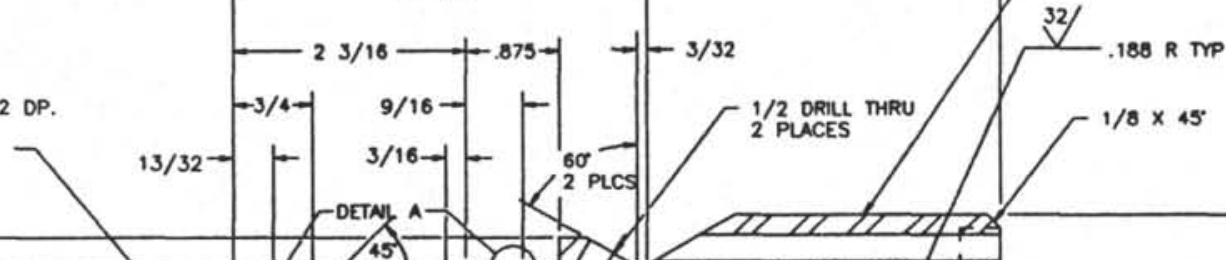
(1/16 X 45. $1.875-8$ STUB ACME
REF. DWG. OD1318
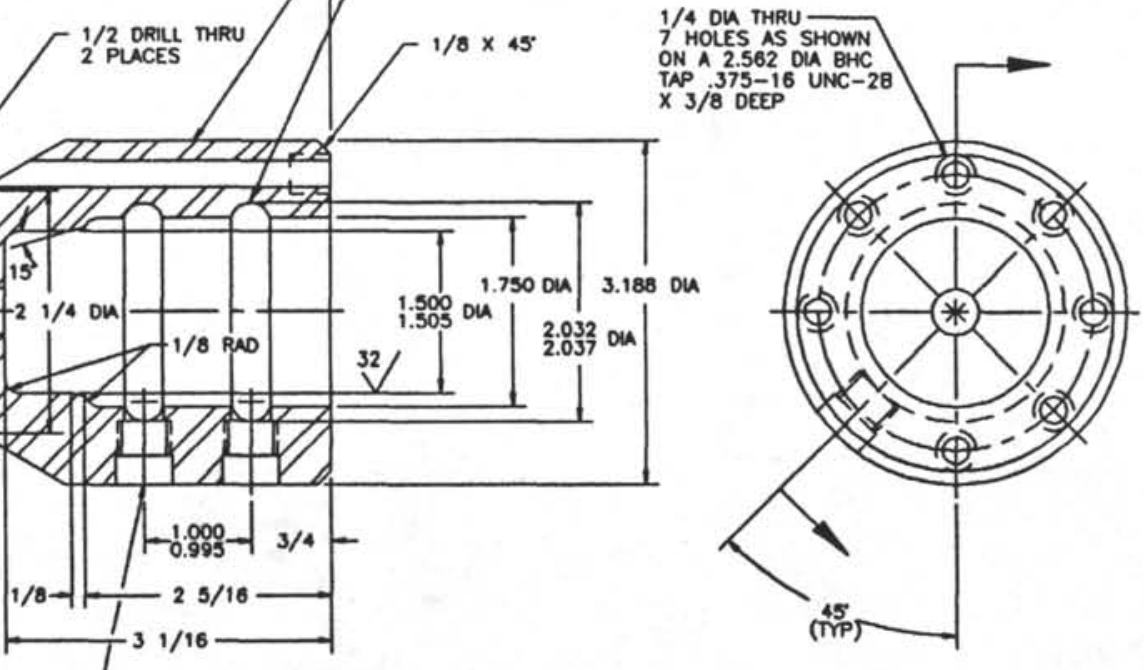

L.375 OU THRU

TNP $1 / 2-13 \times .562$ DEEP

CEORE.ST2 $\times .250$ DEEP

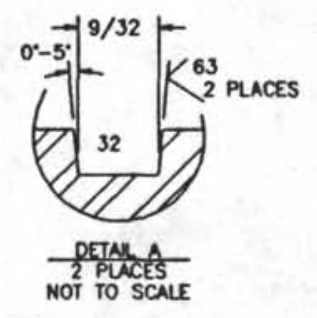

NOTE: O-RINGS REO'O.

O-RING 2-220-90 (003220)

O-RING 2-228-90 (003226)

\begin{tabular}{|c|c|c|}
\hline \multirow{2}{*}{ 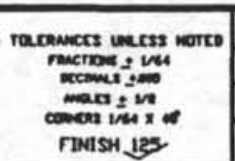 } & 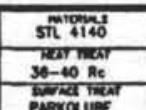 & $\begin{array}{l}\text { OCEAN DRILLING PROGRAM } \\
\text { TEXAS A\&LI UNIVERSITY } \\
\text { COUner STATION, TX. }\end{array}$ \\
\hline & ond pus & FION, FX. \\
\hline CONCENTRECIYY ALL & & (OP6201) \\
\hline & & $\left.{ }^{1}\right]^{m} \quad 0 P 0213$ \\
\hline
\end{tabular}




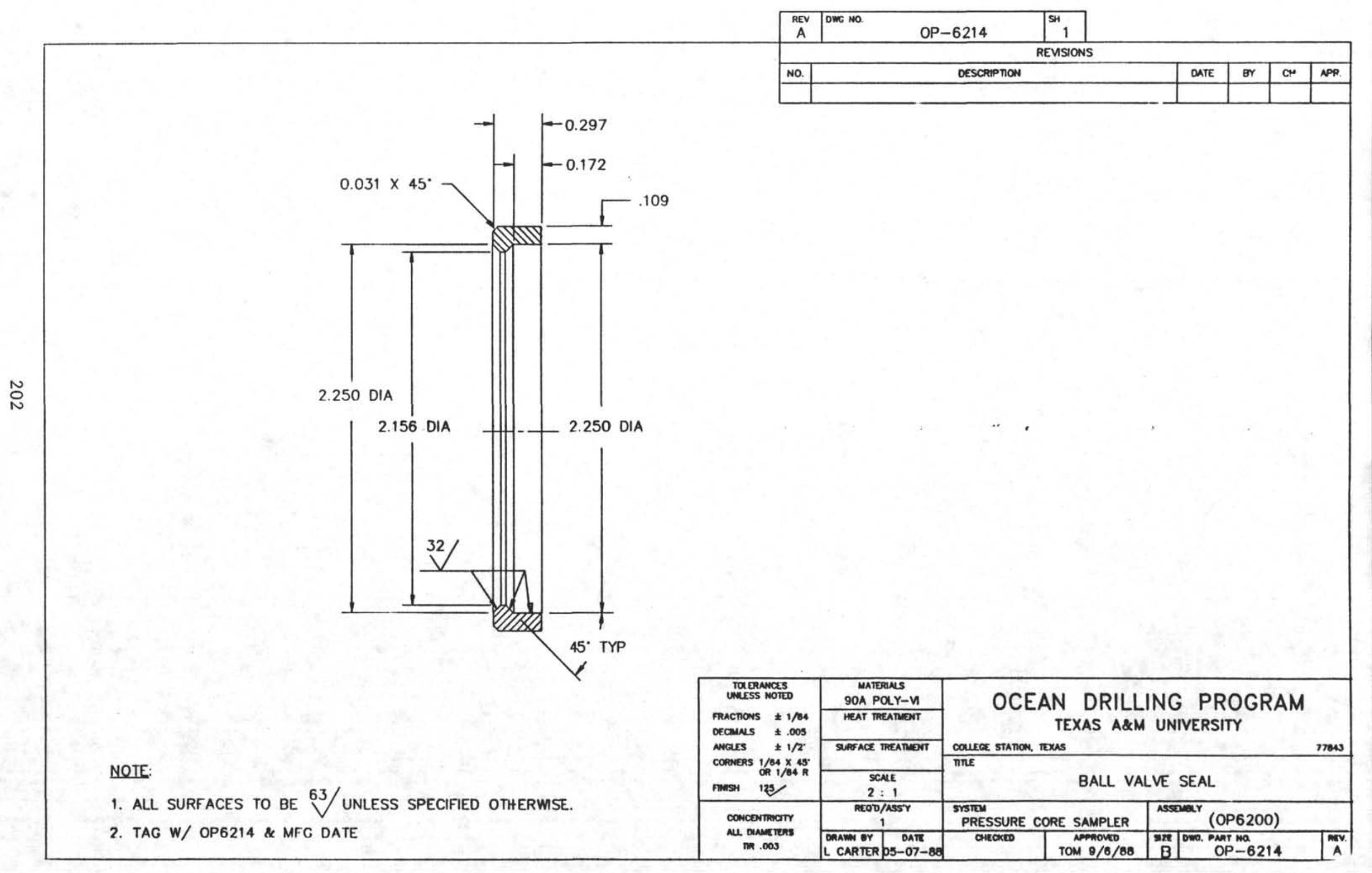




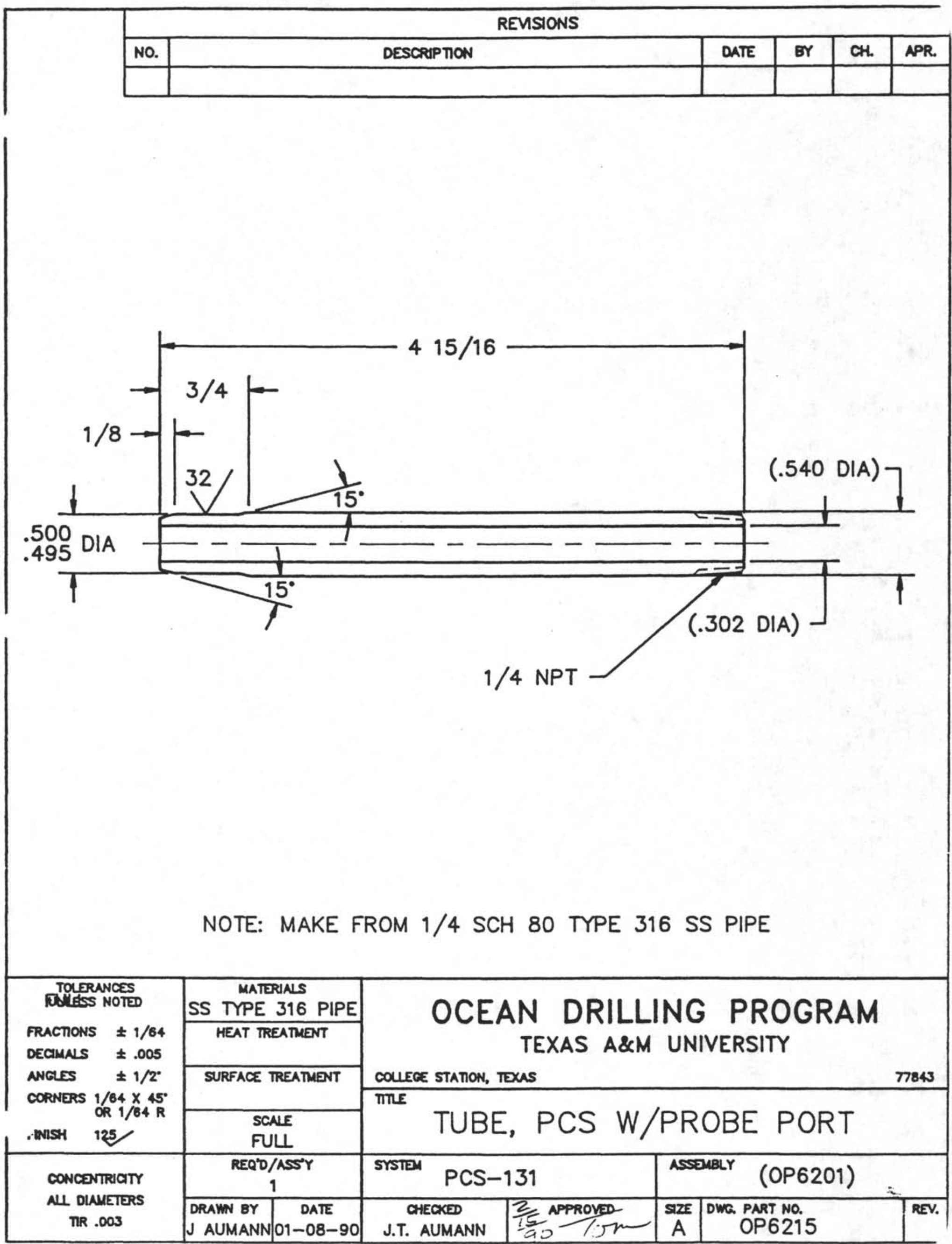




\begin{tabular}{|c|c|c|c|c|c|}
\hline \multicolumn{6}{|c|}{ REVSIONS } \\
\hline No. & DESCRIPTION & DATE & BY & $\mathrm{CH}$. & APR. \\
\hline
\end{tabular}

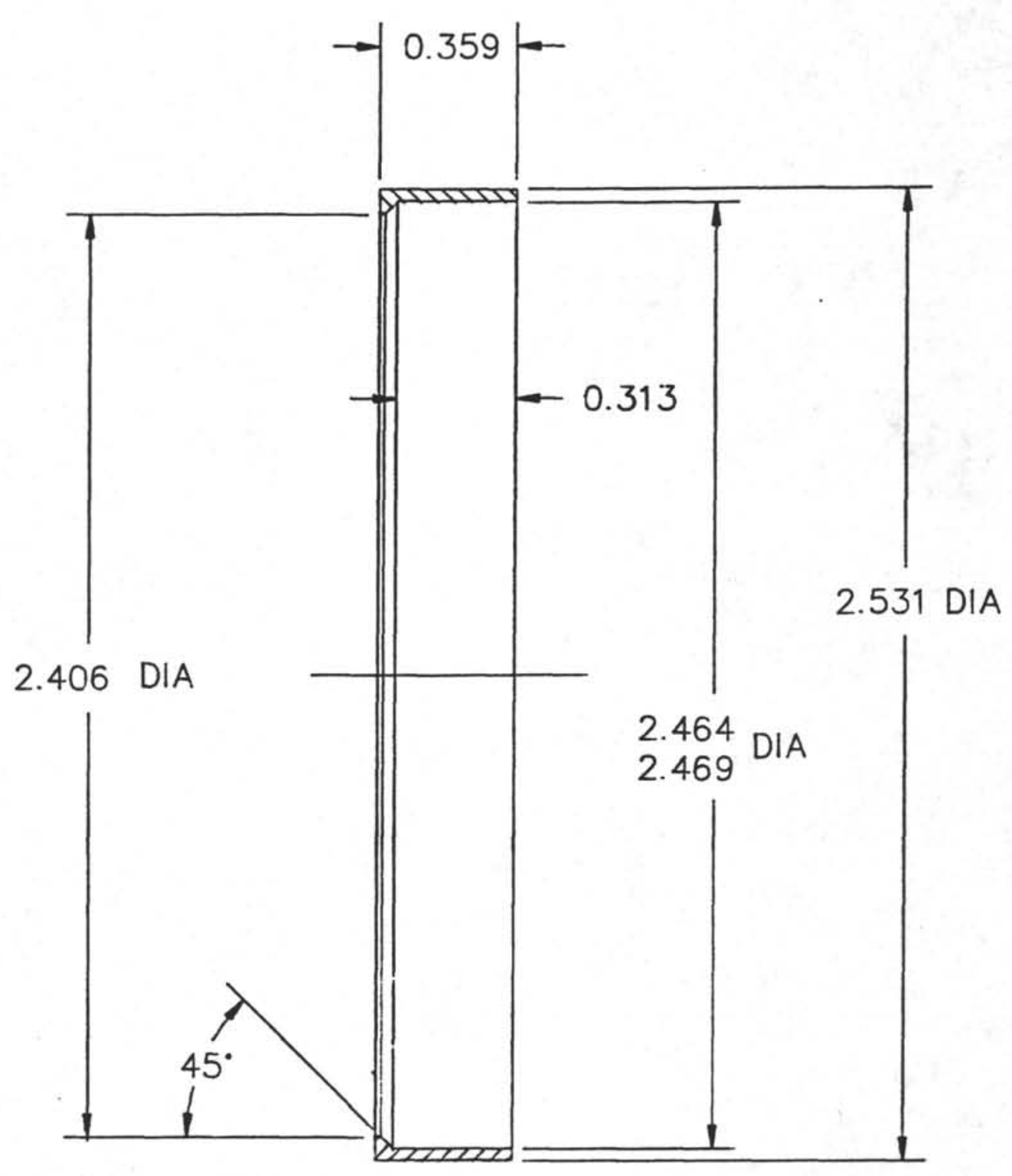

NOTE:

1. TAG W/ OP6216 \& MFG DATE.

\begin{tabular}{|c|c|c|c|c|c|c|c|}
\hline \multicolumn{2}{|c|}{$\begin{array}{l}\text { TOLERANCES } \\
\text { UNLESS NOTED }\end{array}$} & \multirow{2}{*}{$\begin{array}{c}\text { MATERIALS } \\
\text { BRONZE CDA-932 } \\
\text { HEAT TREATMENT }\end{array}$} & \multicolumn{5}{|c|}{ OCEAN DRILLING PROGRAM } \\
\hline \multirow{2}{*}{\multicolumn{2}{|c|}{$\begin{array}{ll}\text { FRACTIONS } & \pm 1 / 64 \\
\text { DECIMALS } & \pm .005 \\
\text { ANGLES } & \pm 1 / 2\end{array}$}} & & \multicolumn{5}{|c|}{ TEXAS A\&M UNIVERSITY } \\
\hline & & \multirow[t]{2}{*}{ SLRFACE TREATMENT } & \multicolumn{4}{|c|}{ COLLEGE STAMON, TEXAS } & 77843 \\
\hline \multirow{2}{*}{\multicolumn{2}{|c|}{$\begin{array}{ll}\text { CORNERS } & 1 / 64 \times 45^{\circ} \\
& \text { OR } 1 / 64 R \\
\text { rINISH } & 125\end{array}$}} & & \multirow{2}{*}{\multicolumn{5}{|c|}{ ETAINER }} \\
\hline & & $\begin{array}{l}\text { SCAIE } \\
2: 1\end{array}$ & & & & & \\
\hline \multirow{2}{*}{\multicolumn{2}{|c|}{$\begin{array}{l}\text { CONCENTRICITY } \\
\text { ALL DIAMETERS } \\
\text { TIR .003 }\end{array}$}} & $\begin{array}{c}\text { REO'U/ASS': } \\
1\end{array}$ & \multicolumn{2}{|c|}{$\begin{array}{l}\text { SYSTEM } \\
\text { PRESSURE CORE SAMPLER }\end{array}$} & \multicolumn{3}{|c|}{ ASSEMBLY (OP6200) } \\
\hline & & \begin{tabular}{|l|c|} 
DRAWN BY & DATE \\
L CARTER & $05-07-88$ \\
\end{tabular} & CHECKED & $\begin{array}{c}\text { APPROVED } \\
\text { OM } 9 / 6 / 83\end{array}$ & $\stackrel{\mathrm{SIZE}}{\mathrm{A}}$ & $\begin{array}{l}\text { DWG. PART NO. } \\
\text { OP-6216 }\end{array}$ & $\therefore$ \\
\hline
\end{tabular}




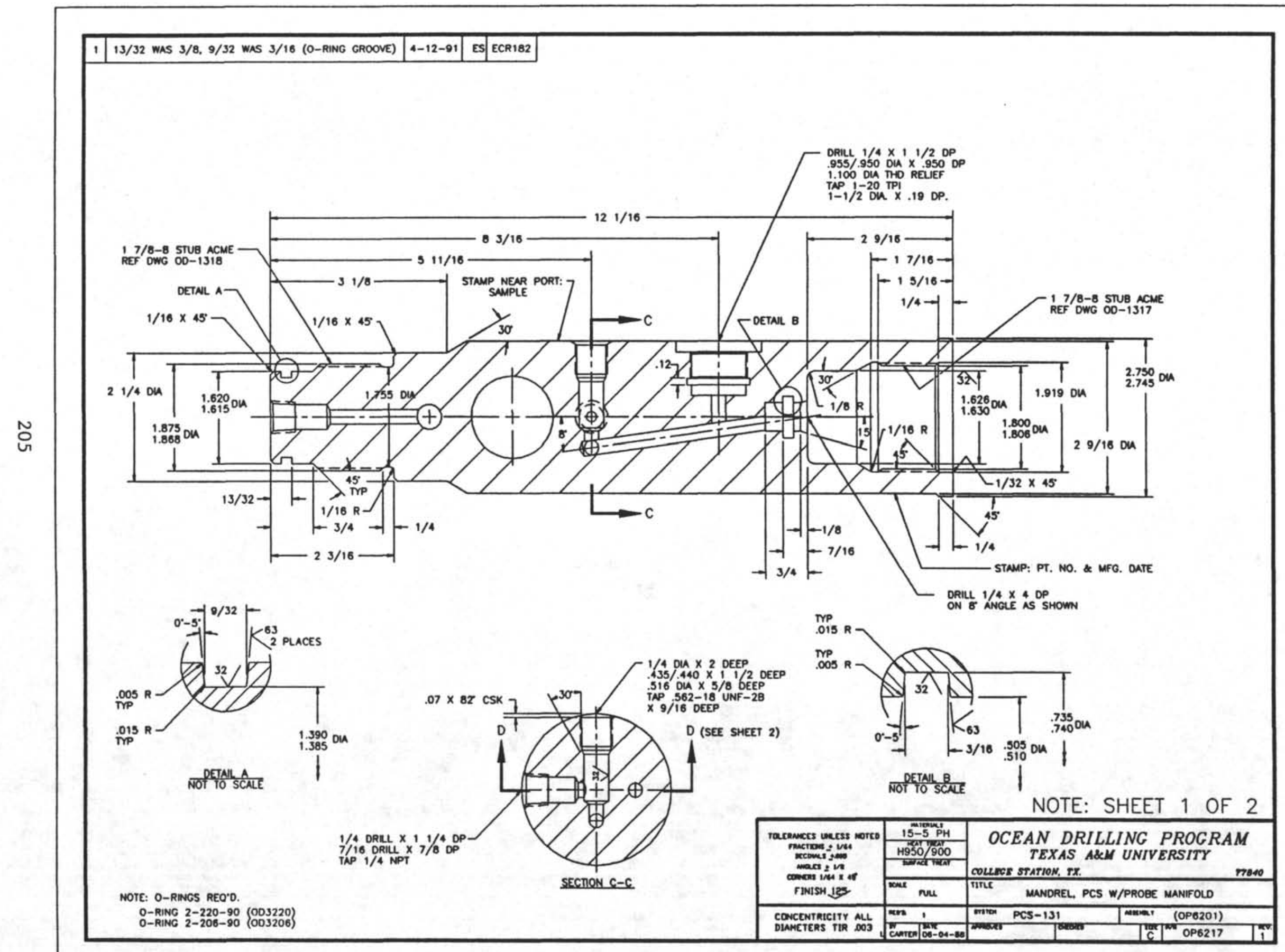




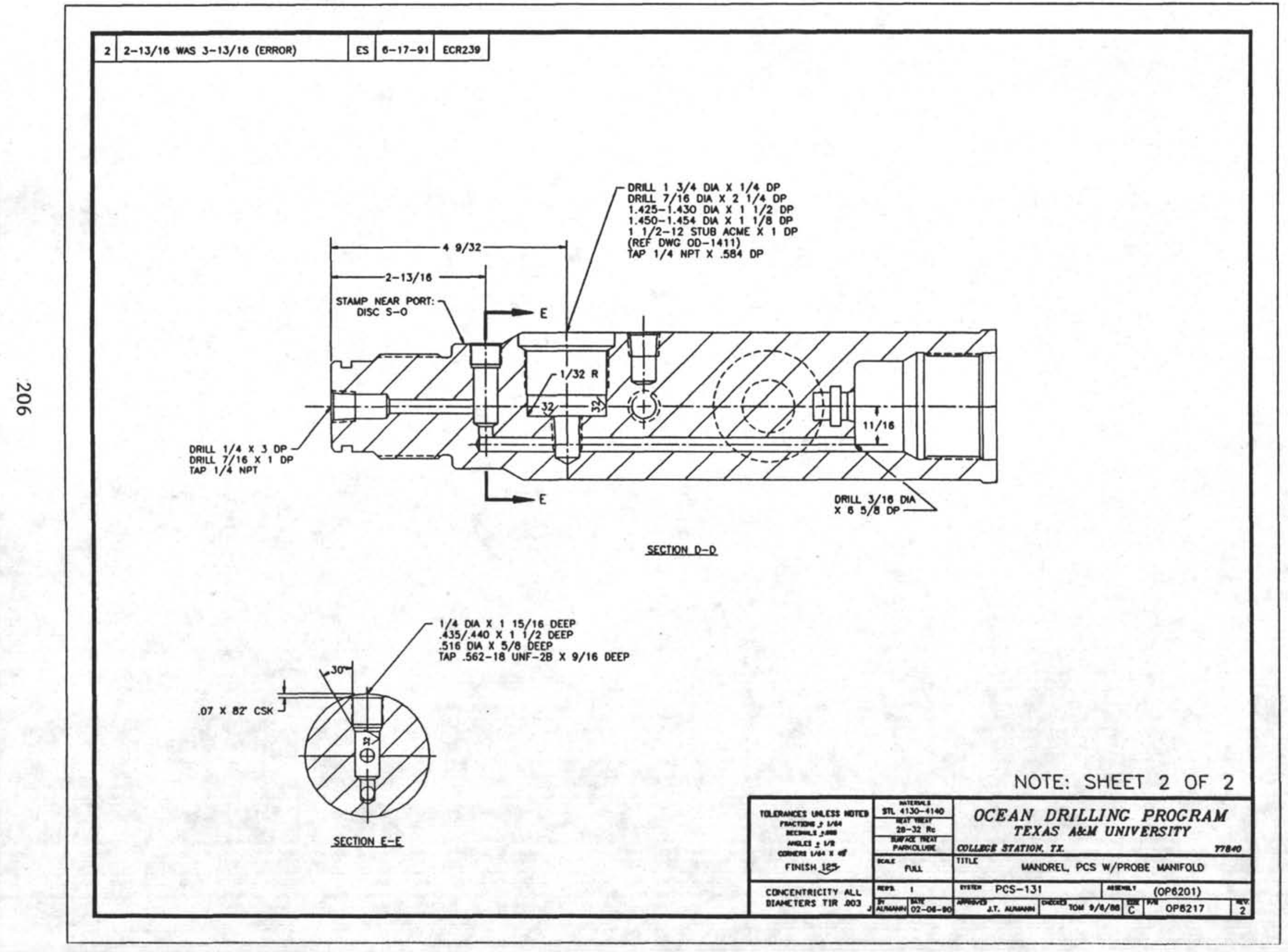




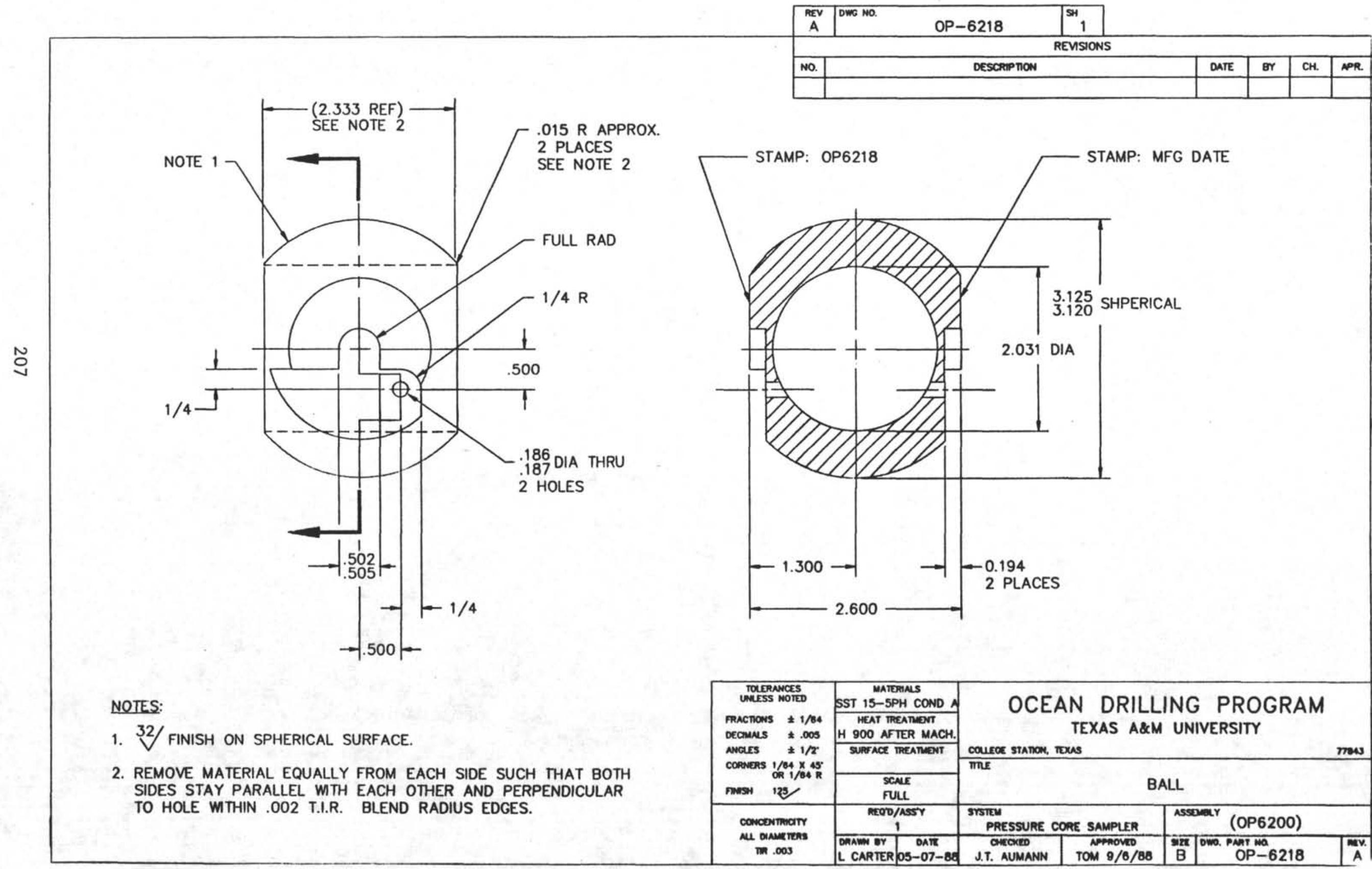




\begin{tabular}{|c|c|c|c|c|c|}
\hline NO. & DESCRIPTION & DATE & BY & CH. & APR. \\
\hline & & & & & \\
\hline
\end{tabular}

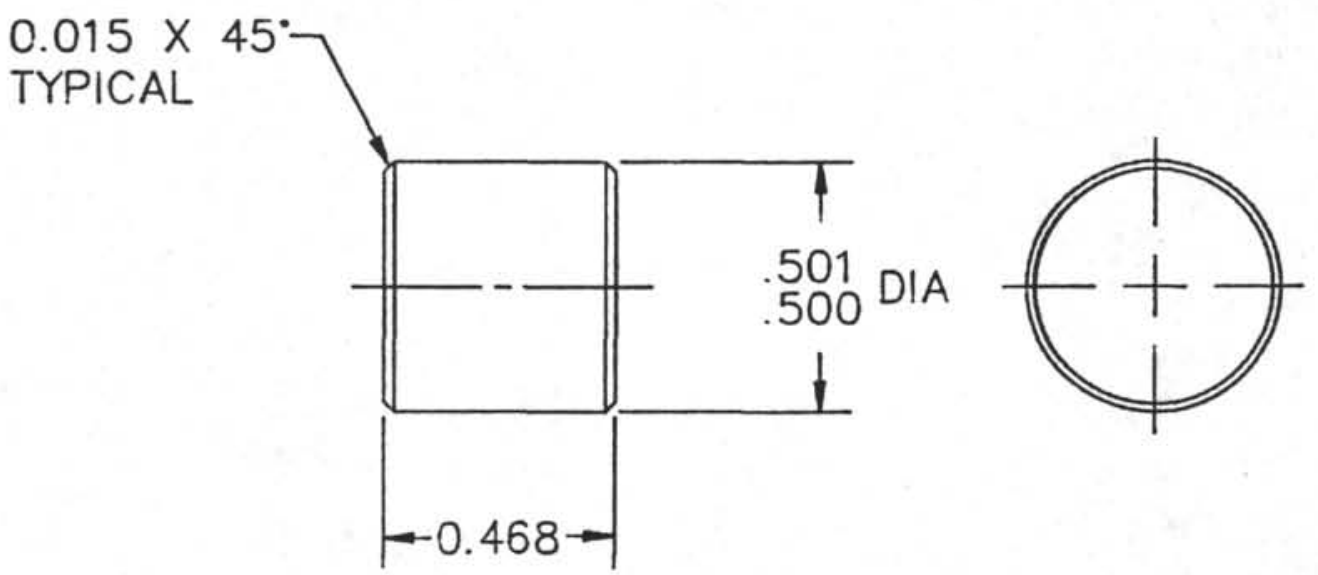

NOTE:

1. PLACE IN BAG OR BOX MARKED

W/ OP6220 \& MFG DATE

\begin{tabular}{|c|c|c|c|c|c|}
\hline $\begin{array}{l}\text { TOLERANCES } \\
\text { UNLESS NOTED }\end{array}$ & $\begin{array}{l}\text { MATER!AL.S } \\
\text { DRILL ROD }\end{array}$ & & & & \\
\hline FRACTIONS $\pm ! / 64$ & HEAT TPEATMENT & S 18,1 & 110 & DY & \\
\hline DEC!MALS \pm .005 & & AS A\&C & UN & ERSII & \\
\hline ANGLES $\quad \pm 1 / 2^{\circ}$ & \multirow[t]{2}{*}{ SLRFACE TREATMENT } & \multicolumn{3}{|l|}{ COUEGE STATON, IEXAS } & 77843 \\
\hline - ARNERS $1 / 64 \times 45^{\circ}$ & & \multirow{2}{*}{\multicolumn{3}{|c|}{ TILE }} & \\
\hline FINISH & $\begin{array}{l}\text { SCA:C } \\
2: i\end{array}$ & & & & \\
\hline \multirow{2}{*}{$\begin{array}{l}\text { CONCENTR!CITY } \\
\text { ALL DIAMETERS } \\
\text { T!P. . } 003\end{array}$} & $\begin{array}{l}\text { REO'D/ASS'? } \\
2\end{array}$ & $\begin{array}{l}\text { SVSIEM } \\
\text { PRESSURE CORE SAMPLER }\end{array}$ & \multicolumn{2}{|c|}{$\begin{array}{l}\text { ASSEMBLY } \\
\text { (OP6200) }\end{array}$} & \\
\hline & \begin{tabular}{|l|c|} 
DRAWN EY & DATE \\
CAPTEP & $-07-88$ \\
\end{tabular} & \begin{tabular}{c|c} 
CHECKED & APPPOVED \\
$\therefore T$ ALINANN & TOM $9 / 6 / 88$
\end{tabular} & SIZE & $\begin{array}{l}\text { DWG. PART NO. } \\
\text { OP }-6220\end{array}$ & $\begin{array}{c}\text { REV. } \\
\text { A }\end{array}$ \\
\hline
\end{tabular}




\section{REVISIONS}

\begin{tabular}{|c|c|c|c|c|c|}
\hline NO. & DESCRIPTION & DATE & BY & CH. & APR. \\
\hline & & & & & \\
\hline
\end{tabular}

STAMP: OP6222 \& MFG DATE

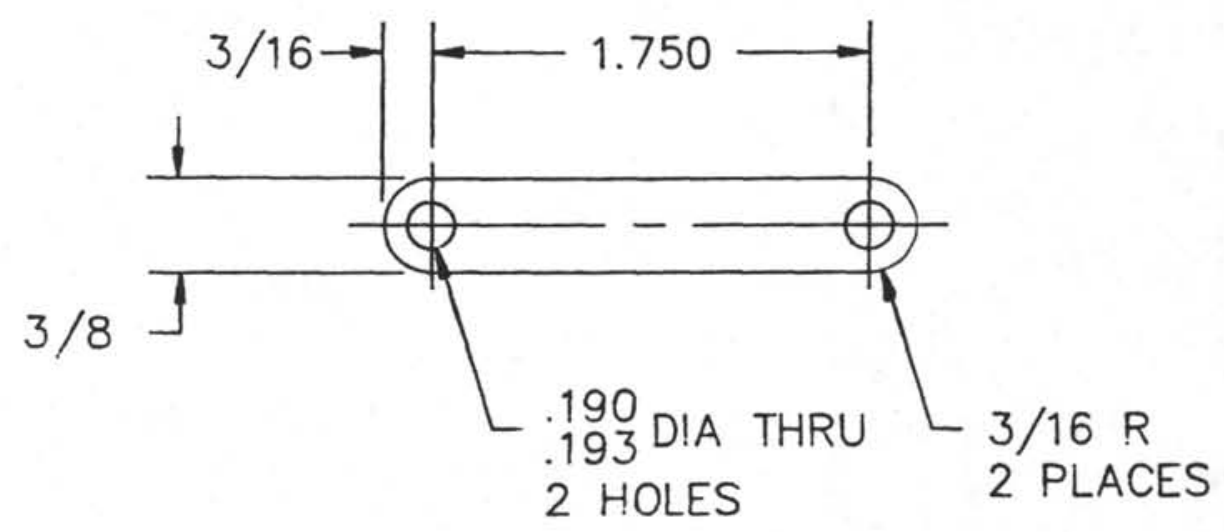

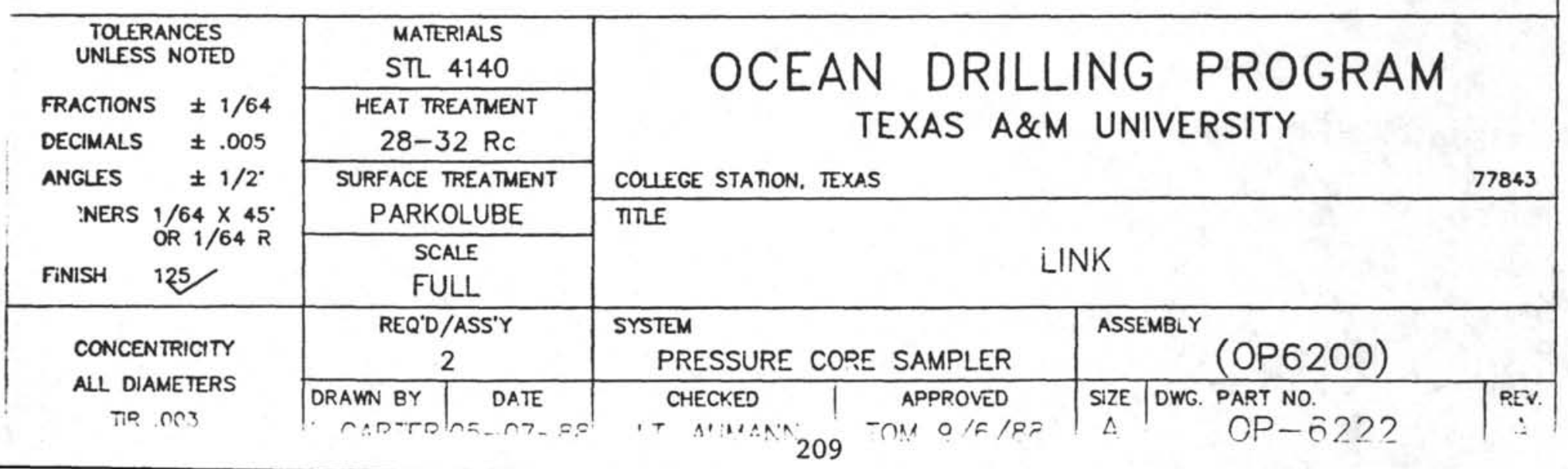




\begin{tabular}{|c|c|c|c|c|c|}
\hline \multicolumn{6}{|c|}{ REVSIONS } \\
\hline No. & DESCRIPTION & DATE & BY & $\mathrm{CH}$. & AFR. \\
\hline
\end{tabular}

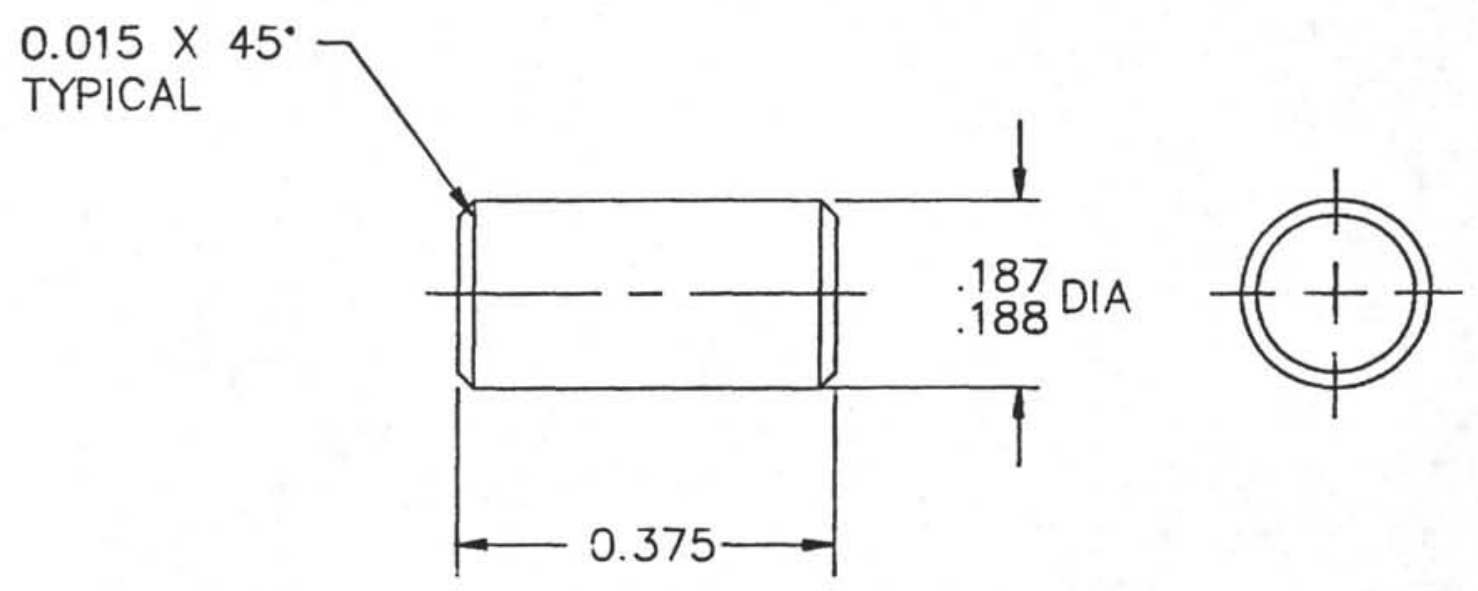

NOTE:

1. PLACE IN BAG OR BOX MARKED

W/ OP6224 \& MFG DATE

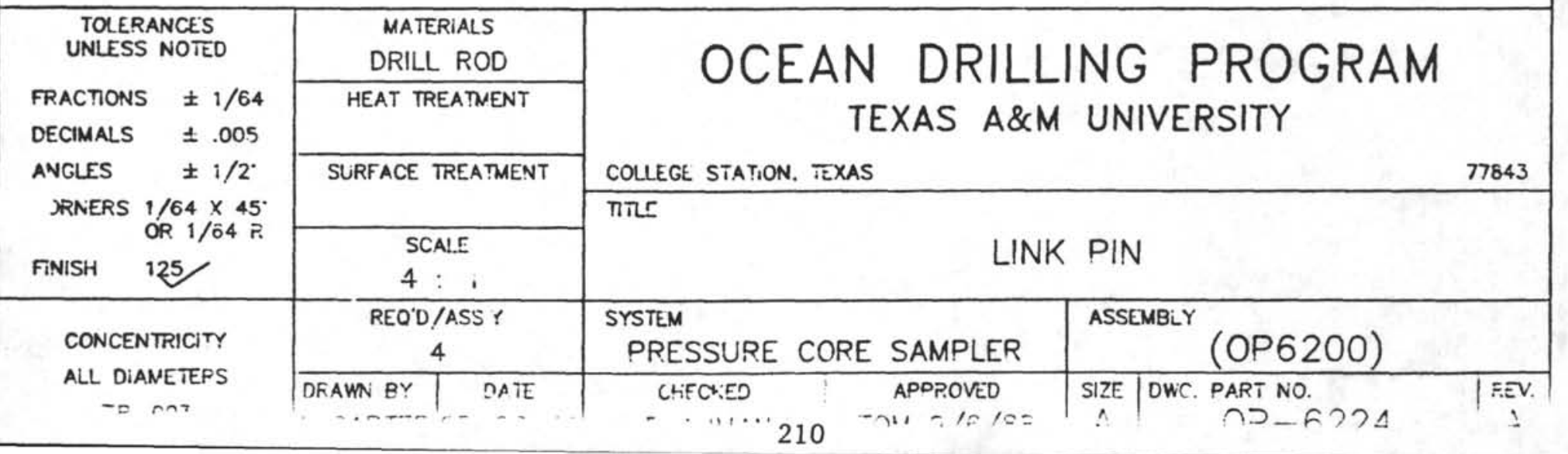




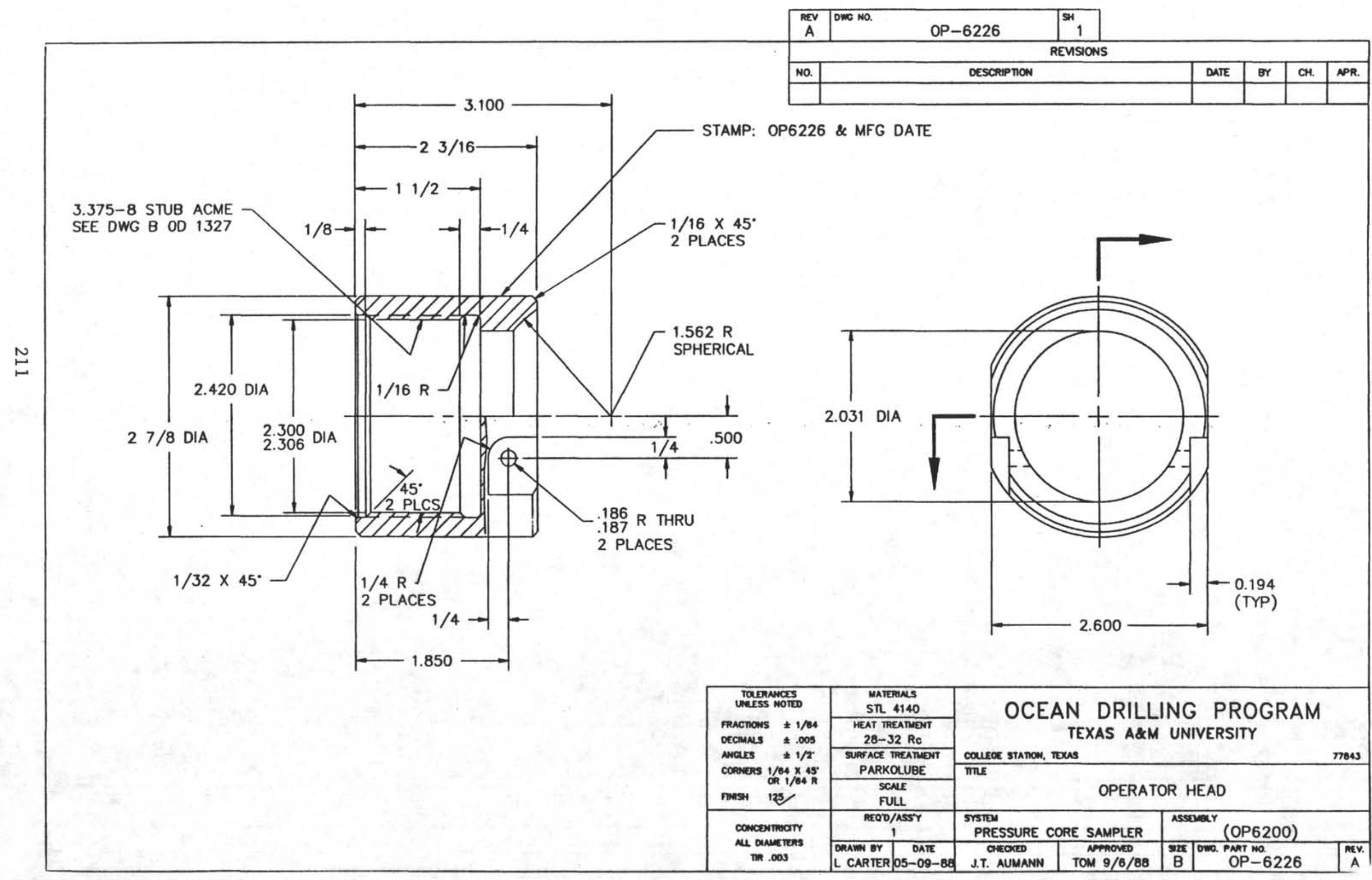




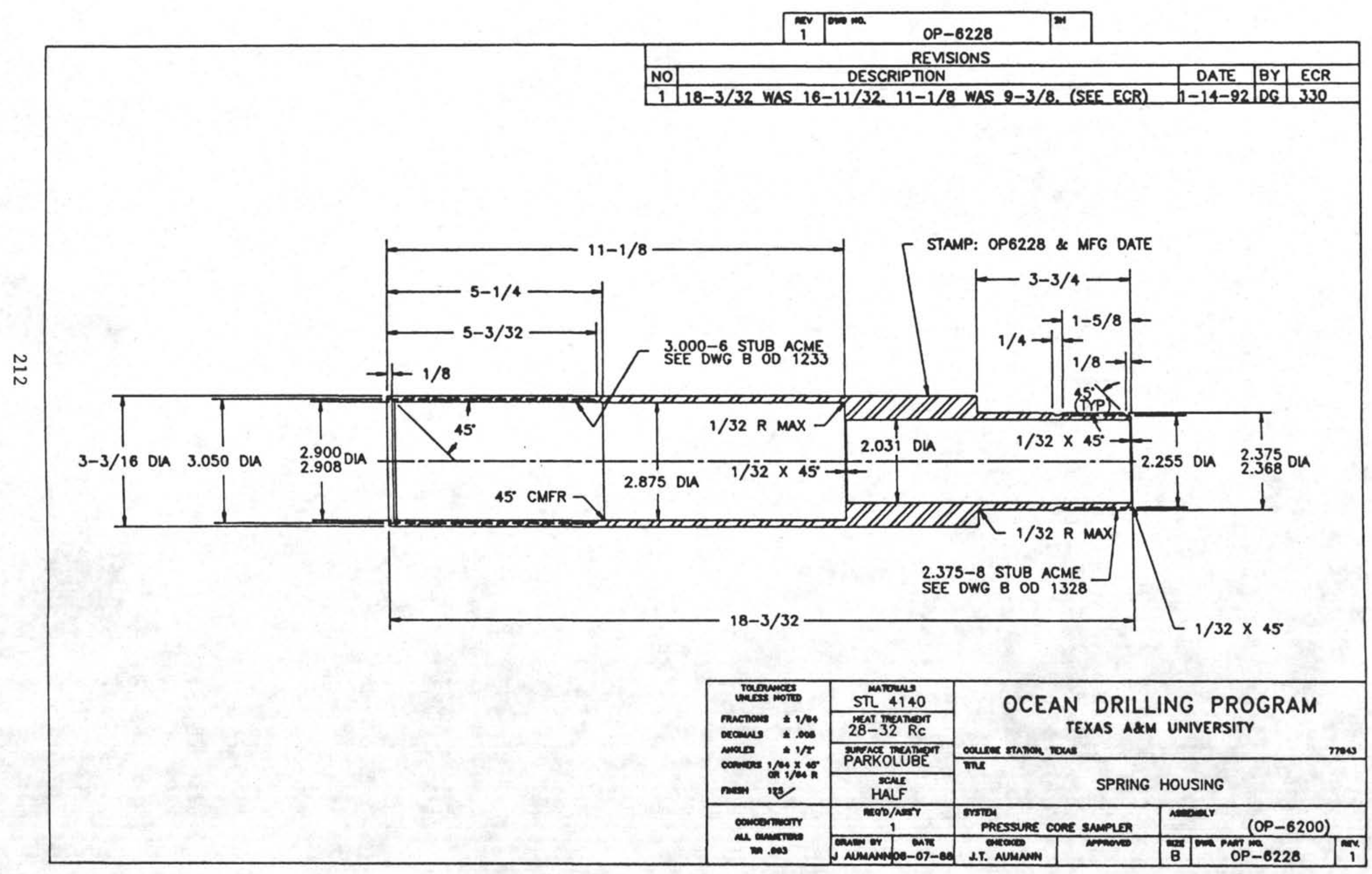




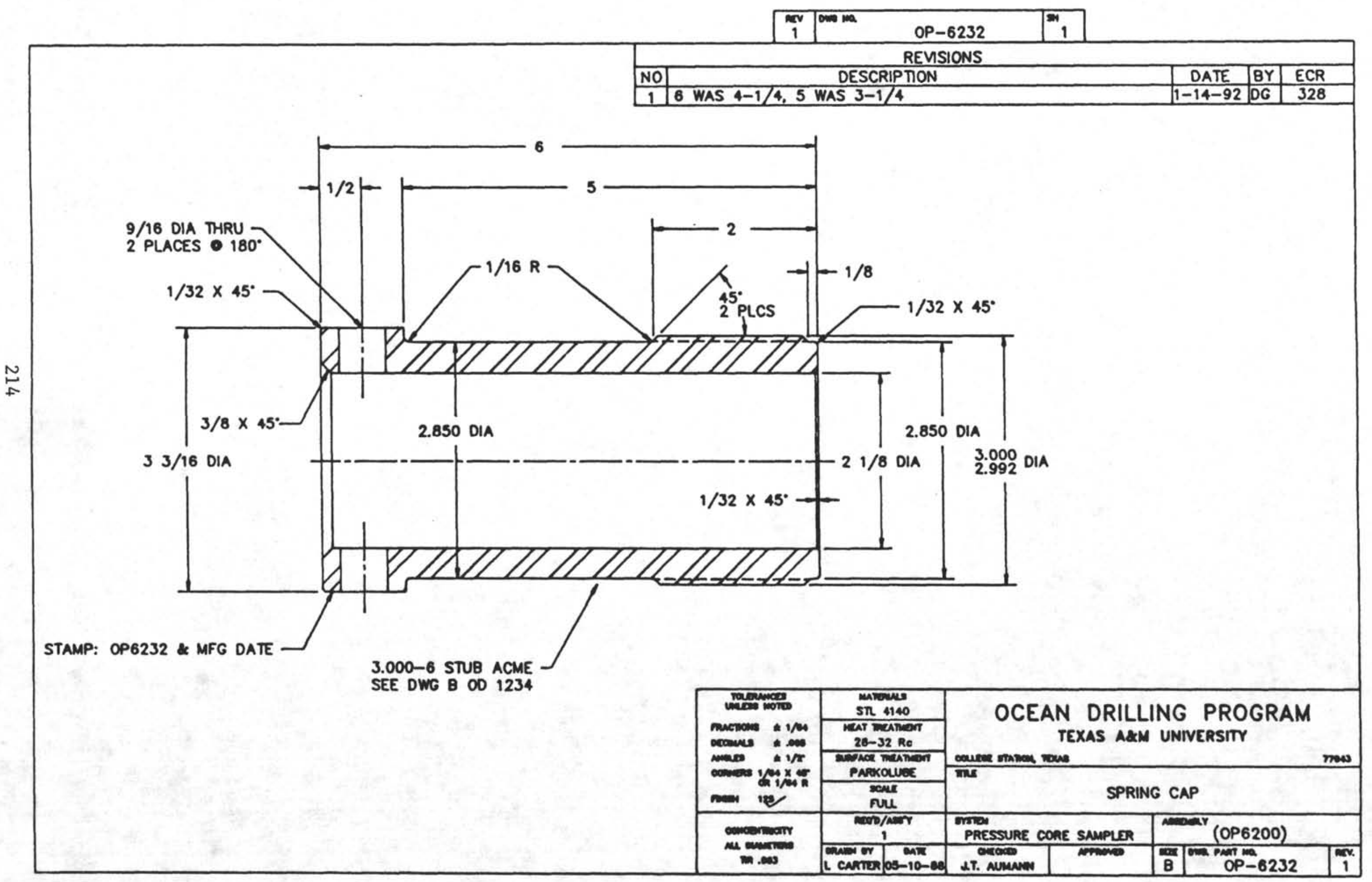




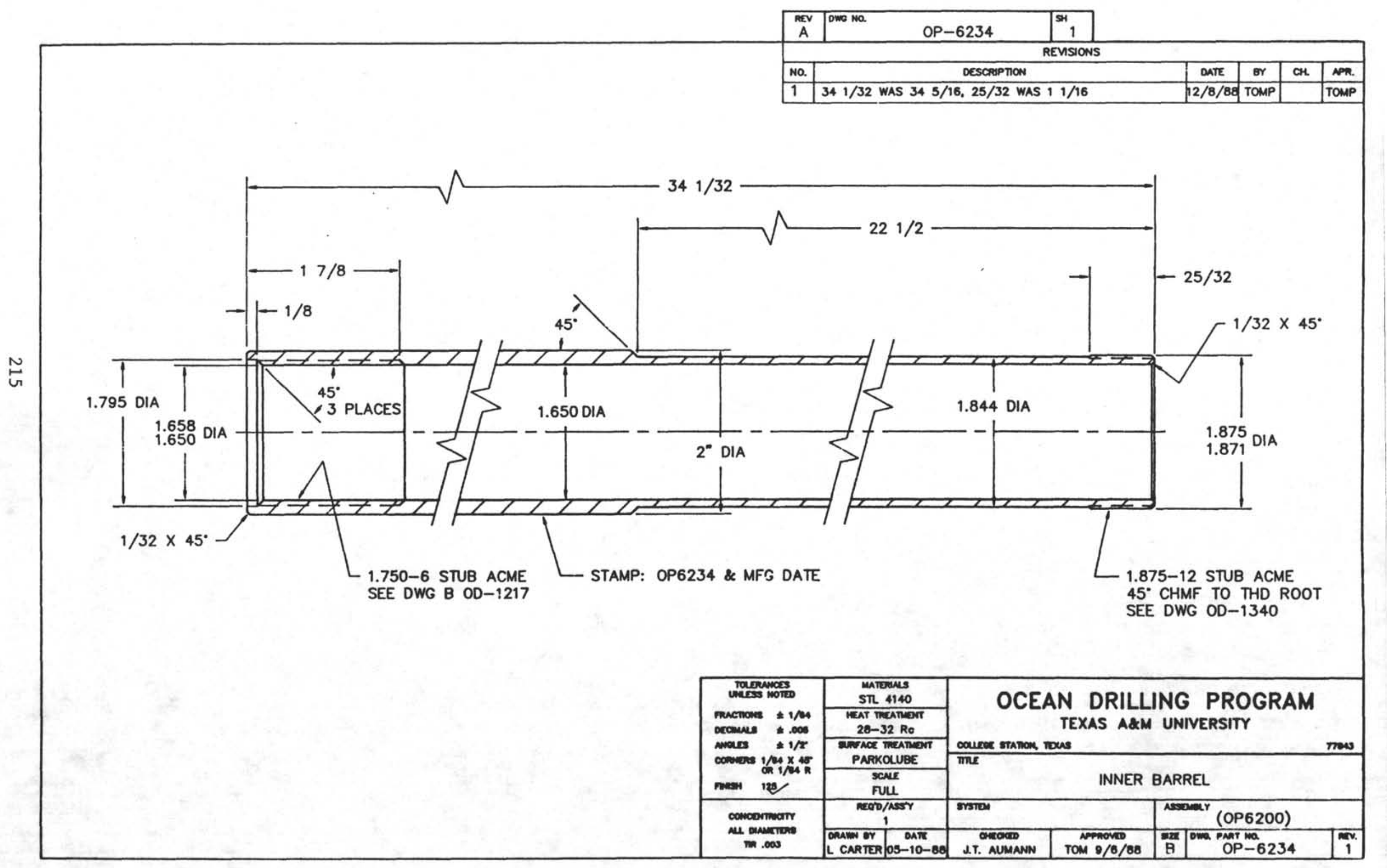




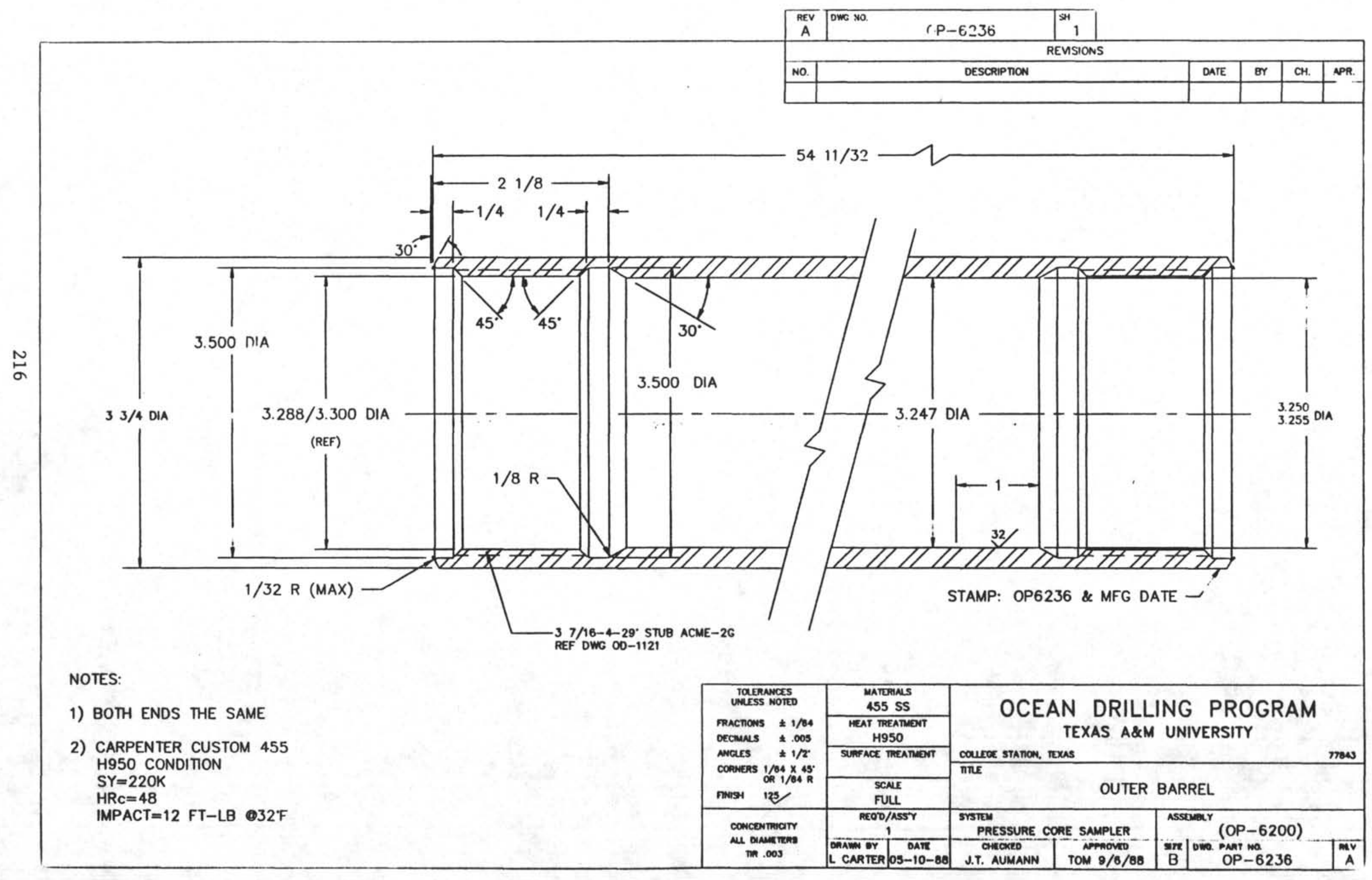




\begin{tabular}{|c|c|c|c|c|c|c|}
\hline & \multicolumn{4}{|c|}{ REVSIONS } \\
\hline NO. & DESCRIPTION & DATE & BY & CH. & APR. \\
\hline 1 & .412 wAS $.343, .990$ WAS $.865, .412$ WAS.343 & $9-30-88$ & ES & $\checkmark$ & foN \\
\hline
\end{tabular}

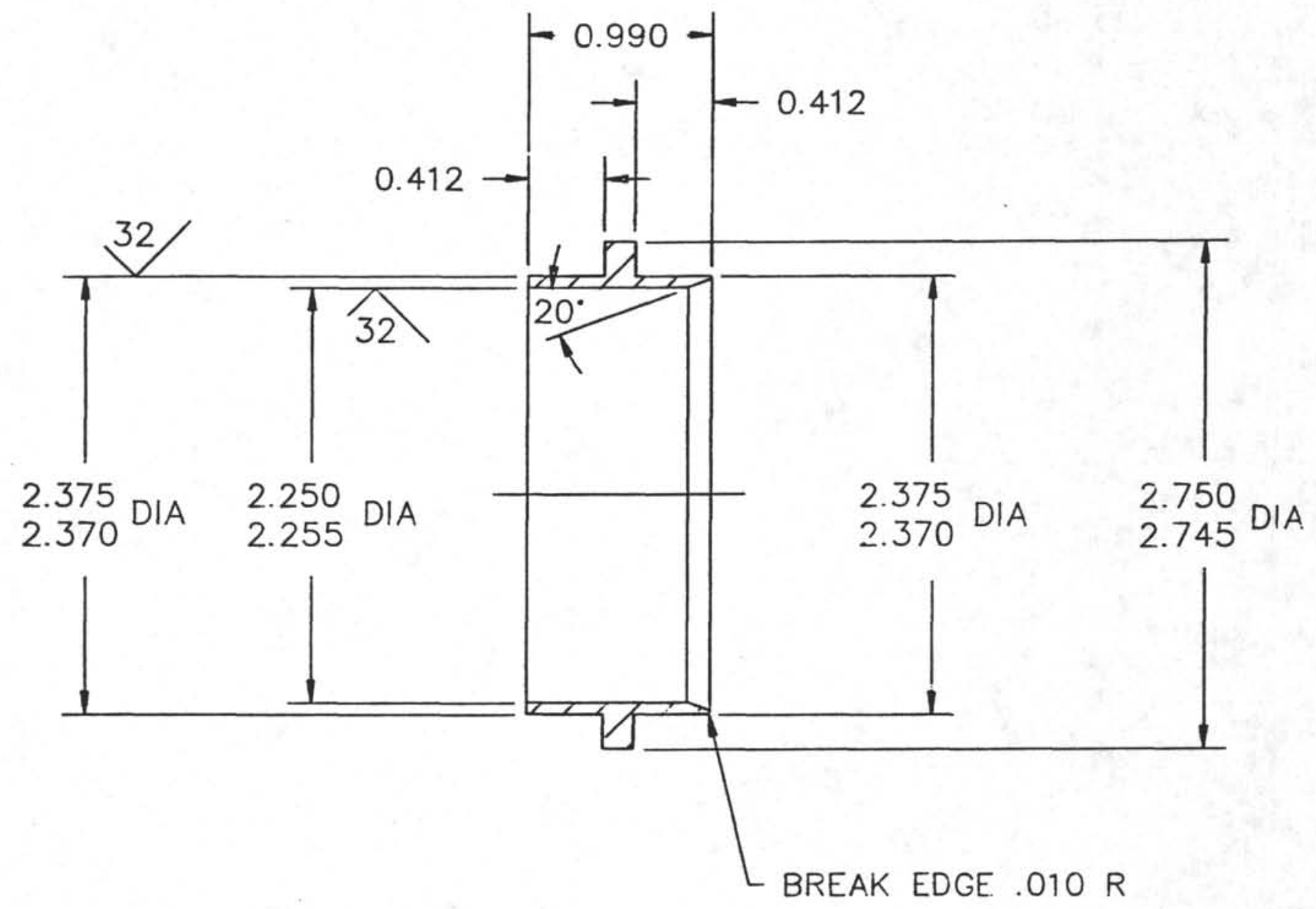

NOTE:

1. TAG W/ OP6242-1\& MFG DATE

\begin{tabular}{|c|c|c|c|c|c|c|c|}
\hline \multirow{2}{*}{\multicolumn{2}{|c|}{$\begin{array}{l}\text { TOLERANCES } \\
\text { UNLESS NOTED }\end{array}$}} & \multirow{2}{*}{$\begin{array}{l}\text { MATERIALS } \\
\text { SST } 410\end{array}$} & \multirow{2}{*}{\multicolumn{5}{|c|}{ OCEAN DRILLING PROGRAM }} \\
\hline & & & & & & & \\
\hline \multirow{3}{*}{$\begin{array}{l}\text { FRACTIONS } \\
\text { DECIMALS } \\
\text { ANGLES } \\
\text { CORNERS }\end{array}$} & \multirow{2}{*}{$\begin{array}{l} \pm 1 / 64 \\
\pm .005 \\
\pm 1 / 2\end{array}$} & $\begin{array}{l}\text { HEAT TREATMENT } \\
25-30 \text { Rc }\end{array}$ & \multicolumn{5}{|c|}{ TEXAS A\&M UNIVERSITY } \\
\hline & & SURFACE TREATMENT & \multicolumn{4}{|c|}{ COLLEGE STATON, TEXAS } & 77843 \\
\hline & $\begin{array}{l}1 / 64 \times 45^{\circ} \\
O R 1 / 64 R\end{array}$ & & $\pi T L E$ & & & & \\
\hline & 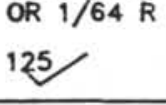 & $\begin{array}{l}\text { SCALE } \\
\text { FULLL }\end{array}$ & \multicolumn{5}{|c|}{ SEAL CARRIER } \\
\hline \multirow{2}{*}{\multicolumn{2}{|c|}{$\begin{array}{c}\text { CONCENIRICITY } \\
\text { ALL DIAMETERS } \\
\text { TIR .003 }\end{array}$}} & REO'D/ASS'Y & \multicolumn{2}{|c|}{$\begin{array}{l}\text { SYSTEM } \\
\text { PRESSURE CORE SAMPLER }\end{array}$} & \multicolumn{3}{|c|}{$\begin{array}{l}\text { ASSEMBLY } \\
(O P-6200)\end{array}$} \\
\hline & & \begin{tabular}{l|c} 
DRAWN BY & DATE \\
L CARTER & $05-11-88$
\end{tabular} & $\begin{array}{l}\text { CHECKED } \\
\text { J.T. AUMANN }\end{array}$ & $\begin{array}{c}\text { APPROVED } \\
\text { TOM } 9 / 6 / 88\end{array}$ & SIZE & $\begin{array}{l}\text { DWG. PART NO. } \\
\text { OP-62 }\end{array}$ & PEV. \\
\hline
\end{tabular}




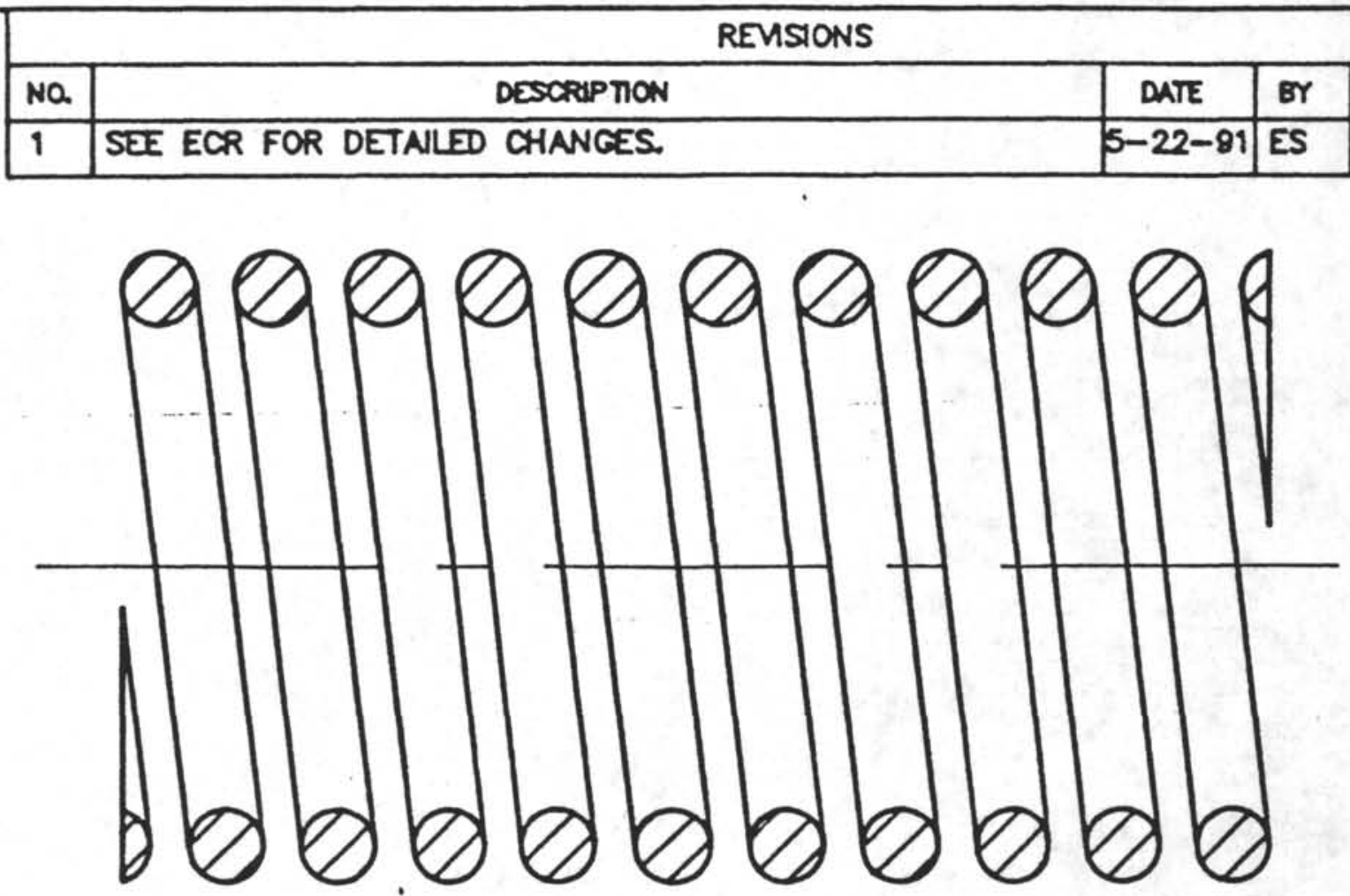

NOTE:

1) THE ABOVE ILLUSTRATION IS FOR CAD ASSEMBLY/MERGE PURPOSES ONLY.

2) TAG W/ OP-6244 \& MFG DATE

\section{SPECIFICATIONS}

1) MATERIAL: $.343^{\prime \prime}$ DIA. BETA-C TITANIUM.

SPRING MUST MTHSTAND SHORT TIME EXPOSURE TO $350^{\circ} \mathrm{C}$

(662F) IN SEA WATER WTH H2S AND $\mathrm{CO} 2$ IN SOLUTIONL

2) SPRING MUST FIT FREELY OVER A $2125^{\circ}$ DIA. ROD WHEN RELAXED.

3) SPRING MUST FTT FREELY WITHIN A $2.875^{\prime \prime}$ DIA. BORE WHEN COMPRESSED SOUD.

4) LOAD AT $5.125^{\circ}$ HEGHT $=300$ LBS. MIN.

5) TOTAL COILS $=11.3$

6) SPRING RATE $=71$ LBS. $/ \mathrm{N}$.

7) SOLD HEGHT $=3.875^{\circ}$ MAX.

8) ENDS CLOSED AND GROUND.

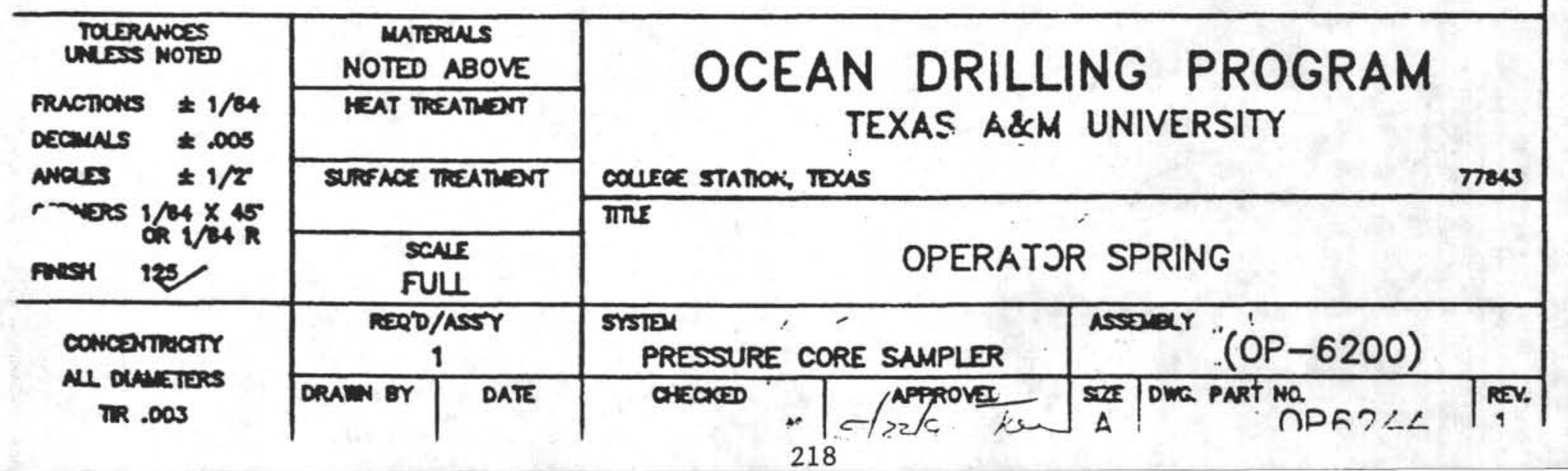




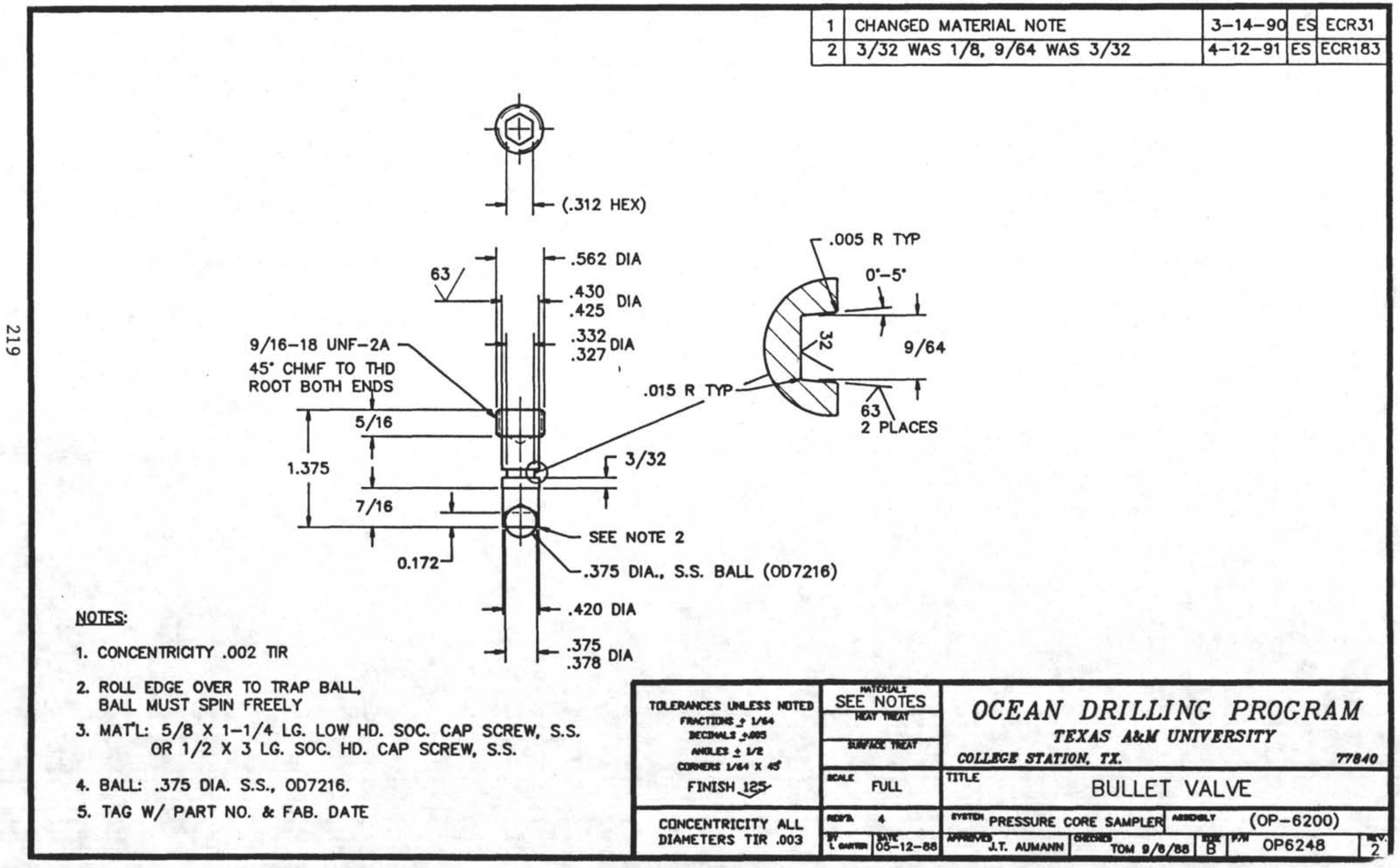




\begin{tabular}{|c|c|c|c|c|c|c|}
\hline & \multicolumn{3}{|c|}{ REVSIONS } \\
\hline NO. & DESCRIP TON & DATE & BY & CH. & APR. \\
\hline & & & & & \\
\hline
\end{tabular}

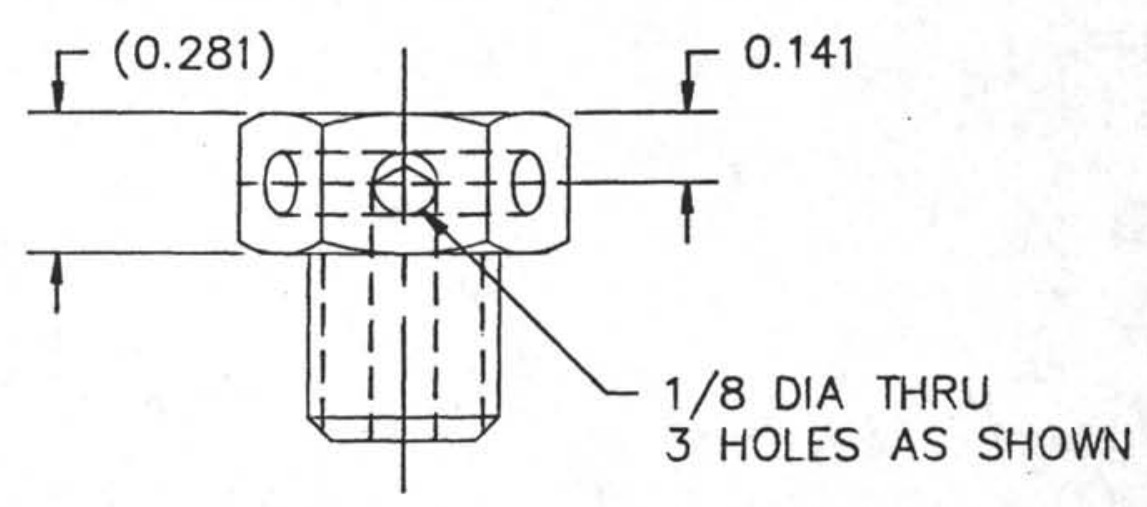

NOTE:

1) TAG W/ OP-6250 \& MFG DATE

2) MATERIAL: $3 / 8-16 \times 3 / 8$ LG HEX HD CAP SCREW

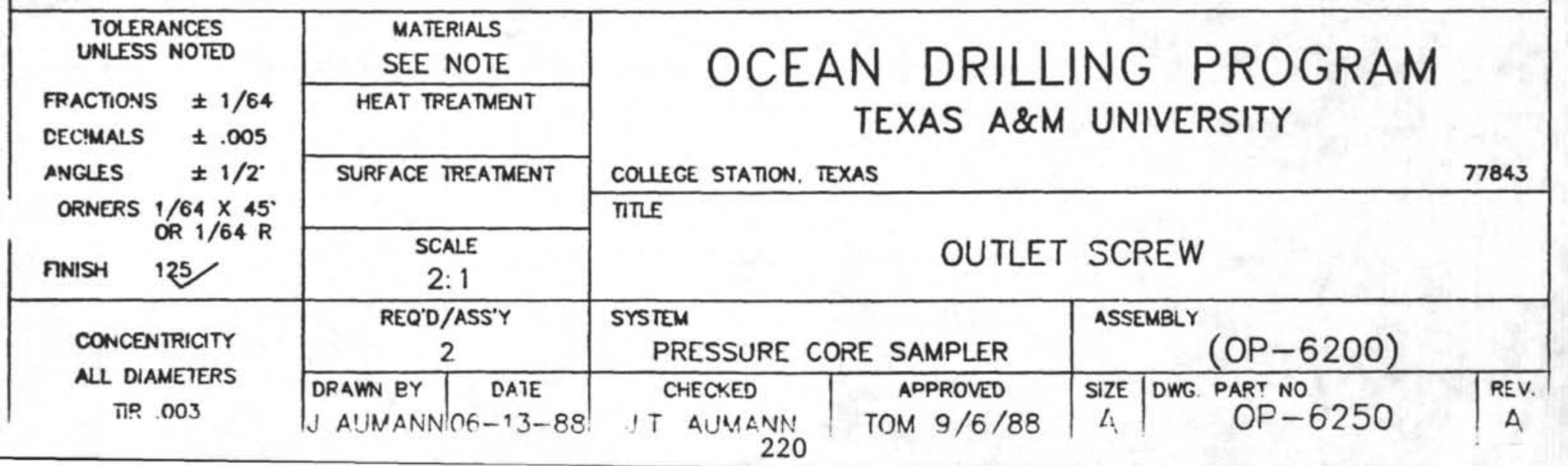




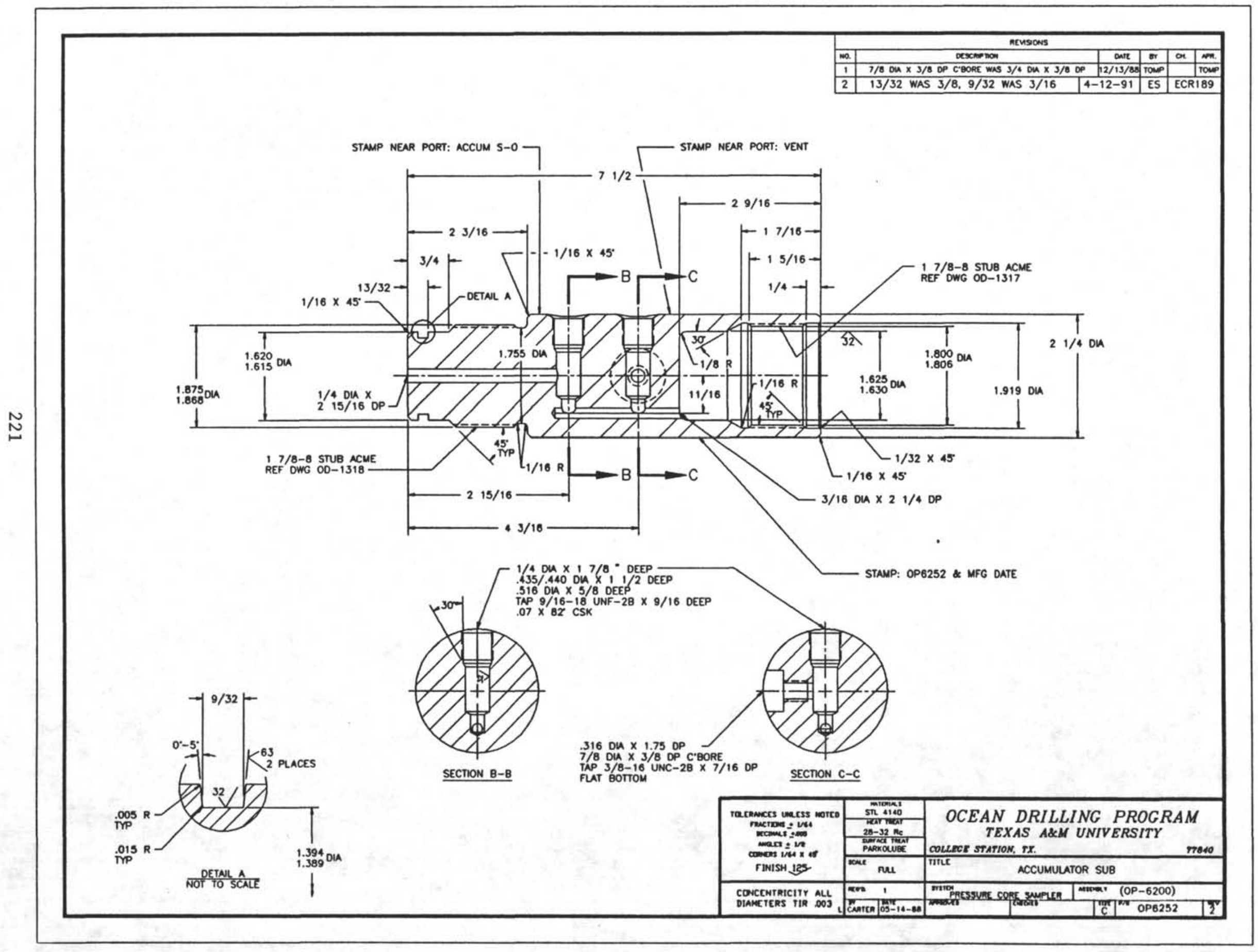




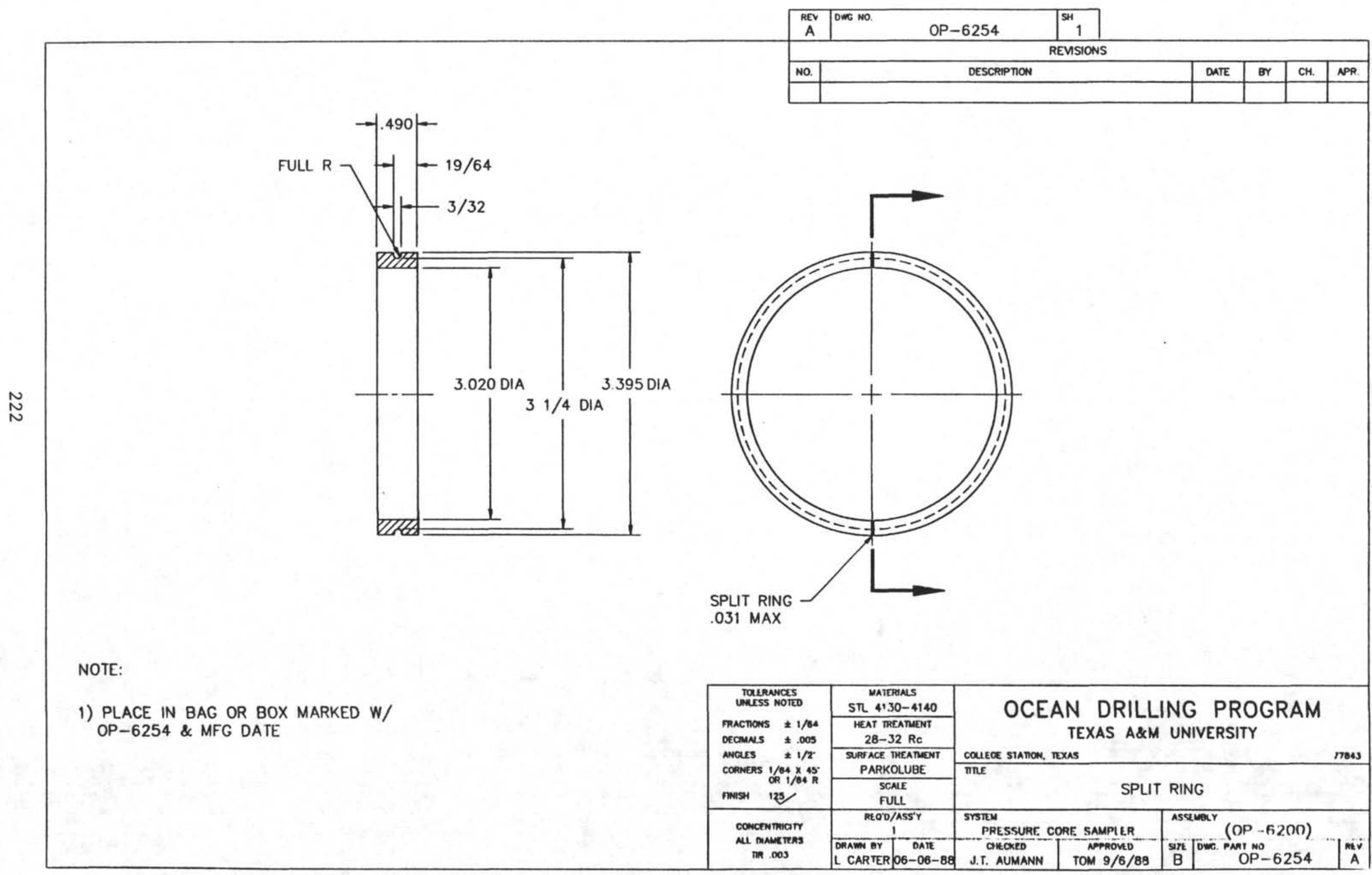




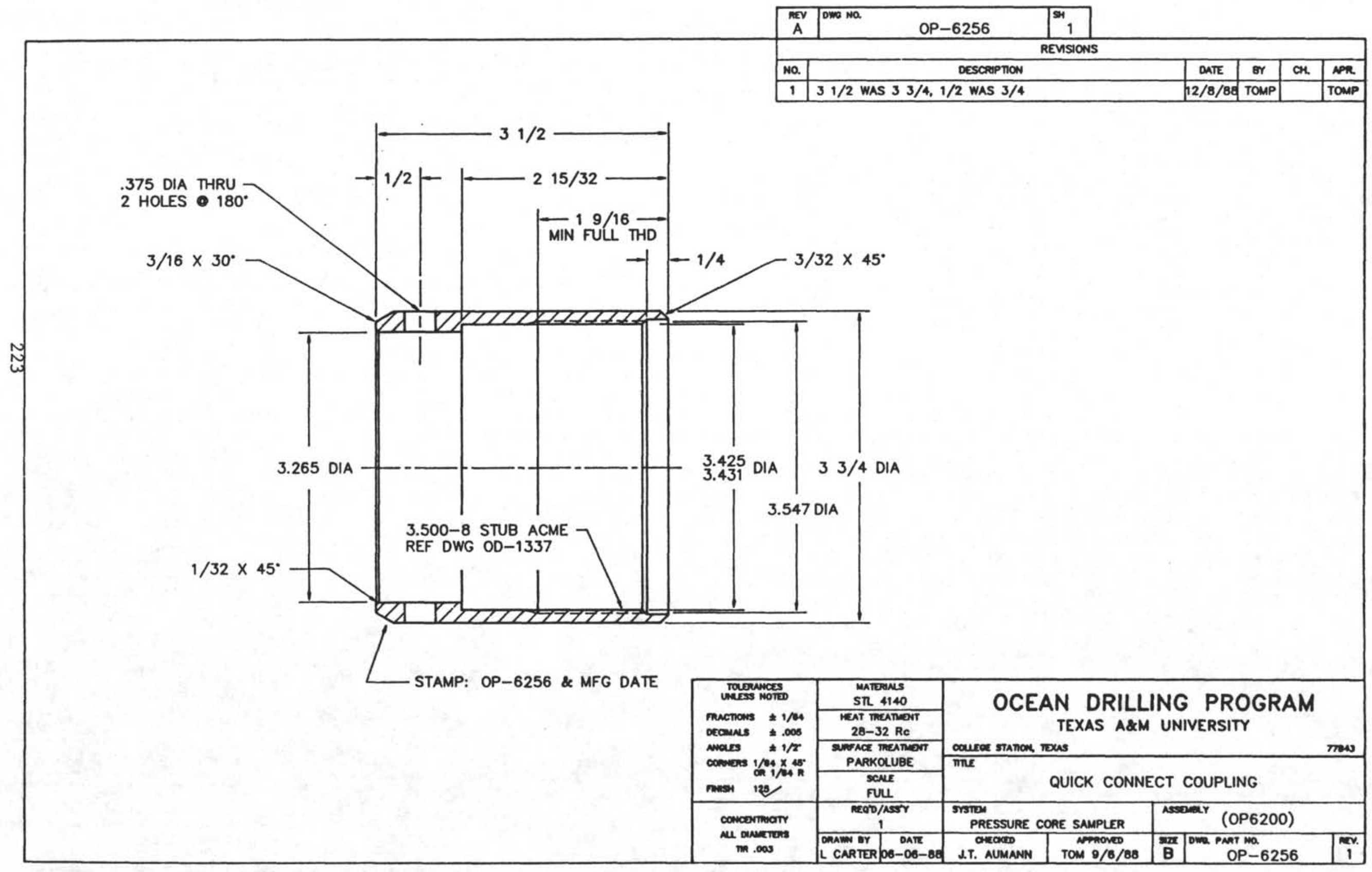




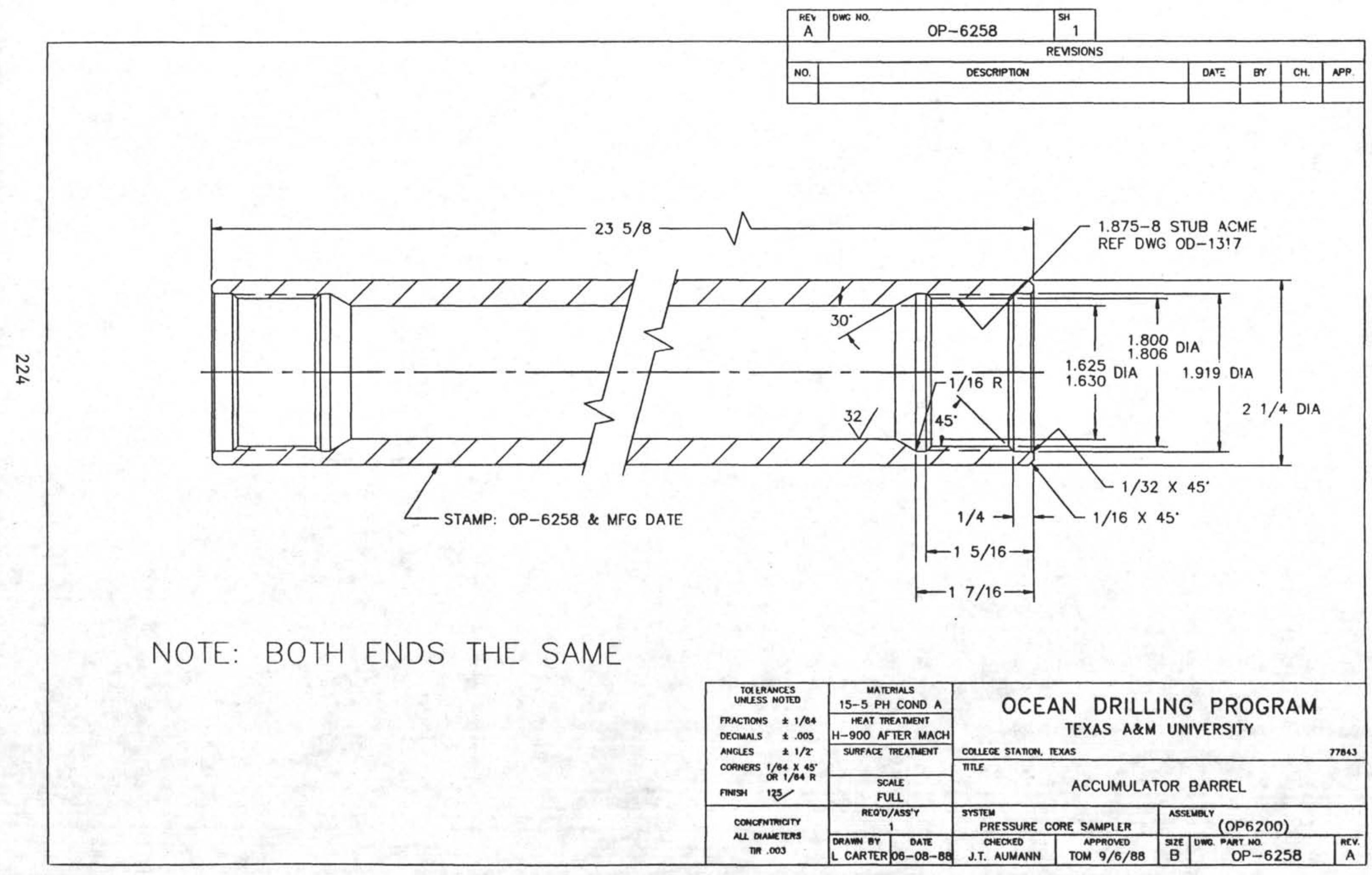




\begin{tabular}{|c|c|c|c|c}
\hline REMSIONS \\
\hline NO. & DESCRIPTON & DATE & BY & \\
\hline 1 & $1 / 2$ WAS $7 / 16,9 / 32$ WAS $3 / 16$ 0-RING GROOVE & $4-91$ & ES & ECR190 \\
\hline
\end{tabular}

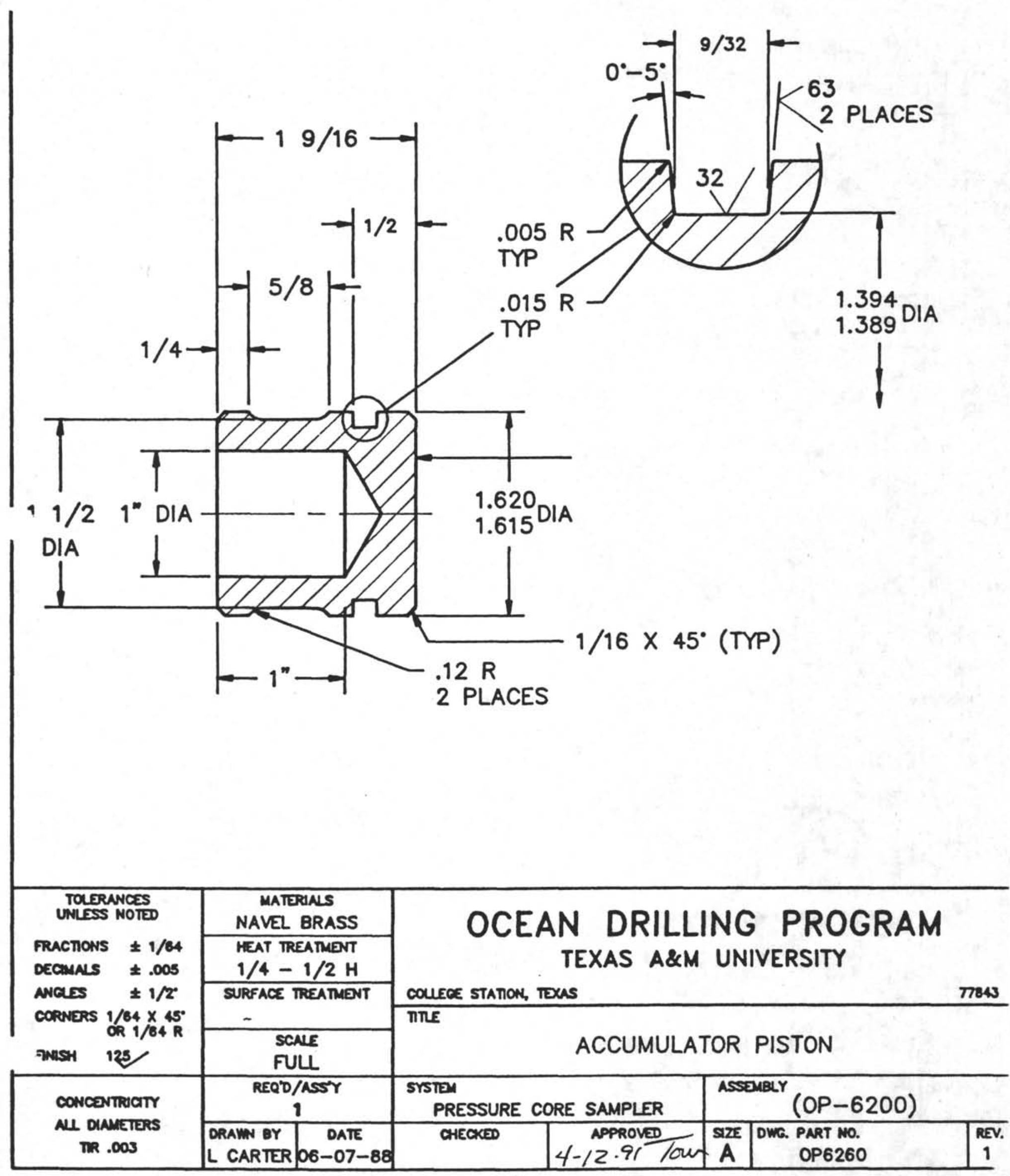




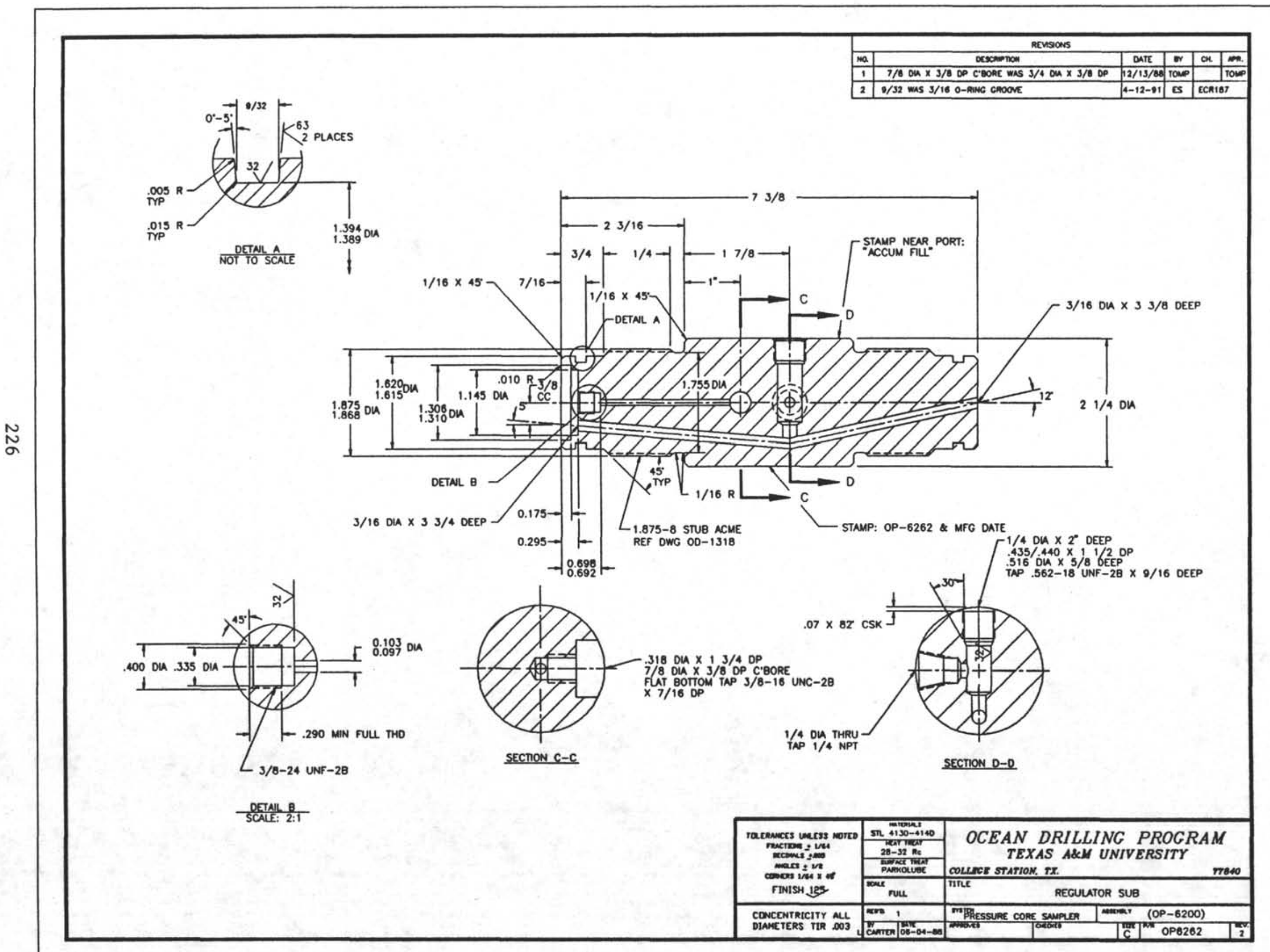




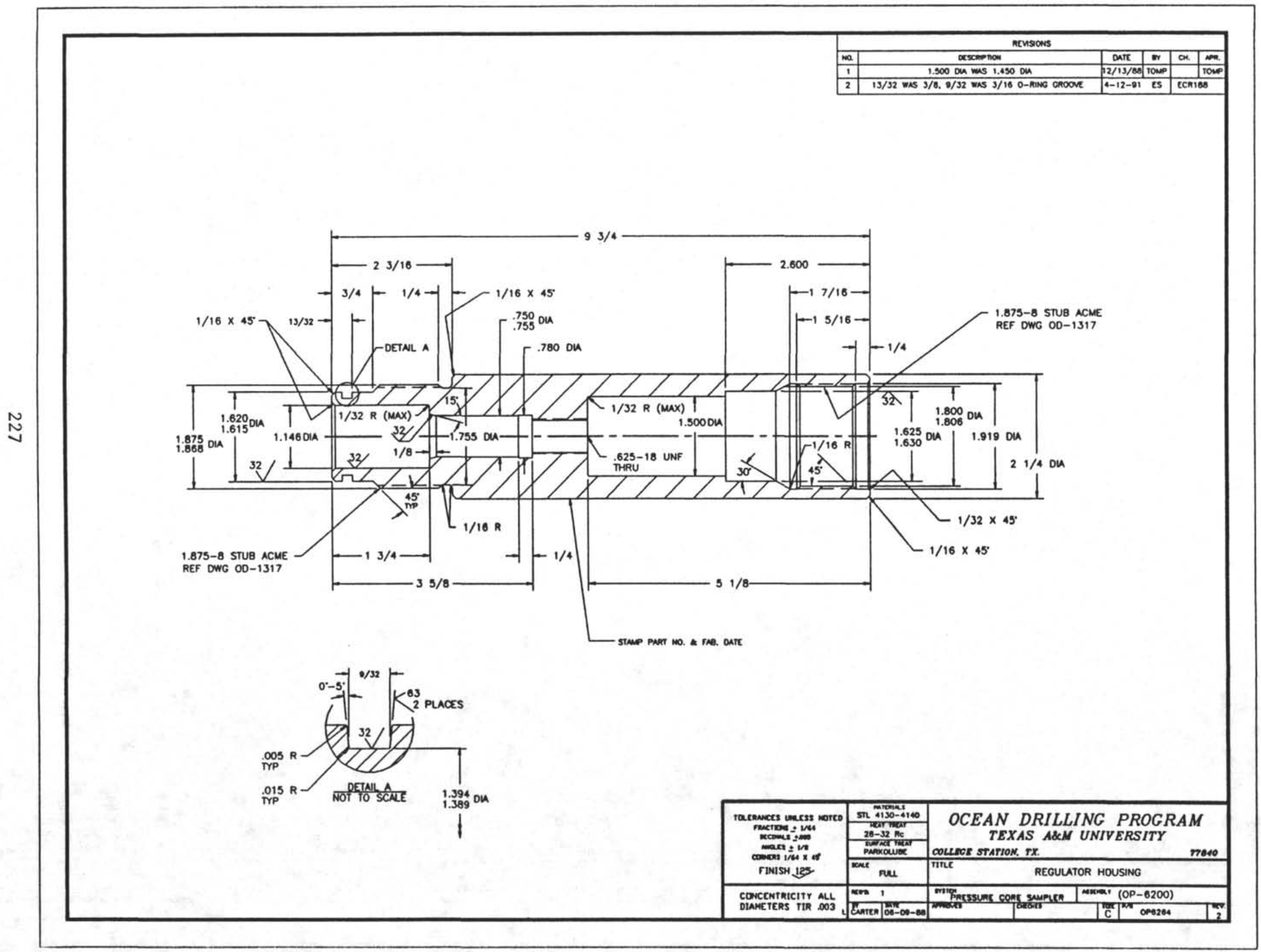




\begin{tabular}{|c|c|c|c|c|c|c|}
\hline \multicolumn{3}{|c|}{ REVSIONS } \\
\hline NO. & DESCRIPTON & DATE & BY & CH. & AFR. \\
\hline & & & & & \\
\hline
\end{tabular}

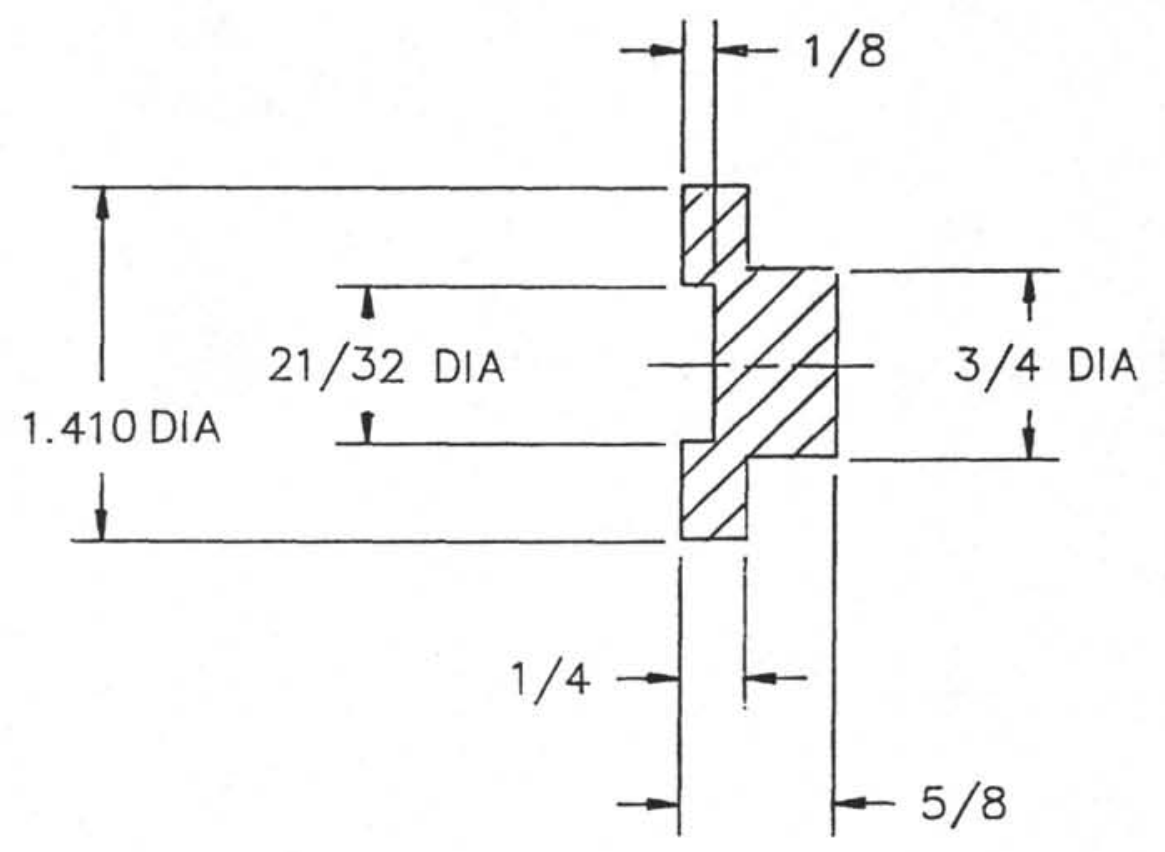

NCTE:

1) PLACE IN BAG OR BOX MARKED W/ OP-6266 \& MFG DATE

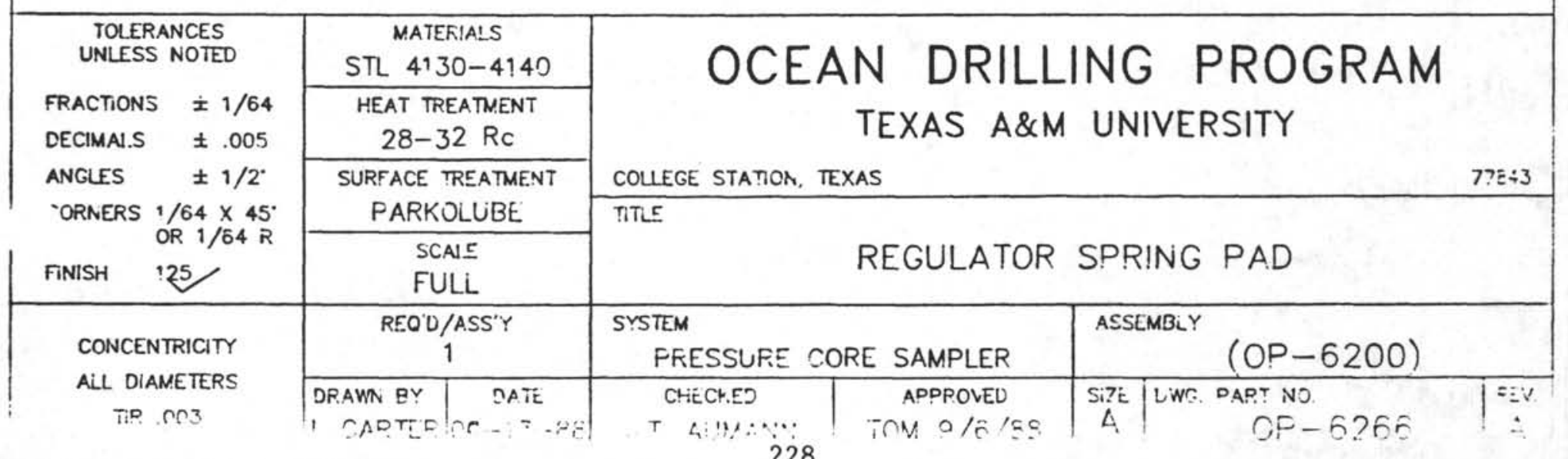




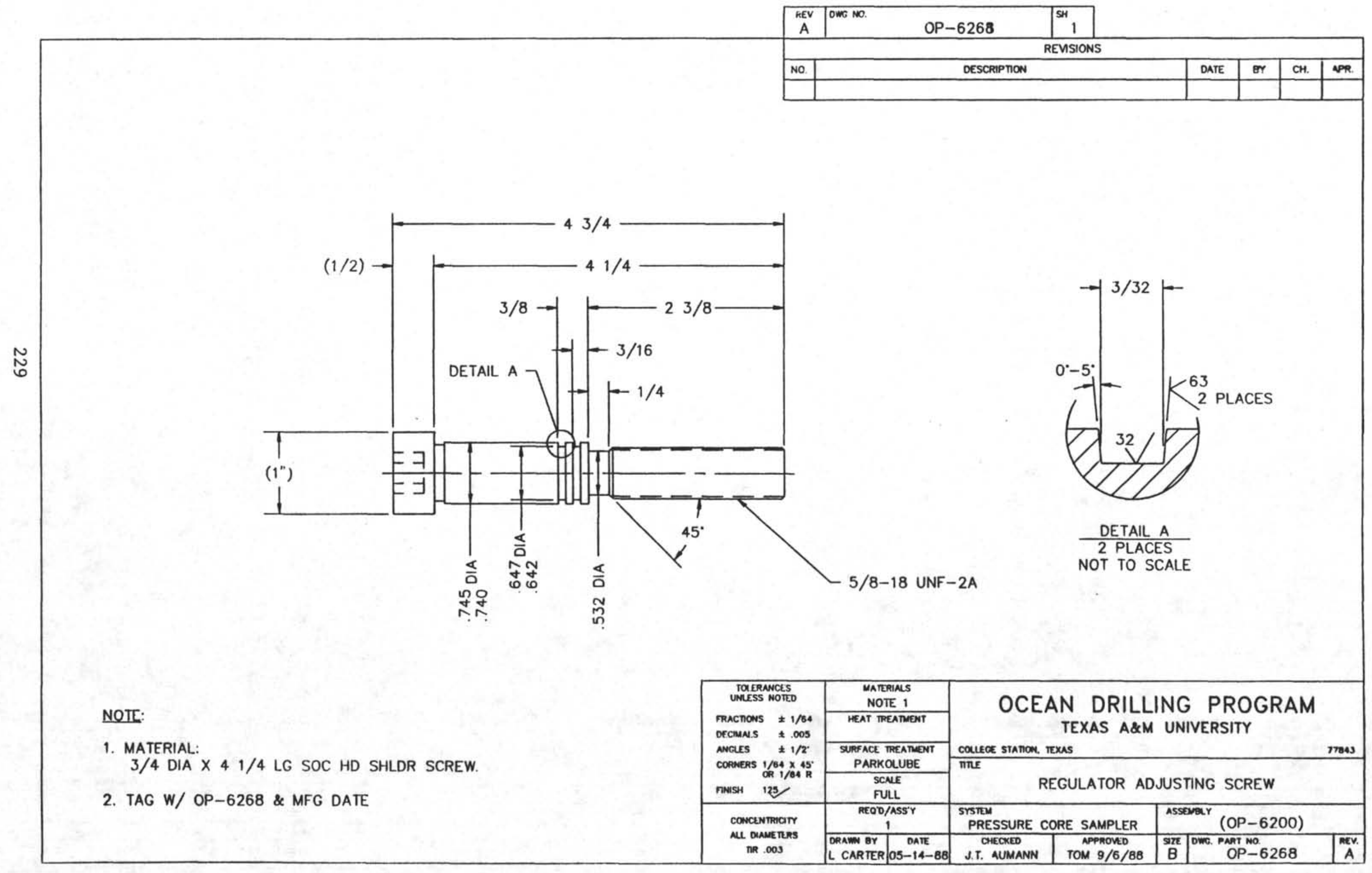




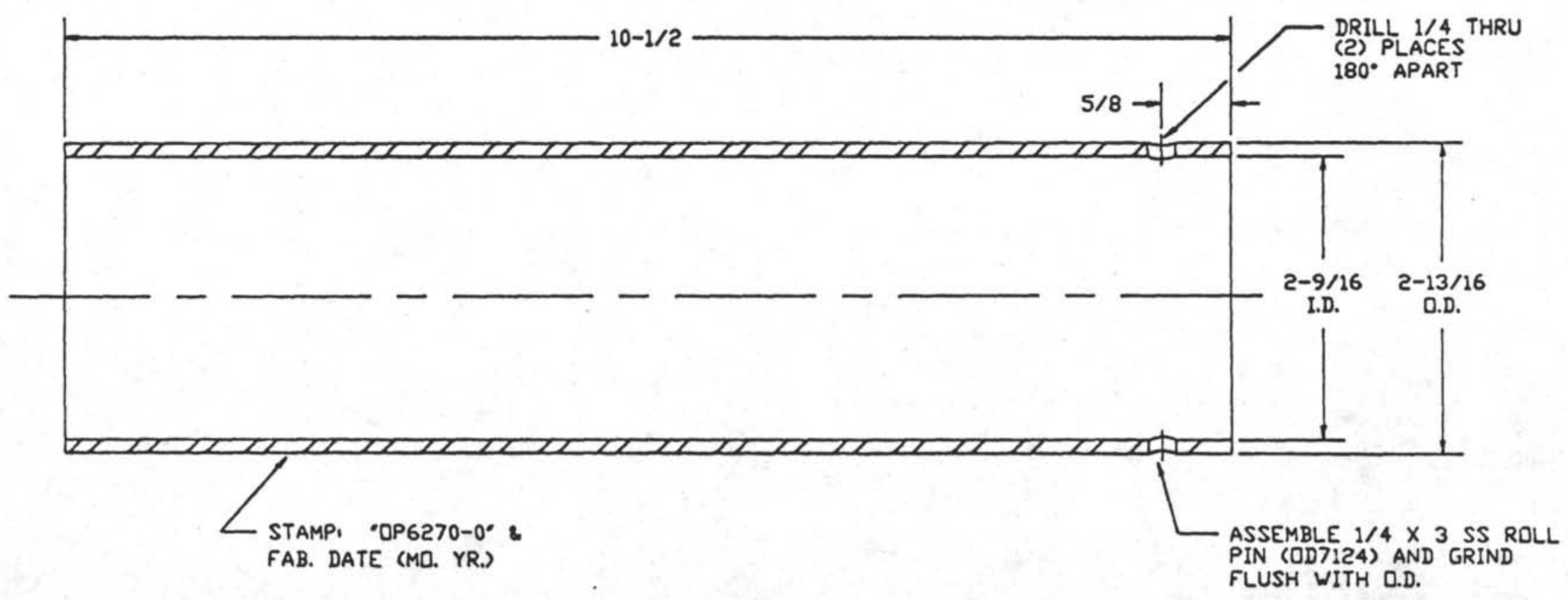

\begin{tabular}{|c|c|c|}
\hline \multirow{2}{*}{ 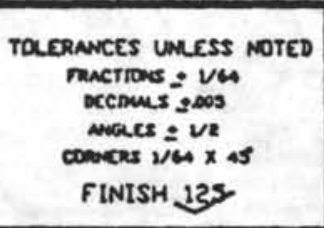 } & 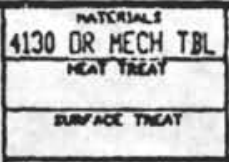 & $\begin{array}{l}\text { OCEAN DRILLING PROGRAM } \\
\text { TEXAS A\&LN UNIVERSITY } \\
\text { COLLECE STATION, TX. }\end{array}$ \\
\hline & sone & PCS KICKDUT BODY \\
\hline \multirow{2}{*}{$\begin{array}{l}\text { CONCENTRICITY ALL } \\
\text { DIAMETERS TIR } .003\end{array}$} & $\infty$ & (DP6200) \\
\hline & pec & \\
\hline
\end{tabular}


STD. INNER BBL. THD. SEE DWG. WOD1000

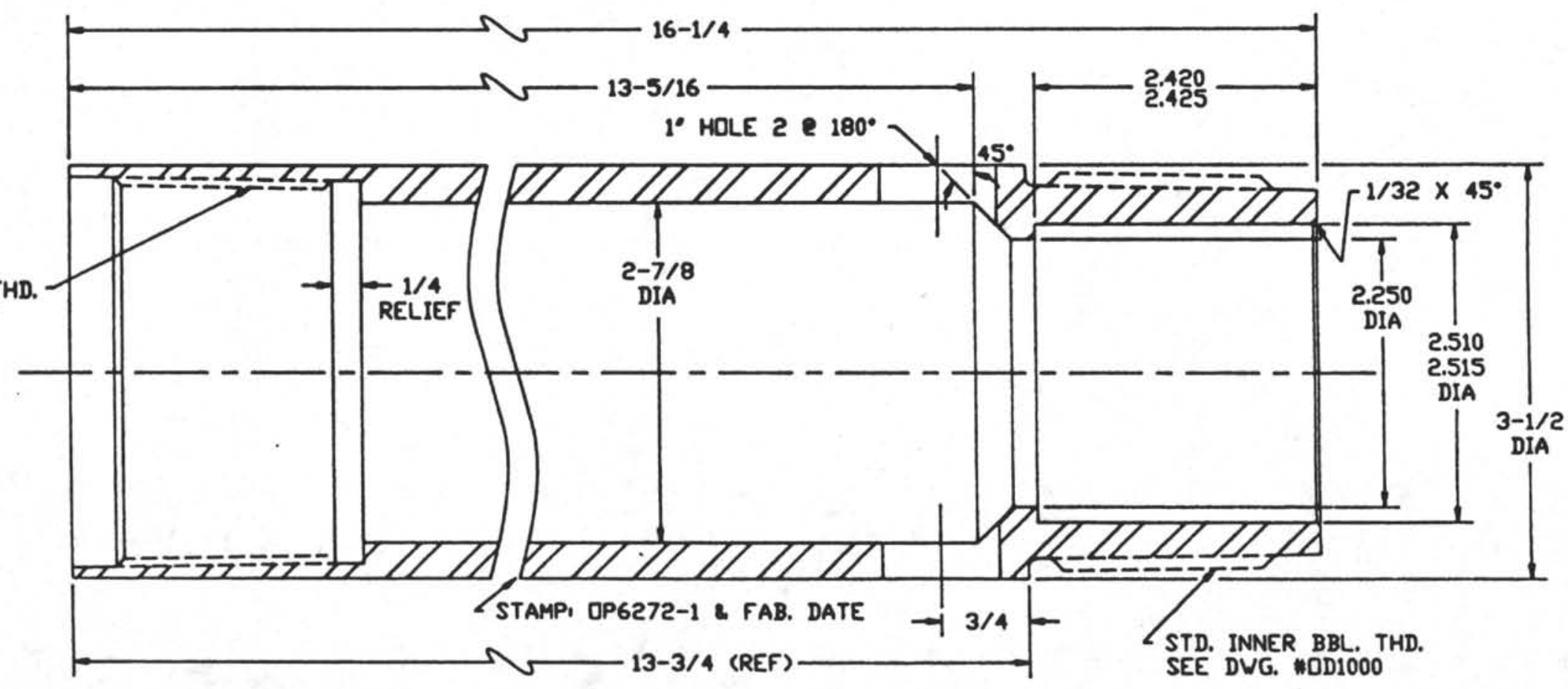

\begin{tabular}{|c|c|c|}
\hline \multirow{2}{*}{ 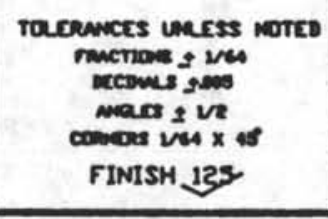 } & $\begin{array}{c}4130 \text { RR } 4140 \\
R C 28-32 \\
R \\
\end{array}$ & $\begin{array}{c}\text { OCEAN } \\
\text { TEXAS ARN UNTVERSITY }\end{array}$ \\
\hline & FULL & PCS CDLLET SUB \\
\hline CONCENTRICITY ALL & $\min$ & (DP6200) \\
\hline
\end{tabular}




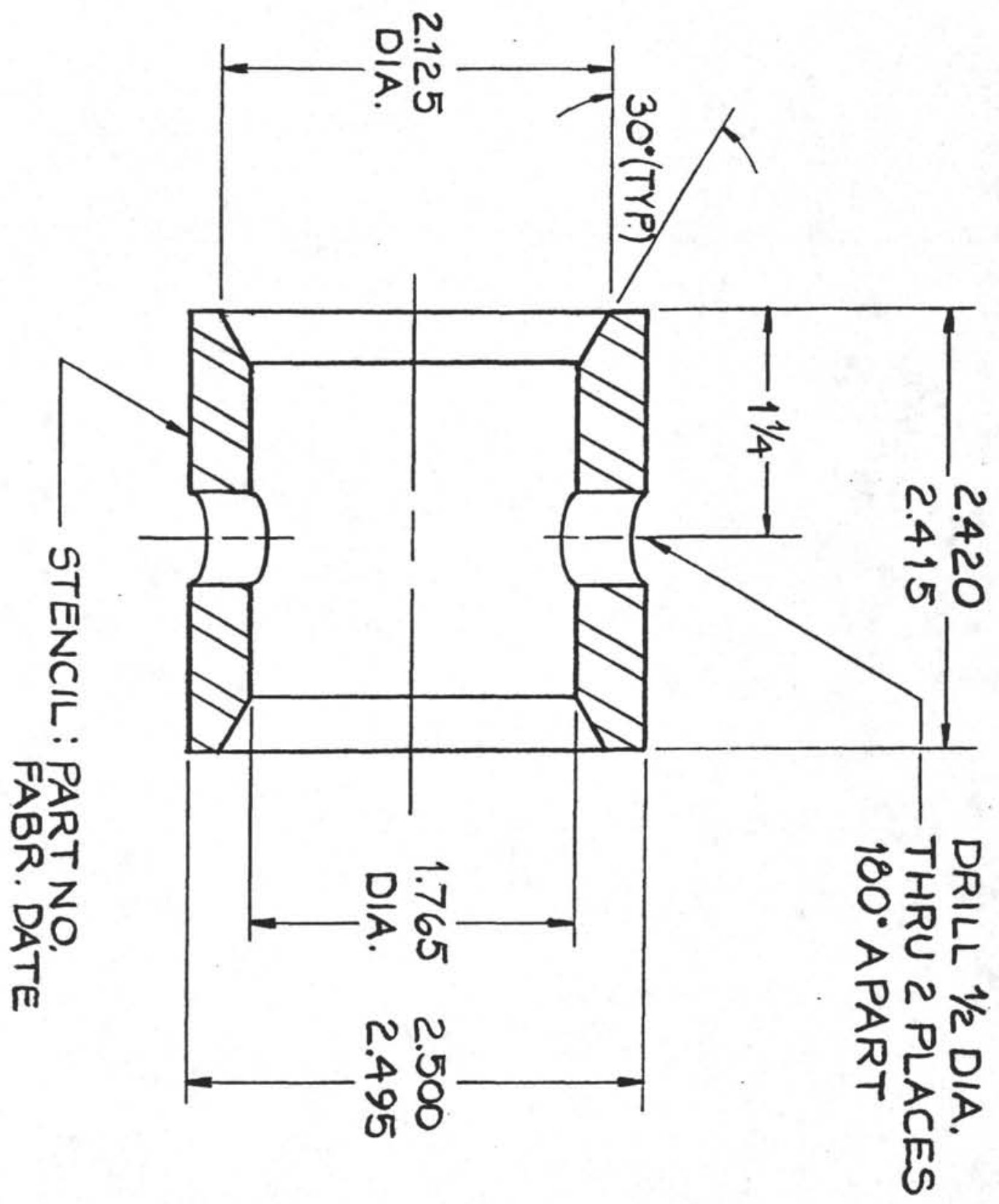

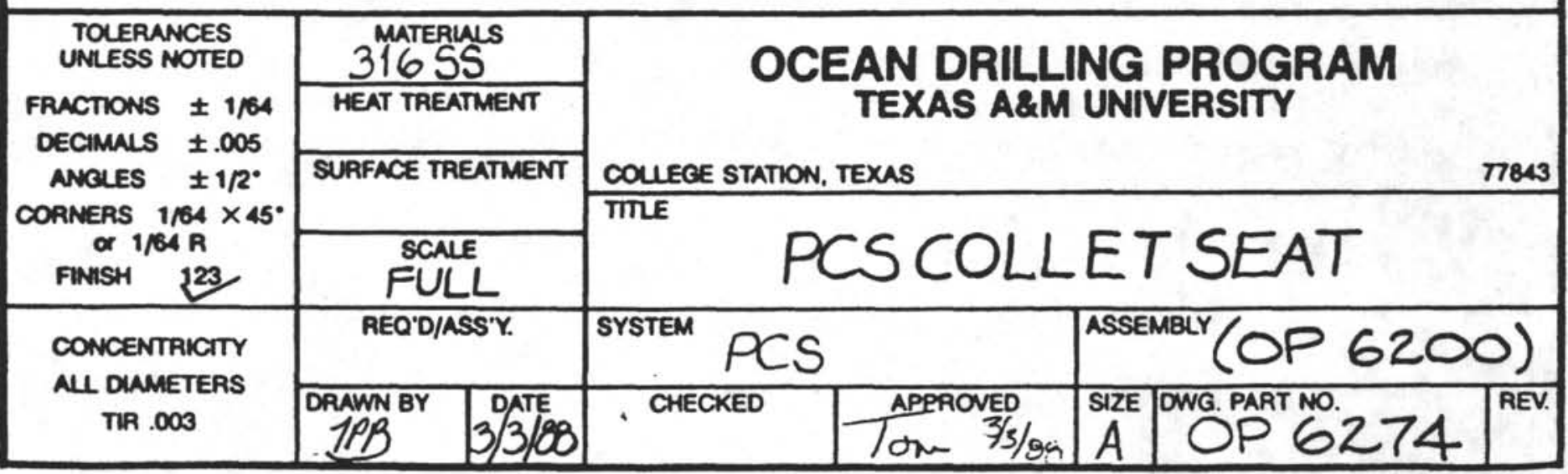




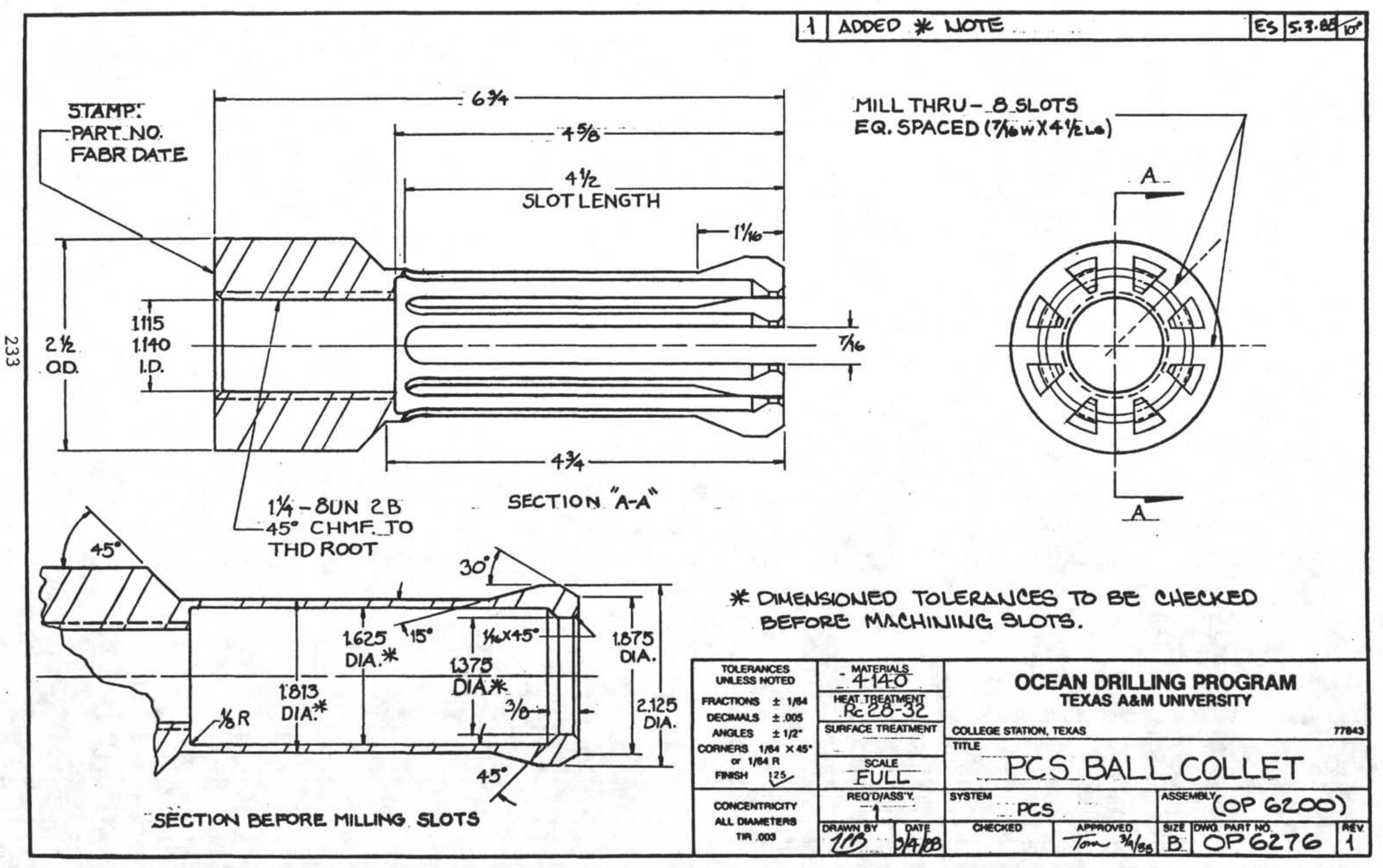




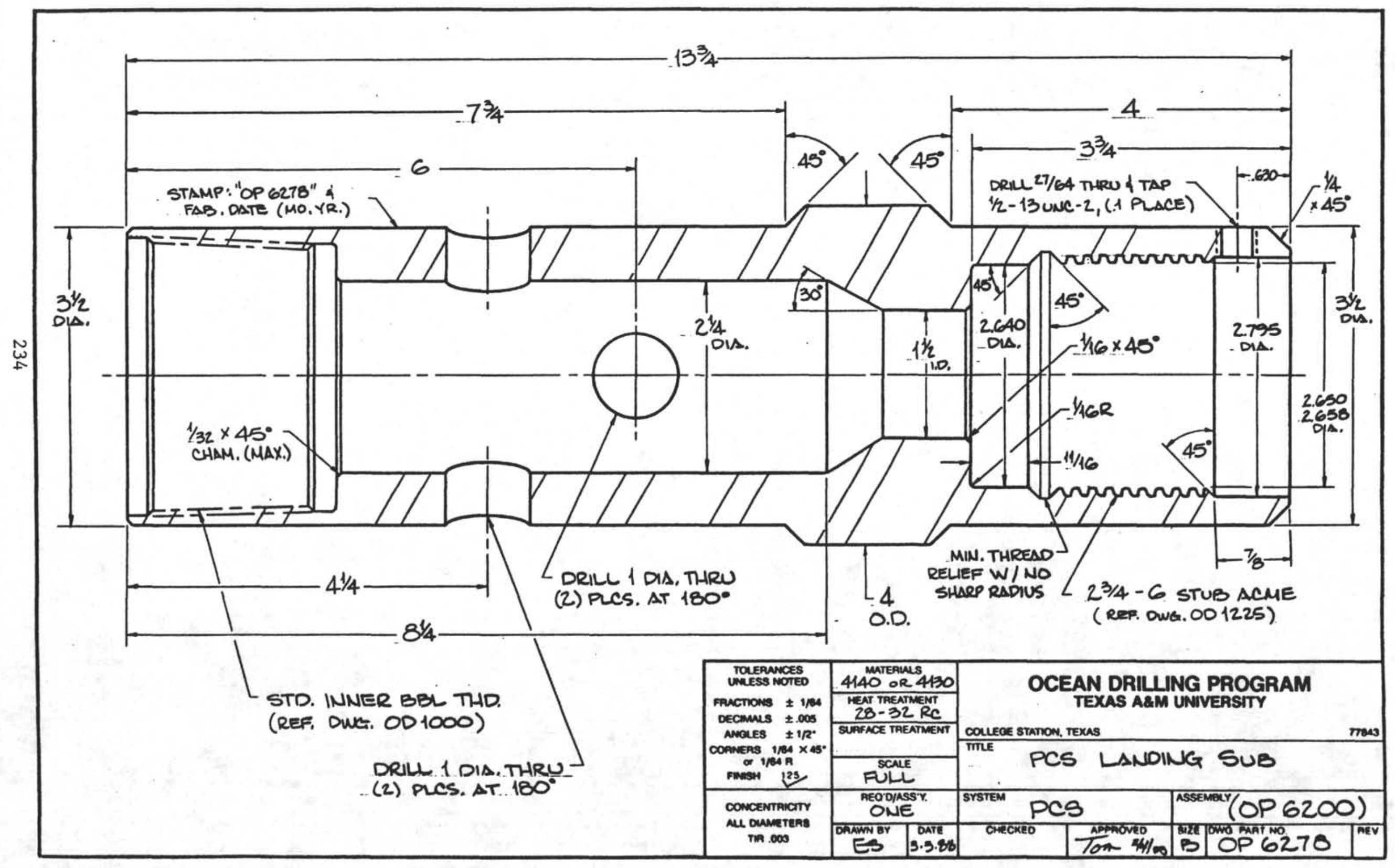



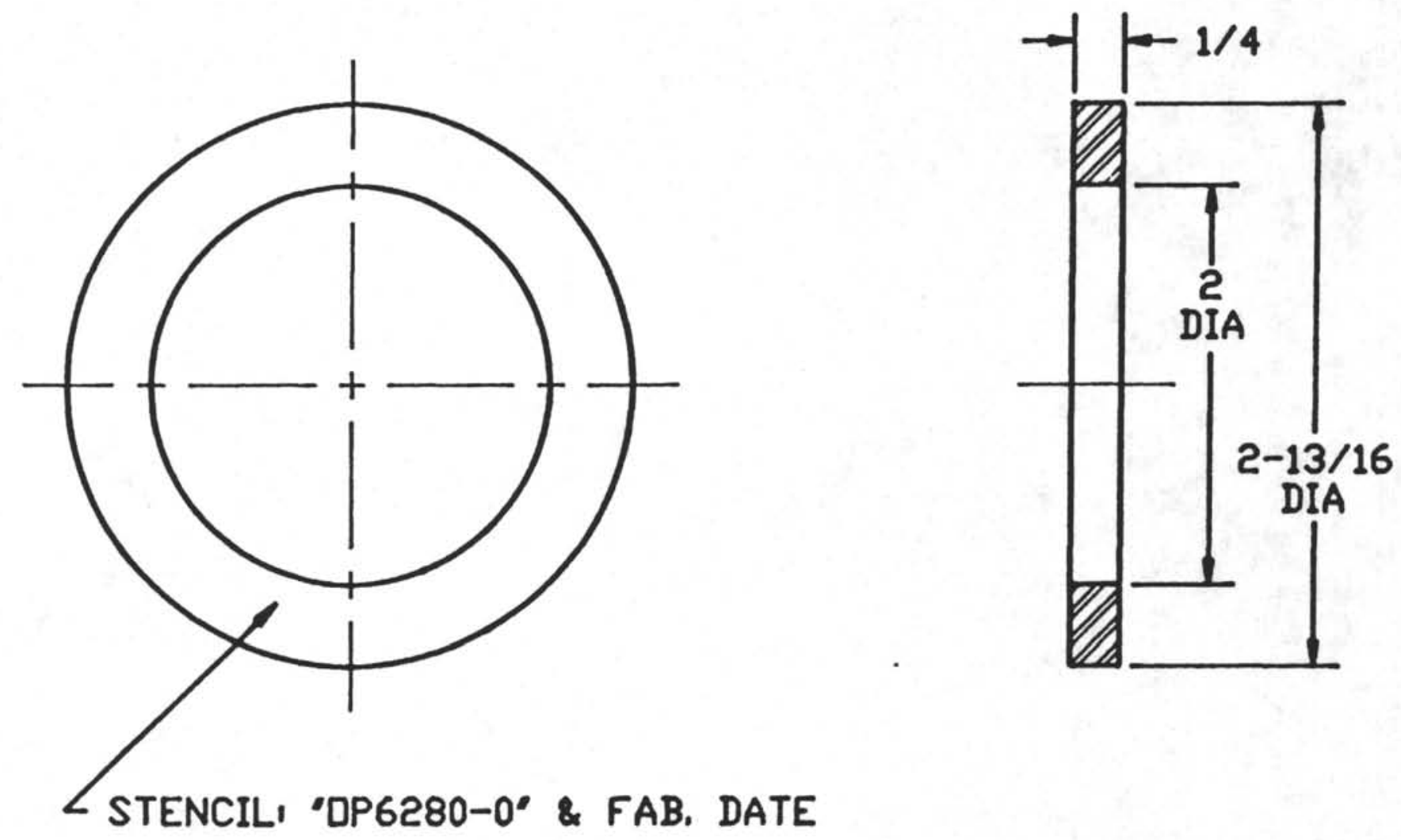

TOERANCES UNESS NOTED mactions \& 2res cocours seos nase $\pm 2 / 2$ concers ves $\times$ is FINISH 135

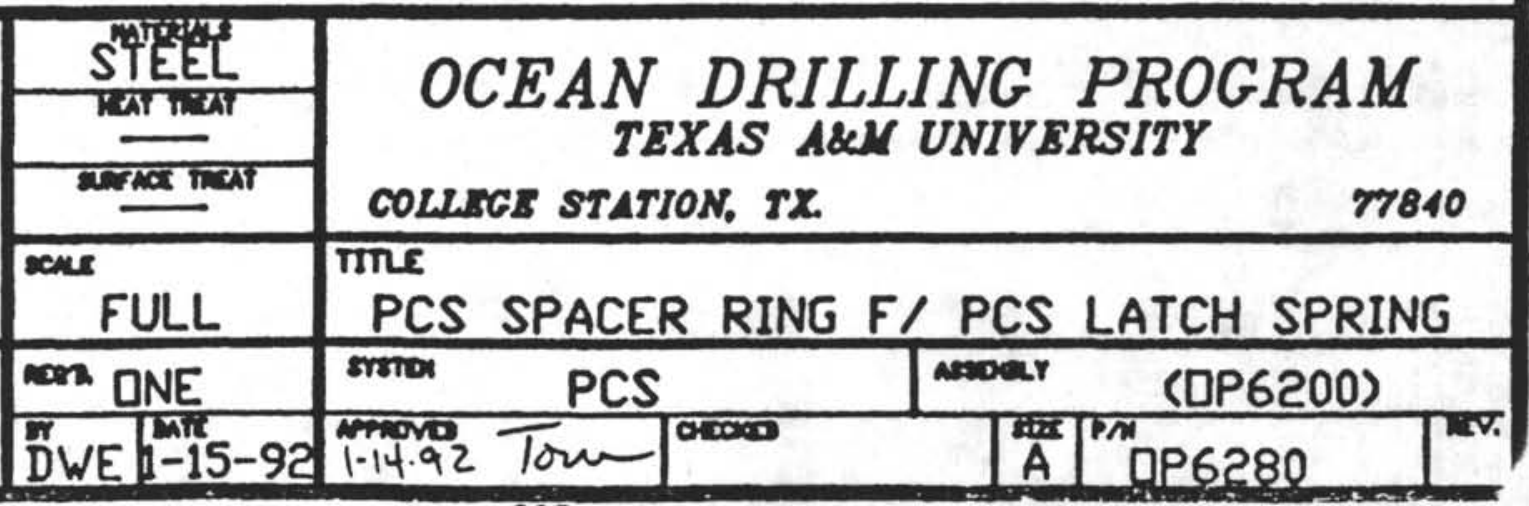




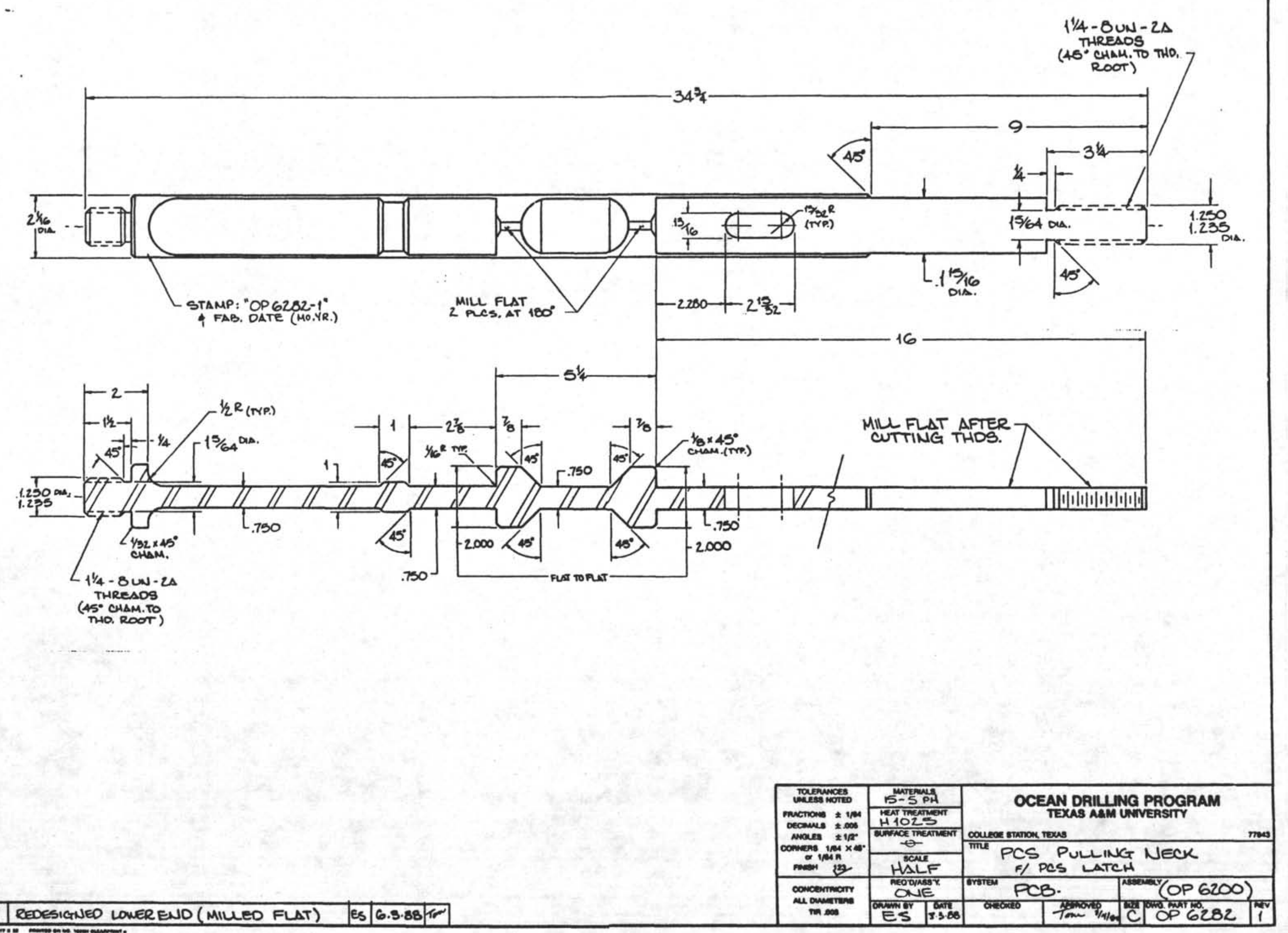




\begin{tabular}{|l|l|l|l|l|}
\hline \multicolumn{5}{|c|}{ REMSIONS } \\
\hline NO. & DESCRIPTON & DATE & BY & \\
\hline 1 & SEE ECR FOR DETAILED CHANGES & $5-22-91$ & ES & ECR 229 \\
\hline
\end{tabular}

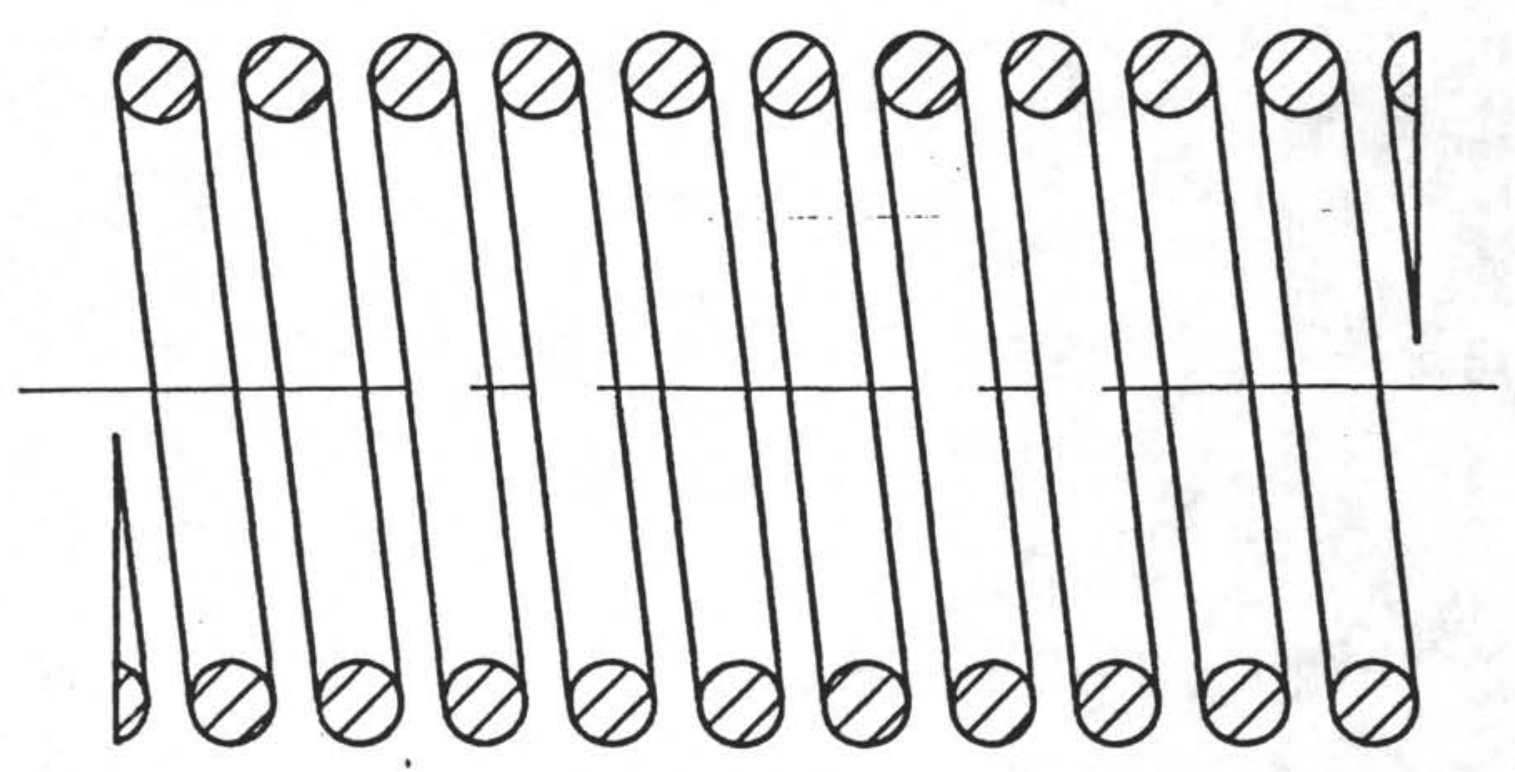

NOTE:

1) THE ABOVE ILLUSTRATION IS FOR CAD ASSEMBLY/MERGE PURPOSES ONLY.

2) TAG W/ OP6284 \& MFG. DATE

\section{SPECIFICATIONS}

1) MATERIAL: .218" DIA. BETA-C TITANIUM

SPRING MUST WTHSTAND SHORT TIME EXPOSURE TO $350^{\circ} \mathrm{C}$

(662F) SEA WATER WTH H2S AND CO2 IN SOLUTION.

2) SPRING MUST FIT FREELY OVER A $2.063^{\prime \prime}$ DIA. ROD WHEN RELAXED.

3) SPRING MUST FIT WTHIN A $2563^{\text {ph }}$ DIA. BORE WHEN COMPRESSED SOLD.

4 LOAD AT 5.3" HEIGHT = 100 LBS. MIN.

5) TOTAL COILS $=13.3$

6) SPRING RATE $=12$ LBS. $/ \mathrm{N}$.

7) SOLD HEIGHT $=3.625^{\prime \prime}$ MAX.

8) ENDS CLOSED AND GROUND.

\begin{tabular}{|c|c|c|c|c|c|c|}
\hline \multirow{2}{*}{\multicolumn{2}{|c|}{ 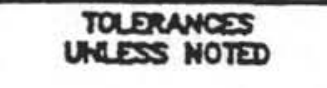 }} & \multicolumn{2}{|c|}{ MATISRNS } & \multirow{3}{*}{\multicolumn{3}{|c|}{$\begin{array}{c}\text { OCEAN DRILLIVG PROSRAM } \\
\text { TEXAS A\&M UNIVERSITY }\end{array}$}} \\
\hline & & \multirow{2}{*}{\multicolumn{2}{|c|}{$\begin{array}{l}\text { NOTED ABOVE } \\
\text { BEAT TEEATMENT }\end{array}$}} & & & \\
\hline \multirow{4}{*}{\multicolumn{2}{|c|}{ 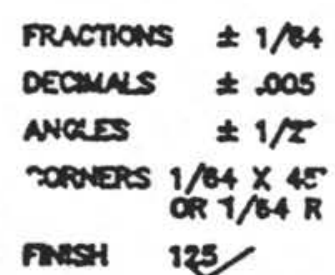 }} & & & & & \\
\hline & & \multicolumn{2}{|c|}{ SURACE TESATMET } & \multicolumn{2}{|c|}{ couroe station, TDES Trow } & $\pi 7343$ \\
\hline & & \multicolumn{2}{|c|}{ SUFACE TREATMET } & \multirow{2}{*}{\multicolumn{3}{|c|}{ घारद }} \\
\hline & & & & & & \\
\hline \multirow{2}{*}{\multicolumn{2}{|c|}{ 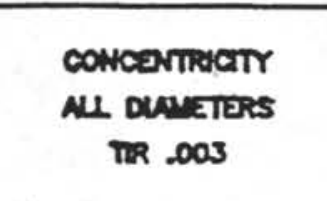 }} & \multicolumn{2}{|c|}{$\begin{array}{c}\text { ReOD/ASST } \\
1\end{array}$} & $\begin{array}{l}\text { STSTEM } \\
\text { PRESSURE CÓRE SAMPLER }\end{array}$ & ASSEMSYY ' $(O P-6200)$ & \\
\hline & & DRANA $8 Y$ & DATE & 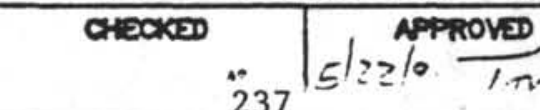 & \begin{tabular}{|l|l|} 
STI & DWG PART Ma \\
OP 6284
\end{tabular} & $\frac{1}{1}$ \\
\hline
\end{tabular}




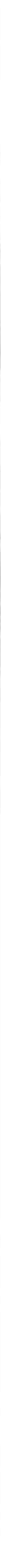




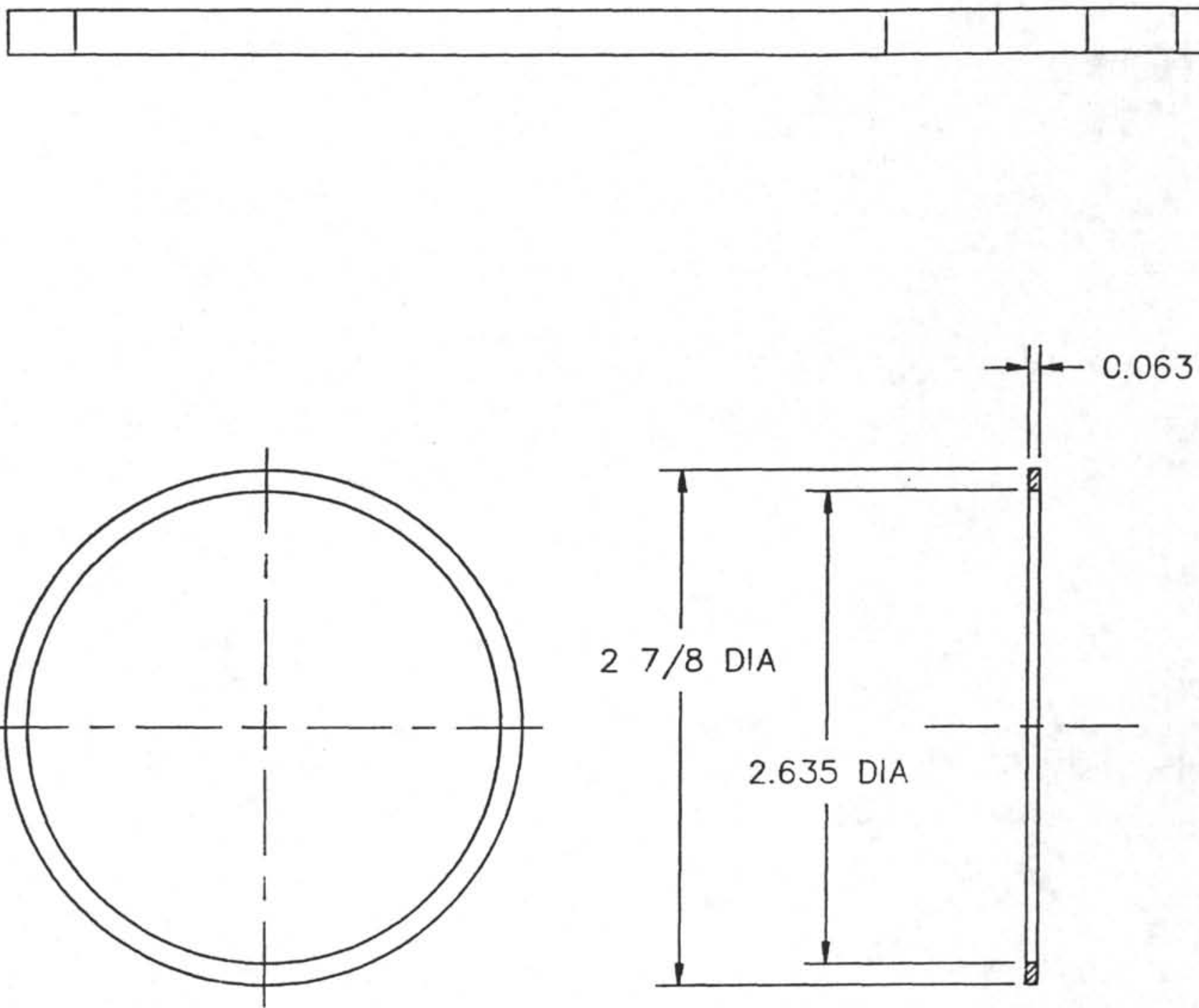

NOTE:

1) PLACE IN BAG OR BOX MARKED W/ OP-6288 \& MFG DATE

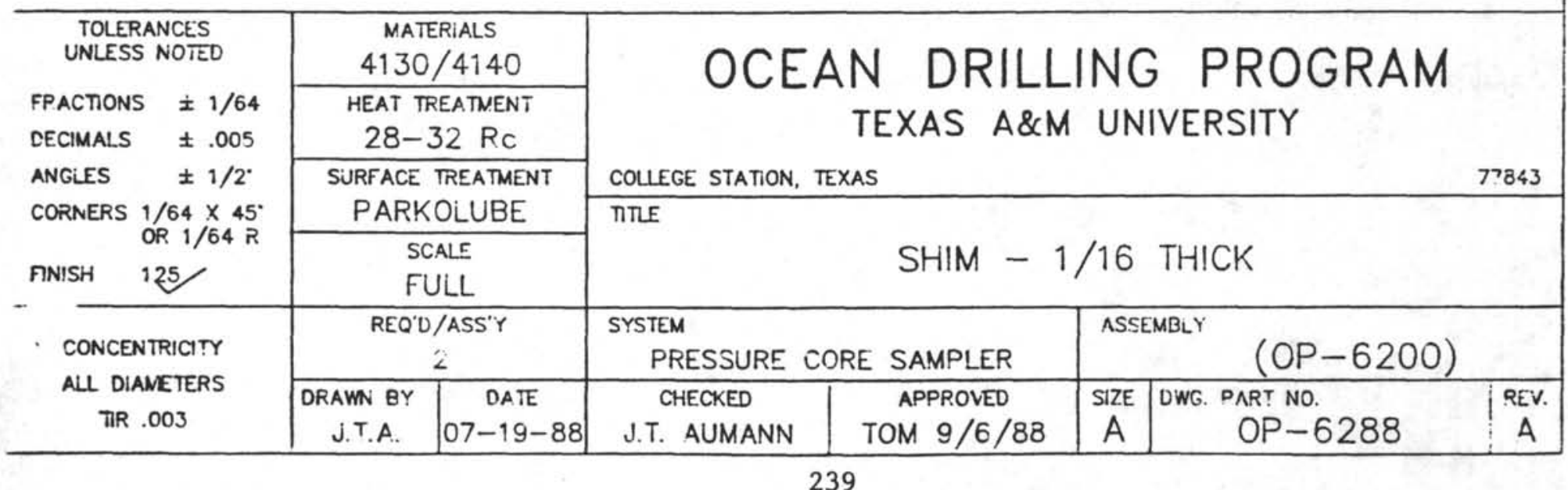




\begin{tabular}{|c|c|c|c|c|c|}
\hline NO. & DESCRIPTON & OATE & OY & CH. & APR \\
\hline & & & & & \\
\hline
\end{tabular}
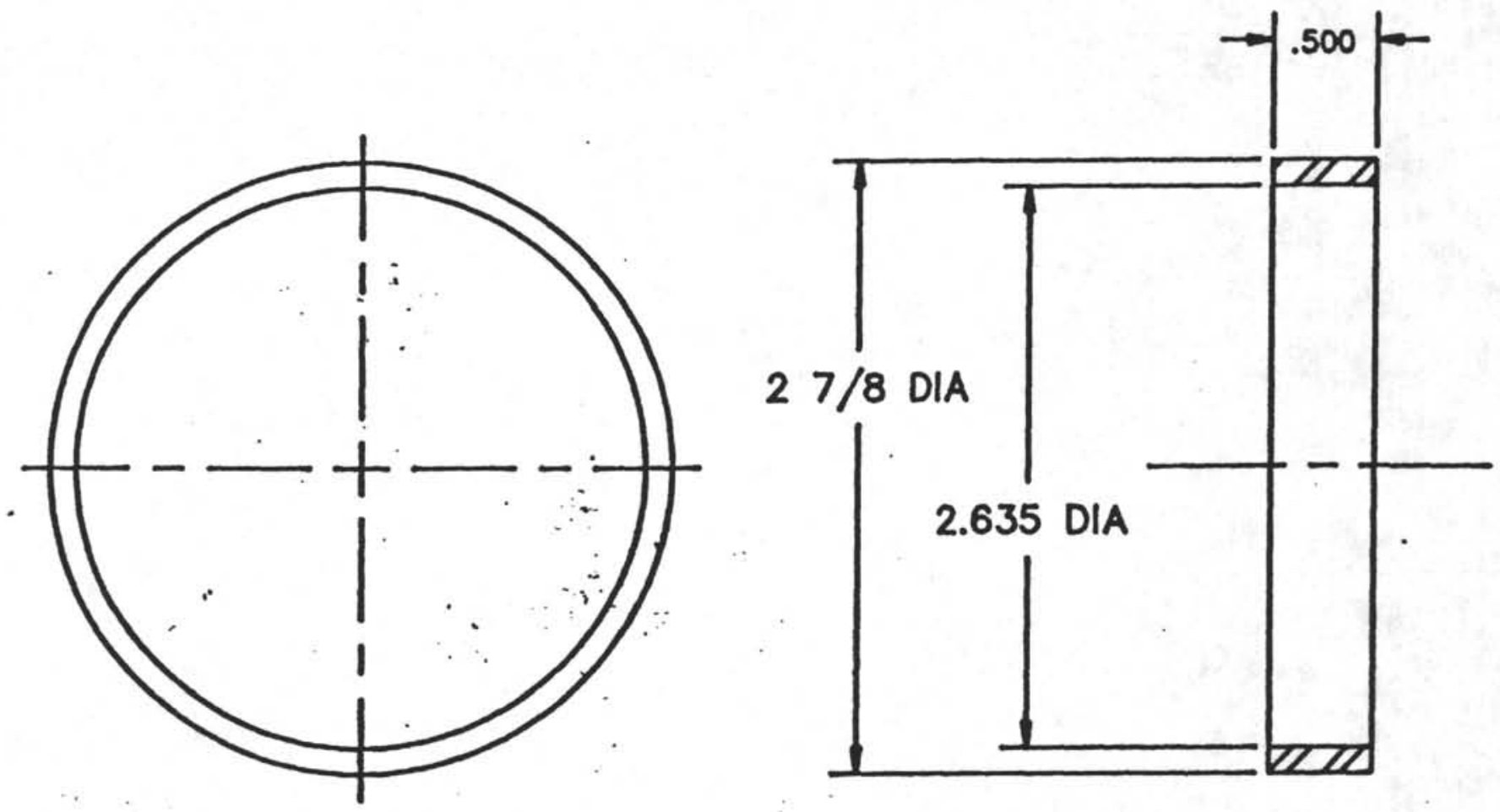

\section{NOTE:}

1) PLACE IN BAG OR BOX MARKED W/ OP-6289 \& MFG DATE

\begin{tabular}{|c|c|c|c|c|}
\hline $\begin{array}{l}\text { Tougrances } \\
\text { untess notid }\end{array}$ & $\begin{array}{l}\text { MATESLS } \\
4130 / 4140\end{array}$ & \multirow{2}{*}{\multicolumn{2}{|c|}{$\begin{array}{l}\text { OCEAN DRILLING PROGRAM } \\
\text { TEXAS A\&M UNIVERSITY }\end{array}$}} & \multirow[b]{3}{*}{ Trow } \\
\hline \multirow{3}{*}{ 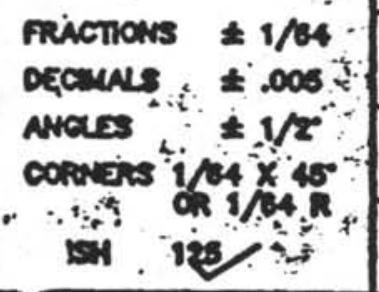 } & $\begin{array}{l}\text { HEAT MEATENT } \\
28-32 \text { RC }\end{array}$ & & & \\
\hline & $\begin{array}{l}\text { SHFACE.TWANMEN } \\
\text { PARKOLUBE: }\end{array}$ & & & \\
\hline & PARKOLUBE: & \multicolumn{2}{|c|}{ of } & \\
\hline \multirow{2}{*}{ 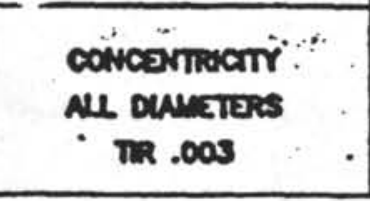 } & Mego/Ast & STSTM PRESURE CORE SAMPLER & \multicolumn{2}{|l|}{ Assamer $(O P-6200)$} \\
\hline & 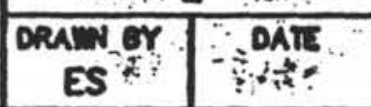 & 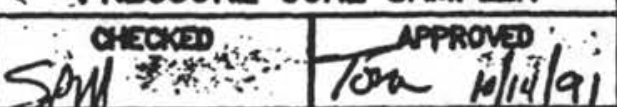 & \begin{tabular}{c|c} 
STEF & DWa PART MQ, \\
A & OP6289 \\
\end{tabular} & rav. \\
\hline
\end{tabular}




\begin{tabular}{|c|c|c|c|c|c|c|}
\hline \multicolumn{3}{|c|}{ REVSIONS } \\
\hline NO. & DESCRIPTON & DATE & BY & CH. & APR. \\
\hline & & & & & \\
\hline
\end{tabular}
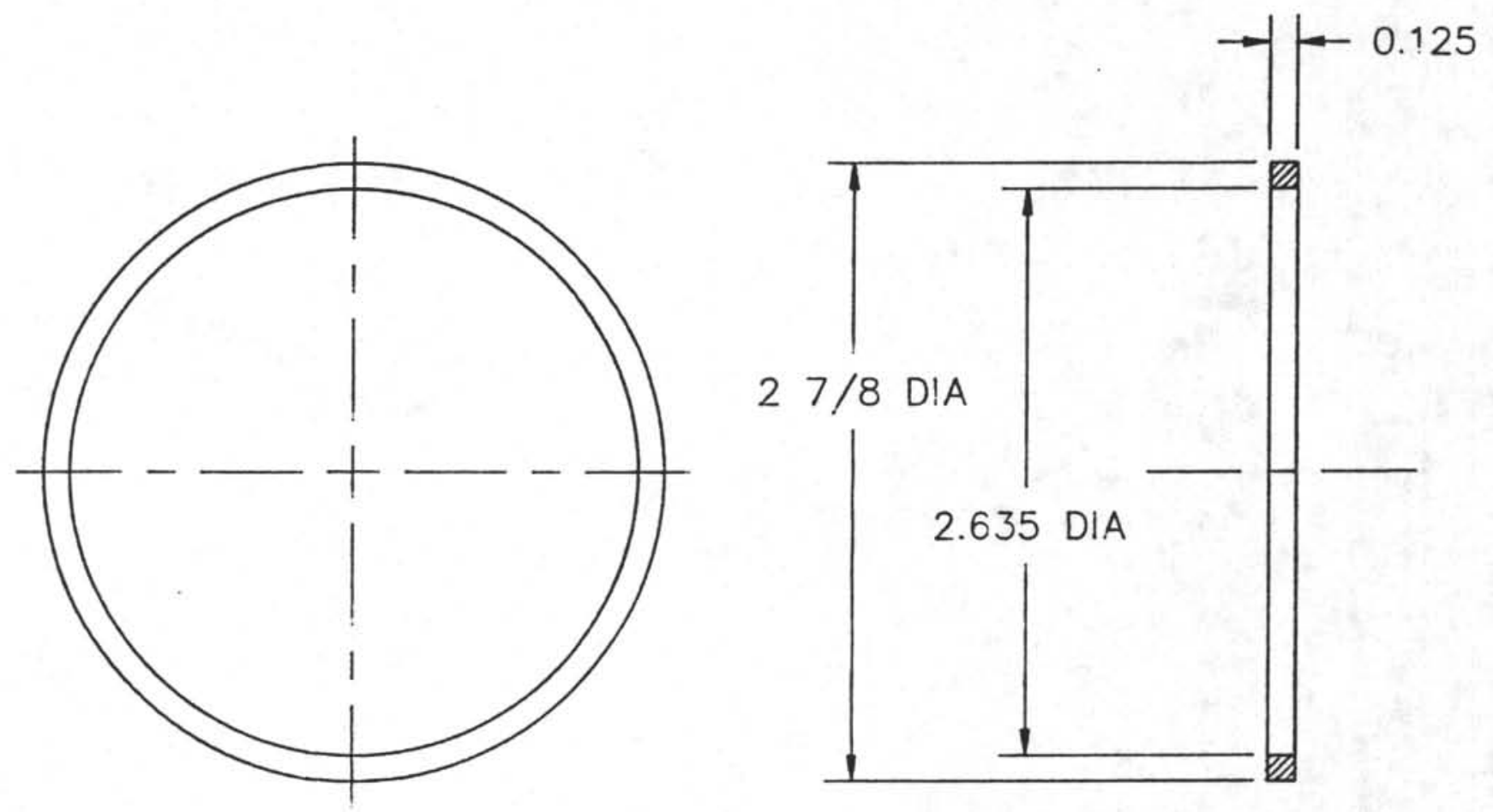

NOTE:

1) PLACE IN BAG OR BOX MARKED W/ OP-6290 \& MFG DATE

\begin{tabular}{|c|c|c|}
\hline $\begin{array}{l}\text { TOLERANCES } \\
\text { UNLESS NOTED }\end{array}$ & $\begin{array}{c}\text { MATER!A!S } \\
4130 / 4140\end{array}$ & \multirow[b]{2}{*}{ TEXAS A\&M UNIVERSITY } \\
\hline $\begin{array}{ll}\text { FRACTIONS } & \pm 1 / 64 \\
\text { DECIMALSS } & \pm .005\end{array}$ & $\begin{array}{l}\text { HEAT TREATNENT } \\
28-32 \mathrm{RC}\end{array}$ & \\
\hline $\pm 1 / 2$ & \multirow{2}{*}{$\begin{array}{l}\text { SURFACE TREATMENT } \\
\text { PARKOLUBE }\end{array}$} & COLLEGE STATION. TEXAS \\
\hline $\begin{array}{l}1 / 64 \times 45^{\circ} \\
\text { OR } 1 / 64 ?\end{array}$ & & \multirow[b]{2}{*}{$1 / 8$ THICK } \\
\hline FiNiSH 125 & $\begin{array}{l}\text { SCA!.ㄷ } \\
\text { FULL }\end{array}$ & \\
\hline CONCENTRICITY & $\begin{array}{l}\text { REQ'U/ASS'Y } \\
2 \\
\end{array}$ & $\begin{array}{l}\text { SYSTEM } \\
\text { FRESSLIFE CORE SAMPLER }\end{array}$ \\
\hline $\begin{array}{l}\text { ALI. DIAME!ERS } \\
\text { TIP. OOS }\end{array}$ & \begin{tabular}{c|r} 
DFAWN BY & DATE \\
TT &
\end{tabular} & \begin{tabular}{c|c} 
SIZE & DWG. DAPT NO. \\
$\triangle$ & $7 D f-3 n$
\end{tabular} \\
\hline
\end{tabular}




\begin{tabular}{|c|c|c|c|c|c|c|}
\hline NO. & DESCRIPTON & DATE & BY & CH. & APR. \\
\hline & & & & & \\
\hline
\end{tabular}
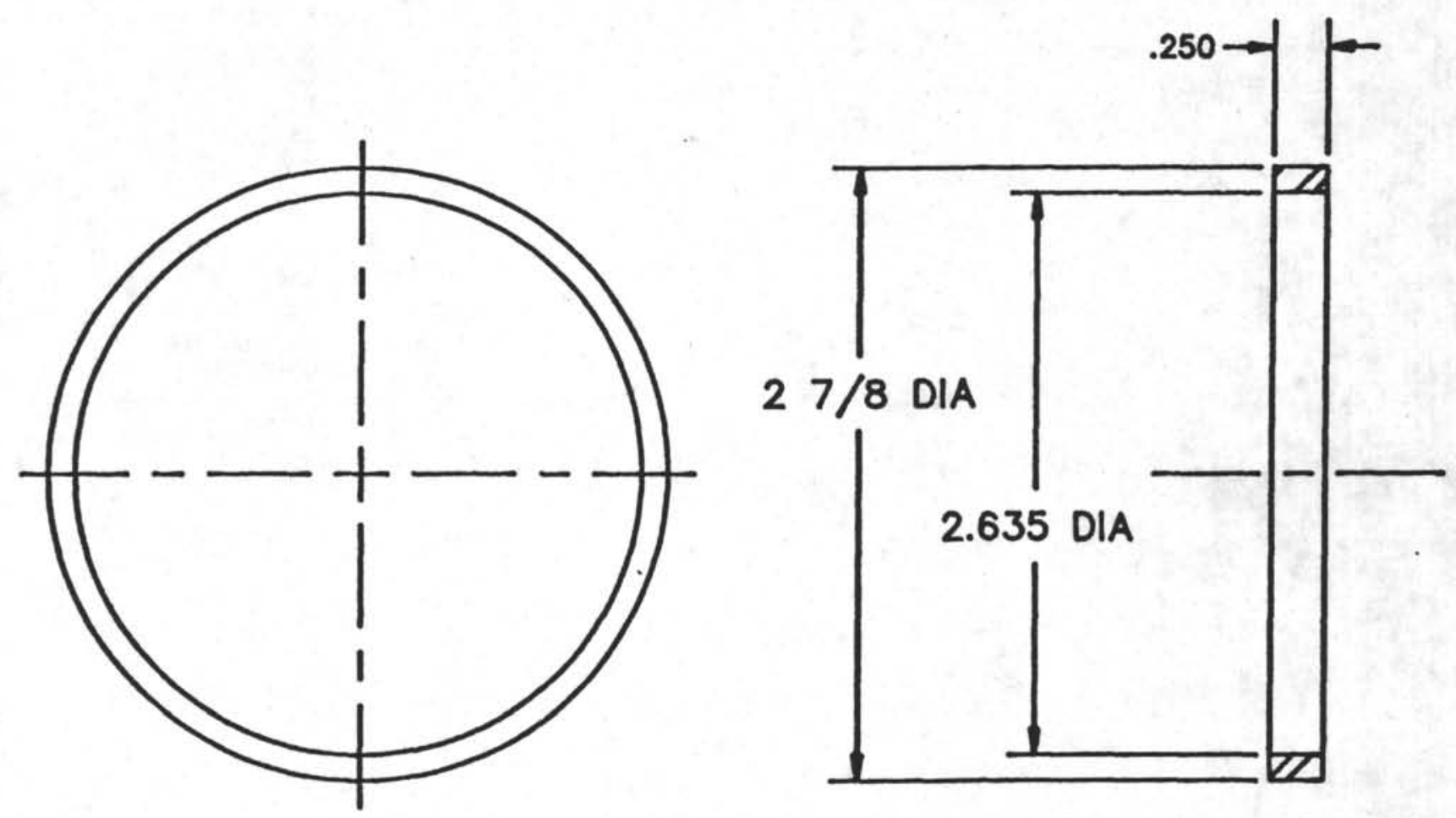

NOTE:

1) PLACE IN BAG OR BOX MARKED W/ OP-629.I. \& MFG DATE

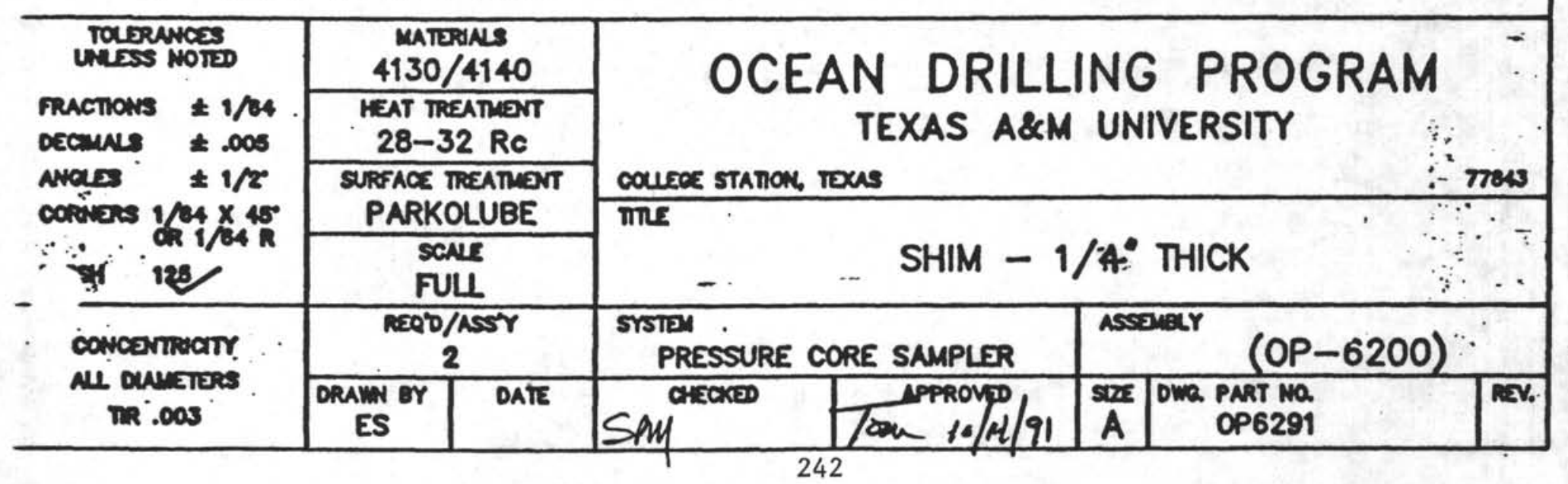




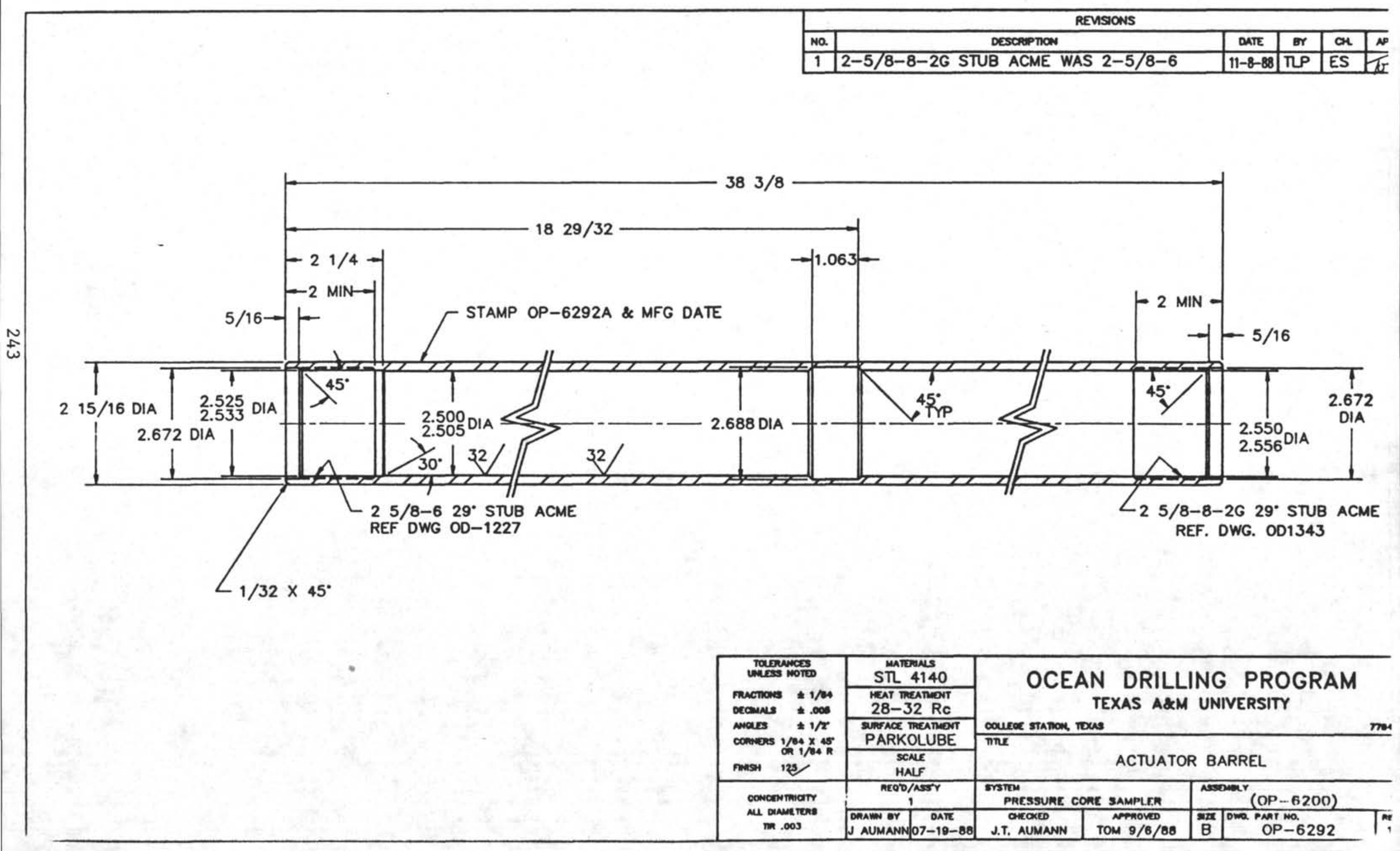




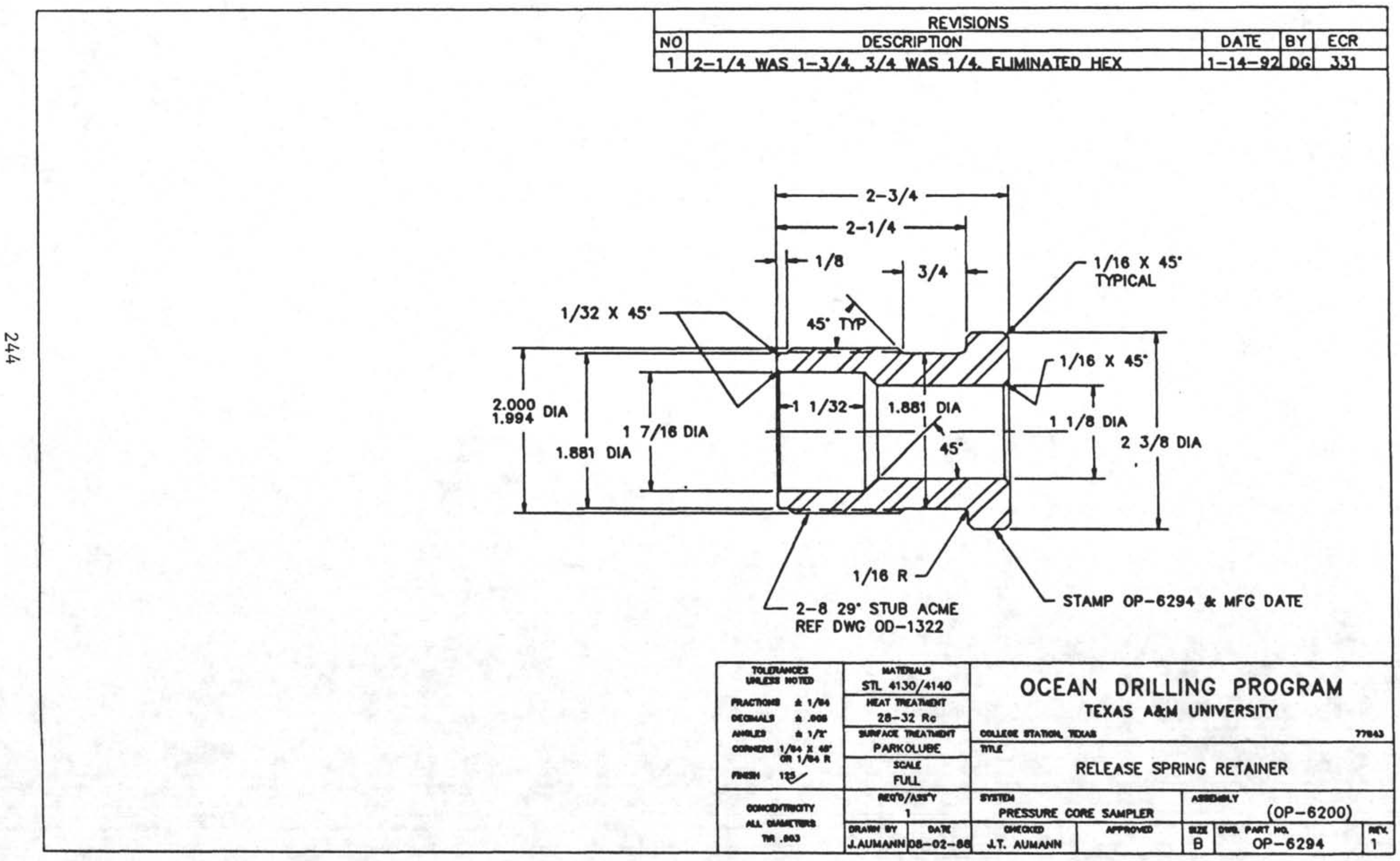




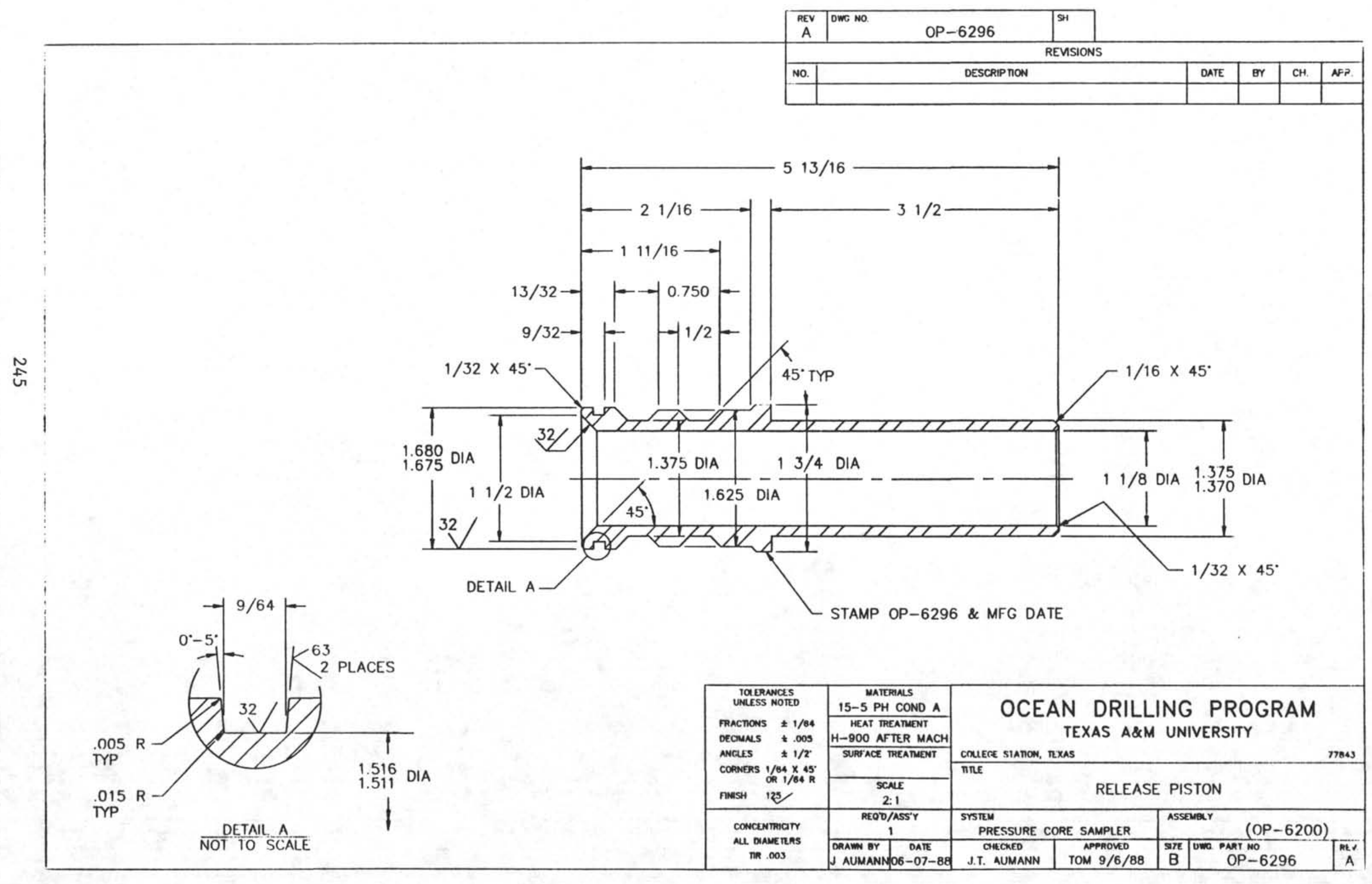




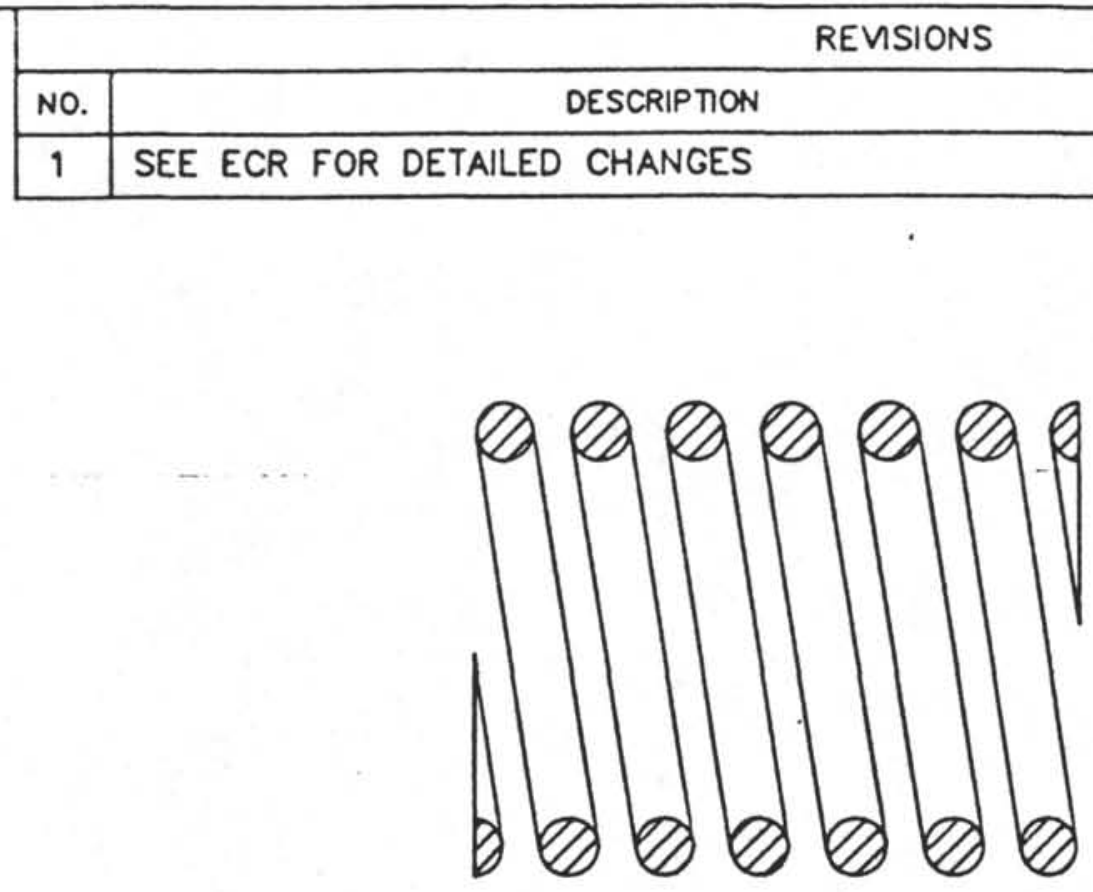

NOTE:

1. THE ABOVE ILLUSTRATION IS FOR CAD ASSEMBLY/MERGE PURPOSES ONLY.

2. TAG WITH OP-6298 \& MFG DATE.

SPECIFICATIONS

1) MATERIAL: .250" DIA. BETA-C TITANIUM.

SPRING MUST WTHSTAND SHORT TIME EXPOSURE TO $350^{\circ} \mathrm{C}$

(662F) SEA WATER WTH H2S AND CO2 IN SOLUTION.

2) SPRING MUST FIT FREELY OVER A 1.375" DIA. ROD WHEN RELAXED.

3) SPRING MUST FIT FREELY WTHIN A 1.925". DIA. BORE WHEN COMPRESSED.

4) LOAD AT 2.375" HEIGHT = 200 LBS. MIN.

5) TOTAL COILS $=9.2$

6) SPRING RATE $=\leqq$ LBS./IN.

7) SOLID HEIGHT $=2.312 \mathrm{MAX}$.

8) ENDS CLOSED AND GROUND.

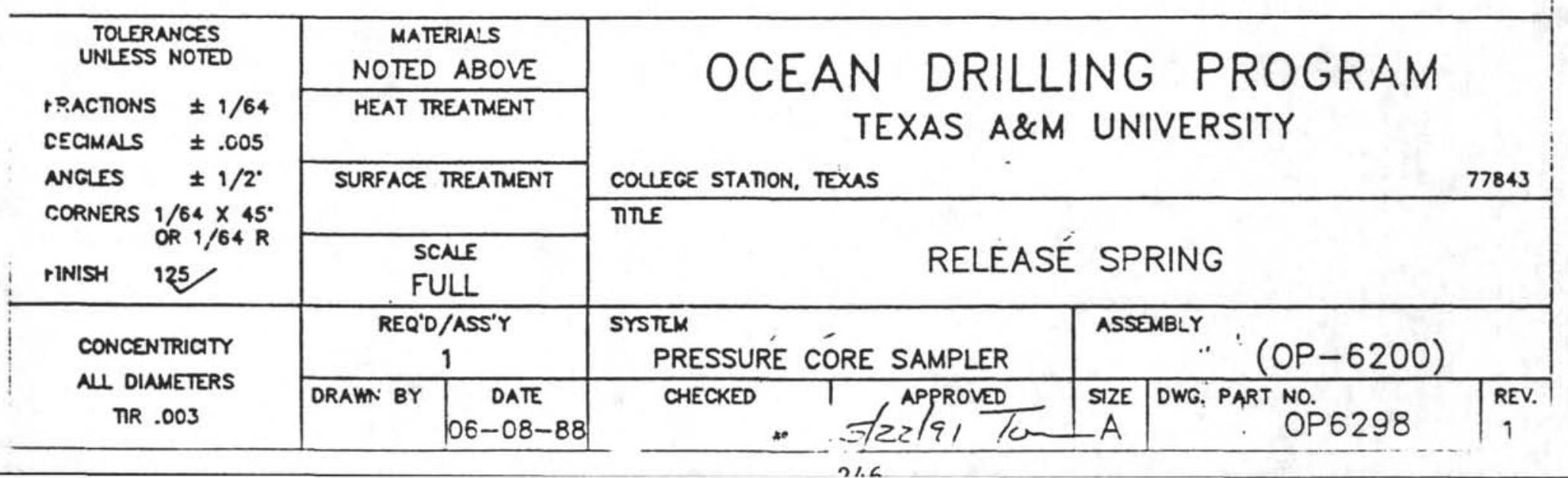




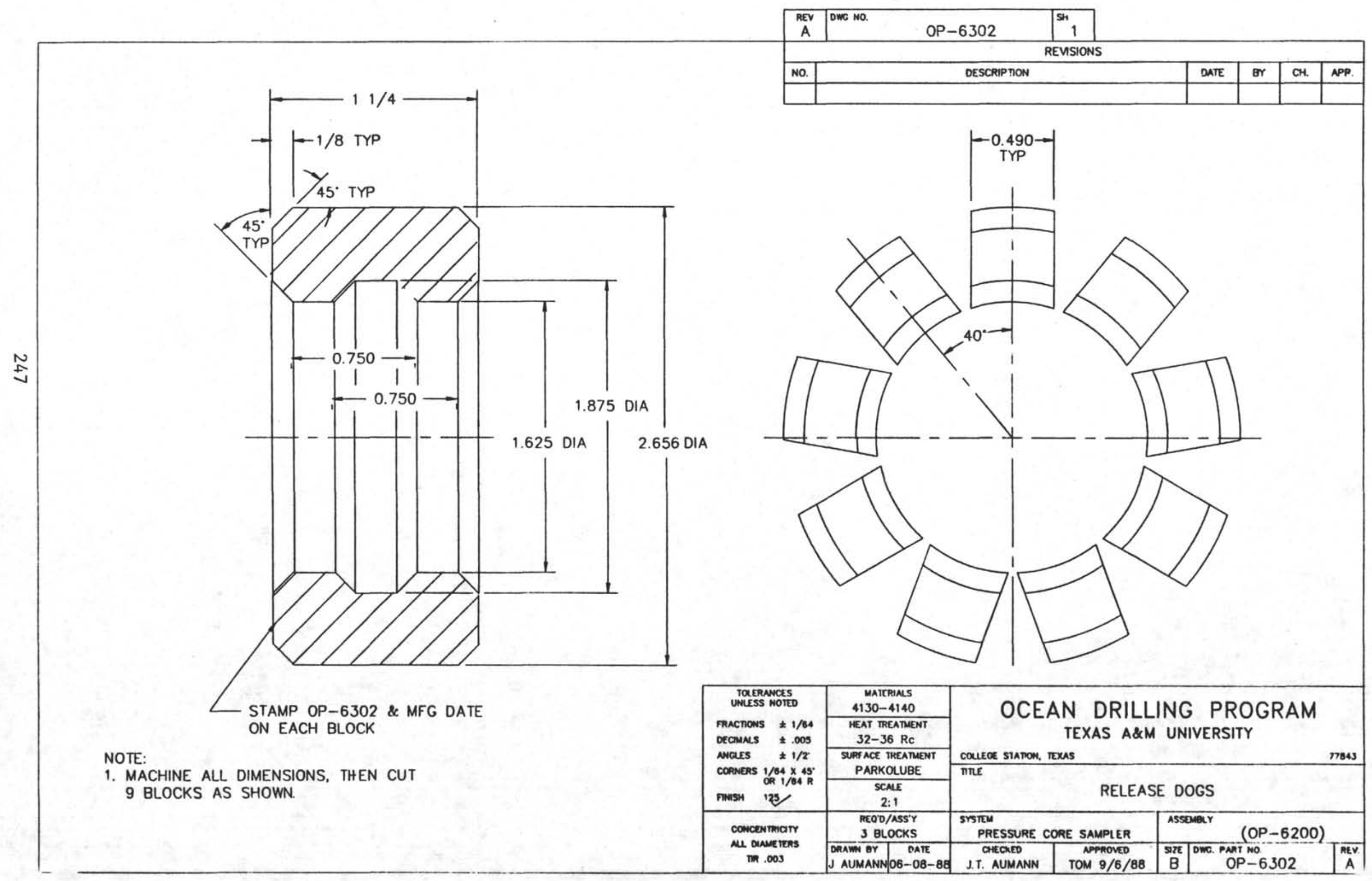




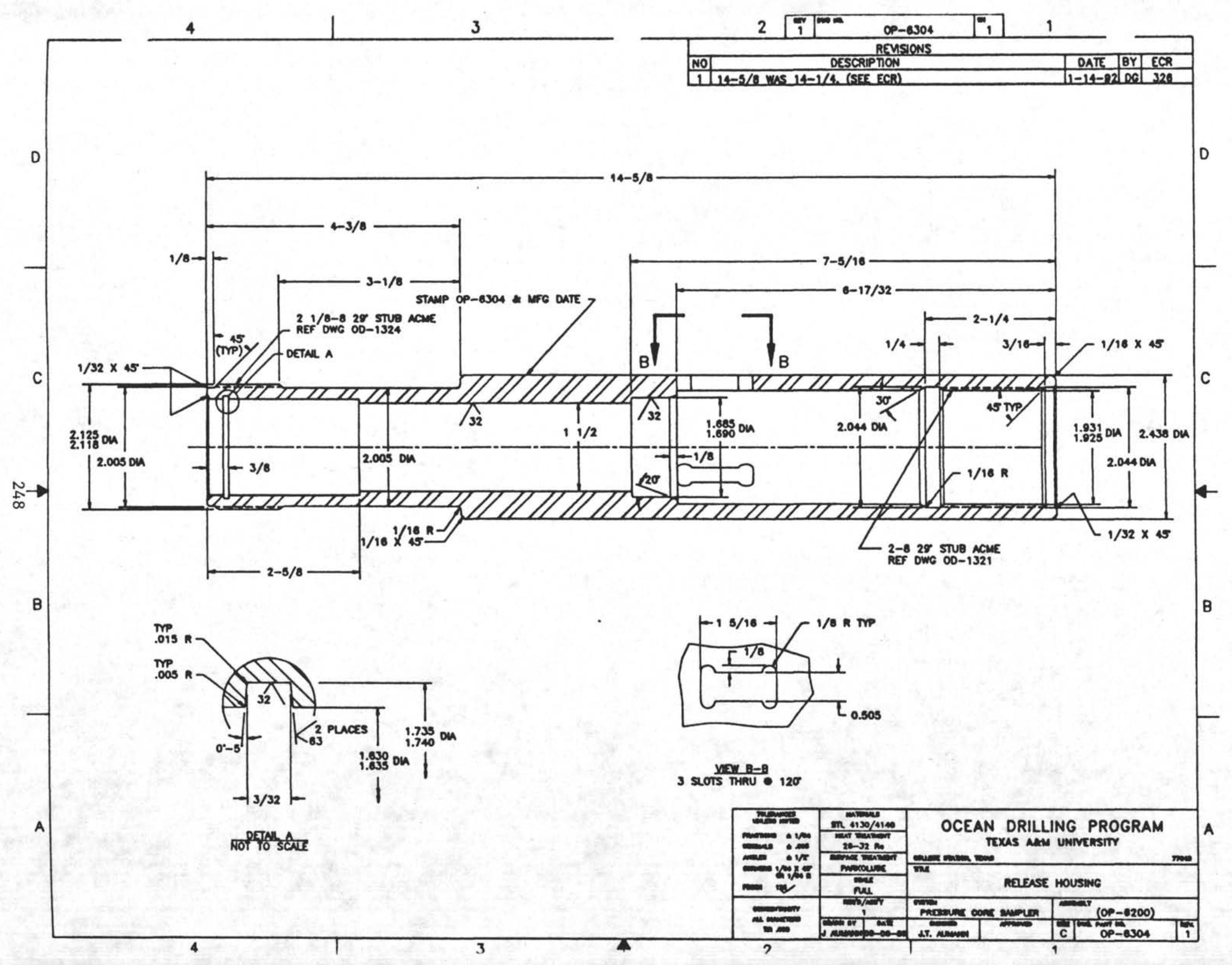




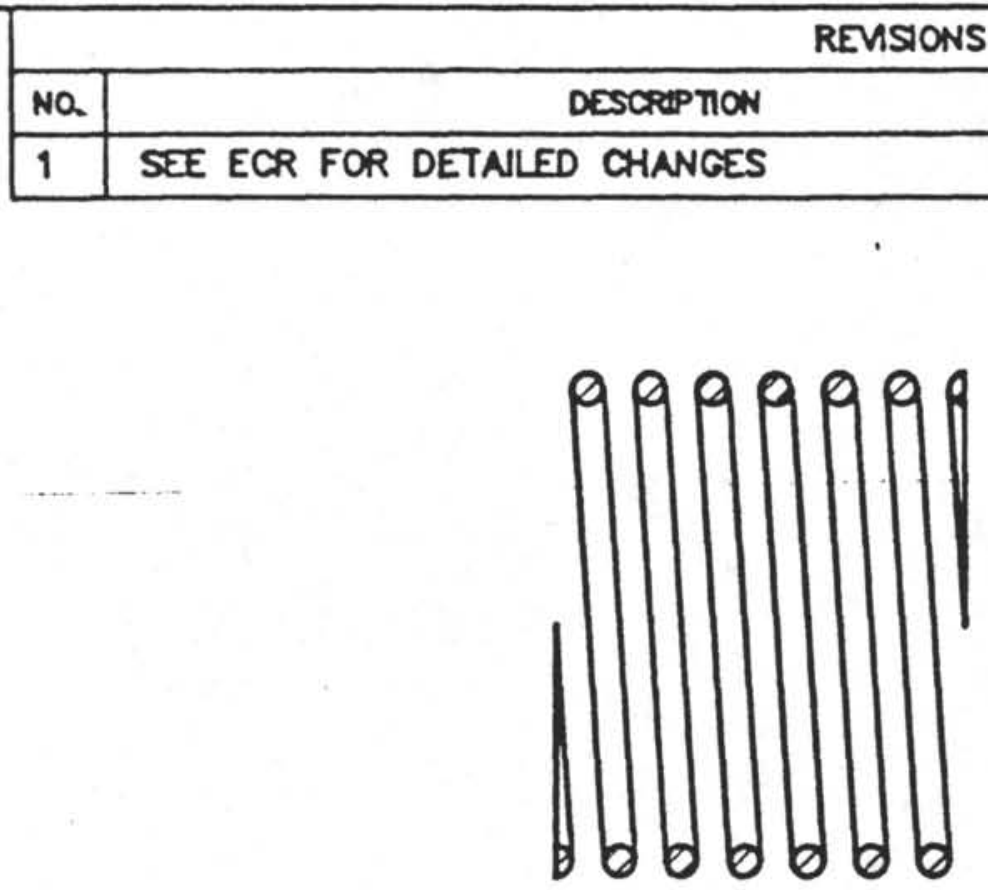

NOTE:

1) THE ABOVE ILUUSTRATION IS FOR CAD ASSEMBLY/MERGE PURPOSES ONLY.

2) TAG WITH OP-6306 \& MFG DATE

\section{- SPECIFICATIONS}

1) MATERIAL: $.159^{\prime \prime}$ DIA. BETA-C TITANIUM SPRING MUST WTHSTAND $350^{\circ} \mathrm{C}$ (662F) SEA WATER WTH H2S AND $\mathrm{CO} 2$ IN SOLUTION.

2) SPRING MUST FIT FREEY Y OVER A $1.625^{\prime \prime}$ DIA. ROD WHEN RELAXED.

3 SPRING MUST FIT FREELY WTHIN A $2.050^{\circ}$ DIA. BORE WHEN COMPRESSED.

4) LOAD AT $1.625=55$ LBS. MIN.

5) TOTAL COILS $=9.3$

6) SPRING RATE $=11$ LBS. $/ \mathrm{N}$.

7) SOLD HEIGHT $=1.500^{\circ} \mathrm{MAX}$.

8) ENDS CLOSED AND GROUND.

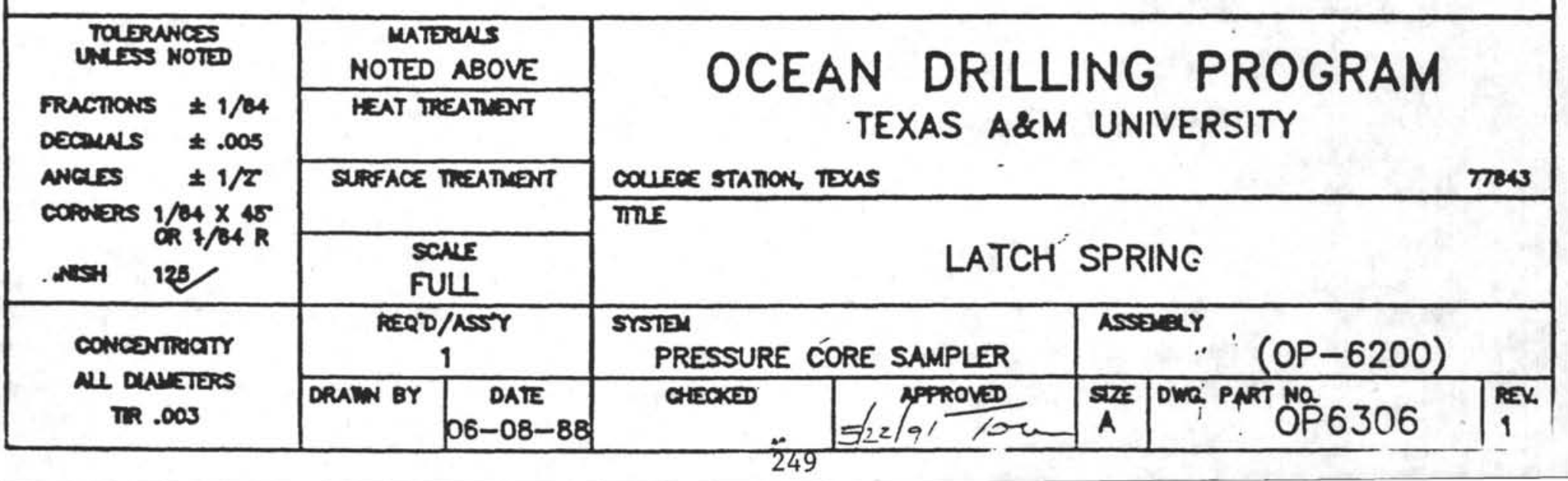




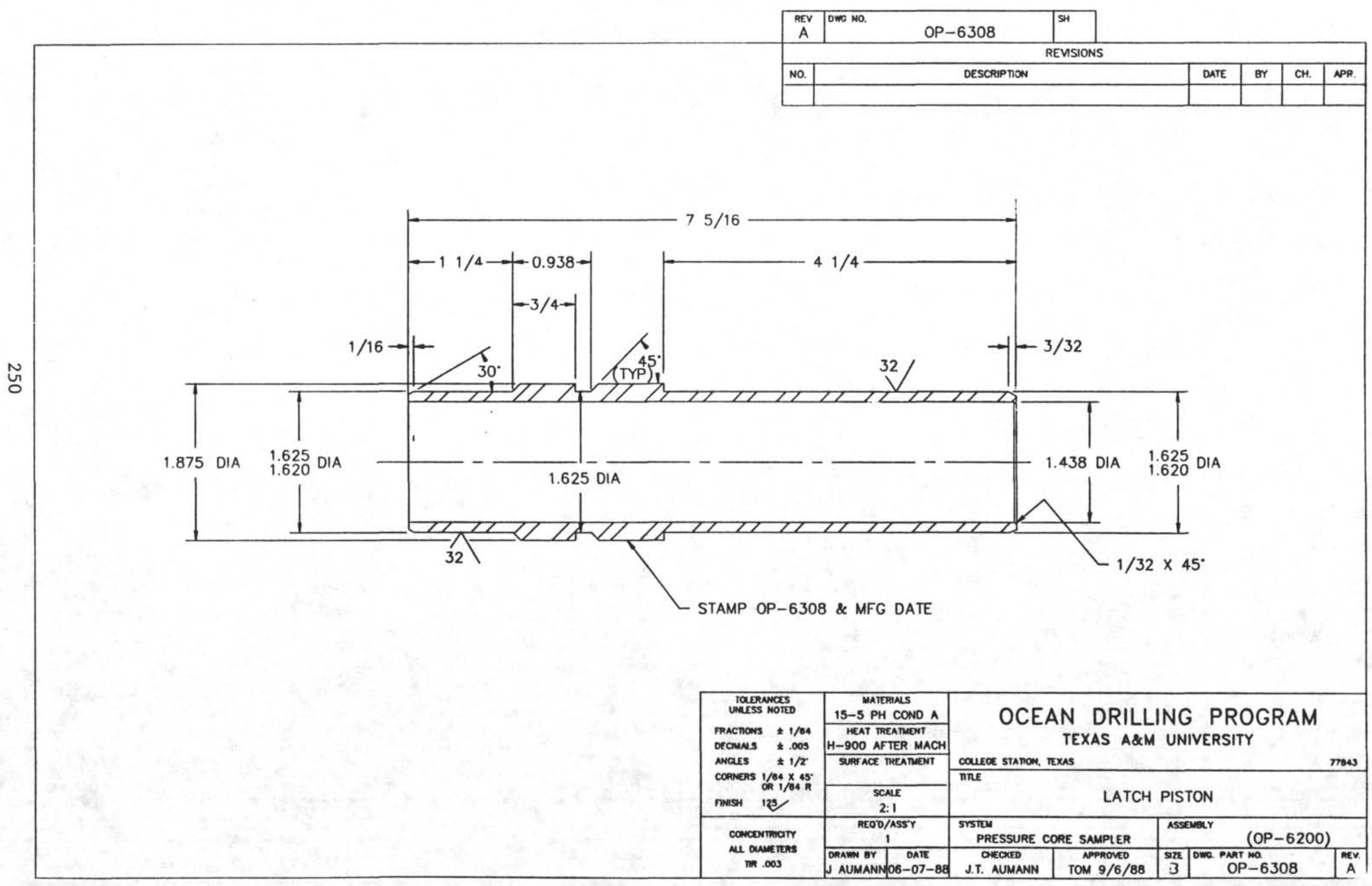




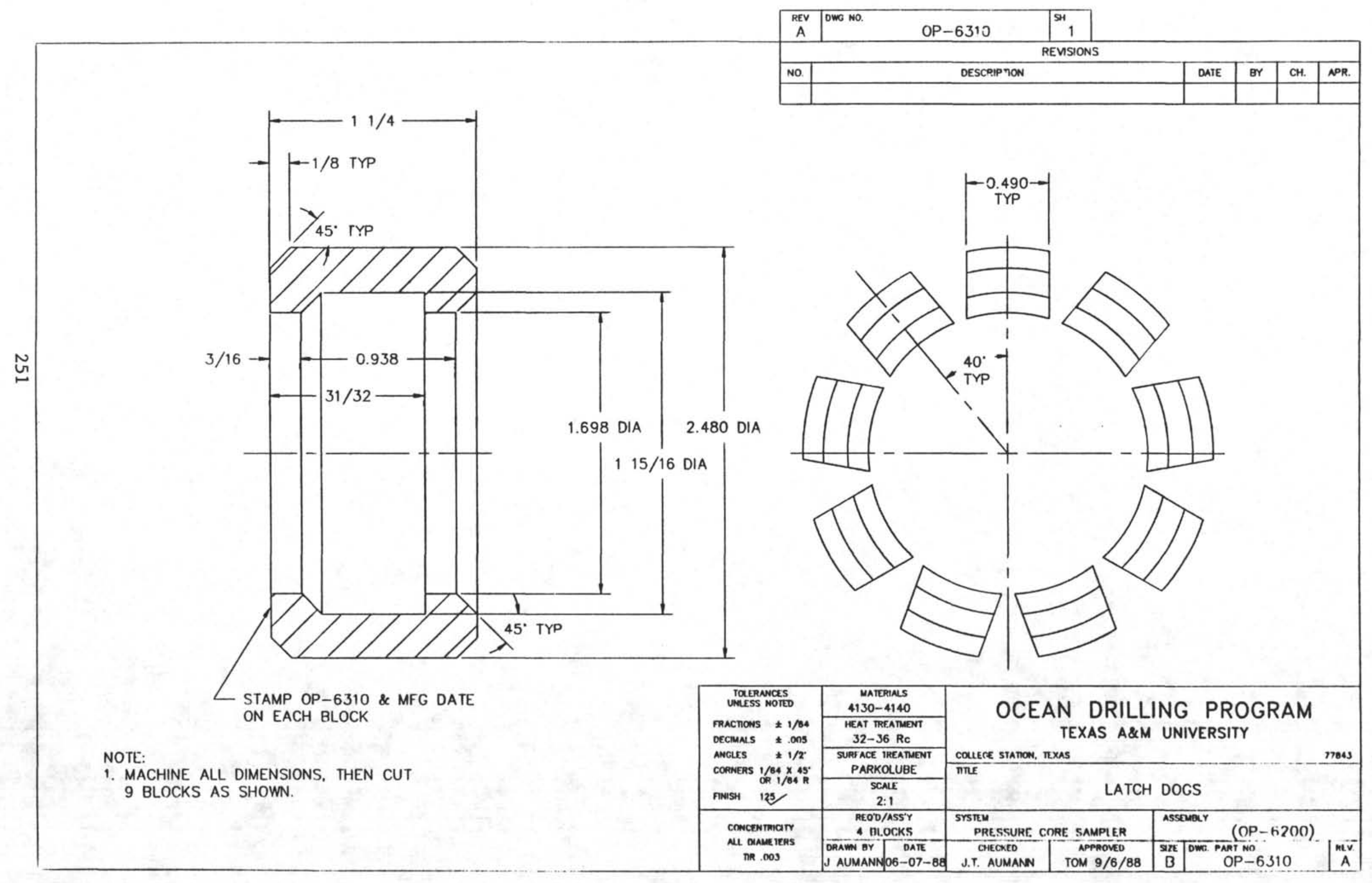




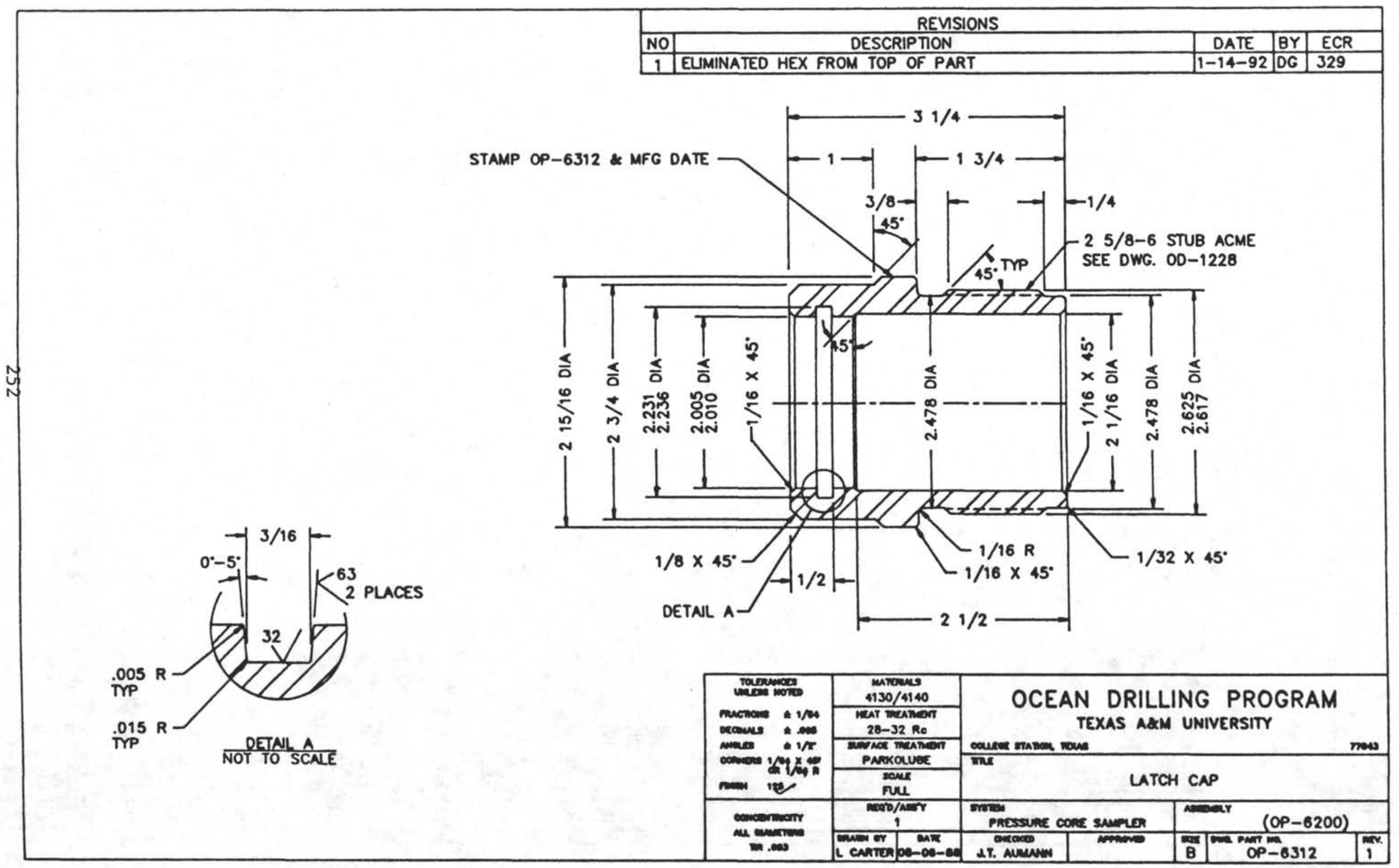




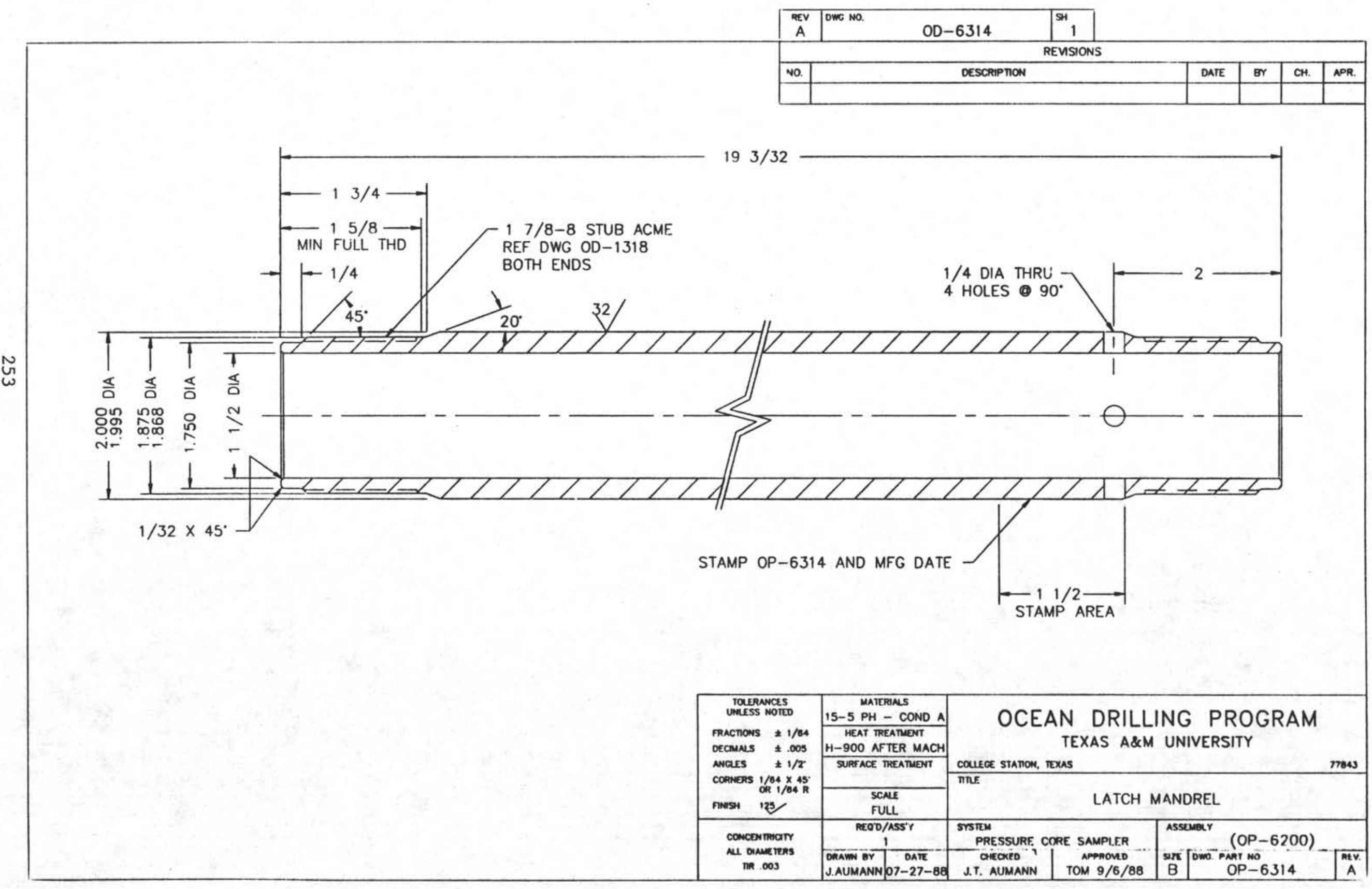




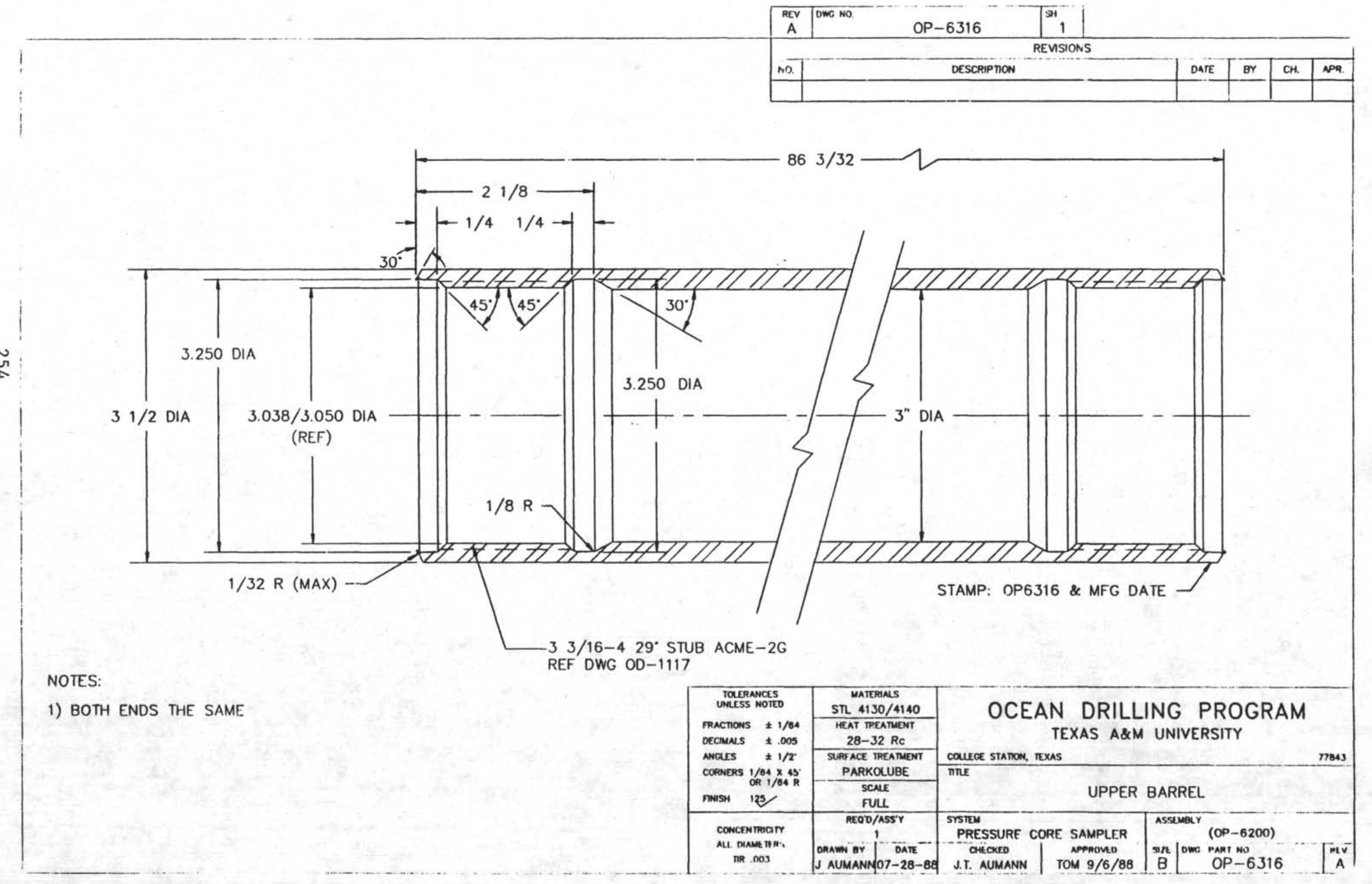




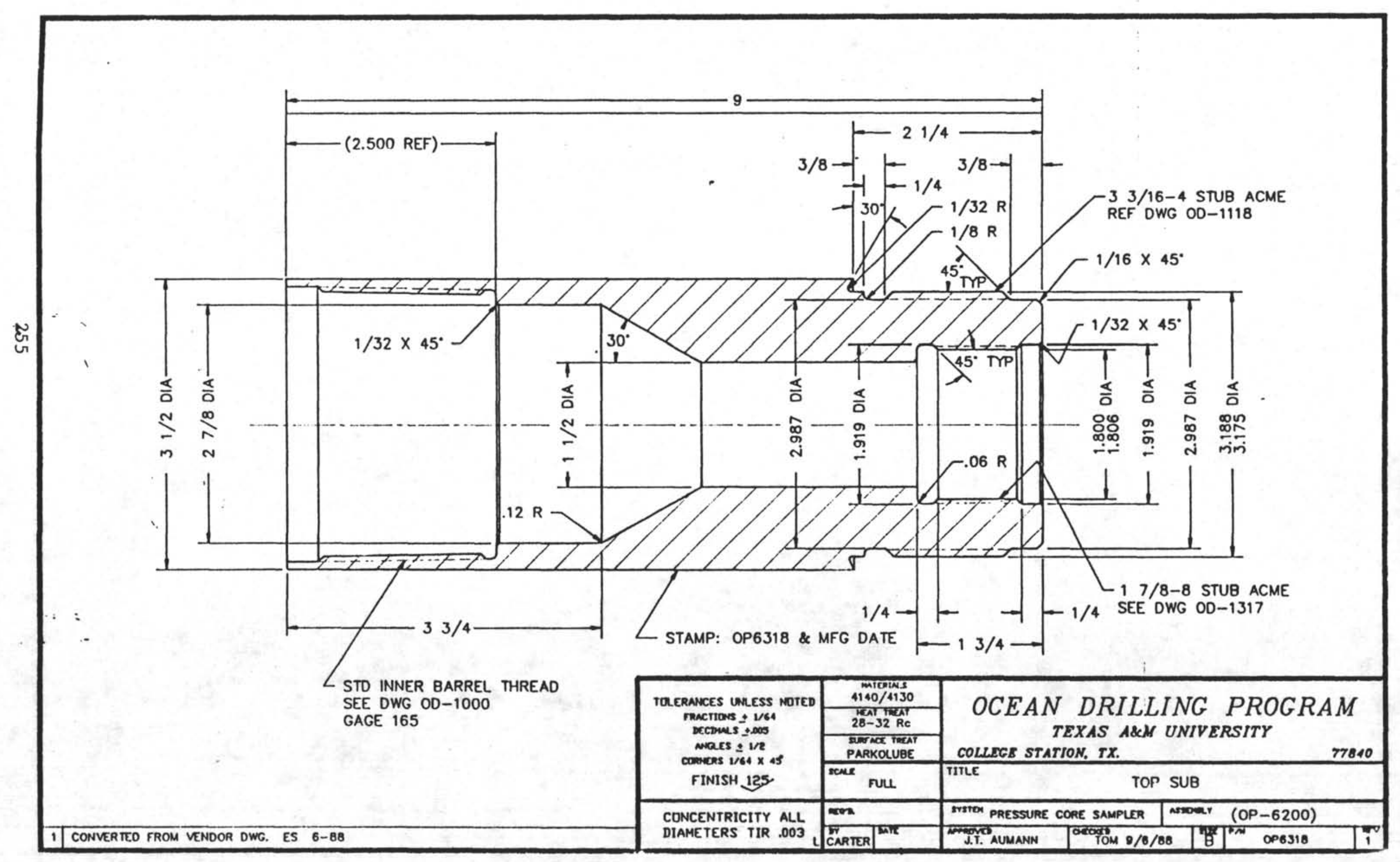




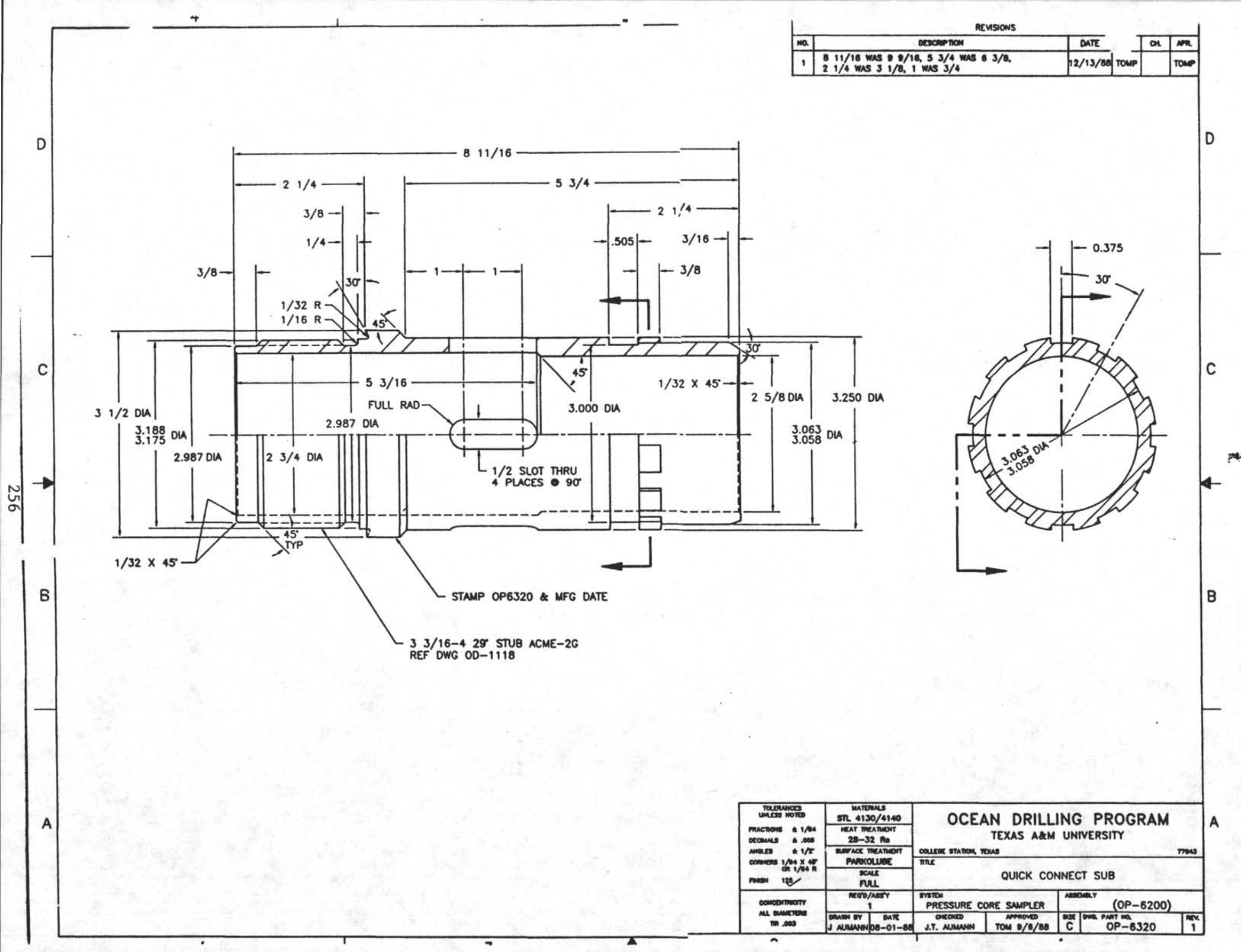




\begin{tabular}{|c|c|c|c|c|c|}
\hline , & $0 / 32=0.96$ & 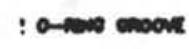 & $4-12-1$ & $\mathbf{x}$ & Eenten \\
\hline 2 & $1-3 / 4$ wes $2-10 / 3$ & & $\mid-13-02$ & $\infty$ & consense \\
\hline
\end{tabular}

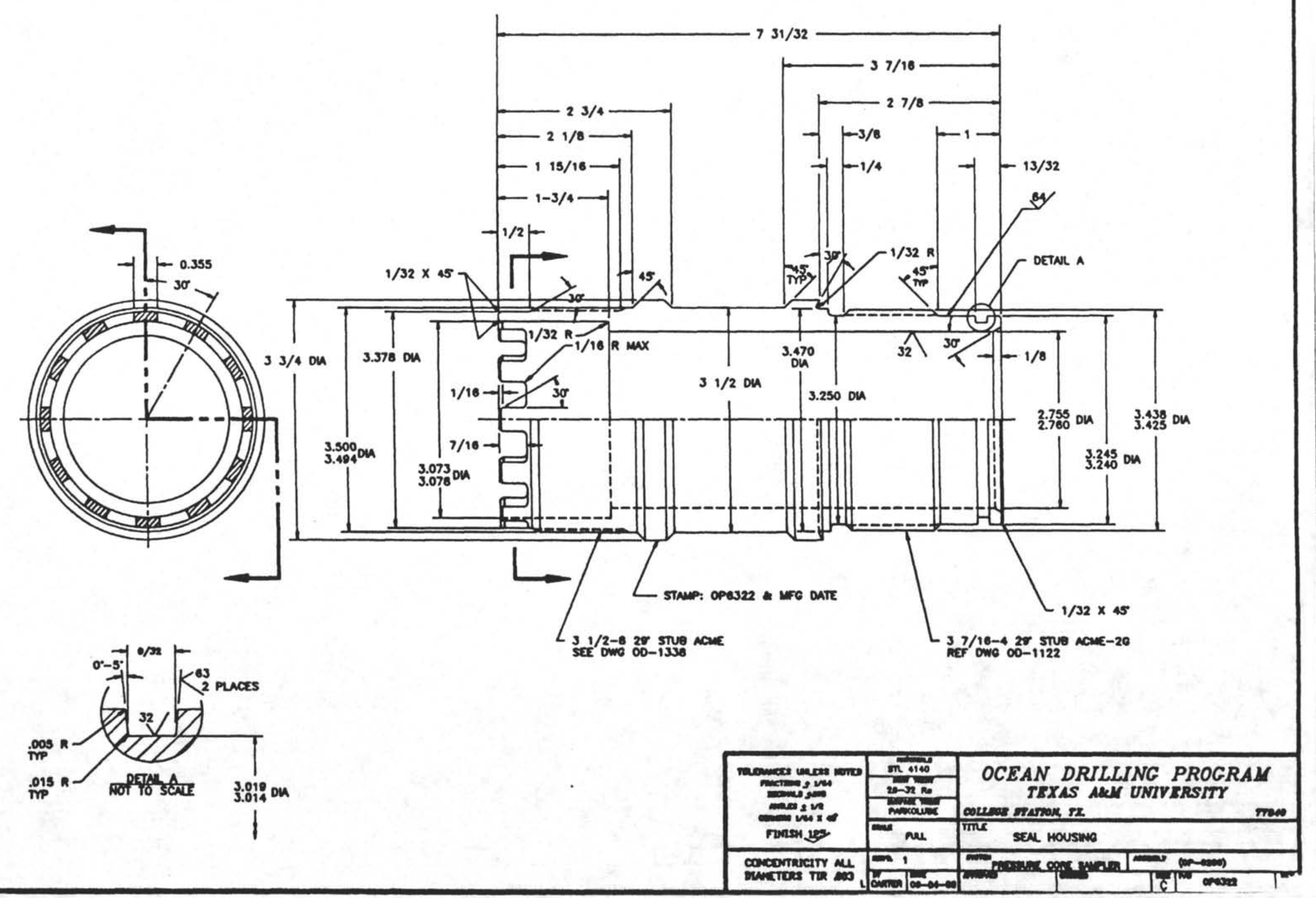




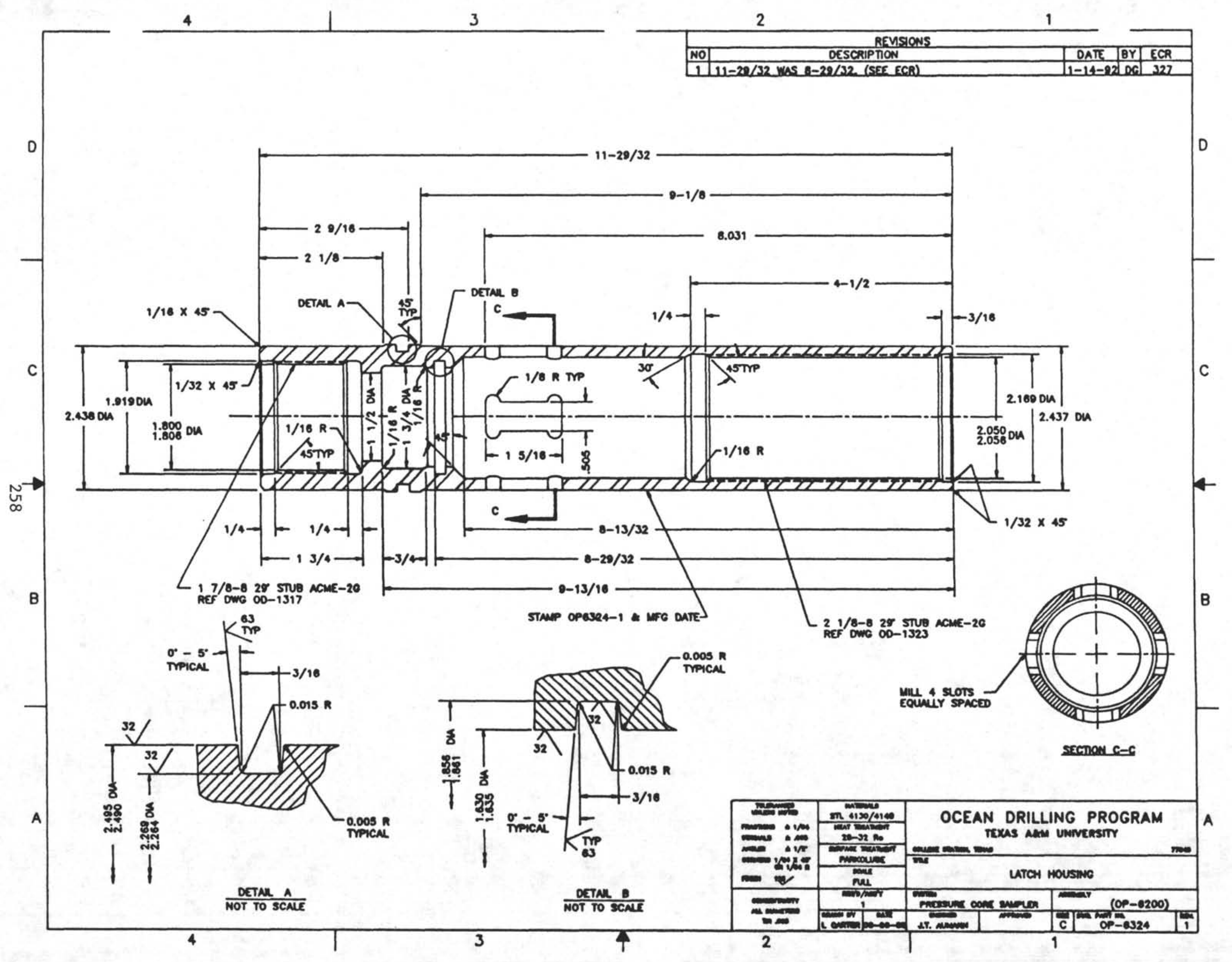




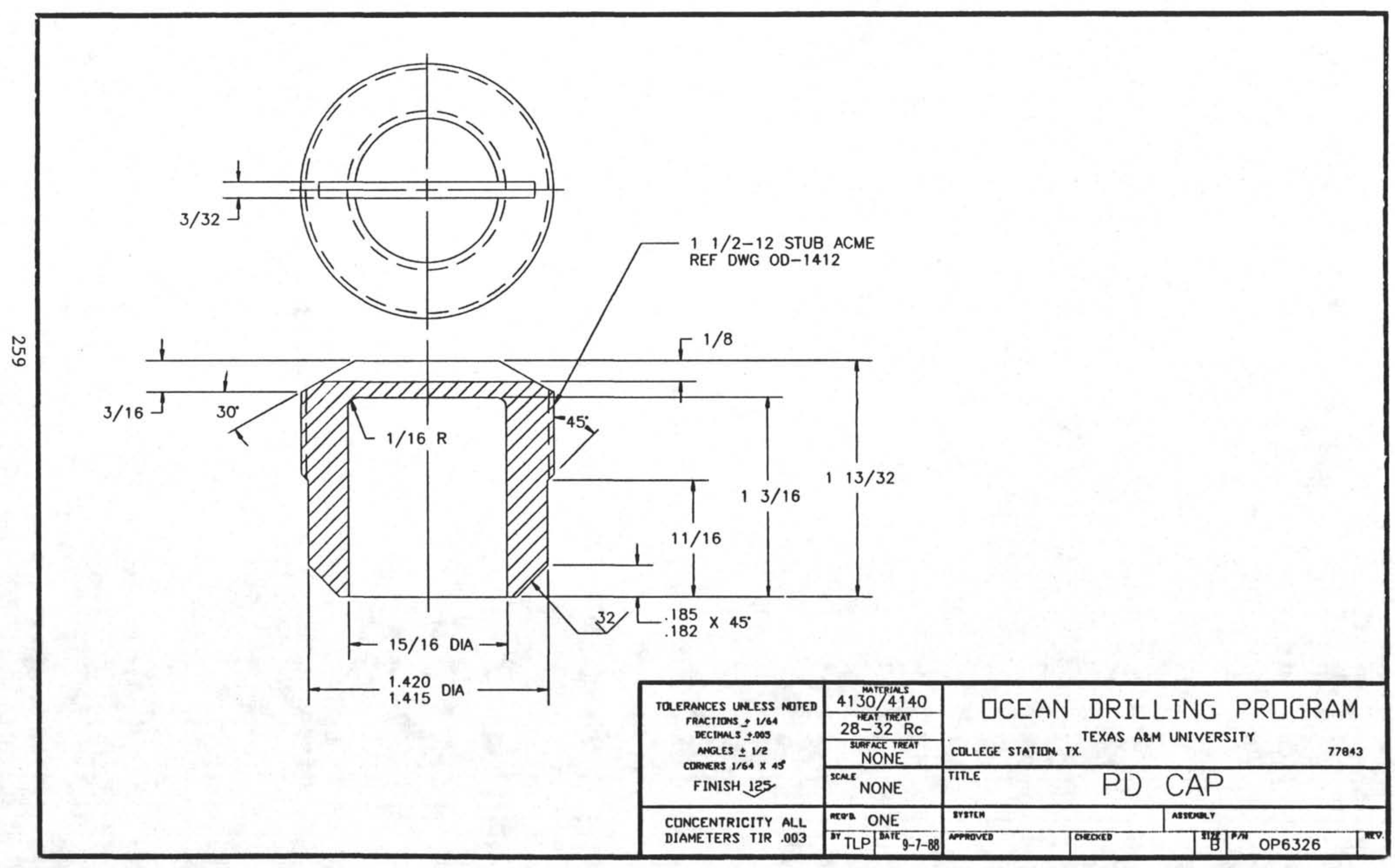




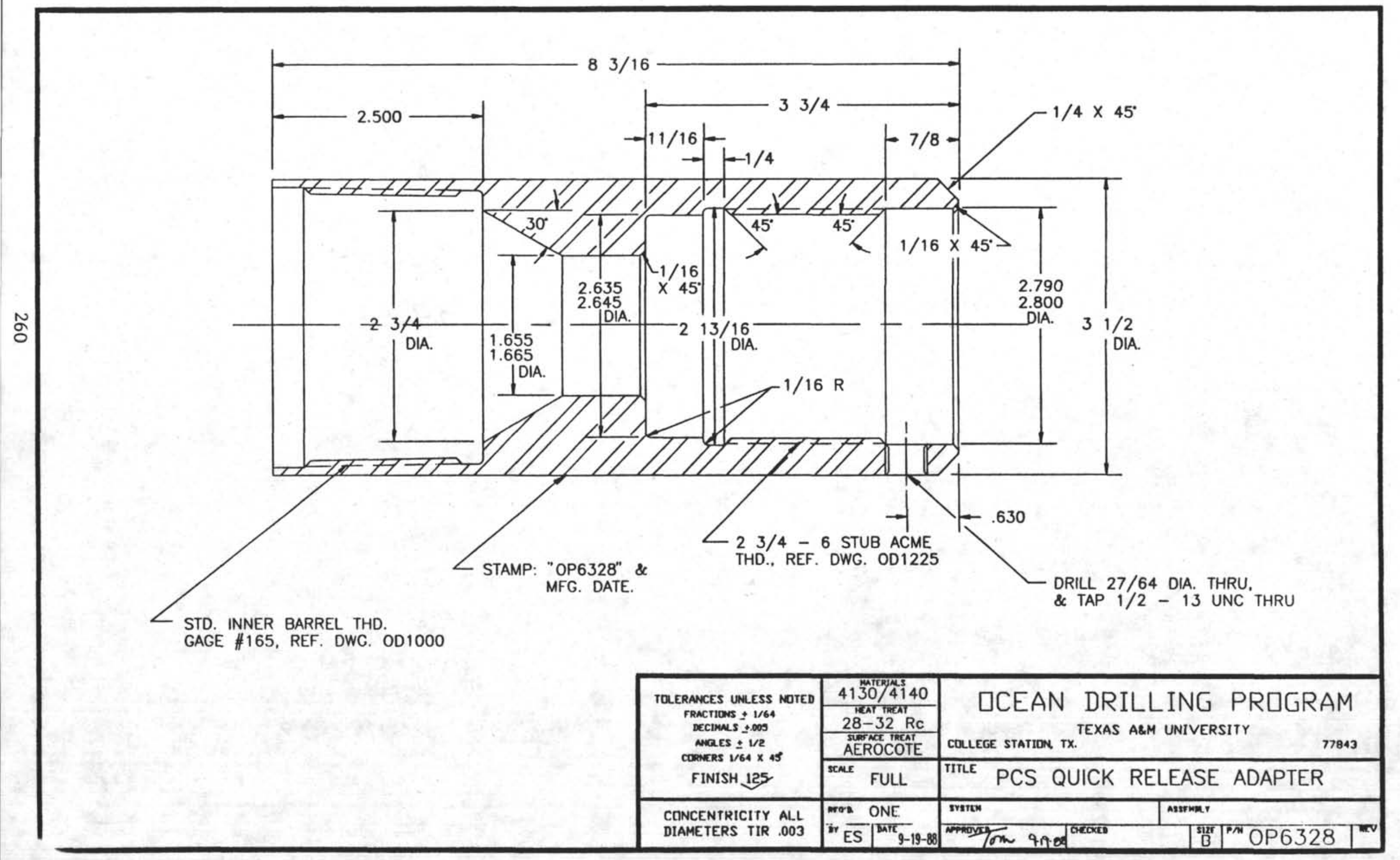



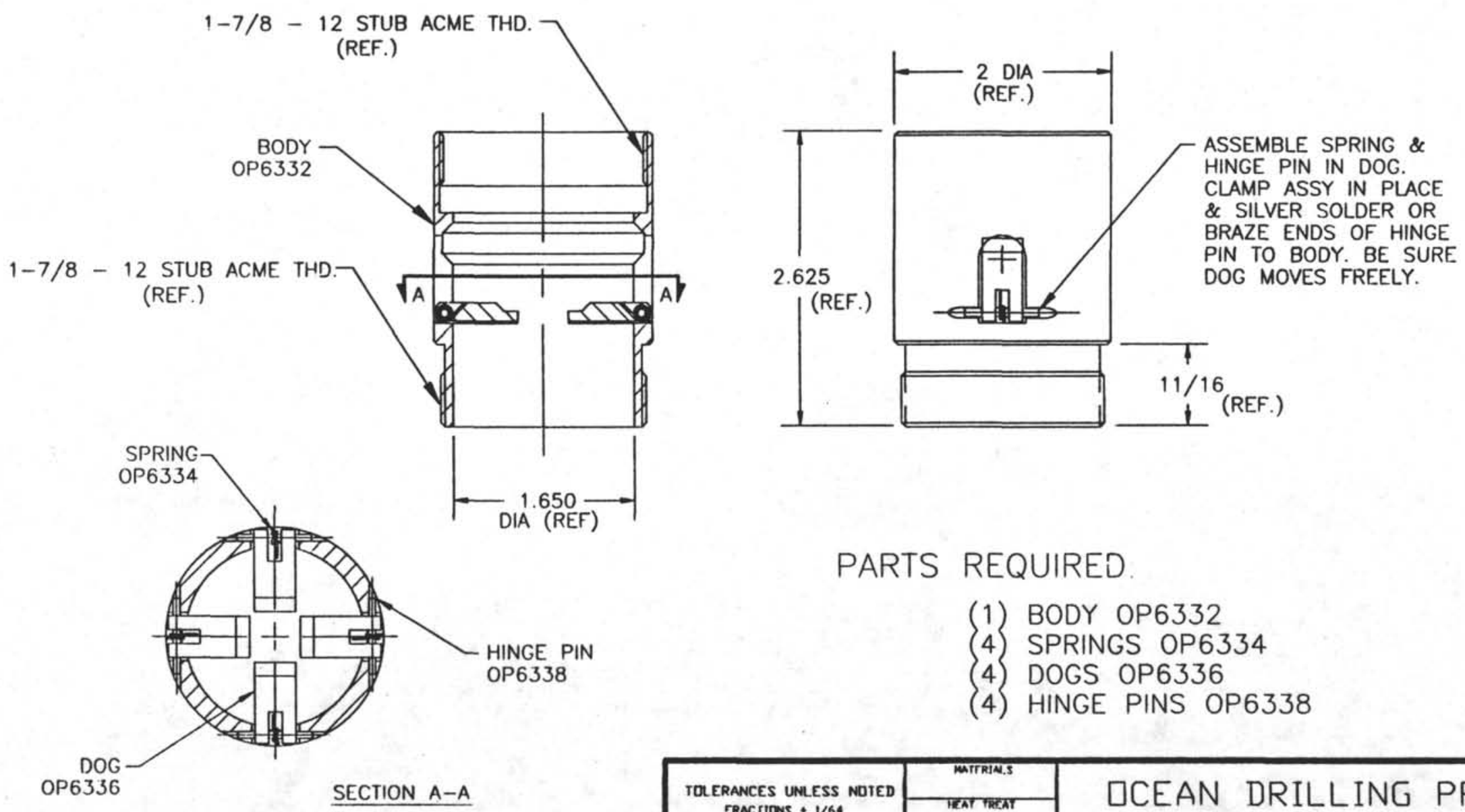

PARTS REQUIRED

(1) BODY OP6332

(4) SPRINGS OP6334

(4) DOGS OP6336

(4) HINGE PINS OP6338

\begin{tabular}{|c|c|c|}
\hline \multirow{3}{*}{ 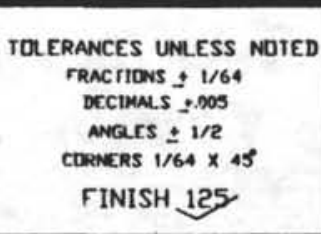 } & & \multirow{2}{*}{$\begin{array}{l}\text { DCEAN DRILLING PRDGRAM } \\
\text { COLLEGE STATION, TX. }\end{array}$} \\
\hline & 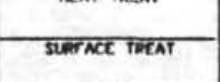 & \\
\hline & ${ }^{\text {scNeE }}$ FULL & ${ }^{\text {TITLE }}$ PCS 4 FINGER CORE CATCHER \\
\hline \multirow{2}{*}{$\begin{array}{l}\text { C.ONCENTRICITY ALL } \\
\text { DIAMETERS TIR } .003\end{array}$} & neor ONE & srsten \\
\hline & 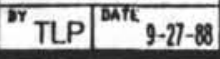 & -10000000 \\
\hline
\end{tabular}




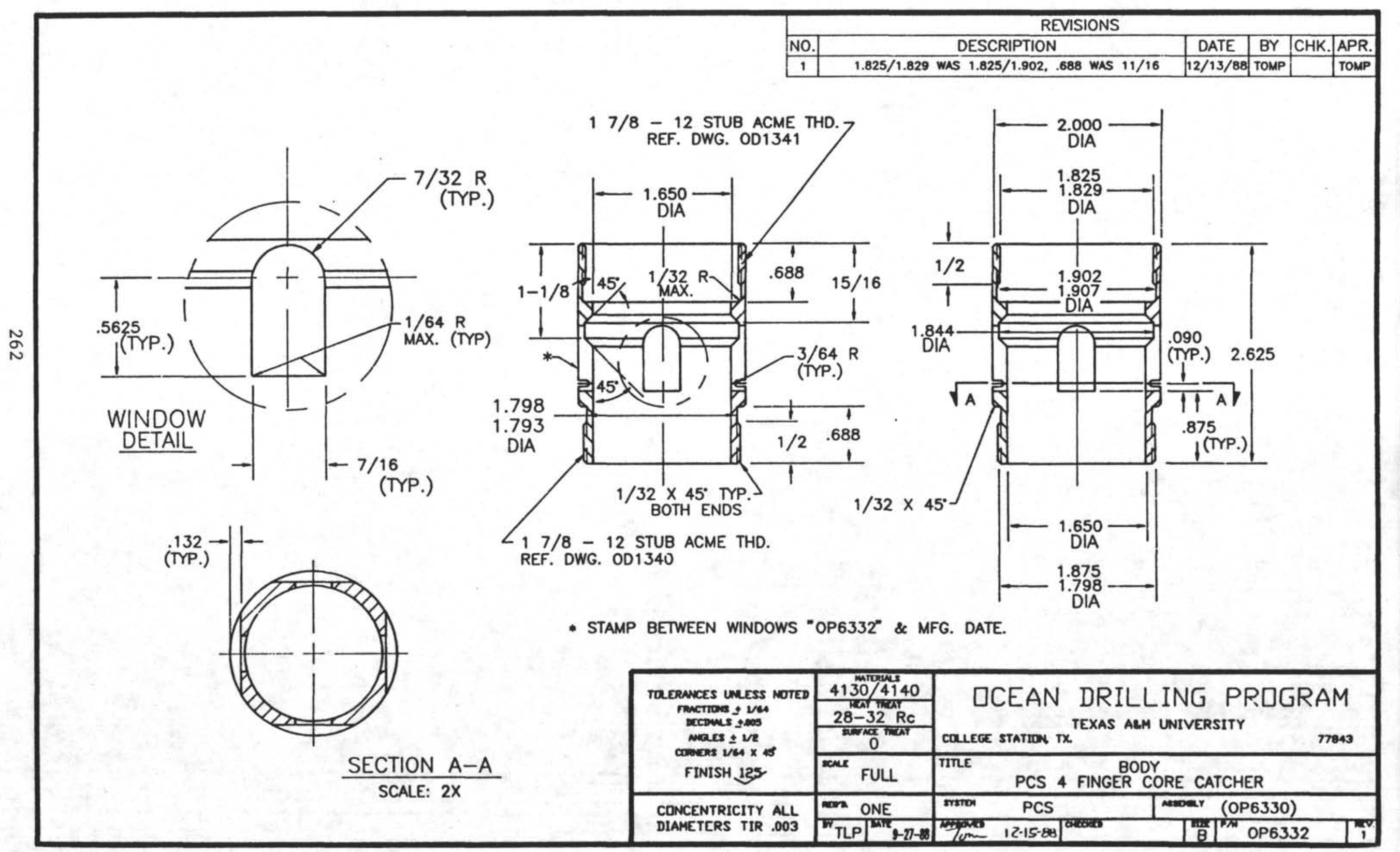




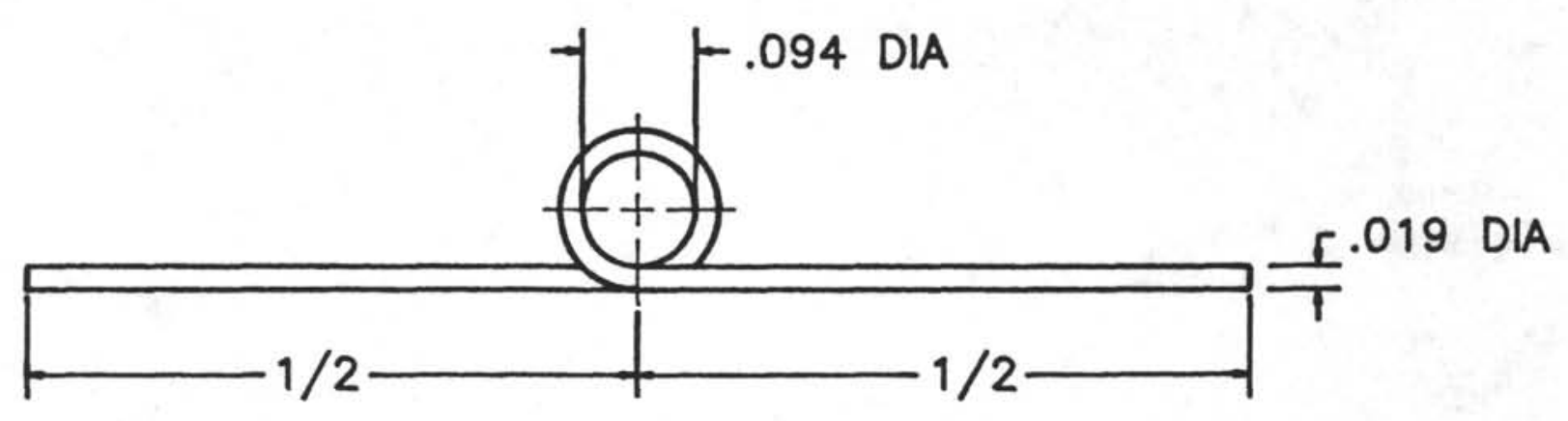

2 - COIL TORSION SPRING

MATERIAL: 17-7 PH OR MUSIC WIRE

NOTE: PLACE IN BAG OR BOX MARKED

W/ OP6334 \& MFG. DATE.

TOLERANCES UMESS NOTED FRACTIONS \& VGA BccDuls \pm Dos wars $\pm 1 / 2$ copuess ע/4 $\times 45$ FINISH 125

CDNCENTRICITY ALL DIAMETERS TIR .003
SEE MTE्यू:

SEE ABOVE क्या पर्य

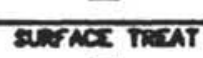
- That

NONE

PCS

creces



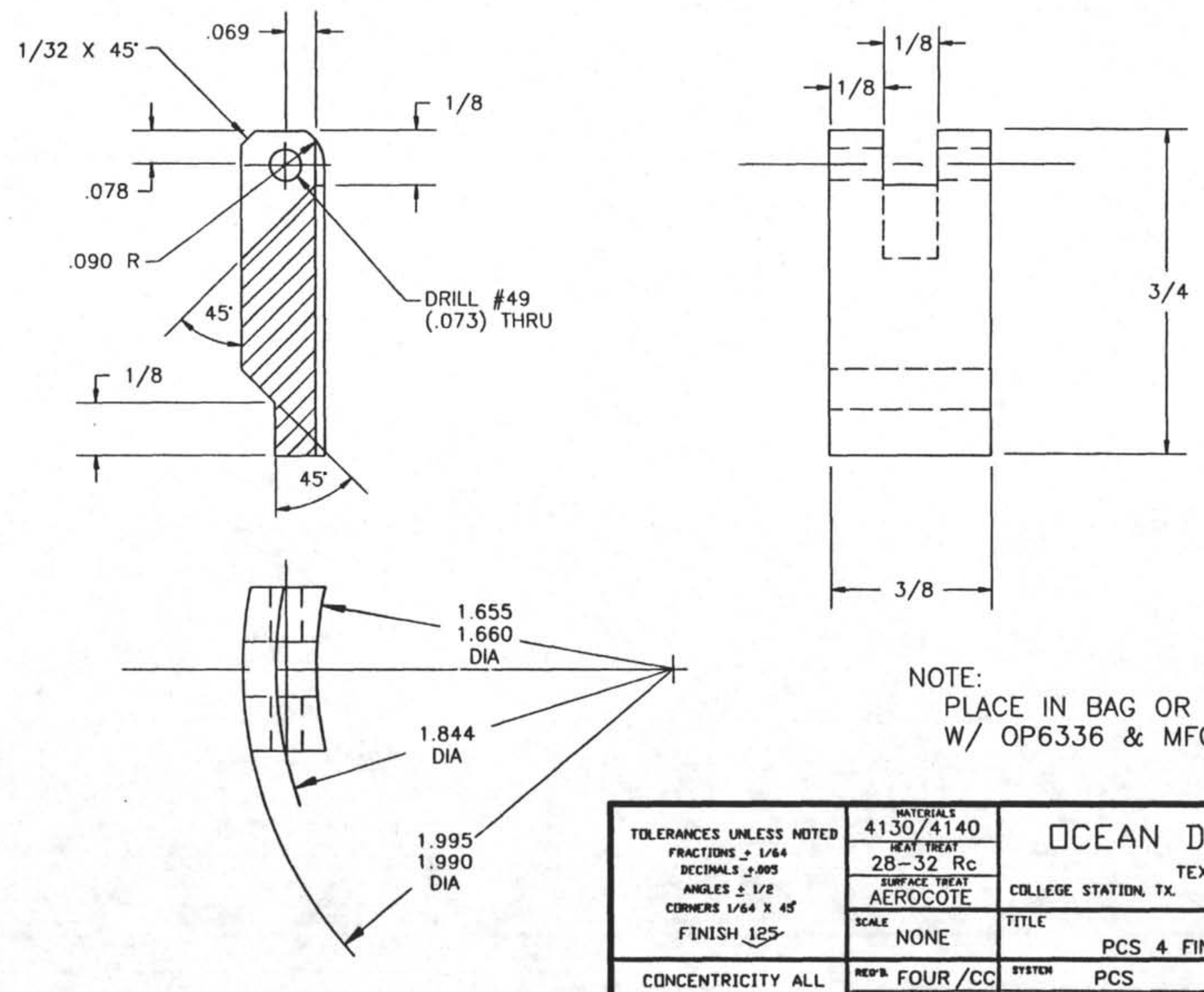

1.655

1.660

DIA

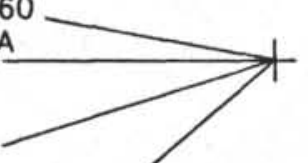

NOTE:

PLACE IN BAG OR BOX MARKED

W/ OP6336 \& MFG. DATE.

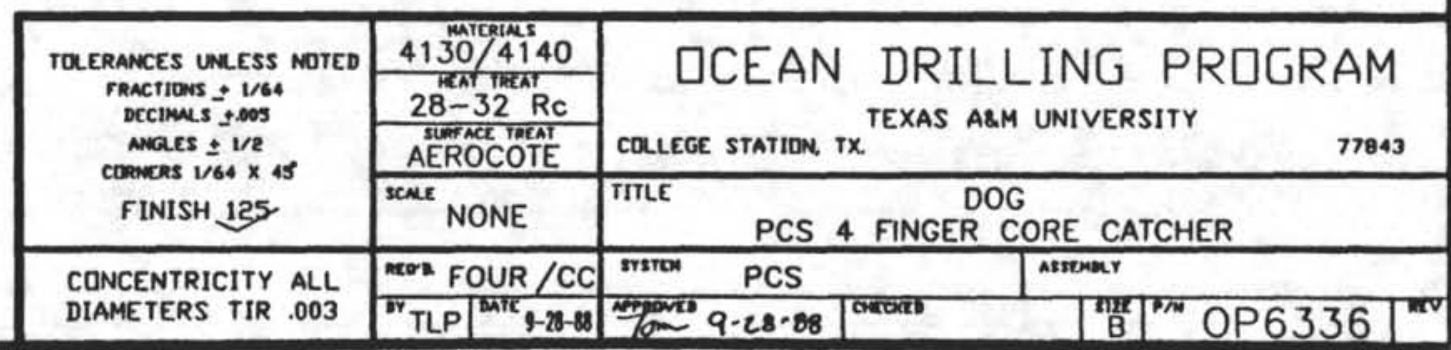




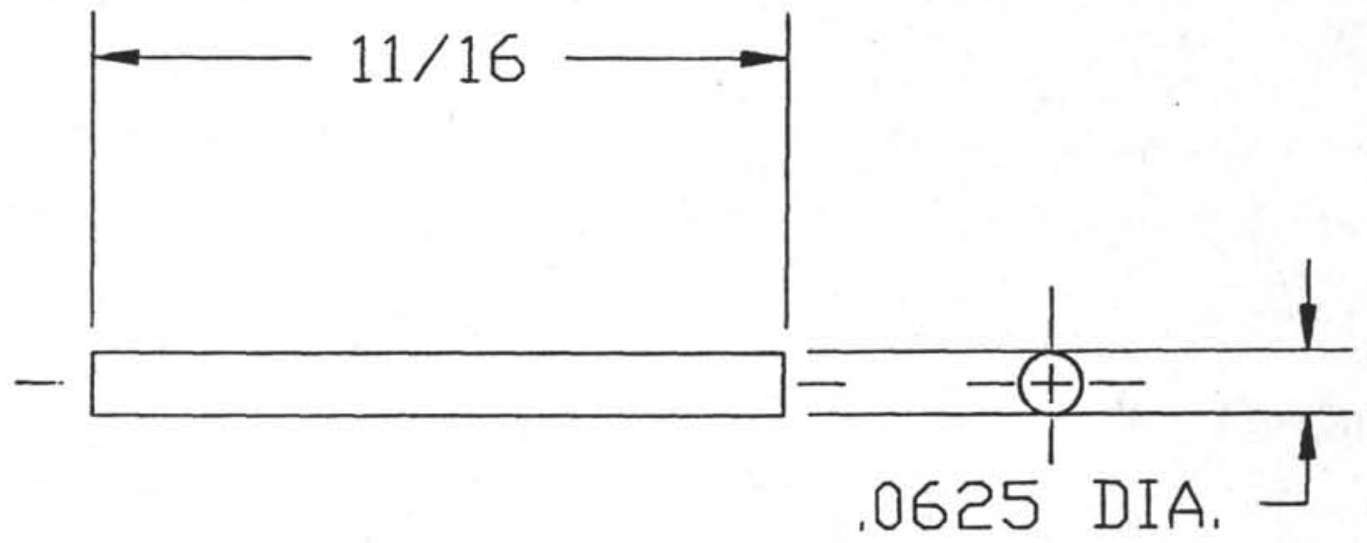

NDTE:

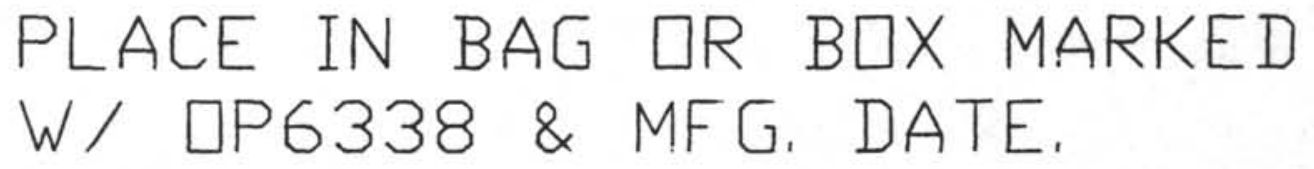

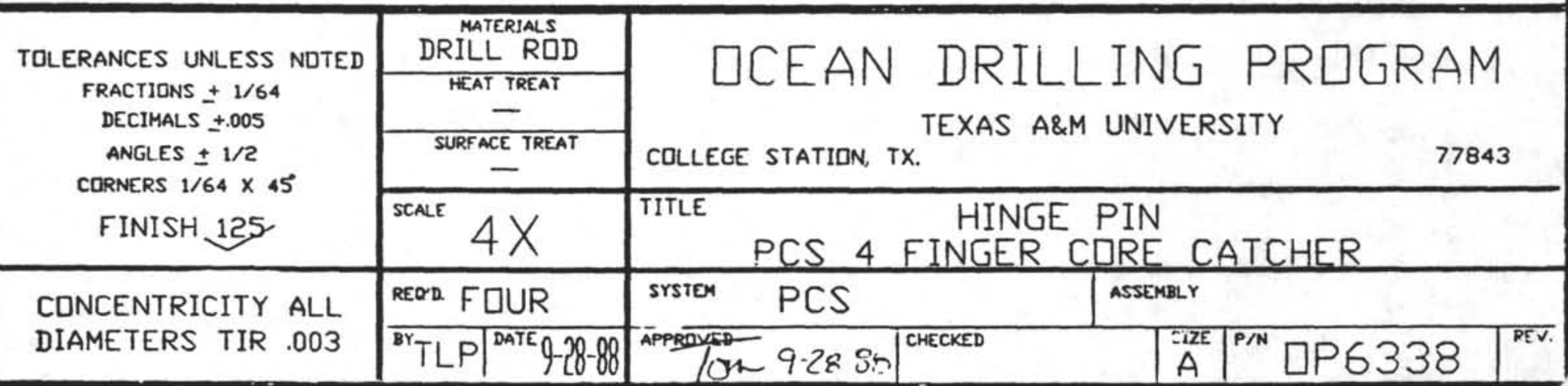




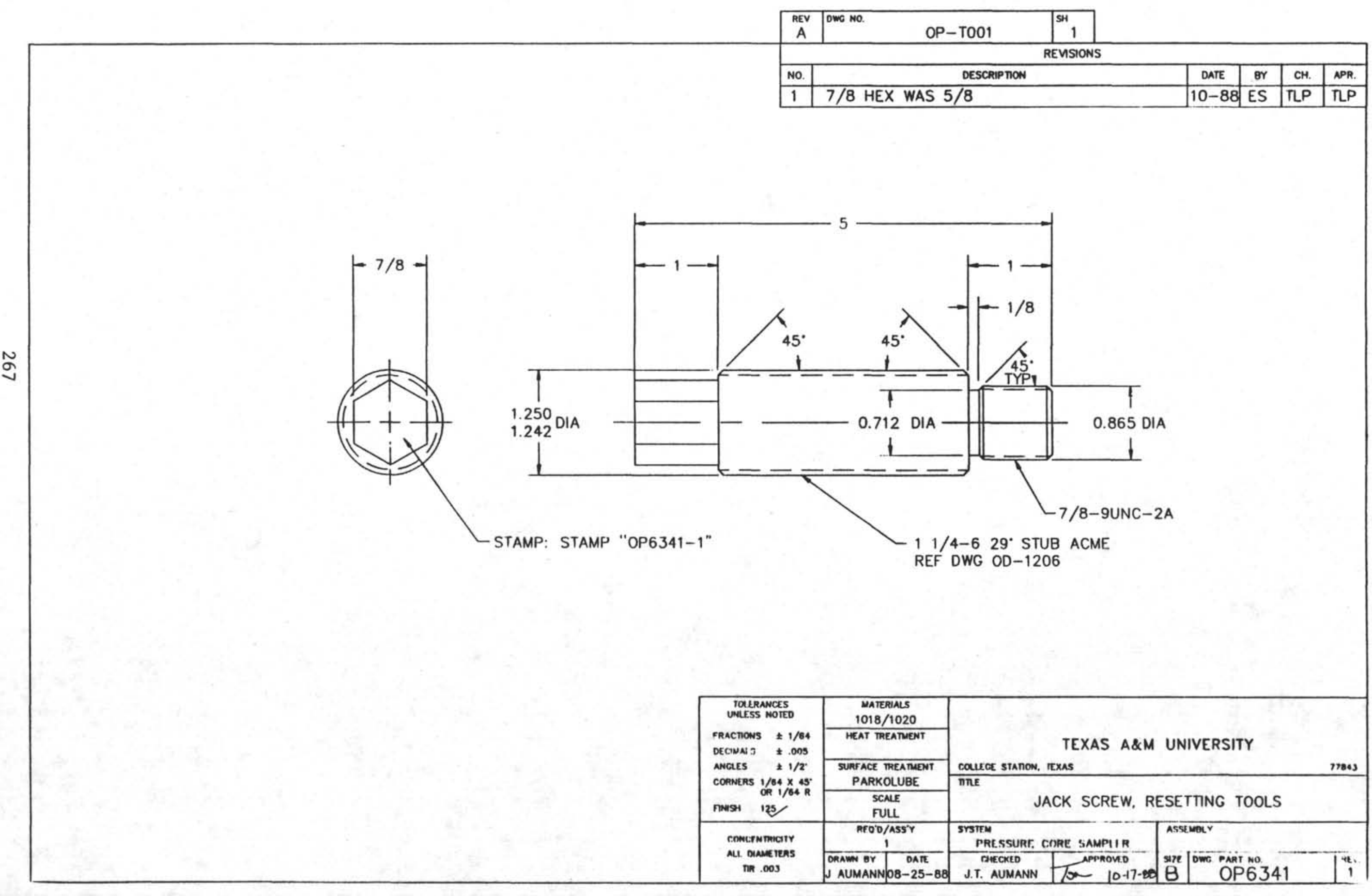




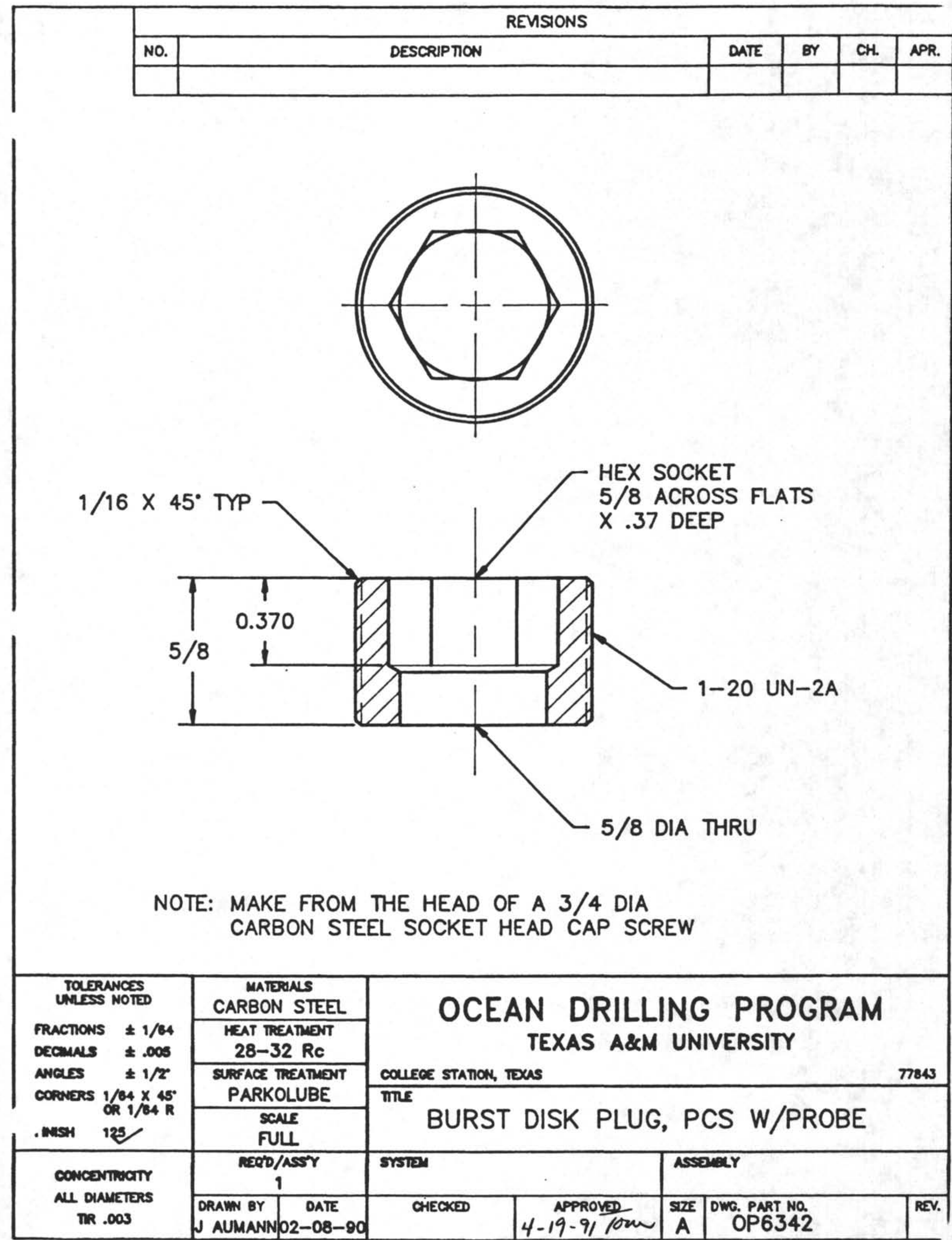




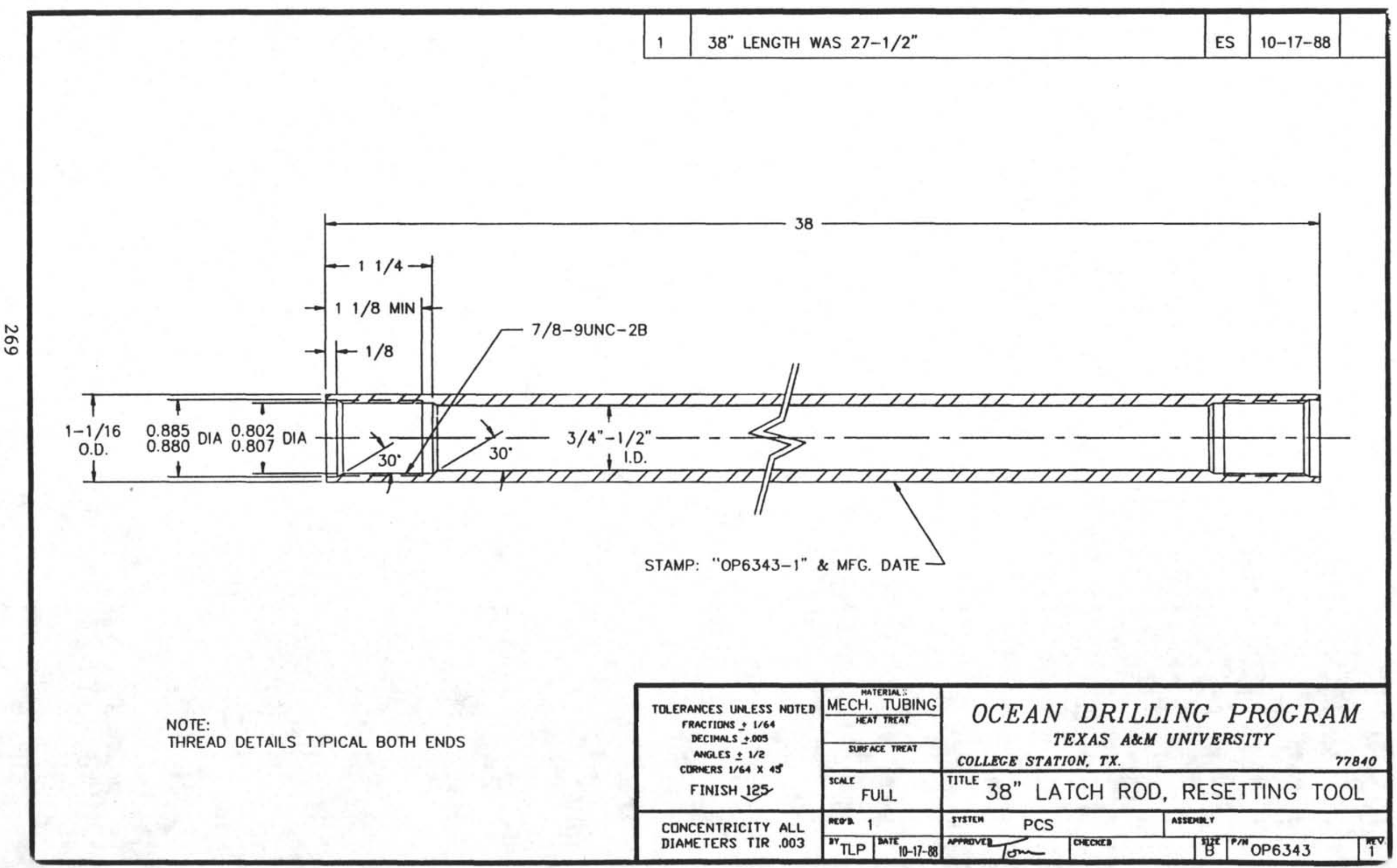




\begin{tabular}{|c|c|c|c|c|c|c|}
\hline \multicolumn{3}{|c|}{ REVSIONS } \\
\hline NO. & DESCRIPTON & DATE & BY & CH. & APR. \\
\hline & & & & & \\
\hline
\end{tabular}

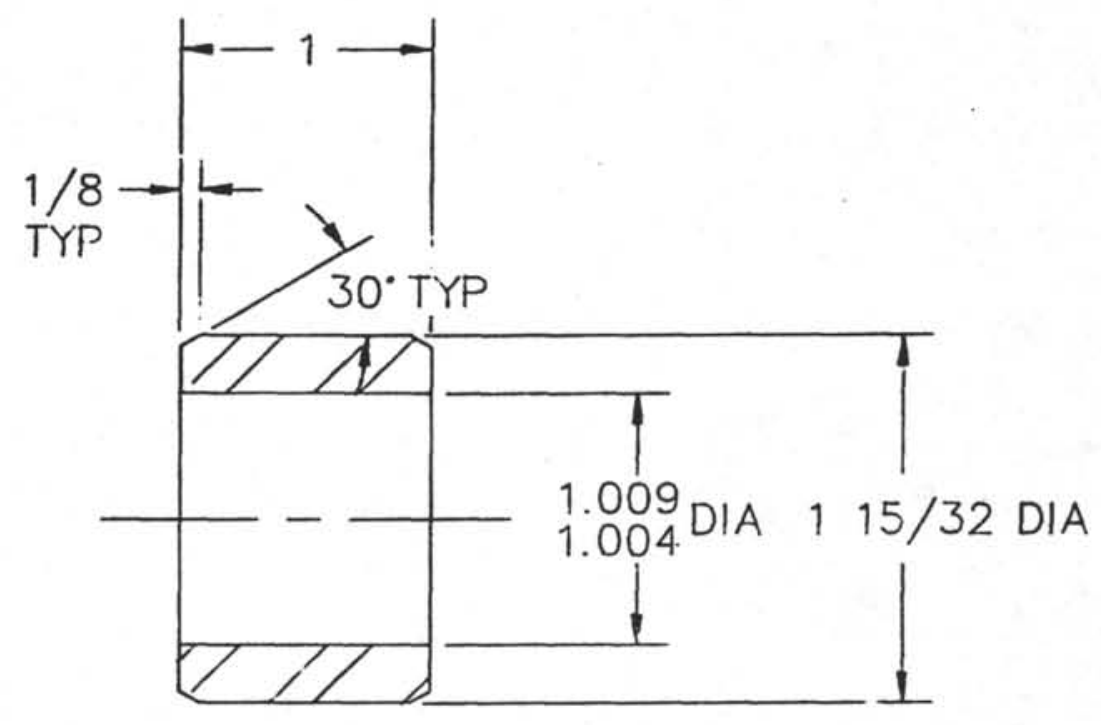

NOTE:

1. TAG OR. BAG MARKED WITH OP6344 \& MFG. DATE

\begin{tabular}{|c|c|c|c|c|c|c|c|}
\hline \multicolumn{2}{|c|}{$\begin{array}{l}\text { TOLERANCES } \\
\text { UNLESS NOIED }\end{array}$} & $\begin{array}{l}\text { MATERIALS } \\
\text { STL } 1018\end{array}$ & \multicolumn{5}{|c|}{ OCFAN DRIIING PROGRAM } \\
\hline \multirow{4}{*}{\multicolumn{2}{|c|}{$\begin{array}{ccc}\text { FRACTIONS } & \pm 1 / 64 \\
\text { CECIMAI.S } & \pm .005 \\
\text { ANGLES } & \pm 1 / 2 . \\
\text { CORNERS } & 164 \times 45^{\circ} \\
& \text { OR }: / 64 \quad \mathrm{R} \\
\text { NISH } & 125\end{array}$}} & HEAT TREATMENT & \multicolumn{5}{|c|}{ TEXAS A\&M UNIVERSITY } \\
\hline & & \multirow{2}{*}{$\begin{array}{l}\text { SURFACE TREATMENT } \\
\text { PARKOLUBE }\end{array}$} & COLLEGE SiATON & EXAS & & & 77843 \\
\hline & & & \multicolumn{5}{|c|}{ nTLE } \\
\hline & & $\begin{array}{l}\text { SCALE } \\
\text { FULL }\end{array}$ & \multicolumn{5}{|c|}{ LATCH HEAD, RELEASE TOOL } \\
\hline \multirow{2}{*}{\multicolumn{2}{|c|}{$\begin{array}{l}\text { CONCENTR:CITY } \\
\text { A.L. DIAMETEOS } \\
\text { הR .003 }\end{array}$}} & $\begin{array}{c}\text { REOU/ASS'Y } \\
1\end{array}$ & \multicolumn{2}{|c|}{$\begin{array}{l}\text { SYSTEM } \\
\text { PRESSURE CORE SAMPLER }\end{array}$} & \multicolumn{3}{|c|}{ ASSEMBLY } \\
\hline & & \begin{tabular}{|l|c|} 
DRAWN BY & DATE \\
J AUMANII & $06-06-88$ \\
\end{tabular} & $\begin{array}{l}\text { CHECKED } \\
\text { JT. AUMANIN }\end{array}$ & APPROVED & SIZE & $\begin{array}{l}\text { DWC. PART NO. } \\
\text { OP } 6344\end{array}$ & PEV. \\
\hline
\end{tabular}




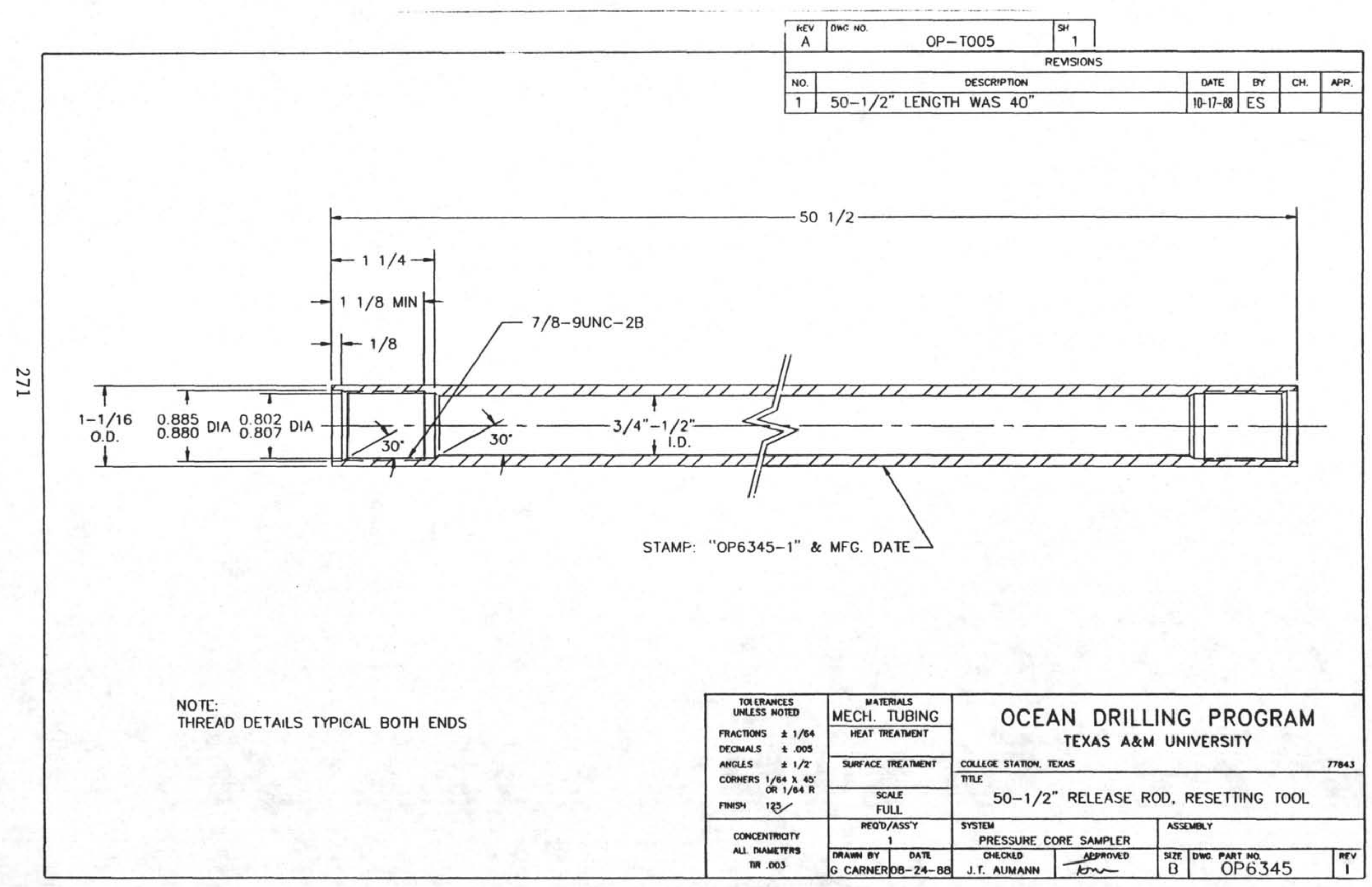




\begin{tabular}{|c|c|c|c|c|c|}
\hline NO. & DESCRIPTION & DATE & BY & $\mathrm{CH}$. & APR. \\
\hline
\end{tabular}

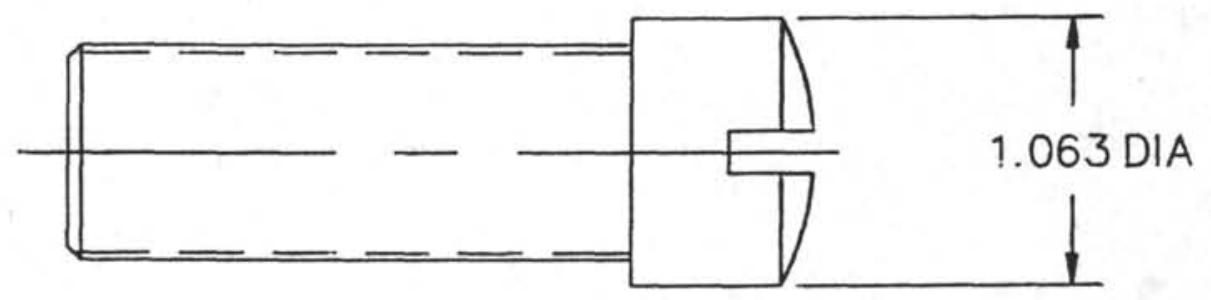

NOTES:

1. MATL: 7/8-9UNC FILISTER HEAD CAP SCREW.

i. TAG OR BAG AND LABEL OP6347 \& MFG. DATE

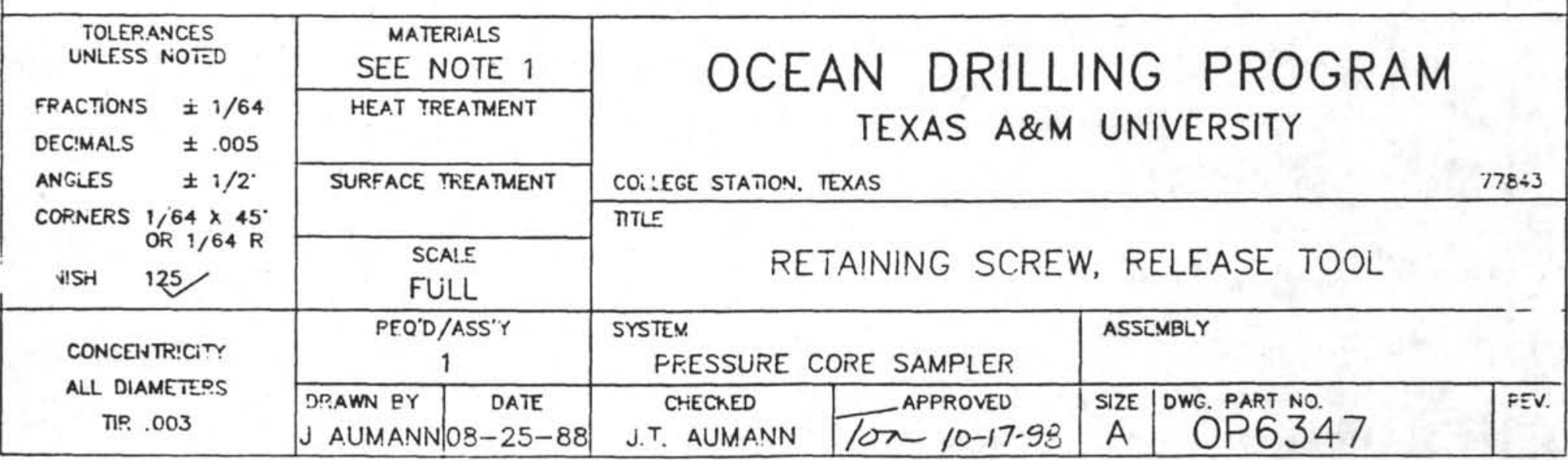


OP6348 PCS BACK PRESSURE REGULATOR VALVE SEAT RETAINER

ORDER AS:

"TESCOM BACK PRESSURE REGULATOR VALVE SEAT RETAINER, PN 1743-2"

SOURCE:

TESCOM CORPORATION

PRESSURE CONTROLS DIVISION

12616 INDUSTRIAL BLVD

ELK RIVER, MINNESOTA 55330

(612) $441-6330$

VIA;

SYSTEM CONTROL

11922 CUTTEN ROAD

HOUSTON, TEXAS 77066

(713) 444-7894

\begin{tabular}{|c|c|c|}
\hline \multirow{3}{*}{ 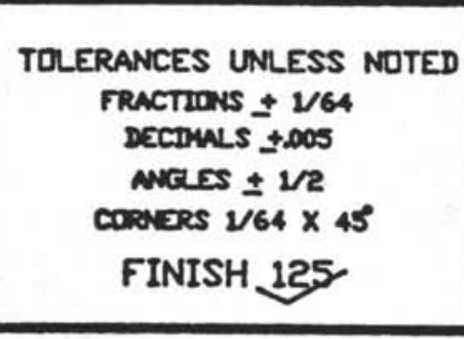 } & MEDTWES TREAT & OCEAN $\underset{T E X A S}{D R I L L I N G} \underset{\text { A\&N UNIVERSITY }}{P R O G R A M}$ \\
\hline & SHFACE TEAT & COLLEGE STATION, TX. \\
\hline & $\operatorname{sen}$ & $\begin{array}{l}\text { TITLEPCS BACK PRESSURE REGULATOR } \\
\text { VALVE SEAT RETAINER }\end{array}$ \\
\hline \multirow{2}{*}{$\begin{array}{l}\text { CDNCENTRICITY ALL } \\
\text { DIAMETERS TIR } .003\end{array}$} & 2002 & assouer OP6200 \\
\hline & \begin{tabular}{l|l|} 
TOMP & $12 / 15 / 88$ \\
\end{tabular} & 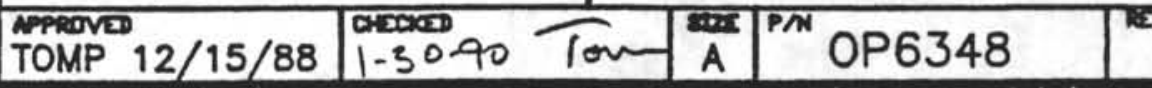 \\
\hline
\end{tabular}




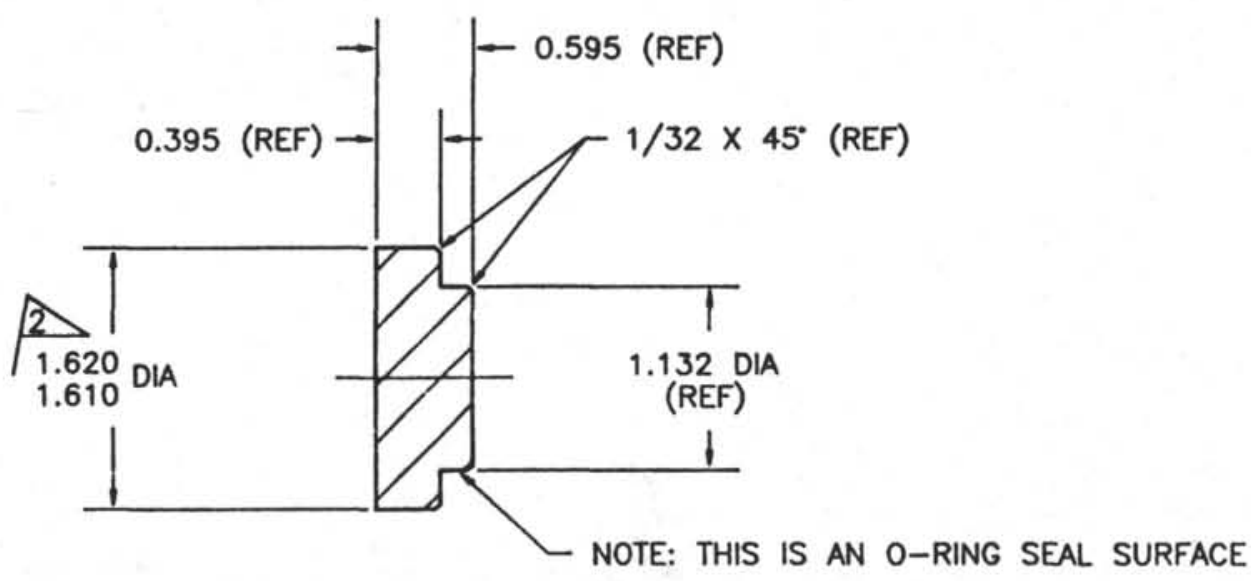

NOTES:

1) THE SENSOR ASSEMBLY (ODP PN OP6354) IS PURCHASED AS AN ASSEMBLY FROM TESCOM (TESCOM PN 1738-20) VIA SYSTEM CONTROL, HOUSTON AND IS MADE UP OF THE FOLLOWING TESCOM PARTS;

1. SPRING PAD (TESCOM PN 1741-1)

2. SENSOR BACK-UP (TESCOM PN 1010-2)

2. SENSOR BACK-UP (TESCO

4. SPACER (TESCOM PN 2287-2)

5. BACK-UP RING (TESCOM PN 5475-012)

6. 0-RING (TESCOM PN 5200-000127)

7. SPRING (TESCOM PN 1022)

8. VALVE STEM (TESCOM PN 1744-2)

9. SENSOR (TESCOM PN 1742-2)

2) THE SENSOR BACK-UP (TESCOM PN 1010-2) OD MUST BE TURNED DOWN TO $1.620 / 1.610$ DIA. AS INDICATED ABOVE.

\begin{tabular}{|c|c|c|}
\hline \multirow{3}{*}{ 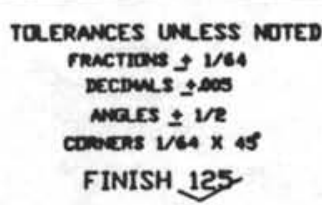 } & & \multirow{2}{*}{$\begin{array}{c}\text { OCEAN DRILLING PROGRAM } \\
\text { TEXAS A\&M UNIVERSITY } \\
\text { COLLAGE STATION, TX. }\end{array}$} \\
\hline & \multirow{2}{*}{ 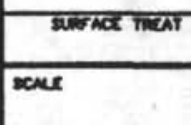 } & \\
\hline & & PCS SENSOR ASSEMBLY \\
\hline \multirow{2}{*}{$\begin{array}{l}\text { CDNCENTRICITY ALL } \\
\text { DIAMETERS TIR } .003\end{array}$} & menan & s "raton \\
\hline & the & 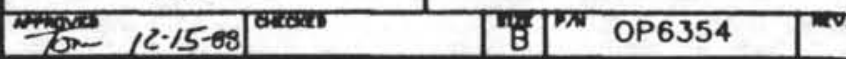 \\
\hline
\end{tabular}


OP6356 PCS BACK PRESSURE REGULATOR LOAD SPRING

ORDER AS:

"TESCOM BACK PRESSURE REGULATOR LOAD SPRING, PN 1051"

SOURCE:

TESCOM CORPORATION

PRESSURE CONTROLS DIVISION

12616 INDUSTRIAL BLVD

ELK RIVER, MINNESOTA 55330

(612) $441-6330$

VIA:

SYSTEM CONTROL

11922 CUTTEN RD

HOUSTON, TEXAS 77066

(713) $444-7894$

TOLERANCES UNLESS NDTED

FRACTIONS — 1/64

DECDULS \pm 005

ANG: $: s \pm 1 / 2$

CORNERS $1 / 64 \times 45^{\circ}$

FINISH 125

CDNCENTRICITY ALL

DIAMETERS TIR .003

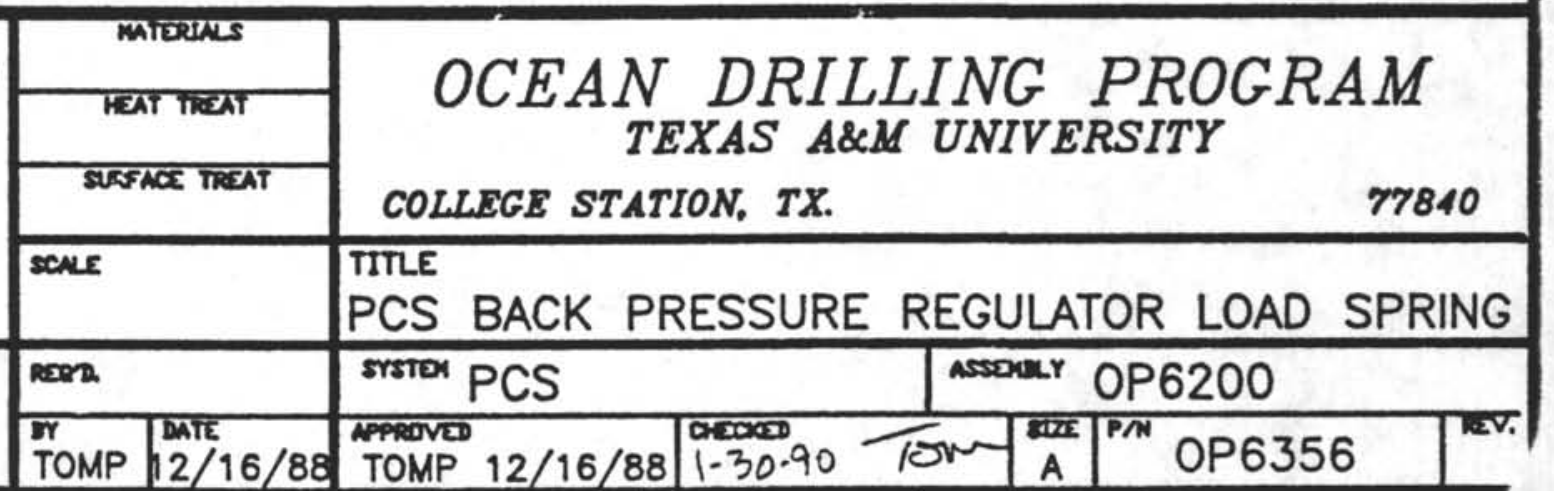


OP6358 PCS PRESSURE TRANSDUCER

ORDER AS:

"BP312DV, MODEL A-205 GAGE PRESSURE TRANSDUCER, 150-10,000 PSI RANGE"

SOURCE:

SENSOTEC, INC.

1200 CHESAPEAKE AVE.

COLUMBUS, OHIO 43212

(614) $486-7723$

NOTE:

MATING CONNECTOR;

AA111, PT1H-10-6P

\begin{tabular}{|c|c|c|}
\hline $\begin{array}{l}\text { TOLERANCES UNLESS NOTED } \\
\text { FRACTIONS } \pm 1 / 64 \\
\text { DECDWLS } \pm+005\end{array}$ & महका Tास्था & OCEAN $\underset{T E X A S}{D R I L L I N G} \underset{\text { A\&M UNIVERSITY }}{P R O G R A M}$ \\
\hline $\begin{array}{l}\text { MUESS } \pm 1 / 2 \\
\text { CDRERS } 1 / 64 \times 45\end{array}$ & SIFAACE TREAT & COLLEGE STATION, TX. \\
\hline FINISH 125 & $\operatorname{sen} 1$ & ${ }^{\text {TITLE }}$ PCS PRESSURE TRANSDUCER \\
\hline \multirow{2}{*}{$\begin{array}{l}\text { CDNCENTRICITY ALL } \\
\text { DIAMETERS TIR } .003\end{array}$} & 10202 & Assoury OP6200 \\
\hline & \begin{tabular}{|l|l|} 
TOMP & MATE \\
TOM & 19 \\
\end{tabular} & 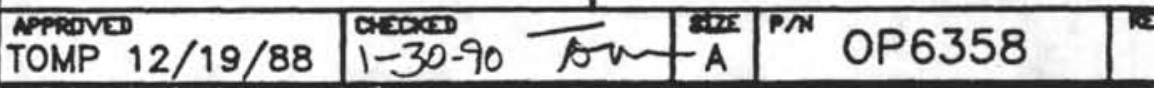 \\
\hline
\end{tabular}




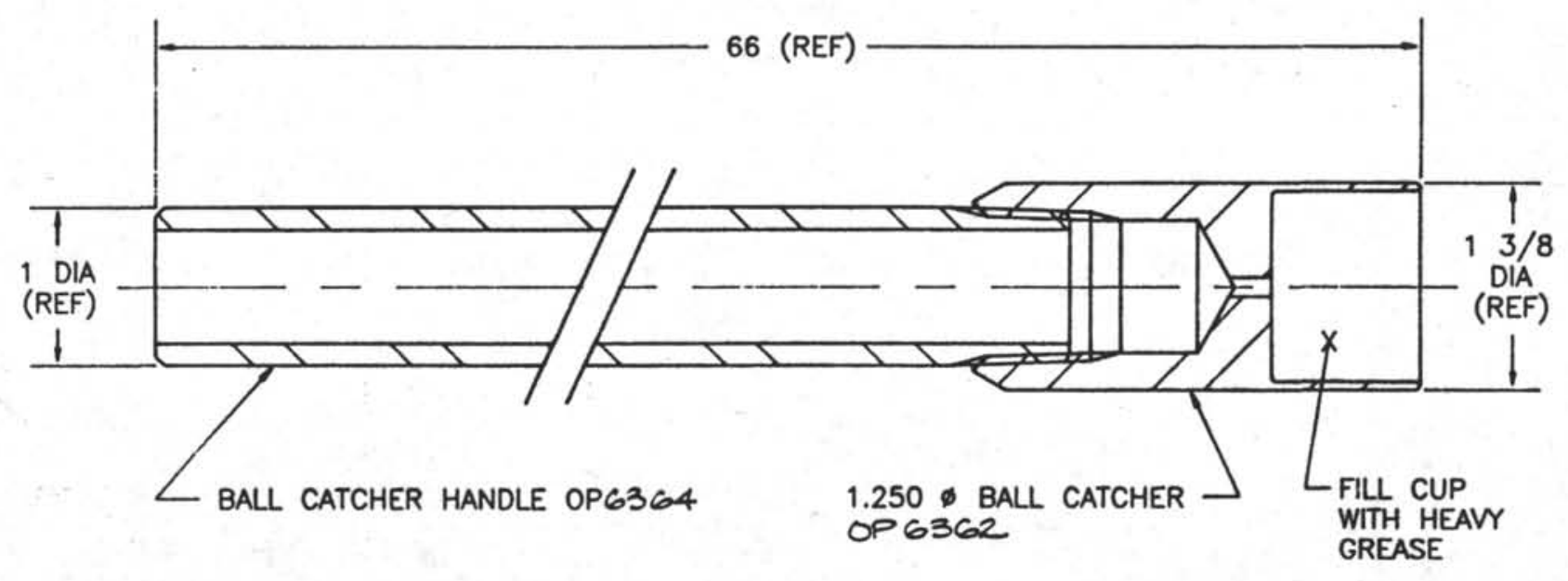

\begin{tabular}{|c|c|c|}
\hline \multirow{2}{*}{ 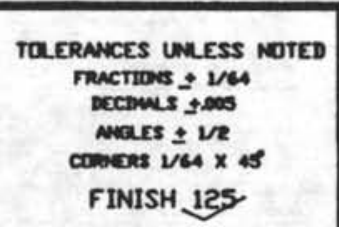 } & 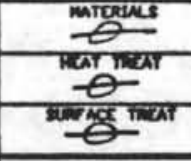 & $\begin{array}{l}\text { OCEAN DRILLING PROGRAM } \\
\text { TEXAS A\&N UNIVERSITY } \\
\text { COLLAGE STATION, TX. }\end{array}$ \\
\hline & scons FULL & TITLE $1-1 / 4^{\prime \prime}$ DIA. BALL CATCHER TOOL ASSEMBLY \\
\hline \multirow{2}{*}{$\begin{array}{l}\text { CONCENTRICITY ALL } \\
\text { DIAMETERS TIR } .003\end{array}$} & 0 & newoer $(O P G 200)$ \\
\hline & & 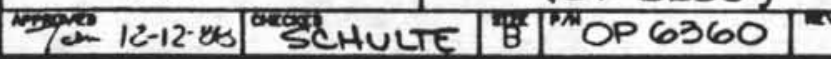 \\
\hline
\end{tabular}




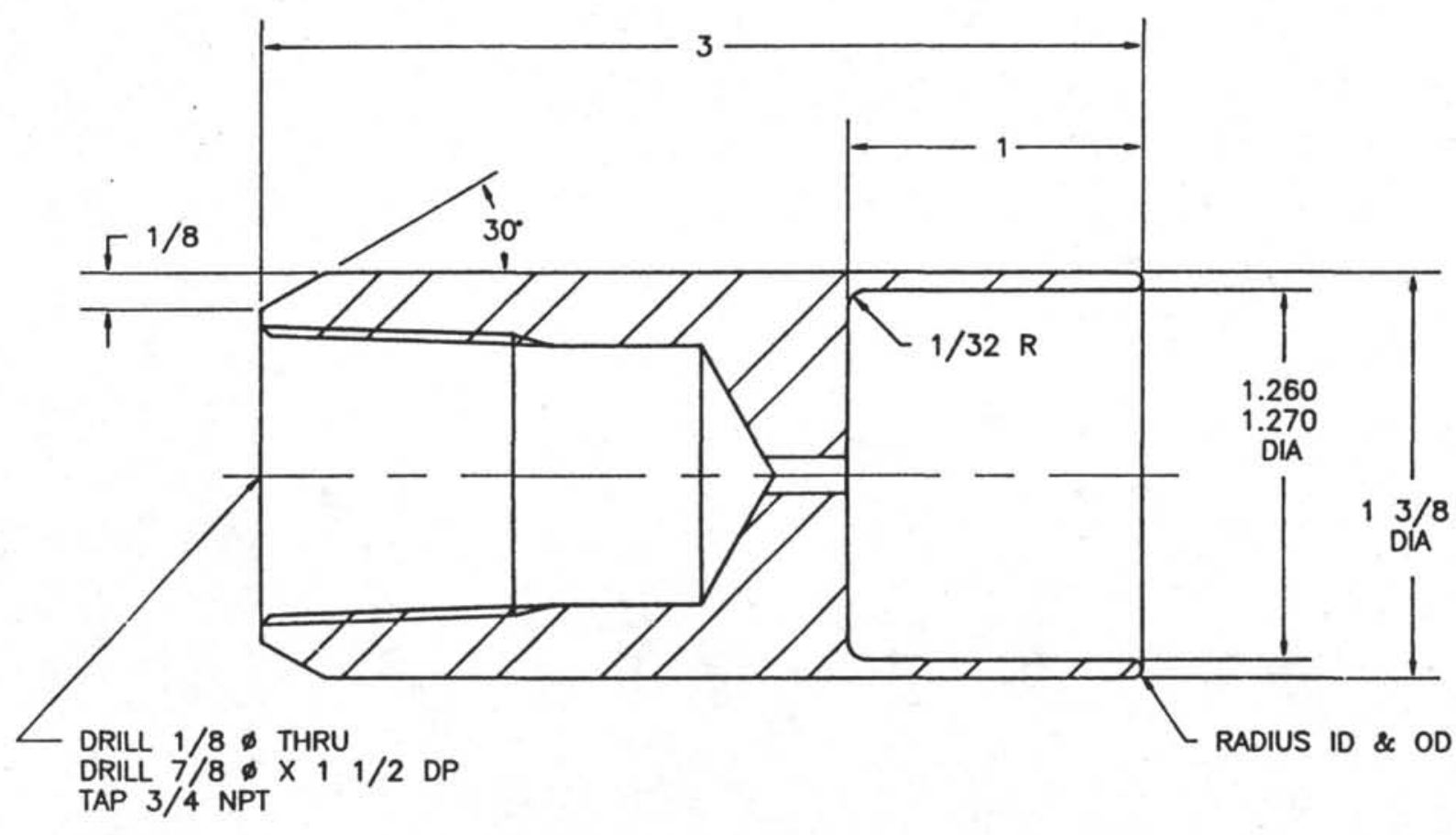

NOTE:

MATL: $4130 / 40 \quad 1018 / 20$

\begin{tabular}{|c|c|c|}
\hline \multirow{2}{*}{ 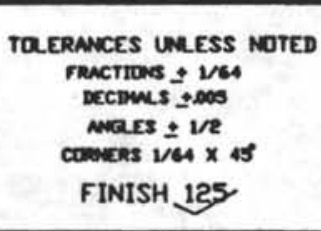 } & 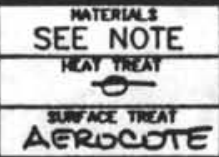 & $\begin{array}{l}\text { OCEAN DRILLING PROGRAM } \\
\text { TEXAS A\&M UNIVERSITY } \\
\text { COLLBCE STATTON, TX. }\end{array}$ \\
\hline & $2 x$ & BALL CATCHER, 1.250 \\
\hline \multirow{2}{*}{$\begin{array}{l}\text { CDNCENTRICITY ALL } \\
\text { DIAMETERS TIR } .003\end{array}$} & ONE & $\left(0 P_{6200)}\right.$ \\
\hline & HLP & $0 P 6362$ \\
\hline
\end{tabular}




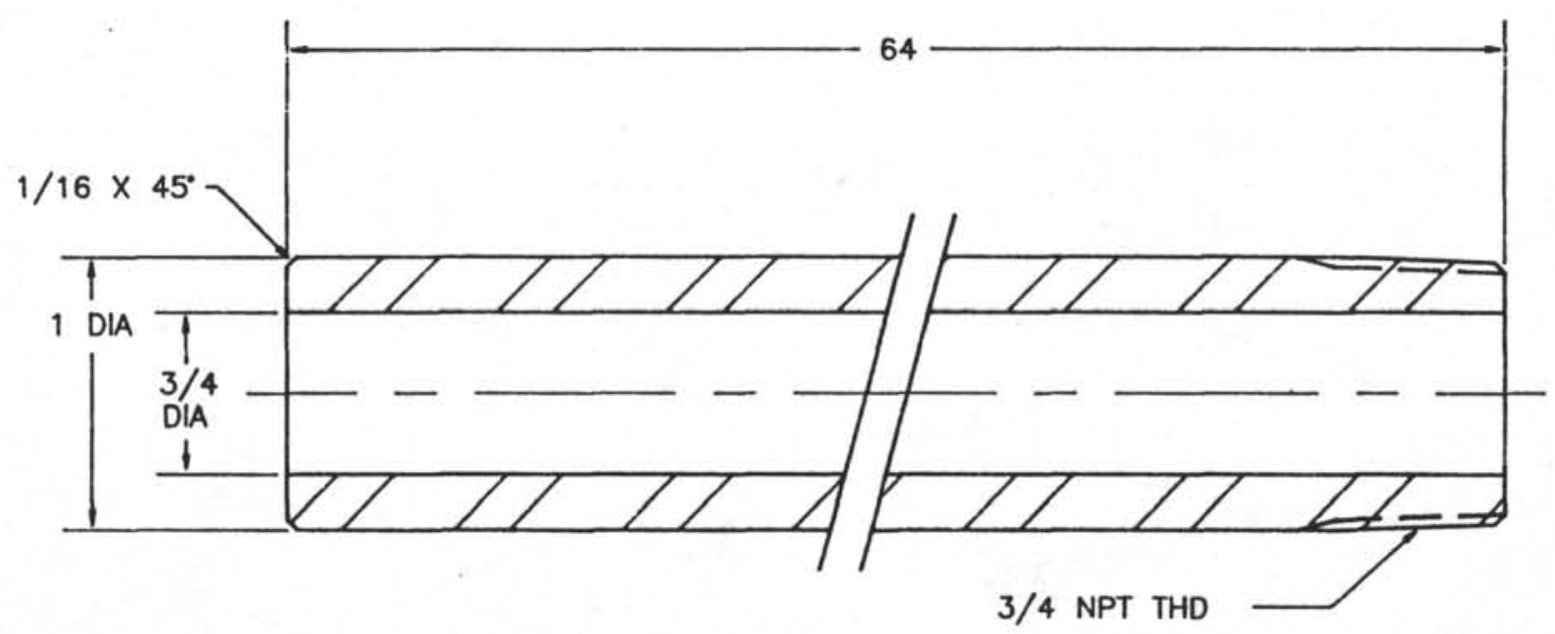

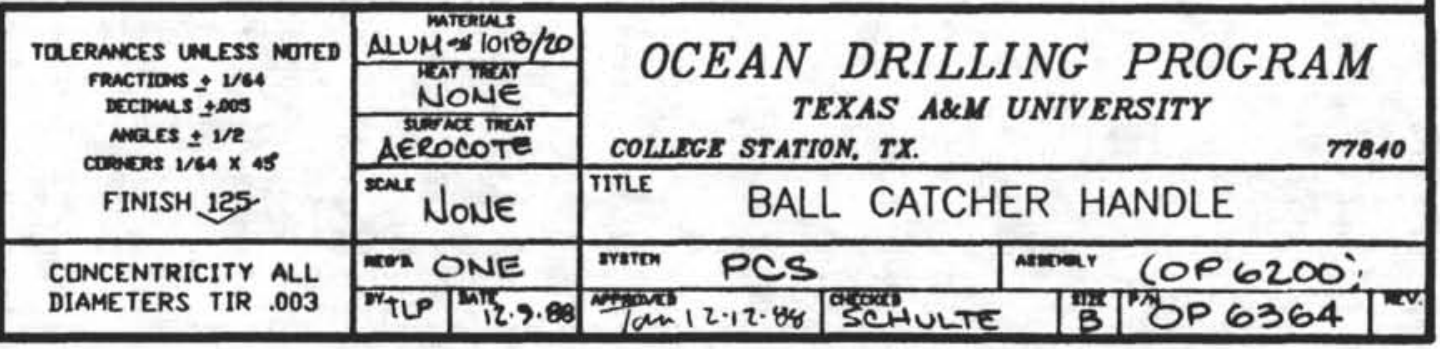




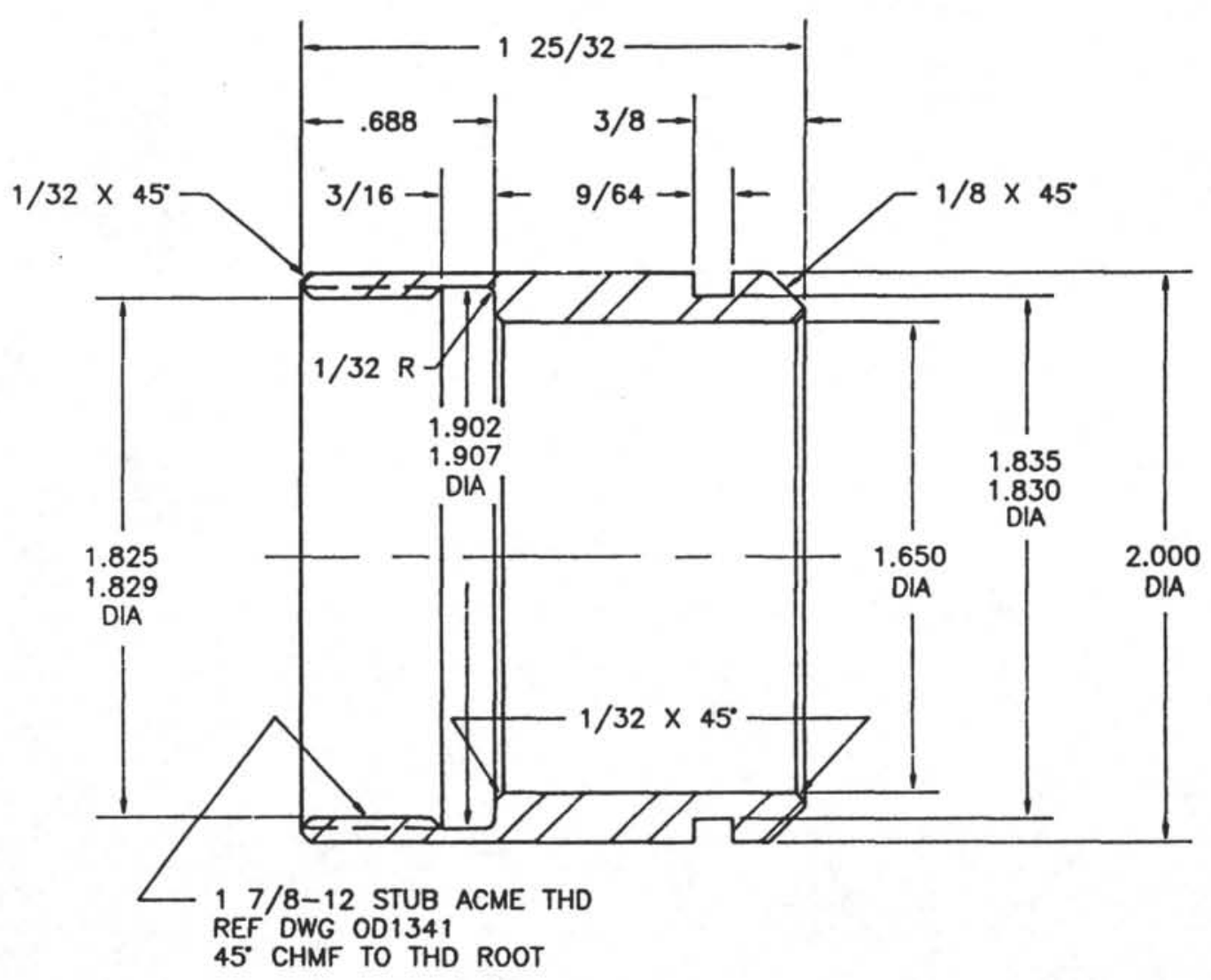

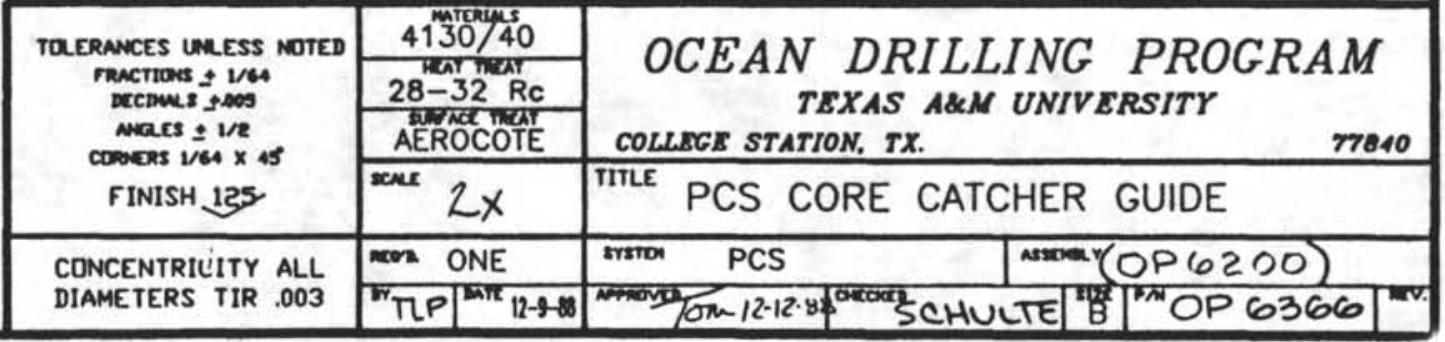




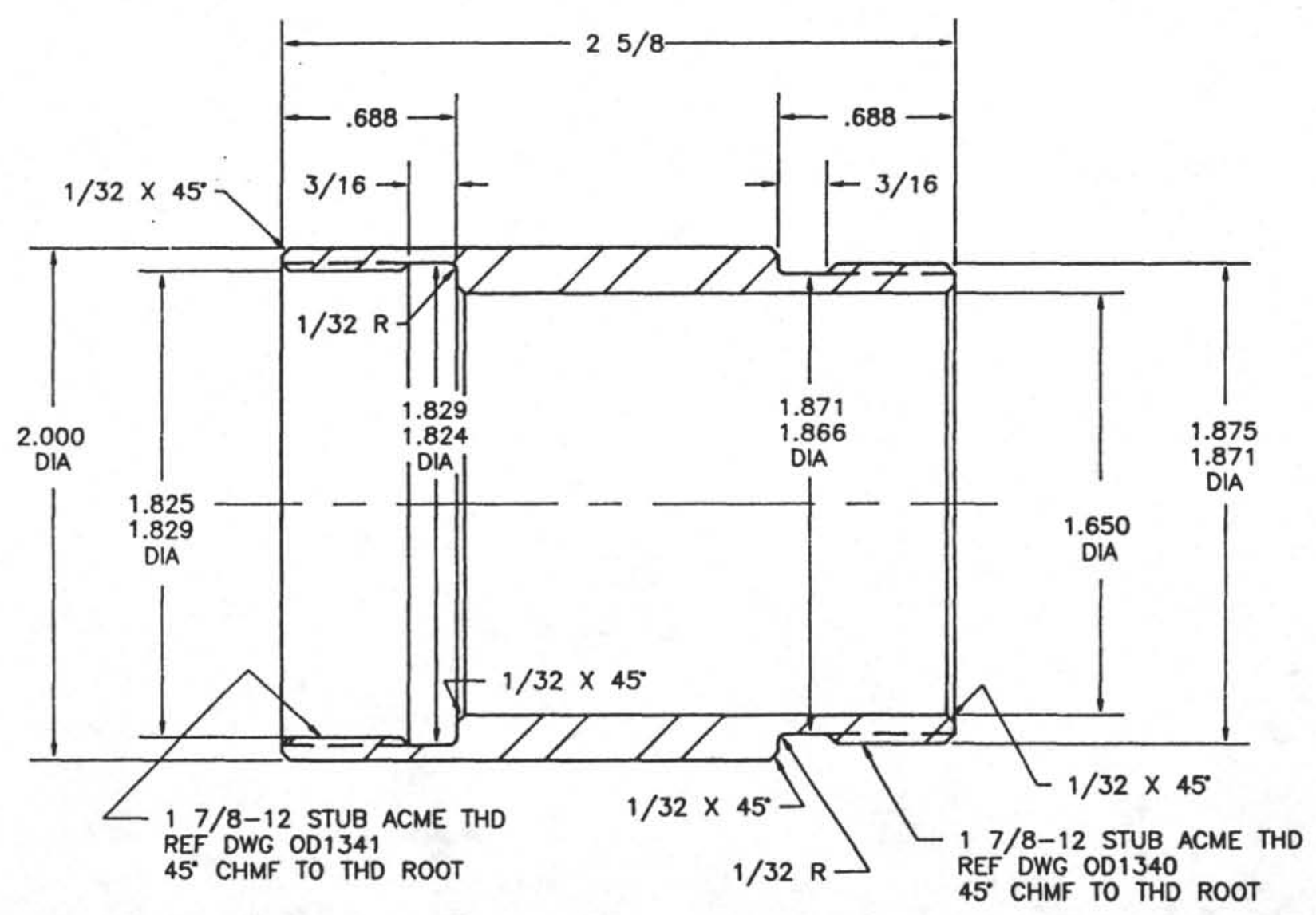

NOTE: THIS SPACER REPLACES THE PCS COG CORE CATCHER

\begin{tabular}{|c|c|c|}
\hline \multirow{3}{*}{ 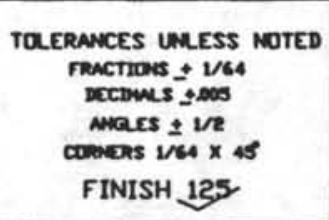 } & 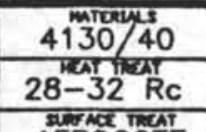 & \multirow{2}{*}{$\begin{array}{l}\text { OCEAN DRILLING PROGRAM } \\
\text { TEXAS A\&N UNIVERSITY } \\
\text { COLLAGE STATION, TX. }\end{array}$} \\
\hline & $\begin{array}{l}\text { AEROCOTE } \\
\text { scur }\end{array}$ & \\
\hline & $2 x$ & \\
\hline \multirow{2}{*}{$\begin{array}{l}\text { CONCENTRICITY ALL } \\
\text { DIAMETERS TIR } .003\end{array}$} & ONE & (66200) \\
\hline & LP & LTE \\
\hline
\end{tabular}




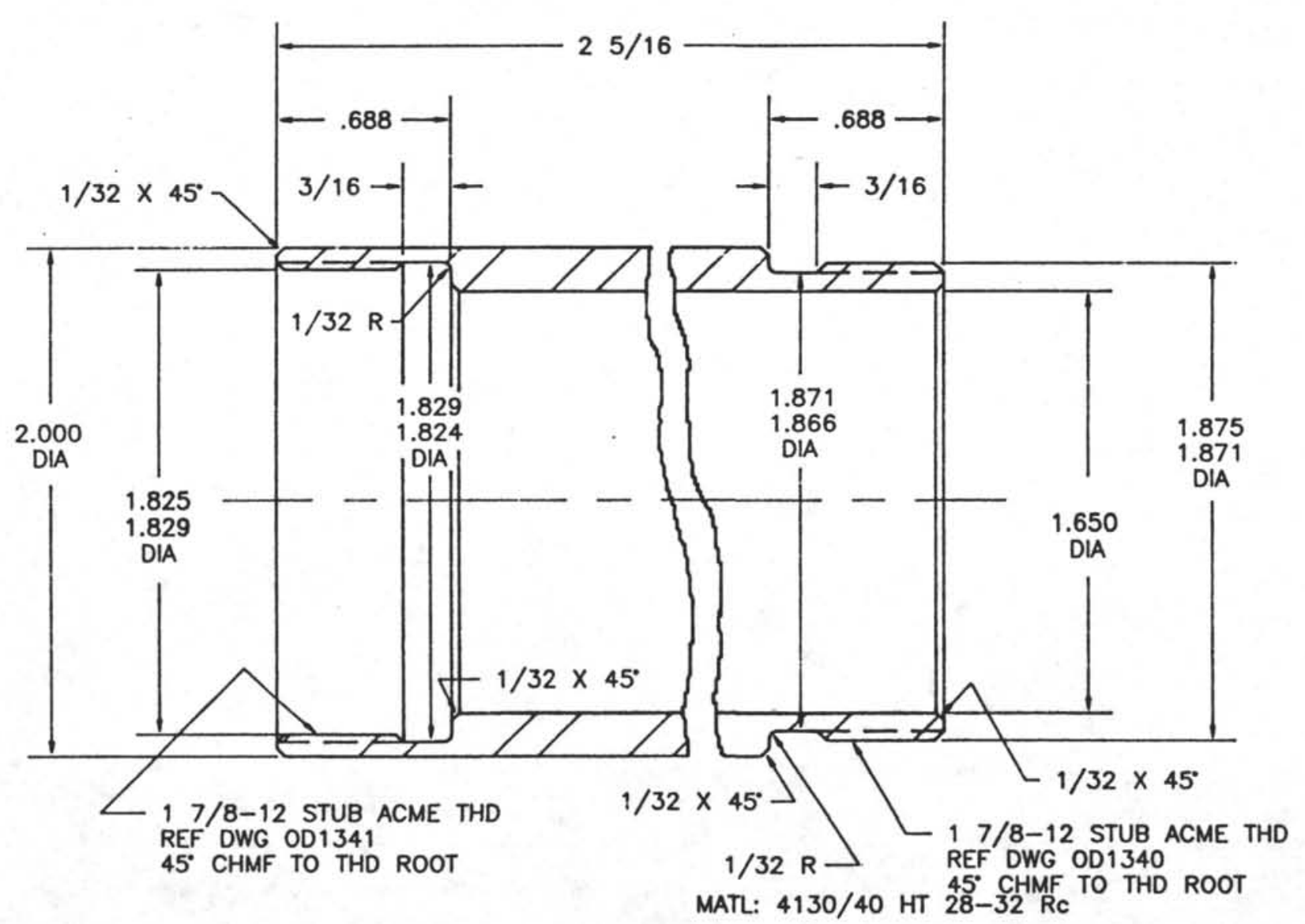

NOTE: THIS SLEEVE IS USED WHEN RUNNING TWO DOG CC IN THE PCS

\begin{tabular}{|c|c|c|}
\hline 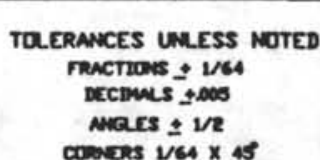 & 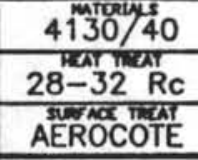 & $\begin{array}{l}\text { OCEAN DRILLING PROGRAM } \\
\text { TEXAS ARM UNIVERSITY } \\
\text { COLLBGE STATION, TX. }\end{array}$ \\
\hline FINISH 125 & $2 x$ & 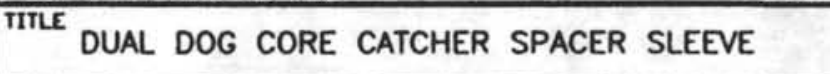 \\
\hline C & ONE & nosoar (OP 6200) \\
\hline
\end{tabular}




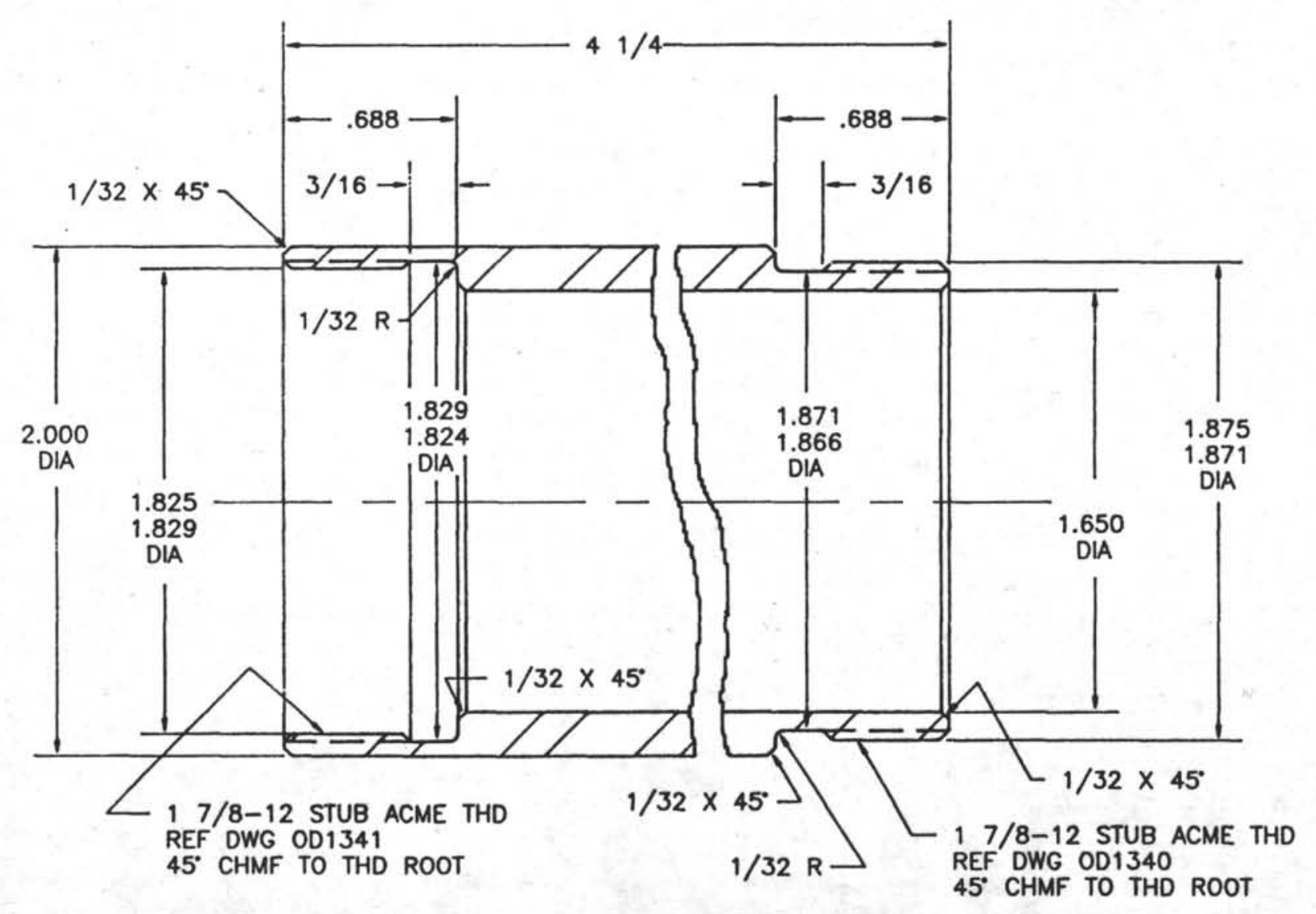

NOTE: THIS SPACER REPLACES THE PCS

\begin{tabular}{|c|c|c|}
\hline 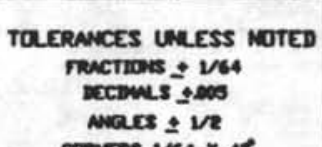 & 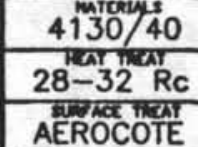 & $\begin{array}{l}\text { OCEAN DRILLING PROGRAM } \\
\text { TEXAS A\&N UNIVERSITY } \\
\text { COLLAGE STATION, TX. }\end{array}$ \\
\hline FINISH 125 & $2 x$ & TITLE FLAPPER CORE CATCHER SPACER SLEEVE \\
\hline & $\operatorname{mon} 0$ & mast: PCS \\
\hline
\end{tabular}



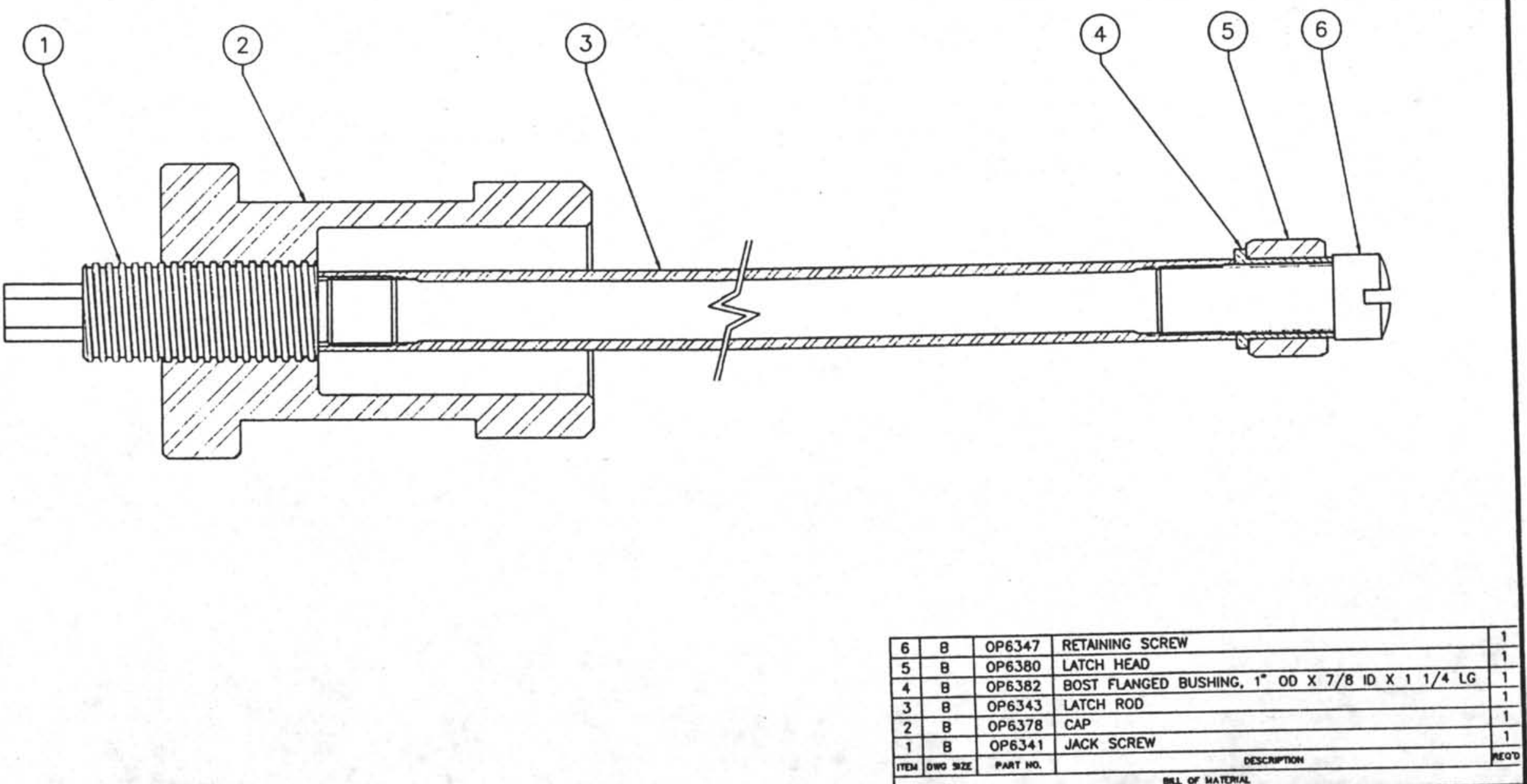

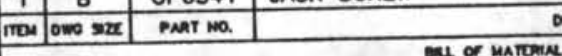

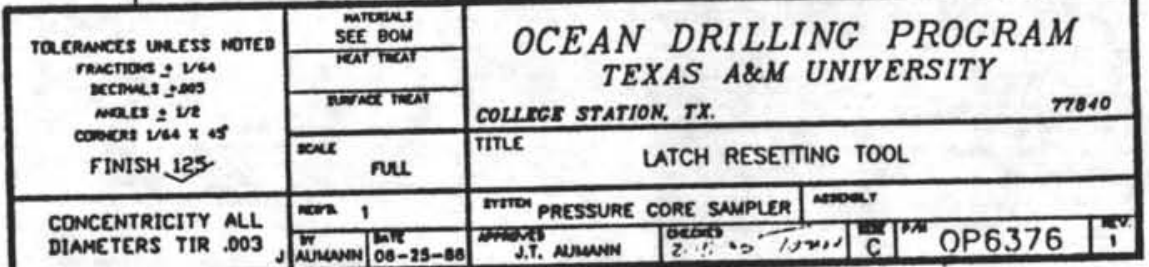




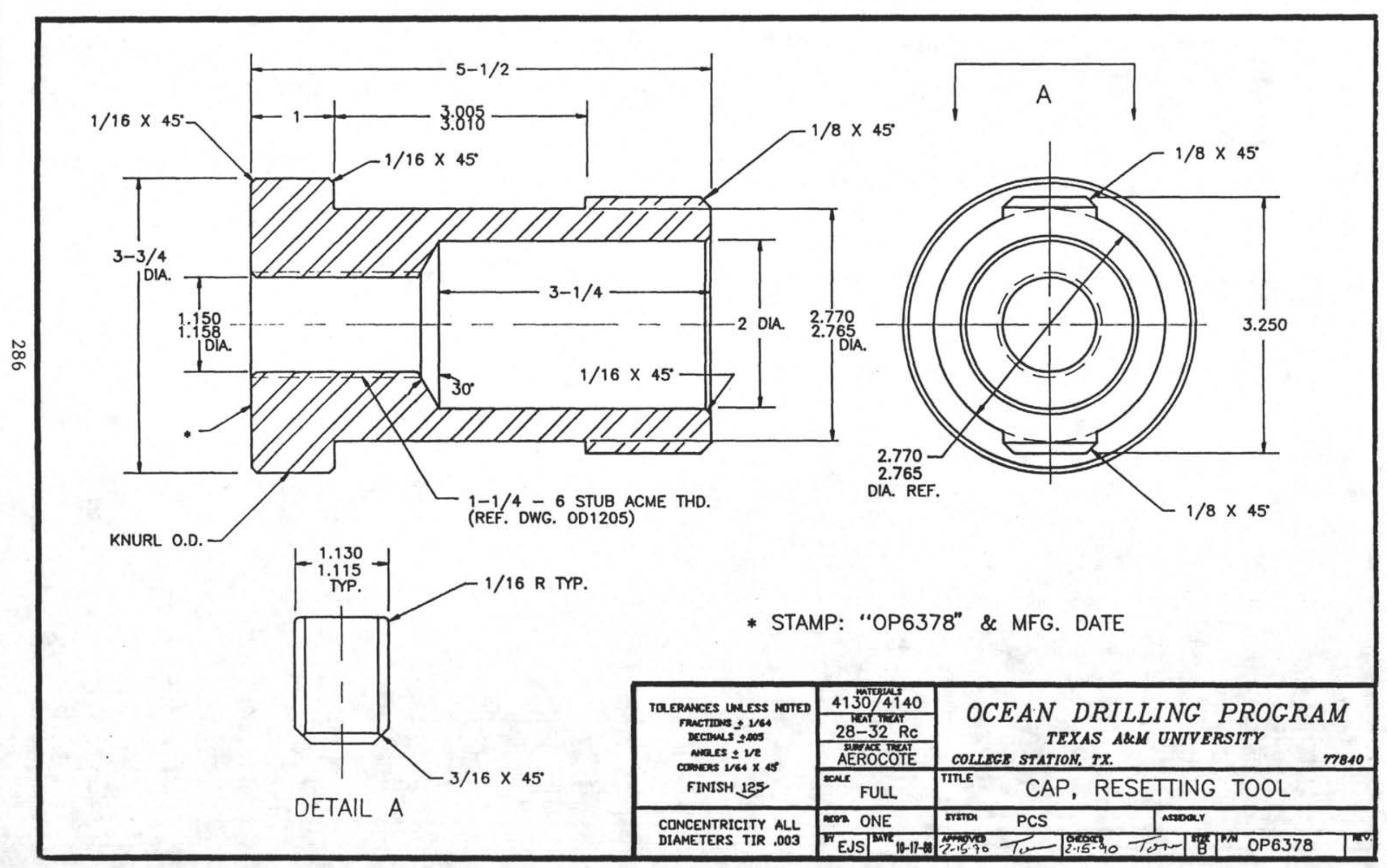




\section{REMSIONS}

\begin{tabular}{|c|c|c|c|c|c|}
\hline NO. & DESCRIPTON & DATE & BY & CH. & APR \\
\hline & & & & & \\
\hline
\end{tabular}

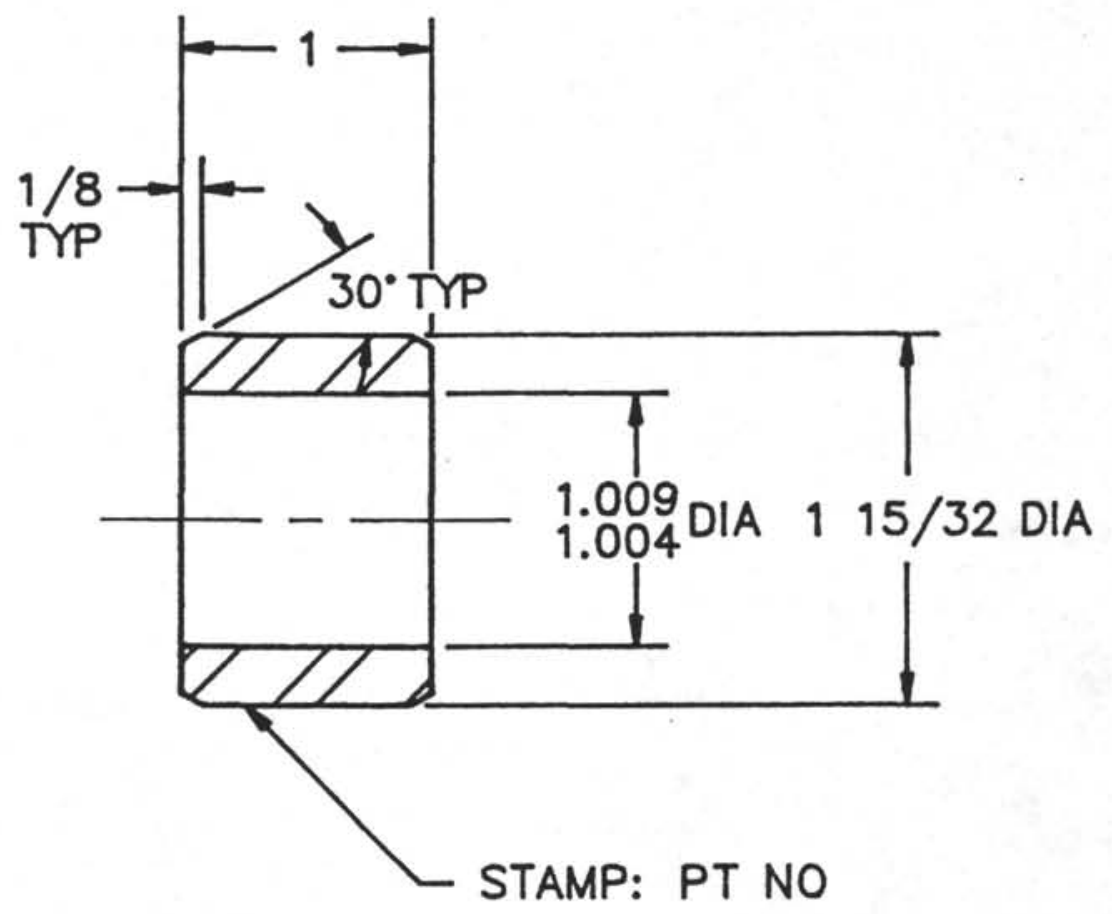

NOTE:

1. TAG OR BAG MARKED WTH OP6380 \& MFG. DATE

\begin{tabular}{|c|c|c|c|c|c|c|}
\hline \multicolumn{2}{|c|}{$\begin{array}{l}\text { TOLERANCES } \\
\text { UNLESS NOTED }\end{array}$} & $\begin{array}{l}\text { MATERIALS } \\
\text { STL } 1018\end{array}$ & & & & \multirow[b]{3}{*}{77843} \\
\hline $\begin{array}{l}\text { FRACTIONS } \\
\text { DECIMALS }\end{array}$ & $\begin{array}{l} \pm 1 / 64 \\
\pm .005\end{array}$ & HEAT TREATMENT & \multirow{2}{*}{\multicolumn{3}{|c|}{$\begin{array}{l}\text { TEXAS A\&M UNIVERSITY } \\
\text { COUECE STATON, TEXAS }\end{array}$}} & \\
\hline ANGES & $\pm 1 / 2$ & \multirow{2}{*}{$\begin{array}{l}\text { SURFACE TREATMENT } \\
\text { PARKOLUBE }\end{array}$} & & & & \\
\hline \multirow{2}{*}{$\begin{array}{l}\text { CORNERS } \\
\text { WNSH }\end{array}$} & \multirow{2}{*}{$\begin{array}{l}1 / 64 \times 45^{\circ} \\
\text { OR } 1 / 64 R \\
125\end{array}$} & & \multirow{2}{*}{\multicolumn{4}{|c|}{$\pi T E$}} \\
\hline & & $\begin{array}{l}\text { SCNE } \\
\text { FULL }\end{array}$ & & & & \\
\hline \multirow{2}{*}{\multicolumn{2}{|c|}{$\begin{array}{c}\text { CONCENTRICTY } \\
\text { NLL OAMETERS } \\
\text { TR .003 }\end{array}$}} & $\begin{array}{c}\text { REQD/ASS'Y } \\
1\end{array}$ & $\begin{array}{l}\text { STSTEM } \\
\text { PRESSURE CORE SAMPLER }\end{array}$ & \multicolumn{2}{|c|}{ ASSEMBLY } & \\
\hline & & \begin{tabular}{|l|c|} 
DRAWN BY & DATE \\
$J$ AUMANN & $06-06-88$ \\
\end{tabular} & \begin{tabular}{c|c} 
CHECKED & $\frac{1}{15}$ APPRQVED \\
J.T. AUMANN & $\frac{1}{60} \frac{\text { gur }}{}$
\end{tabular} & AIZE & $\begin{array}{l}\text { DWG. PART NO. } \\
\text { OPG } 380\end{array}$ & REV. \\
\hline
\end{tabular}



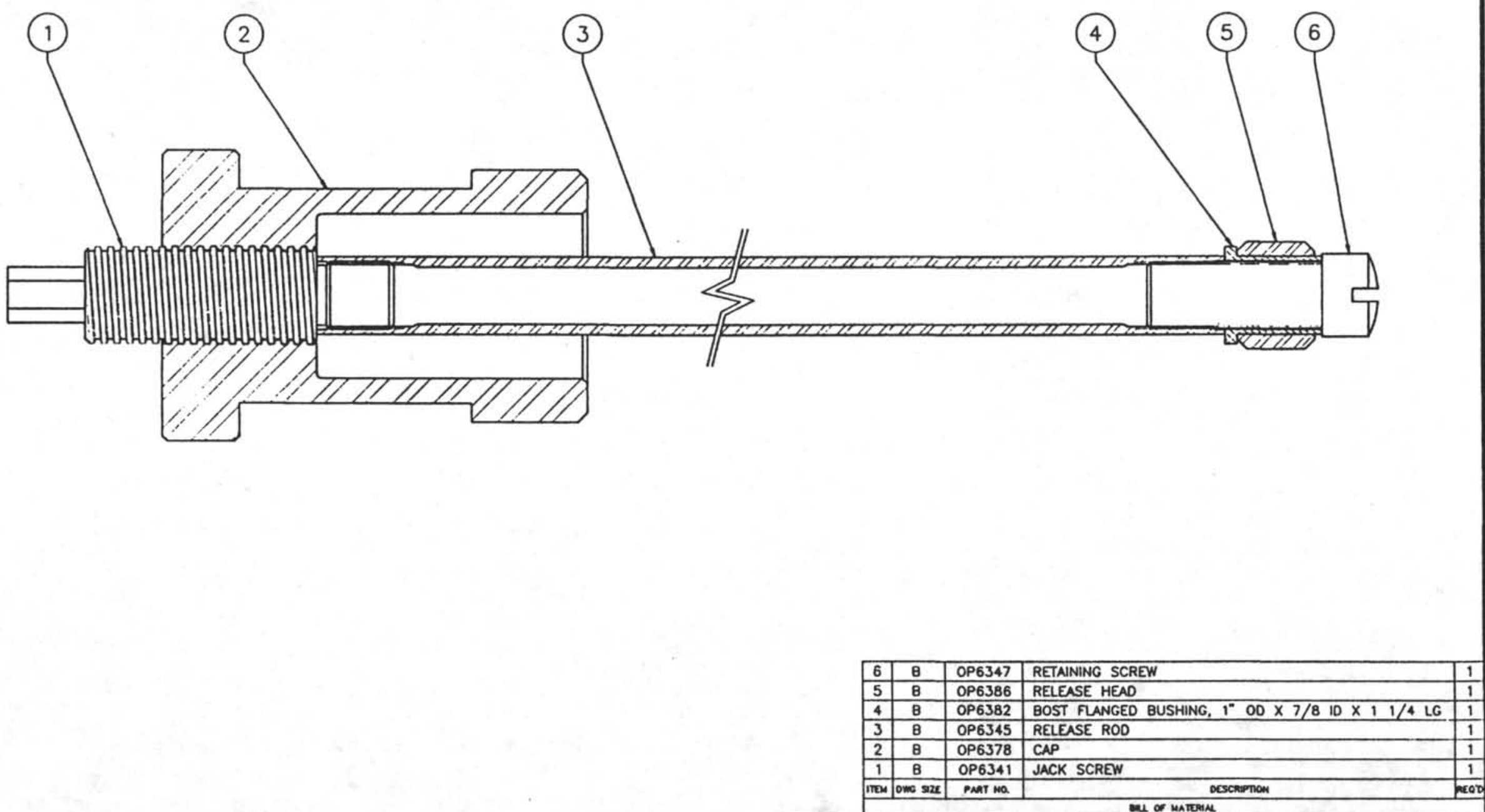

\begin{tabular}{|c|c|c|c|}
\hline \multirow{3}{*}{ 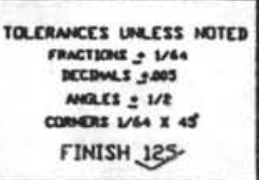 } & \multirow{2}{*}{ 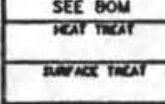 } & \multicolumn{2}{|c|}{$\begin{array}{c}\text { OCEAN DRILLING PROGRAM } \\
\text { TEXAS A\&M UNIVERSITY }\end{array}$} \\
\hline & & COLIRE STATION, TX. & m7840 \\
\hline & sons pul & \multicolumn{2}{|c|}{ TITLE RELEASE RESETTING TOOL } \\
\hline \multirow{2}{*}{$\begin{array}{l}\text { CONCENTRICITY ALL } \\
\text { DIAMETERS TIR .003, }\end{array}$} & $\operatorname{mon}$ & \multirow{2}{*}{\multicolumn{2}{|c|}{ 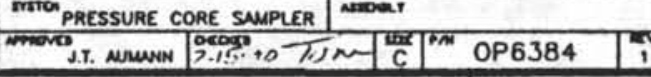 }} \\
\hline & Nunuw & & \\
\hline
\end{tabular}




\begin{tabular}{|c|c|c|c|c|c|c|}
\hline & \multicolumn{4}{|c}{ REMSIONS } \\
\hline NO. & DESCRIPTON & DATE & BY & CH. & APR. \\
\hline & & & & & \\
\hline
\end{tabular}

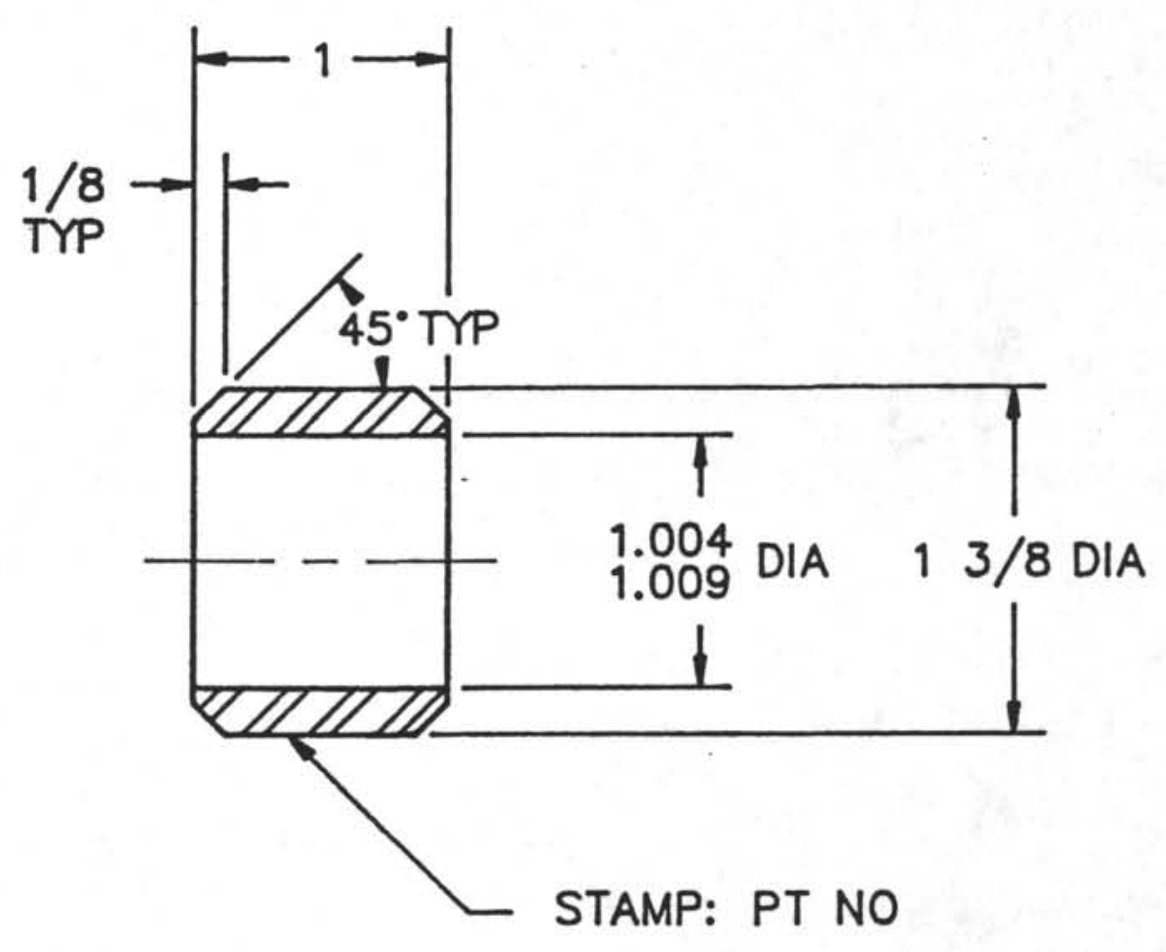

NOTE:

1. TAG OR BAG MARKED WITH OP6386 \& MFG. DATE

\begin{tabular}{|c|c|c|c|c|c|c|}
\hline \multicolumn{2}{|c|}{$\begin{array}{l}\text { TOUERANCES } \\
\text { UNLESS NOTED }\end{array}$} & $\begin{array}{l}\text { MATERIALS } \\
\text { STL } 1018\end{array}$ & \multirow{2}{*}{\multicolumn{3}{|c|}{$\begin{array}{r}\text { OCEAN DRILLING PRO } \\
\text { TEXAS A\&M UNIVERSITY }\end{array}$}} & \\
\hline $\begin{array}{l}\text { FRACTIONS } \\
\text { DECIMALS }\end{array}$ & $\begin{array}{l} \pm 1 / 64 \\
\pm .005\end{array}$ & HEAT TREATMENT & & & & \\
\hline aNGES & $\pm 1 / 2$ & \multirow{2}{*}{$\begin{array}{l}\text { SURFACE TREATMENT } \\
\text { PARKOLUBE }\end{array}$} & \multicolumn{3}{|l|}{ COUECE STATION, TEXAS } & 77843 \\
\hline CORNERS & $1 / 64 \times 45^{\circ}$ & & \multirow{2}{*}{\multicolumn{3}{|c|}{ RELEASE HEAD, RESETTING TOOL }} & \\
\hline & 125 & $\begin{array}{l}\text { SCNE } \\
\text { FULL }\end{array}$ & & & & \\
\hline \multirow{2}{*}{\multicolumn{2}{|c|}{$\begin{array}{l}\text { CONCENTRICITY } \\
\text { NL DIAMETERS } \\
\text { TR .003 }\end{array}$}} & $\begin{array}{c}\text { REQ'D/ASS'Y } \\
1\end{array}$ & $\begin{array}{l}\text { STSTEM } \\
\text { PRESSURE CORE SAMPLER }\end{array}$ & \multicolumn{2}{|c|}{ ASSEMBLY } & \\
\hline & & \begin{tabular}{|l|c|} 
DRAWN BY & DATE \\
J AUMANN & $08-25-88$ \\
\end{tabular} & \begin{tabular}{c|l} 
CHECKED & $\frac{2}{15}$ APPROVED \\
J.T. AUMANN & $\frac{15}{10} \frac{15 m}{}$ \\
\end{tabular} & AIEE & DWG. PA & REV. \\
\hline
\end{tabular}




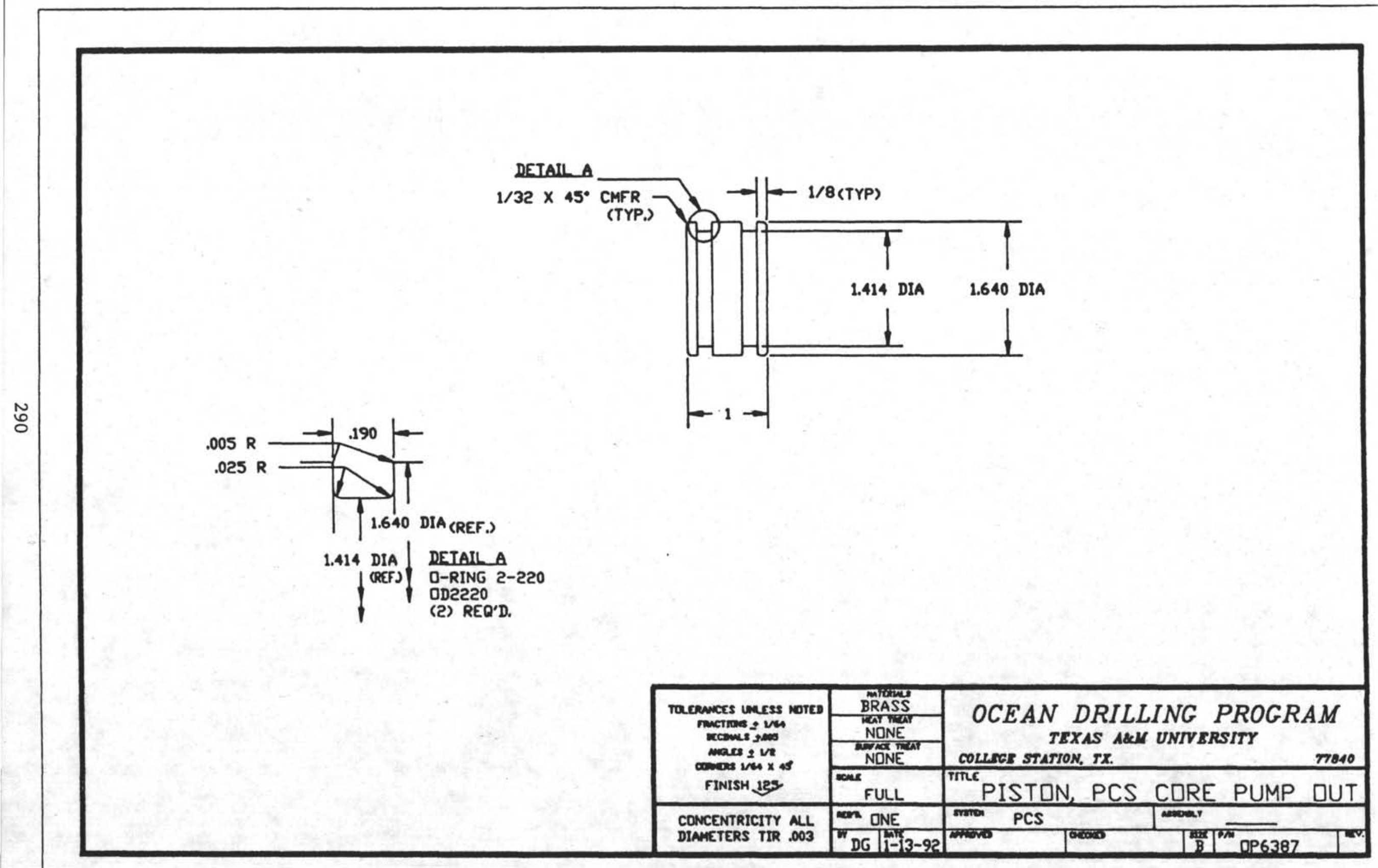




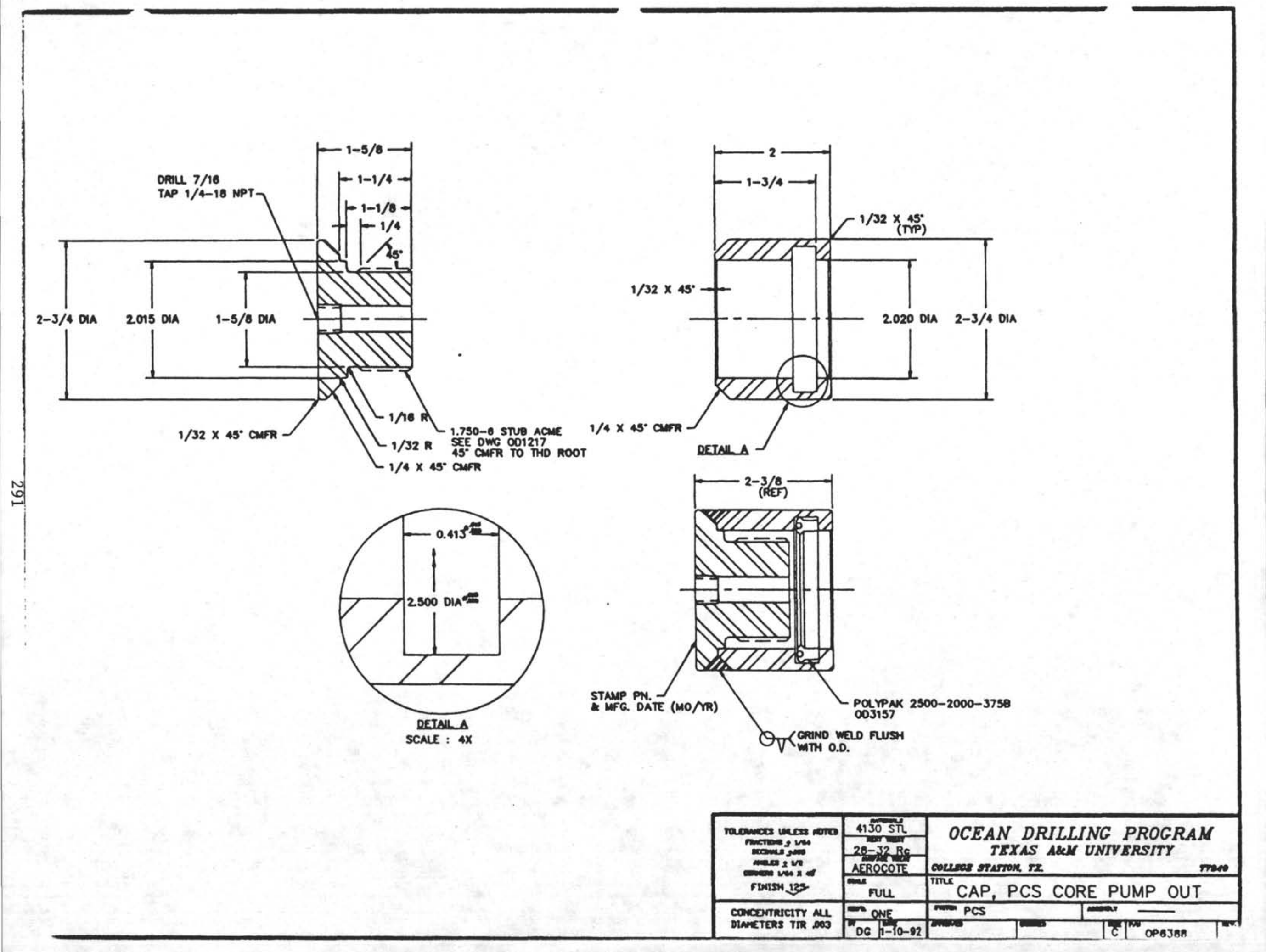

